\title{
MAGNETIC AND ELECTROMAGNETIC SURVEYING OF LAVA TUBES AT LAVA BEDS NATIONAL MONUMENT, CALIFORNIA
}

\author{
by:
}

\author{
Andre Skyler Mallozzi
}

Supervisors:
Dr. Claire Samson
École de Technologie Supérieure, Carleton University
Dr. Richard Ernst
Carleton University, Tomsk State University

A thesis submitted to the Faculty of Graduate and Postdoctoral Affairs in partial fulfillment of the requirements for the degree of

Master of Earth Science 
The undersigned recommended to the Faculty of Graduate and Postdoctoral Affairs acceptance of this thesis:

\section{MAGNETIC AND ELECTROMAGNETIC SURVEYING OF LAVA TUBES AT LAVA BEDS NATIONAL MONUMENT, CALIFORNIA}

Submitted by Andre Skyler Mallozzi in partial fulfillment of the requirements of the degree of Master of Earth Science.

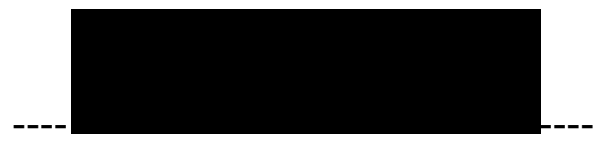

Dr. Claire Samson, Primary Supervisor Department of Construction Engineering École de Technologie Supérieure

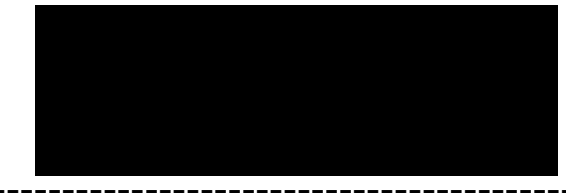

Dr. Richard Ernst, Secondary Supervisor

Department of Earth Sciences Carleton University

Dr. Brian Cousens, Chair Department of Earth Sciences Carleton University 


\section{Abstract}

Lava tubes are targets for future manned missions on Mars because they offer protection from ultraviolet radiation and meteor impacts, as well as stable temperatures. The Astrobiology Training in Lava Tubes (ATiLT) project sets out to not only detect and characterize lava tubes using surface geophysical techniques, but to investigate biosignatures left by microorganisms inside lava tubes. As a contribution to the ATiLT project, this project aimed specifically on the characterization and detection of lava tubes using surface electromagnetic (EM) induction and magnetic techniques, as well as characterization of lava tube floors using EM induction. Two separate field surveys were performed at Lava Beds National Monument (LBNM) in Northern California in 2017 and 2018 using EM induction and magnetics, respectively. In total, over 50 line km of magnetic data and 2 line $\mathrm{km}$ of surface EM data were collected, and the interior of 5 caves were surveyed using EM. Surface EM was inconclusive as the depth of exploration of the EM induction sounder was not sufficient to reach the limiting depth of lava tubes. Interior EM surveys were successful in characterizing cave floors with different conductivity signatures. The EM data were inverted in 1D to reveal structures in the basaltic bedrock. Forward modelling of magnetic data showed that the signature associated with a lava tube is a magnetic low slightly offset from the axis of symmetry. Visual inspection of surface magnetic data did not identify this signature. Applying lowpass filters to the surface magnetic data was successful in observing larger-scale trends of the lava flows at LBNM. Inversion of magnetic data showed good fit over the area of influence of a lava tube with one passage. Inversion also identified susceptibility and remanence signatures that could be related to the eruption sequence. 


\section{Acknowledgements}

I would like first and foremost to thank Dr. Claire Samson for her support and guidance through these past two years. Claire has been a major role model for me and taught me the skills necessary to be an effective geophysicist as I begin my professional career. Claire has been incredibly supportive during times when I questioned my ability to finish this project and has guided me forward and helped me persevere over personal challenges. I also thank Dr. Richard Ernst for joining on as a supervisor after Claire's departure from Carleton University, and his input into the project.

I extend a large thank you to Mike Cunningham and Chris Brown for helping me with data collection. Mike assisted with collecting magnetic data in May 2018 and offered advice and input as I learned how to process and model my magnetic data. I also appreciate his repeated attempts to "break my spirit" during field work, which made me push to prove him wrong. Chris Brown assisted with electromagnetic data collection and gave valuable input during field work to ensure I had sufficient data for the electromagnetic portion of this project.

I thank Scott Holladay for taking time out of his busy schedule to meet and perform

a test survey with the R4 EMIS in Toronto, as well as teaching me how to process and interpret EM datasets. I thank Dr. Fernando Acácio Monteiro Santos for taking time out of his schedule to do the EM inversions. His contributions were vital to the success of the EM component of this research project. 
Finally, I would like to thank my family. I never would have made it through my post-secondary education without my family's unconditional support over the past seven years, whether it be a short message or the hour-long phone calls. I also thank my friends in Ottawa for providing constant encouragement and much-needed coffee breaks when stress was high. 


\section{Statement of Contribution}

A majority of the work done in this research project was performed by me with minimal help, with the exceptions listed below. However, all interpretations for all work was done by me with no outside help.

Chapter 3 - Methods: The R4 EMIS prototype was provided to us by Dr. Scott Holladay of Geosensors Inc. Dr. Claire Samson reached an agreement with Dr. Holladay to allow us to test the R4 EMIS in the field, as long as we provided feedback with any potential shortcomings of the instrument. This was done well before I started the project in May 2017. Additionally, a MATLAB script to create plots and maps of unprocessed data was provided by Dr. Holladay for the purpose of having a "first look" of the data while in the field. All subsequent processing and plotting were done by me using various scripts written in MATLAB or Oasis Montaj.

I sought out, consulted, and negotiated with Geometrics Inc. the renting of the two magnetometers used for the 2018 field season. The only help I received in this manner was budgetary consultation from Dr. Samson.

Chapter 4 - Field Work: Chris Brown, a former master's student of Dr. Samson, assisted in the collection of EM data by alternating carrying the sensor and navigating the survey with me. Additionally, he helped with reconnaissance for which lava tubes to survey in the 2018 field season. Mike Cunningham, a Ph.D. student under Dr. Samson's supervision, assisted in data collection during the 2018 field season by navigating me along the line

while I carried the G-859 Magnetometer the entire field season. Mike and Dr. Samson 
provided input in survey planning while in the field; however, I made the final decision on what was going to be surveyed and planned all lines. Richard Léveillé, Jenny Ni, and Brady O'Connor of McGill University provided valuable input on the regional geology and which lava tubes we should survey during both the 2017 and 2018 field seasons. They did not provide input in survey planning, execution, or processing.

Chapter 5.1.3 - Interior Surveys. The depth - true conductivity models shown in this thesis were performed by Dr. Fernando Acácio Monteiro Santos of the University of Lisbon with input from myself and Dr. Holladay. These inversion models were performed using data collected by me during the 2017 field season. The inversion was done with constant consultation from Dr. Holladay (for the technical aspect) and myself (for the geological and survey conditions). All interpretations after the inversion models were done by me without any outside help. 


\section{Table of Contents}

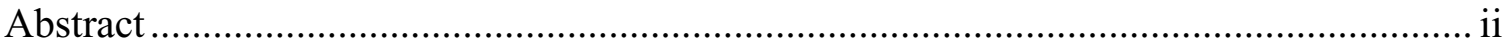

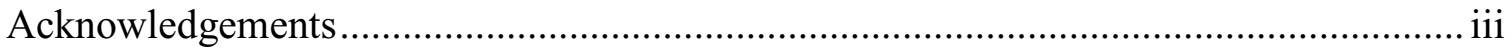

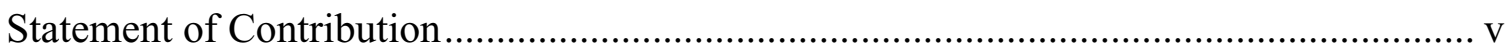

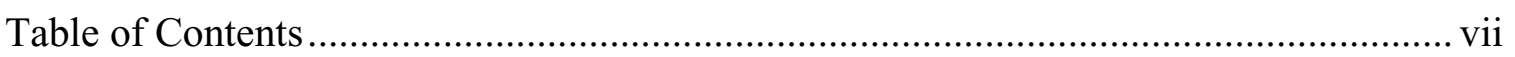

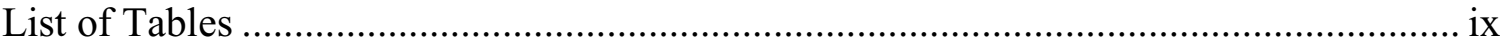

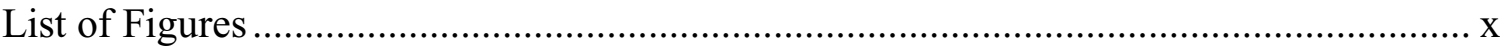

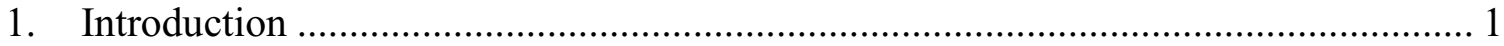

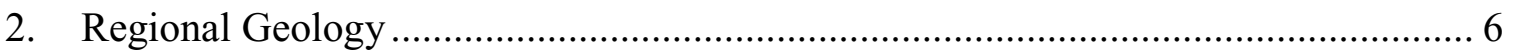

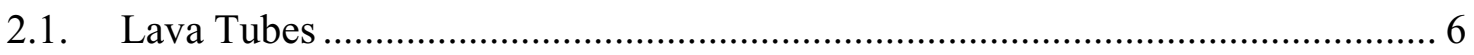

2.2. Lava Beds National Monument (LBNM) ...................................................... 9

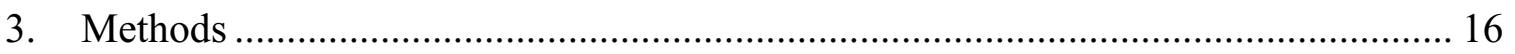

3.1. Electromagnetic Induction ....................................................................... 16

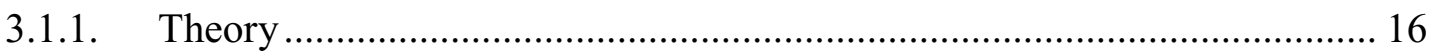

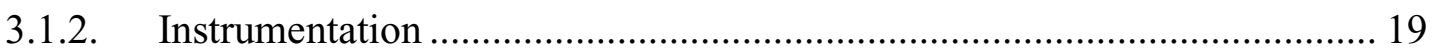

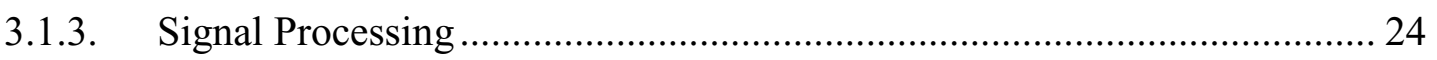

3.1.4. Test Survey at Wilket Creek Park............................................................ 28

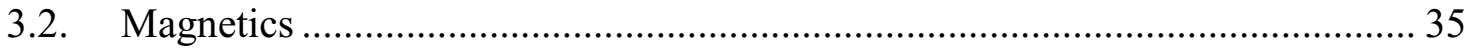

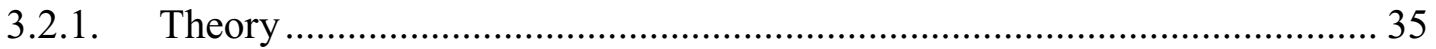

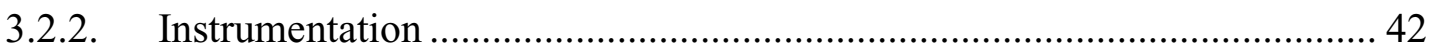

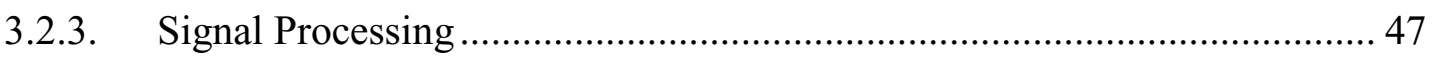

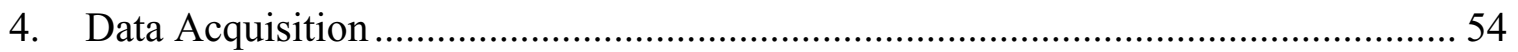

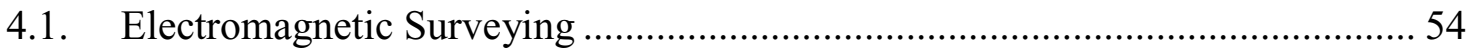

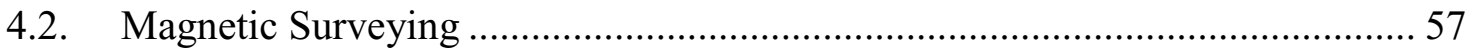

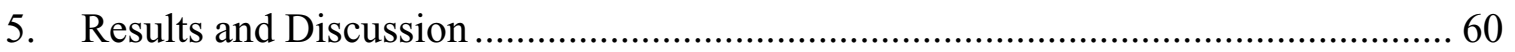

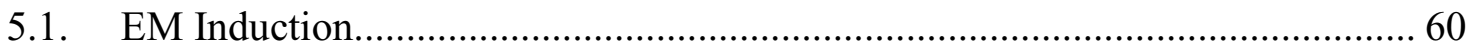

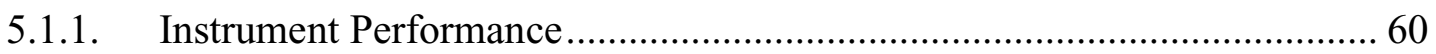

5.1.2. Surface Survey Results and Interpretations ................................................ 67

5.1.3. Interior Surveys Results and Interpretations ............................................. 75

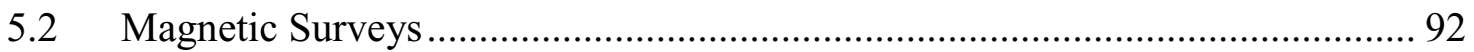

5.2.1. Forward Modelling of a Lava Tube in Basaltic Host Rock ........................ 92

5.2.2. Surface Survey Results and Interpretations ............................................... 103 


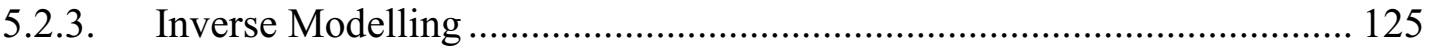

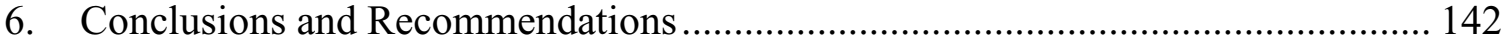

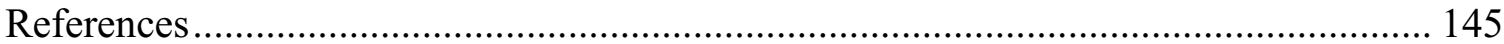

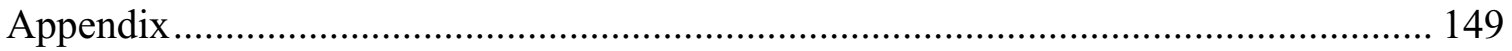

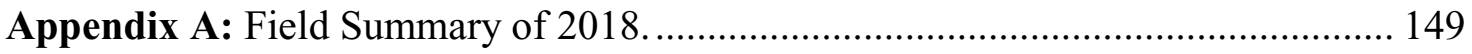

Appendix B: Electromagnetic and Magnetic Datasets......................................... 158 


\section{List of Tables}

Table 1.1: Summary of work done for this research project...................................... 5

Table 3.1: Unit conversions for magnetic susceptibility used in various publications.... 17

Table 3.2: Specifications of the R4 EMIS from Geosensors Inc................................ 20

Table 3.3: Specifications of the Geometrics G-857 base station magnetometer (Geometrics, 2015).

Table 3.4: Specifications of the Geometrics G-859 walking magnetometer (Geometrics, 2011).

Table 4.1: Summary of surface surveys conducted during the 2018 field season. Distance is based on distance between planned coordinates. It does not represent the actual distance surveyed. 58

Table 5.1: Average magnetic susceptibility (IP) and conductivity values (QD) from interior surveys for each receiver, numbered 1 to 4 77

Table 5.2: Parameters used for the forward modelling exercise done in GM-SYS 2D... 92

Table 5.3: Magnetic field parameters used for inversion. 126

Table 5.4: Summary table of the manual inversion models. 128 


\section{List of Figures}

Figure 1.1: Juniper Cave at Lava Beds National Monument........................................... 3

Figure 2.1: Location of Lava Beds National Monument ............................................. 10

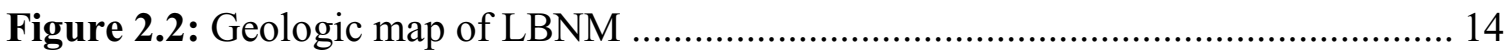

Figure 2.3: Main visitor complex at LBNM........................................................ 15

Figure 3.1: Sketch of the operative principle of the R4 EMIS..................................... 18

Figure 3.2: Internal components of the R4 EMIS in $0^{\circ}$ roll and $90^{\circ}$ roll. ...................... 21

Figure 3.3: User interface of the Geosensors app on Apple IOS.................................... 23

Figure 3.4: .txt file showing raw data extracted from the R4 EMIS............................... 25

Figure 3.5: $\log$ file showing raw data converted from the txt file.............................. 25

Figure 3.6: The Filter Design application in MATLAB. ............................................. 26

Figure 3.7: Comparison of the filter function (left) in MATLAB versus the filtfilt zerophase filtering function (right) using parameters shown in Figure 3.6 ........................... 27

Figure 3.8: Test survey at Wilket Creek Park in Toronto, ON....................................... 30

Figure 3.9: Apparent conductivity results from Receiver 1 at $0^{\circ}$ roll. ............................ 31

Figure 3.10: Magnetic susceptibility results from Receiver 1 at $0^{\circ}$ roll......................... 32

Figure 3.11: Apparent conductivity results from Receiver 1 at $90^{\circ}$ roll......................... 33

Figure 3.12: Magnetic susceptibility results from Receiver 1 at $90^{\circ}$ roll....................... 34

Figure 3.13: Diurnal variations in Earth's magnetic field on May $5^{\text {th }}, 2018 \ldots \ldots \ldots \ldots \ldots . . . . .37$

Figure 3.14: Plot of magnetization I against inducing magnetic field $\mathrm{H}$ showing how NRM occurs. NRM in this case Ir after the saturation point is reached. .................................. 39

Figure 3.15: The G-857 magnetometer set up as a base station in LBNM...................... 43

Figure 3.16: Surveying with the G-859 magnetometer with the backpack apparatus ..... 45

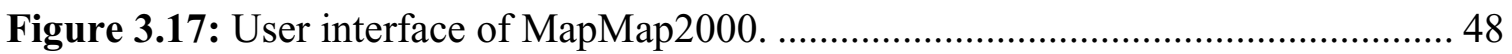

Figure 3.18: Raw data from the G-957 base-station magnetometer in .stn format.......... 48

Figure 3.19: Raw data from the G-859 magnetometer in .bin format (top) and .dat format (bottom)

Figure 3.20: Base station data from May 5th, 2018 before and after moving average.... 51

Figure 3.21: Comparison of TMI for the Juniper Cave survey before (left) and after (right)

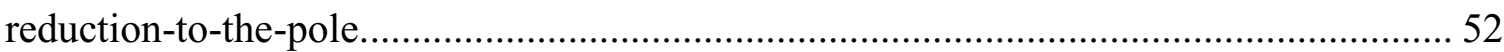

Figure 4.1: Northern end of Devils Homestead Flow.................................................... 55 Figure 4.2: Rock collapse located in the middle of Cave Loop, which restricted survey lines for Juniper Cave on the west side. Person is approximately $188 \mathrm{~cm}$ for scale. ........ 59 Figure 4.3: Rock "wall" located on the eastern section of the Juniper Cave, restricting survey lines on the east side.

Figure 5.1: (Top) Apparent conductivity profile of Valentine Cave. (Bottom) internal temperature of the R4 EMIS.

Figure 5.2: Apparent conductivity data for Golden Dome Cave after temperature corrections.

Figure 5.3: (Top) Magnetic susceptibility profile of Golden Dome Cave. (Bottom) Internal temperature of the R4 EMIS. 
Figure 5.4: (Top) Apparent conductivity (Conduct.) and magnetic susceptibility (MagSusc.) profiles of Indian Well Cave at $0^{\circ}$ roll. (Bottom) Changes in pitch and roll of the R4 EMIS. 66

Figure 5.5: (Top) Scatter plot of apparent conductivity data in the vicinity of Indian Well Cave recorded by Receiver 4 at $0^{\circ}$ roll orientation 68

Figure 5.6: (Top) Scatter plot of apparent conductivity data in the vicinity of Indian Well Cave recorded by Receiver 1 at $0^{\circ}$ roll orientation.

Figure 5.7: (Top) Scatter plot of magnetic susceptibility data in the vicinity of Indian Well Cave recorded by Receiver 4 at $0^{\circ}$ roll orientation. 72

Figure 5.8: Scatter plot of magnetic susceptibility data in the vicinity of Indian Well Cave recorded by Receiver 1 at $0^{\circ}$ roll orientation. 73

Figure 5.9: Average apparent conductivities of interior surveys for each receiver, categorized by cave. 78

Figure 5.10: Apparent conductivity profile of Juniper Cave after thermal corrections. The survey was only one way and did not turn around after reaching the end.......................80

Figure 5.11: Inside of Juniper Cave, just past the entrance. ....................................... 81

Figure 5.12: Apparent conductivity profile of Mammoth Cave.................................. 83

Figure 5.13: Apparent conductivity profile of Golden Dome Cave. ............................ 85

Figure 5.14: Apparent conductivity profile of Juniper Cave ...................................... 87

Figure 5.15: Depth models for conductivity (top) and magnetic susceptibility (bottom) derived from the $90^{\circ}$ roll EM data of Juniper Cave...................................................... 90

Figure 5.16: Example of forward modelling results from GM-SYS 2D showing the depth model at the bottom and the calculated response at the top. 94

Figure 5.17: (Top) Depth model showing the placement of the tube for the forward models. (Bottom) Calculated magnetic response of a $3 \mathrm{~m}$ x $8 \mathrm{~m}$ half-dome lava tube at various depths.

Figure 5.18: (Top) Maximum and minimum values of the observed and calculated magnetic responses shown in Figure 5.20. (Bottom) Difference between the maximum and minimum value for each depth. 96

Figure 5.19: (Top) Depth model showing the placement of the tube for the forward models. (Bottom) Calculated magnetic response of a $3 \mathrm{~m}$-tall half-dome lava tube located at a limiting depth of $3 \mathrm{~m}$ with varying widths.

Figure 5.20: (Top) Maximum and minimum values of the observed and calculated magnetic responses shown in Figure 5.22. (Bottom) Difference between the maximum and minimum value for each width. 98

Figure 5.21: (Top) Depth model showing the placement of the tube for the forward models. (Bottom) Calculated magnetic response of a $3 \mathrm{~m}$ x $8 \mathrm{~m}$ half-dome lava tube located at a limiting depth of $3 \mathrm{~m}$ with varying magnetic susceptibility values. 99 Figure 5.22: (Top) Maximum and minimum values of the observed and calculated magnetic responses shown in Figure 5.24. (Bottom) Difference between the maximum and minimum value for each susceptibility. 100 
Figure 5.23: (Top) Depth model showing the placement of the tube for the forward models. (Bottom) Calculated magnetic response of a $3 \mathrm{~m}$ x $8 \mathrm{~m}$ half-dome lava tube located at a limiting depth of $3 \mathrm{~m}$ with varying remanence values.

Figure 5.24: (Top) Maximum and minimum values of the observed and calculated magnetic responses shown in Figure 5.23. (Bottom) Difference between the maximum and minimum value for each susceptibility. 102

Figure 5.25: TMI maps of the Juniper Cave survey with various lowpass filters........ 105

Figure 5.26: TMI maps of the Juniper Cave survey with various highpass filters....... 106

Figure 5.27: TMI maps of the Juniper Cave survey with various bandpass filters. ...... 107

Figure 5.28: Horizontal and vertical derivatives of the Juniper Cave Survey, with the original TMI map shown in the top left for reference. ............................................. 108

Figure 5.29: TMI maps of the Valentine Cave survey with various lowpass filters. .... 112

Figure 5.30: Zoomed-in TMI maps of Valentine Cave. ............................................ 113

Figure 5.31: TMI maps of the Valentine Cave survey with various highpass filters. ... 114

Figure 5.32: TMI maps of the Valentine Cave survey with various bandpass filters.... 115

Figure 5.33: Horizontal and vertical derivatives of the Valentine Cave Survey, with the original TMI map shown in the top left for reference. .............................................. 116

Figure 5.34: TMI maps of the Yellowstone Cave survey with various lowpass filters. 119 Figure 5.35: TMI maps of the Yellowstone Cave survey with various highpass filters. 120 Figure 5.36: TMI maps of the Yellowstone Cave survey with various bandpass filters. 121

Figure 5.37: Horizontal and vertical derivatives of the Yellowstone Cave Survey, with the original TMI map shown in the top left for reference.

Figure 5.38: Locations and names for all inverse models. The TMI maps shown are not reduced to the pole. 129

Figure 5.39: Manual inversion models of the northeast (top) and northwest (bottom) crosssections at Juniper Cave. 132

Figure 5.40: Manual inversion models of the center (top) and south (bottom) cross-sections at Juniper Cave. 133

Figure 5.41: Manual inversion models of Valentine Cave. ......................................... 136

Figure 5.42: Manual inversion models of Yellowstone Cave. .................................. 138

Figure 5.43: (Top) Observed data and calculated magnetic responses from Bell et al. (2018). (Middle) Observed Valentine Cave data from this project and calculated magnetic responses based on replicating the depth model and parameters from Bell et al. (2018). (Bottom) Replicated depth model from Bell et al. (2018) done in GM-SYS 2D. 140 


\section{Introduction}

Current conditions of the surface of Mars are considered very inhospitable for life (National Research Council, 2007). Mean annual surface temperatures are close to $-58^{\circ} \mathrm{C}$ at the equator and $-100^{\circ} \mathrm{C}$ at the poles; surface temperatures fluctuate widely during the day. Because of this, the upper several kilometers on Mars' surface would be frozen to form a thick cryosphere. This cryosphere would be thinner in areas of higher heat flow, such as near volcanoes or possible hydrothermal environments (Schulze-Makuch et al., 2007). The thin atmosphere, averaging a surface pressure of $5.6 \mathrm{mbar}$, allows ultraviolet radiation to pass through unattenuated (National Research Council, 2007). Despite the present unfavourable conditions on the surface of Mars, there is evidence that Mars used to have a habitable environment. This includes high drainage densities suggesting surface runoff requiring rainfall or melting snow, which implies significantly warmer and wetter conditions than the present. Additional evidence includes the discovery of evaporites and fluctuation of the water table at the Mars Exploration Rover landing site on Meridiani Planum, as well as detection of clay minerals from orbit in Noachian terrains (Carr, 2007). Finally, research from various orbiters and rovers suggest that the possibility of an extensive saline groundwater system, high winds and dust storms that imply that Mars used to have a habitable environment (Léveillé and Datta, 2010). Caves could intercept these saline groundwater systems and provide windows into subsurface habitable environments for both past and present lifeforms. Caves on Earth have both microbial growth as well as secondary mineral precipitation, which leads to the formation and preservation of microbial biosignatures (Léveillé and Datta, 2009). The same conditions might be present in caves on Mars, making Mars a prime target for finding evidence of past life. 
The theory that Mars previously had conditions suitable for harbouring life has led various space agencies to pursue astrobiology projects on the surface of Mars for finding evidence of pre-existing life and for determining the habitability of Mars for humans (Des Marais et al., 2015). From the $6^{\text {th }}$ Canadian Space Exploration Workshop in 2009, the first objective is centered around astrobiology, with objective AB1 stating "Detect the presence of habitable environments on other planets, including exoplanets..." and objective AB-5 "Search for direct evidence of extinct or extant life through biosignatures by developing methodologies and instruments for in situ investigation of planetary environments, and validate their operational performance in operational contexts at Canadian analogue sites." (CSEW6, 2009). In addition to astrobiology on Mars being a top priority for Canada, NASA has listed as Objective 2.1 under their astrobiology roadmap as: "Through orbital and surface missions, explore for potentially habitable environments and evidence of life, as indicated by water, organic matter, atmospheric gases, and/or minerals. Study Martian meteorites to guide Mars exploration. To support both exploration at Mars and the first sample return mission, update astrobiology measurement requirements, support site selection studies, and develop/improve relevant technologies and analytical methods." (Des Marais et al., 2008).

As stated before, caves are considered prospective sites of exploration due to the potential presence of microbial life and secondary mineralization. In addition, caves provide stable environmental conditions for life to flourish, even in less-than-favourable surface conditions. An example of a cave that can support microbial life are lava tubes, which are natural subsurface voids common in basaltic flow complexes, particularly pahoehoe flows (Figure 1.1). They originate as roofing over the channel or inflation 
structures in lava flows or, in the case of sea caves, as erosional features. Lava tubes provide stable temperatures even in places where surface temperatures are unfavourable for habitation meaning that lava tubes harbour the deposition, accumulation, and preservation of ice. This in turn allows for precipitation of secondary minerals such as carbonates, sulphides, silica, and clays (Woo et al., 2008a,b) in which microorganisms thrive, leaving behind biosignatures. Therefore, lava tubes are considered suitable targets for finding evidence of past life on Mars.

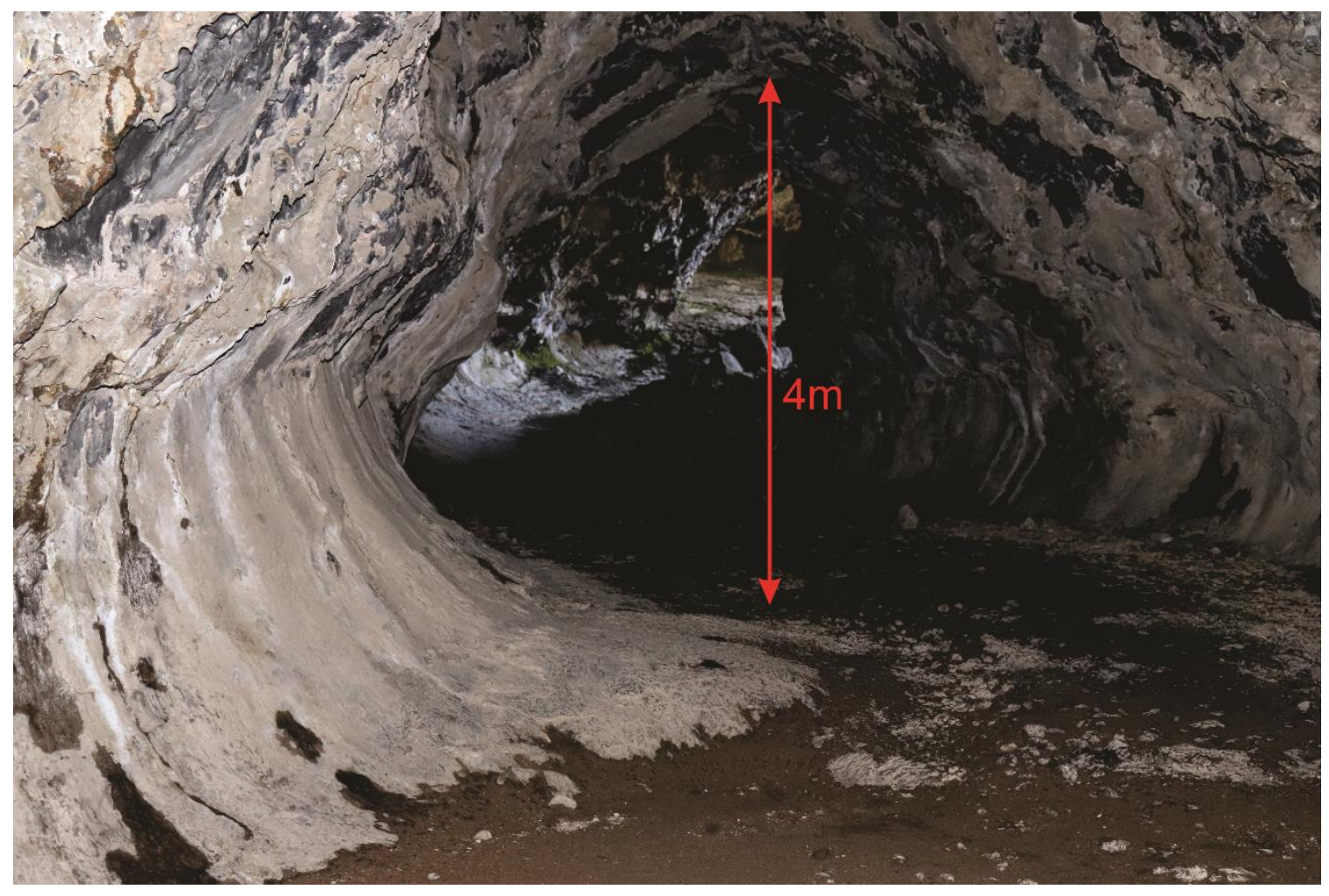

Figure 1.1: Juniper Cave at Lava Beds National Monument, an example of a lava tube. 
In addition to lava tubes being a prospective site for finding evidence of pre-existing life on Mars, they are considered a possible site for habitat in future manned missions to Mars (Daga et al., 2013). The main reason for this is that Martian lava tubes provide protection from UV radiation on a planet where the atmosphere is much thinner than that of Earth (National Research Council, 2007). In addition, the relatively stable environments lava tubes offer will provide a good location for a habitat since large temperature differences pose a problem for human exploration to Mars (Boston et al., 2001a).

Astrobiology Training in Lava Tubes (ATiLT) is a project headed by Richard Léveillé of McGill University, which focuses on Mars astrobiological objectives as outlined during the Canadian Space Agency Exploration Workshop in 2009 (CSEW6, 2009). The project focuses on performing field work and analyses on terrestrial lava tubes with four key objectives: detection and characterization of subsurface lava tubes with geophysical instruments; detection of biosignatures and paleoenvironmental indicators in secondary cave minerals and ice; detection and characterization of extant life; and Marslike science operations (Léveillé et al., 2015). The field work component was executed at Lava Beds National Monument (LBNM) in Northern California. Under objective 1, geophysical methods included in the proposal are: electromagnetic (EM) induction, ground penetrating radar (GPR), and capacitive coupled resistivity (CCR). GPR has been used extensively for investigating lava tubes (Meglich et al., 2003; Bernold and Immer, 2004; Bernold, 2006; Miyamoto et al., 2006); however, EM induction and CCR have not been tested for detection of lava tubes before.

The objective of this project is to detect and characterize lava tubes from the surface geophysical methods such as EM induction and magnetometry. The sub-objectives for the 
EM induction surveys are to test the effectiveness of the R4 EM induction sounder - a prototype instrument designed and built by Geosensors Inc. - in volcanic terrain, as well as the characterization of lava tube floors through interior EM induction surveys. There was an attempt to model the subsurface based on surface magnetic datasets, first with a forward modelling exercise then using the results of the forward modelling exercise to perform a $2 \mathrm{D}$ manual inversion on multiple cross-sections perpendicular to the lava tube. A summary of the work done for this research project is shown in Table 1.1.

Table 1.1: Summary of work done for this research project.

\begin{tabular}{|l|c|c|c|c|c|c|c|c|}
\hline & Units & $\begin{array}{c}\text { Indian Well } \\
\text { Cave }\end{array}$ & $\begin{array}{c}\text { Golden } \\
\text { Dome } \\
\text { Cave }\end{array}$ & $\begin{array}{c}\text { Mammoth } \\
\text { Cave }\end{array}$ & $\begin{array}{c}\text { Skull } \\
\text { Cave }\end{array}$ & $\begin{array}{c}\text { Juniper } \\
\text { Cave }\end{array}$ & $\begin{array}{c}\text { Valentine } \\
\text { Cave }\end{array}$ & $\begin{array}{c}\text { Yellowstone } \\
\text { Cave }\end{array}$ \\
\hline Surface EM & [Line km] & 2.012 & & & & & 0.2 & \\
\hline Interior EM & & & & & & & \\
\hline EM Inversion & [\# of Models] & & & & & 1 & & \\
\hline Surface Magnetic & [Line km] & & & & & 14.128 & 11.908 & 19.435 \\
\hline Manual Inversion & [\# of Models] & & & & & 4 & 3 & 2 \\
\hline
\end{tabular}




\section{Regional Geology}

\subsection{Lava Tubes}

As stated before, lava tubes are natural subsurface cavities that are most common in basaltic flows (Halliday, 2002), particularly pahoehoe flows (Greeley, 1971). The definition of a lava tube is a debatable topic, but it is accepted that a cave is considered a lava tube if one of the four possible mechanisms of formation are observed: a crust develops from the cooled sides - known as levees - to the centre of a confined channel; overflows enhance the levees leading to a arched roof across the lava stream; pahoehoe lobes extend beneath the solidified crust; plates of solidified lava float downstream and merge together to form an extended overcrust on top of the lava flow (Valerio et al., 2008). The first and last mechanisms are the most likely mechanism of formation for the lava tubes at LBNM (DeDecker, 2014). Typically, a basaltic lava flow begins to cool at the surface since it is in contact with air and will cool in the central region of the flow. The crust will be carried downstream by the flow. The transition from a moving crust to a stationary overcrust occurs due to specific variations in topography as well as changes in the original orientation of the flow (Valerio et al., 2008).

Lava tubes usually form along the axis of highest flow velocity with the flow and are often centered on older lava channels or narrow topographic lows such as stream beds, grabens, and rifts (Greeley, 1971). Lava tubes can be used to feed flows: 1) directly from a vent, acting as an extension of the vent; 2) from various holding reservoirs such as lava lakes or filled pit craters; 3) from flows on the flanks of volcanoes. The latter two mechanisms of acting as a conduit are observed at LBNM (see Section 2.2). These conduits allow lava flows to travel significantly farther than surface flows, as surface flows are in contact with the surface, whereas the heat in lava tubes is insulated (Greeley, 1987). 
Lava tubes act as a conduit for preferred water flow, as well as allowing the deposition, accumulation, and preservation of ice since the overcrust acts as an ultraviolet (UV) barrier and provides a stable environment. This in turn allows for precipitation of secondary minerals such as carbonates, sulphides, silica, and clays (Woo et al., 2008a,b). The precipitation of secondary minerals allows microorganisms to thrive in lava tubes. This secondary mineralization, known as speleothemic deposits, which consist of stalactites, stalagmites, flowstone, and cave pool deposits typically formed of calcite. These speleothemic deposits are where microorganisms are present, and commonly modify the composition of fluids and/or influence the precipitation of various minerals in the deposits (Jones, 2001). This implies that these microorganisms can mediate a wide variety of constructive and destructive processes that operate in the biofilms that cover any suitable surface of the lava tube. The biological and non-biological processes leading to secondary mineralization also leave biosignatures that can be preserved (Léveillé and Datta, 2010). Therefore, it is believed that if Mars had a habitable atmosphere, evidence of past life can be found in preserved biosignatures inside Martian lava tubes.

In addition to the potential of Martian lava tubes harbouring preserved biosignatures, they are considered top settlement locations for future manned missions to Mars. Because the surface is exposed to high-intensity UV radiation, it is considered extremely inhospitable for the construction of human habitats. Constructing a manned shelter inside lave tubes will provide UV protection as well as stable year-round temperatures (National Research Council, 2007). In addition to the natural advantages of settling in a lava tube, subsurface settlement will alleviate time, expense, and hazard factors for the astronauts charged with making these shelters (Boston et al., 2003). 
Lava tubes have been discovered on the surface of MARS through MO/THEMIS imagery from various Mars orbiters such as the Viking Orbiter (Hodges and Moore, 1994). These sightings and more have been confirmed by various orbiter imageries such as the Mars Odyssey, Mars Odyssey, Mars Global Surveyor, and other Mars orbiter systems (Hodges and Moore, 1994; Cushing et al., 2007; Keszthelyi et al., 2008; Wynne et al., 2008). These tubes are discovered as collapsed pits or "skylights" which leaves the appearance of a linear channel-like features that are discontinuous in most cases (Cushing et al., 2007). There were lava tubes discovered in the Tartarus Colles, with imagery indicating that the lava tube was formed in the main volcanic channel for the region (Keszthelyi et al., 2008). This is evidenced by the fact that the channel only has an intact roof on a short section of the channel, and that its roof is well below high-lava marks indicating that it formed after the lava level dropped substantially. 


\subsection{Lava Beds National Monument (LBNM)}

LBNM is located on the northeastern flank of Medicine Lake Volcano (MLV), a back-arc shield volcano of the southern Cascades located approximately 55 kilometers east from Mount Shasta (Figure 2.1). MLV is unique as it is located between the Cascade Range and the Basin and Range extensional environment at the intersection of major tectonic features including the Walker Lane fault zone, so there was debate as to whether the volcanism was subduction-related or extension-related (Donnelly-Nolan et al., 2008). The southern Cascades are considered a "transitional zone where horizontal stress is transferred from northwest-southwest dextral shear of the Walker Lane to dominantly east-west direction extension of the Cascade Range to the North" (Blakely et al., 1997). Because of the presence of andesite eruptions occurring throughout the volcano's history, it is more likely for the volcano to be subduction-related than extensional-related (Donnelly-Nolan et al., 2008). Despite the presence of rhyolitic and intermediate eruptions, MLV is a dominantly-basaltic shield volcano. 


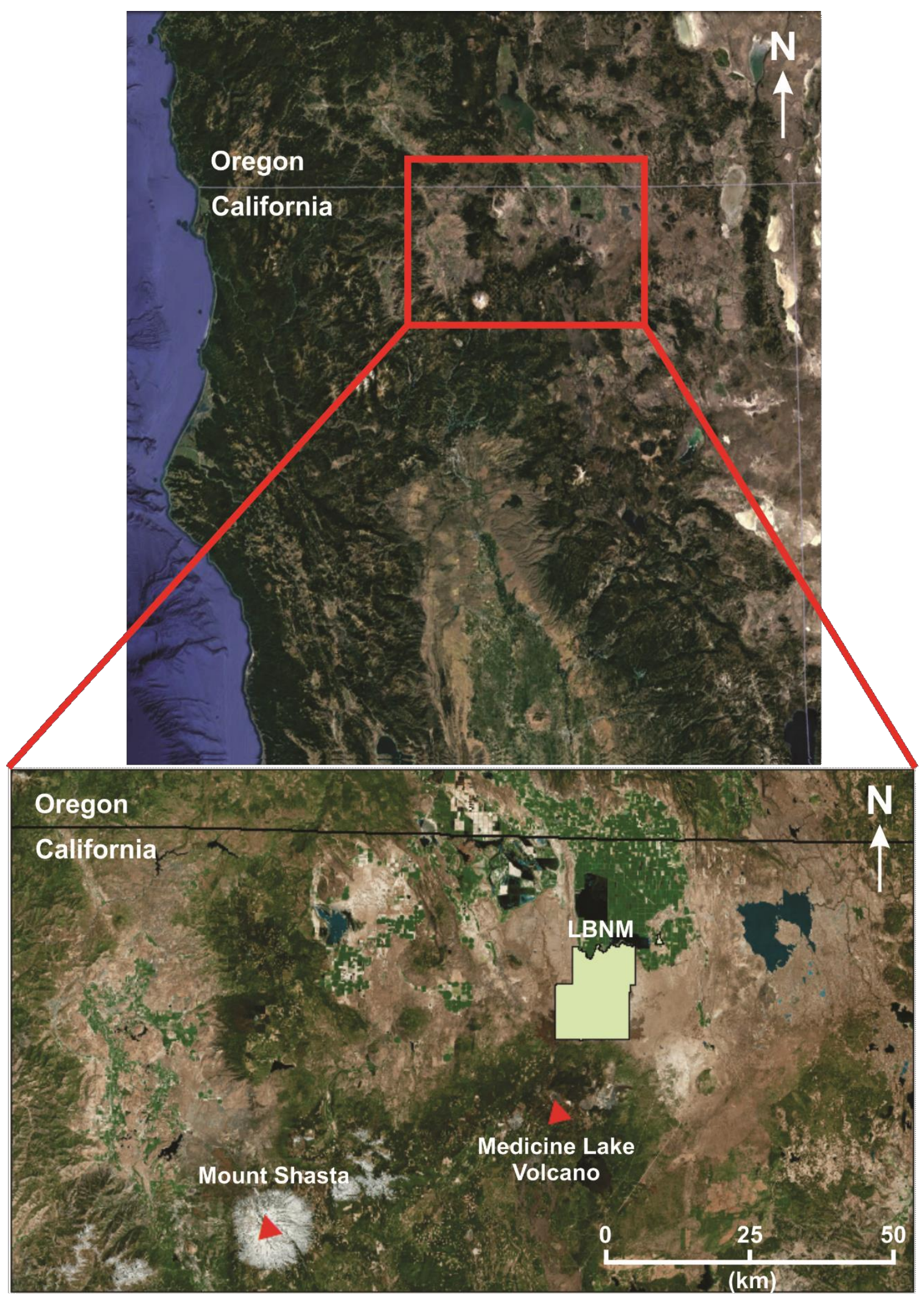

Figure 2.1: Location of Lava Beds National Monument, highlighted in green. Satellite imagery taken from Google Earth. 
The volcano has been active since $\sim 500 \mathrm{ka}$, with the most recent eruption occurring at 950 years before present (Donnelly-Nolan et al., 2007). The eruptive history of MLV is divided into five main stages based on ages and composition of units, although activity within these stages is episodic with respect to frequency of eruptions and composition (Donnelly-Nolan et al., 2008). The first stage consisted of mainly silicic lavas occurring from $\sim 475 \mathrm{ka}$ to $300 \mathrm{ka}$, with 18 different eruptions identified covering only $2.3 \%$ of the total surficial geology of MLV. The second phase had eruptions of basaltic to andesitic composition from $300 \mathrm{ka}$ to $200 \mathrm{ka}$, with approximately one-third of the eruptive units depositing during this interval covering $<10 \%$ of the surficial geology. The third stage consisted of the formation of the caldera rim from $200 \mathrm{ka}$ to $100 \mathrm{ka}$. A dacite episode of eruptions occurred from $200 \mathrm{ka}$ to $180 \mathrm{ka}$, before the only major tuff eruption in the volcano's eruptive history, known as the dacite tuff of Antelope Well. This tuff eruption led to the collapse of the rocks overlying the magma chamber (Donnelly-Nolan et al., 2007, 2008). An eruption at approximately 100 ka provided the distinctive silicic andesite found around the caldera rim. The fourth stage consisted of 24 eruptions occurring from $100 \mathrm{ka}$ to $13 \mathrm{ka}$, including 16 basaltic eruptions. Although there are only 24 units, they cover nearly half the total area of the volcano. The fifth and final stage consisted of episodic eruptions, taking place from vents scattered across the volcano. These eruptions included the eruption of Fleener Chimneys that formed Devils Homestead Flow and the eruptions that formed Valentine Cave. Recent activity of MLV consisted of 5 eruptions of differing compositions from 1230 to 950 years ago (Grove et al., 1997; Donnelly-Nolan et al., 2008). The final eruption formed the Glass Mountain flow, a rhyolitic flow that contains abundant volcanic glass (Grove et al., 1997). 
The surficial geology at LBNM consists primarily of lava flows of dominantly mafic composition, ranging from basalt to andesite (Figure 2.2). The majority of the flows were formed primarily from the series of eruptions occurring from $40 \mathrm{ka}$ to $30 \mathrm{ka}$ at Mammoth Crater (Figure 2.2), a "satellite volcano" located just south of the LBNM (Anderson, 1941; Waters et al., 1990). Because Mammoth Crater formed on the alreadysloping flank of MLV, all flows originating from this crater trend northward and eastward. Six nearby cinder cones acted as barriers to the lavas from Mammoth Crater, forming a "lava lake" (Waters et al., 1990). The majority of the lava stayed in the lake, with lava escaping only by overflows due to constant flow from Mammoth Crater and no outlet. Overflows continued to occur along the sides until a permanent outlet formed underground as the hydraulic pressure from the lake allowed previously blocked lava tubes to reopen (Waters et al., 1990). Skull Cave and the Cave Loop lava tube systems originated from the draining of the lava lake. The lavas from the series of eruptions cover about $225 \mathrm{~km}^{2}$, approximately $70 \%$ of the total area of LBNM (Donnelly-Nolan et al., 2007).

Other major volcanic flows to note at LBNM are Devils Homestead Flow and the flows that formed Valentine Cave. Devils Homestead Flow, a north-trending flow located on the north side of LBNM, originated from the eruption of the Fleener Chimneys occurring at $12 \mathrm{ka}$ (Donnelly et al., 2008). Devils Homestead Flow is primarily pahoehoe close to the Fleener Chimneys, and a'a further away from the source; however, the pahoehoe section of the flow is heavily vegetated making outcrops hard to find. Valentine Cave, a popular attraction at LBNM due to its size and characteristic shape, originated from basaltic-andesitic eruptions from the Tickner Chimneys and other nearby spatter vents just south of LBNM. The eruptions at Tickner Chimneys occurred approximately 100 years 
after the Fleener Chimney eruptions (Donnelly-Nolan et al., 1990). Valentine Cave was thought to be the main drainage outlet for these eruptions but is currently inconclusive due to collapses at either end of the lava tube.

LBNM has the highest concentration of lava tubes in North America, with over 800 documented lava tubes (Waters et al., 1990). The lava tubes at LBNM are above the water table and relatively shallow, with most being 25-40 $\mathrm{m}$ at their maximum depth, meaning that the tubes are relatively accessible (Waters et al., 1990). Immediately beside the visitor's centre is an area of easily accessible tubes known as "Cave Loop", which have a high concentration of individual and connected lava tubes (Figure 2.3). Most of the lava tubes are open to the public year-round; however, some are closed in the summer time as it is a significant maternity roost for Townsends Big-Eared Bats, and the bottom section of Skull Cave is restricted from the public to prevent melting of the ice floor. In addition to lava tubes being restricted to the public, some are considered Class III Management Caves, meaning that not only is access restricted to permission only and an escort is required, the location and name of these lava tubes are not to be used in publications. 


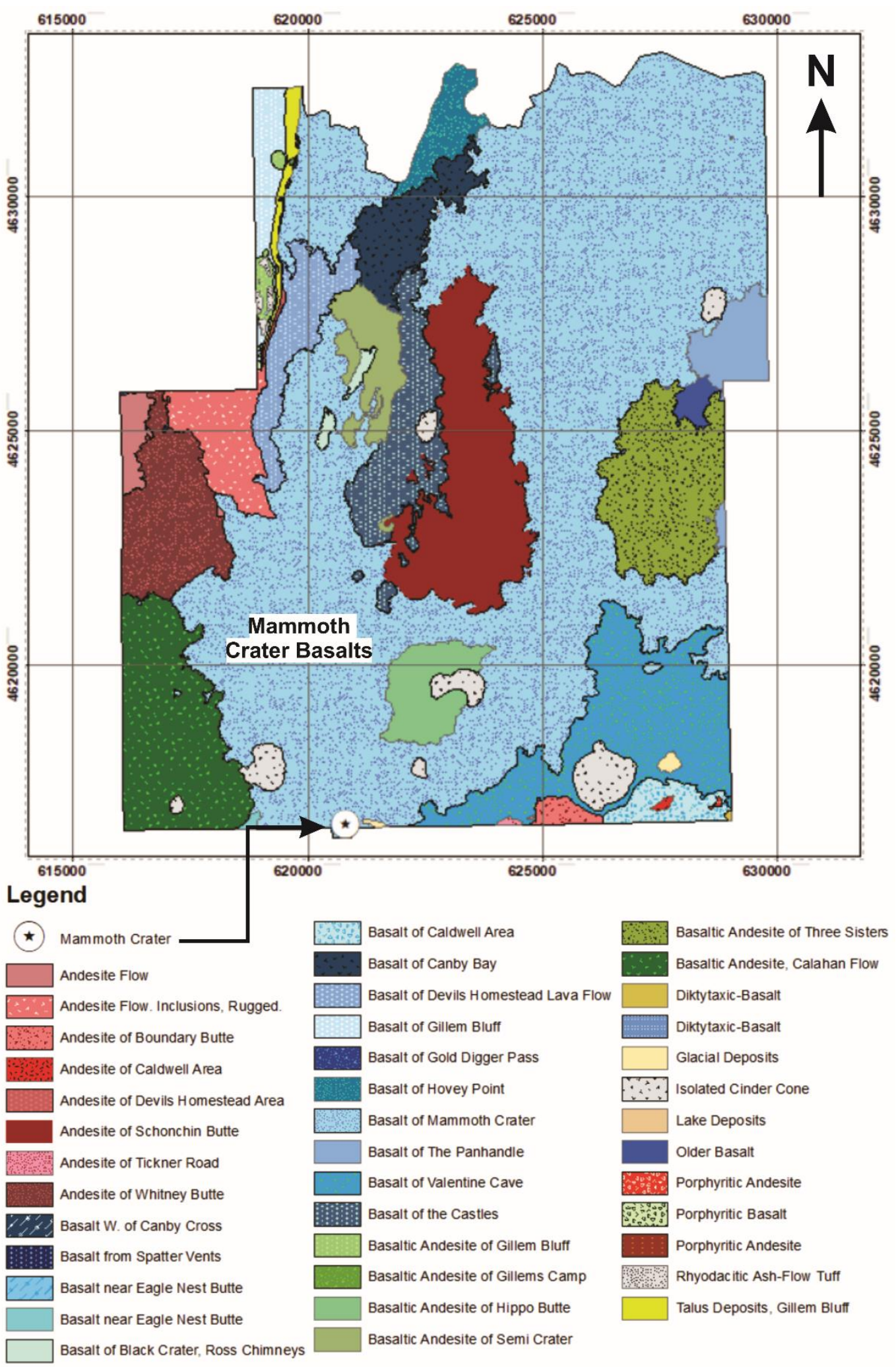

Figure 2.2: Geologic map of LBNM. Derived from Donnelly-Nolan and Champion (1987) and digitized by the GIS Specialist at LBNM. Mammoth Crater is visible on the southern portion of LBNM (black arrow), and the Mammoth Crater Basalts are labelled. 


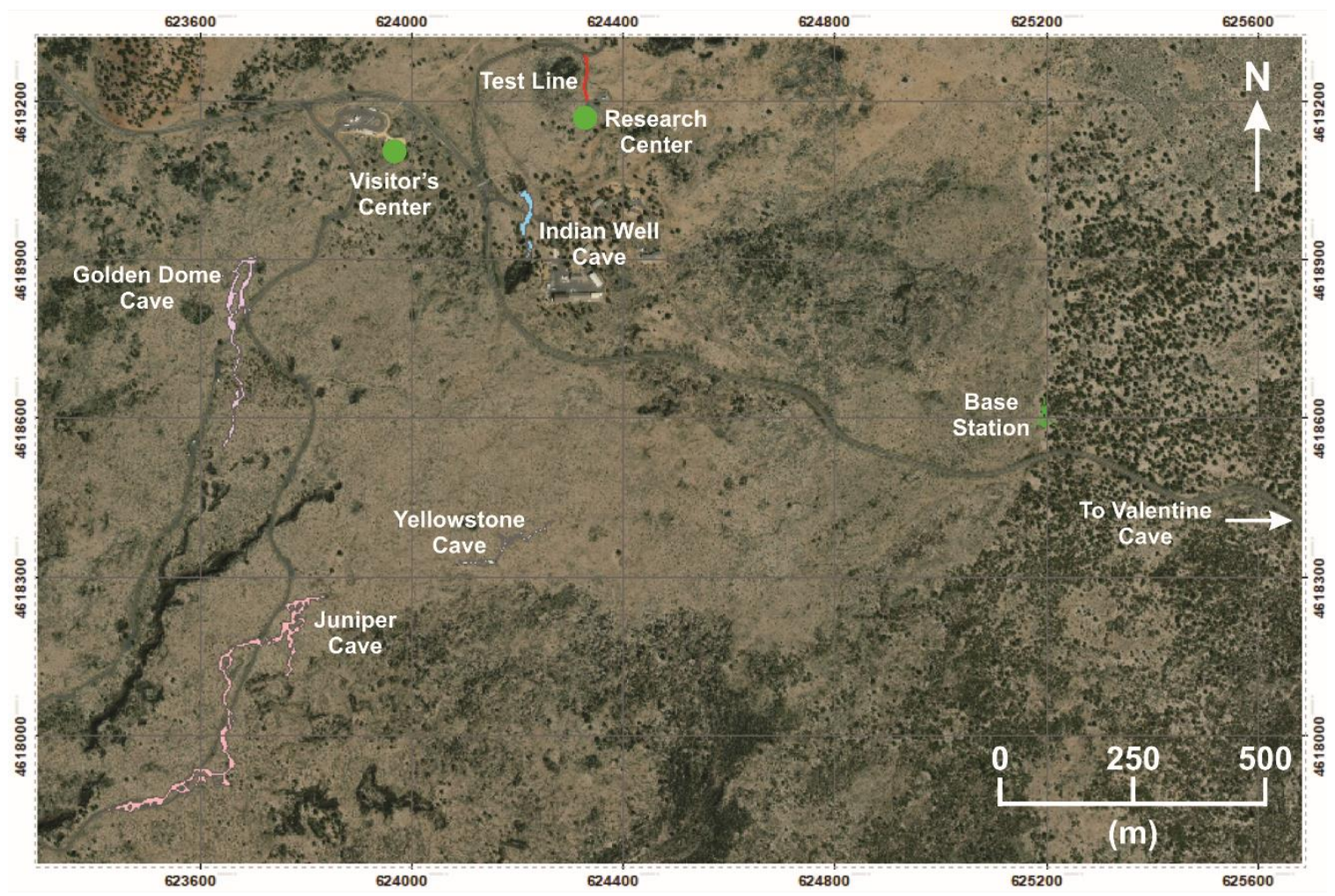

Figure 2.3: Main visitor complex at LBNM. Cave Loop is located southwest of the Visitor's Center. Satellite imagery taken from Google Earth. 


\section{Methods}

\subsection{Electromagnetic Induction}

\subsubsection{Theory}

EM Induction surveying is a geophysical technique in which the electrical conductivity of the surface can be mapped remotely by using a time-varying EM field, known as the "primary field". The operating principle of EM induction surveying is shown in Figure 3.1. The transmitter is a coil in which alternating current passes through, generating the primary EM field. The primary field propagates through the subsurface and induces currents - known as eddy currents - in conductive bodies. These eddy currents will produce a secondary EM field, in the opposite direction of the primary EM field. The secondary magnetic field is sensed by the receiver(s).

There are two classes of EM induction systems: frequency-domain EM (FDEM), and time-domain EM (TDEM). FDEM involves broadcasting a continuous signal at various frequencies, typically as a sinusoidal wave. Because the transmitter signal is continuous, the receiver senses both the primary and secondary fields simultaneously; however, because the primary field is known, it can be filtered out, so the secondary field is isolated (McNeill, 1980). In TDEM, the transmitter signal is sent in pulses rather than as a continuous signal. The secondary field is recorded once the primary signal is turned off, removing the need to filter out the primary field. In TDEM surveying, the rate of decay of the secondary field is measured to estimate subsurface conductivity; eddy currents decay slower when conductive bodies are present, and therefore the secondary field will also show a slow rate of decay (Schultz and Ruppel, 2003).

If a subsurface conductor is modelled as a simple series circuit with a resistance $R$ and an inductance $L$, the secondary field will be a complex function of $\omega L / R$, where $\omega$ is 
the transmitter frequency. The secondary field can be mathematically decomposed into two components: the real component, also known as the "in-phase" component because the response it has the same phase with the primary field; and the imaginary component, known as the "quadrature" component, which is $90^{\circ}$ out-of-phase with respect to the real component (McNeill, 1980a). Therefore, the mathematical function can be written as $\mathrm{P}+$ $\mathrm{iQ}$, where $\mathrm{P}$ is the in-phase component and $\mathrm{Q}$ is the quadrature component. At low induction numbers, in-phase data measures the apparent magnetic susceptibility and quadrature data measures apparent conductivity (McNeill,1980b). This simplifies the signal processing stage significantly. The units used for magnetic susceptibility are dimensionless but can be expressed using different systems of measurement: parts-perthousand (ppt), international system of units (SI), and centimeters-grams-seconds (cgs). The conversion between the three units are shown in Table 3.1 (West, 2007). The units used for conductivity are milliSiemens per meter $(\mathrm{mS} / \mathrm{m})$.

Table 3.1: Unit conversions for magnetic susceptibility used in various publications.

\begin{tabular}{|c|l|c|}
\hline & \multicolumn{1}{|c|}{ cgs } & ppt \\
\cline { 1 - 2 } SI & $\mathrm{SI}=4 \Pi^{*} \operatorname{cgs}$ & $\mathrm{SI}=\mathrm{ppt} / 1000$ \\
\cline { 1 - 2 } ppt & $\mathrm{ppt}=\left(4 \Pi^{*} \operatorname{cgs}\right) / 1000$ & \multicolumn{1}{|c}{} \\
\cline { 1 - 2 } & &
\end{tabular}




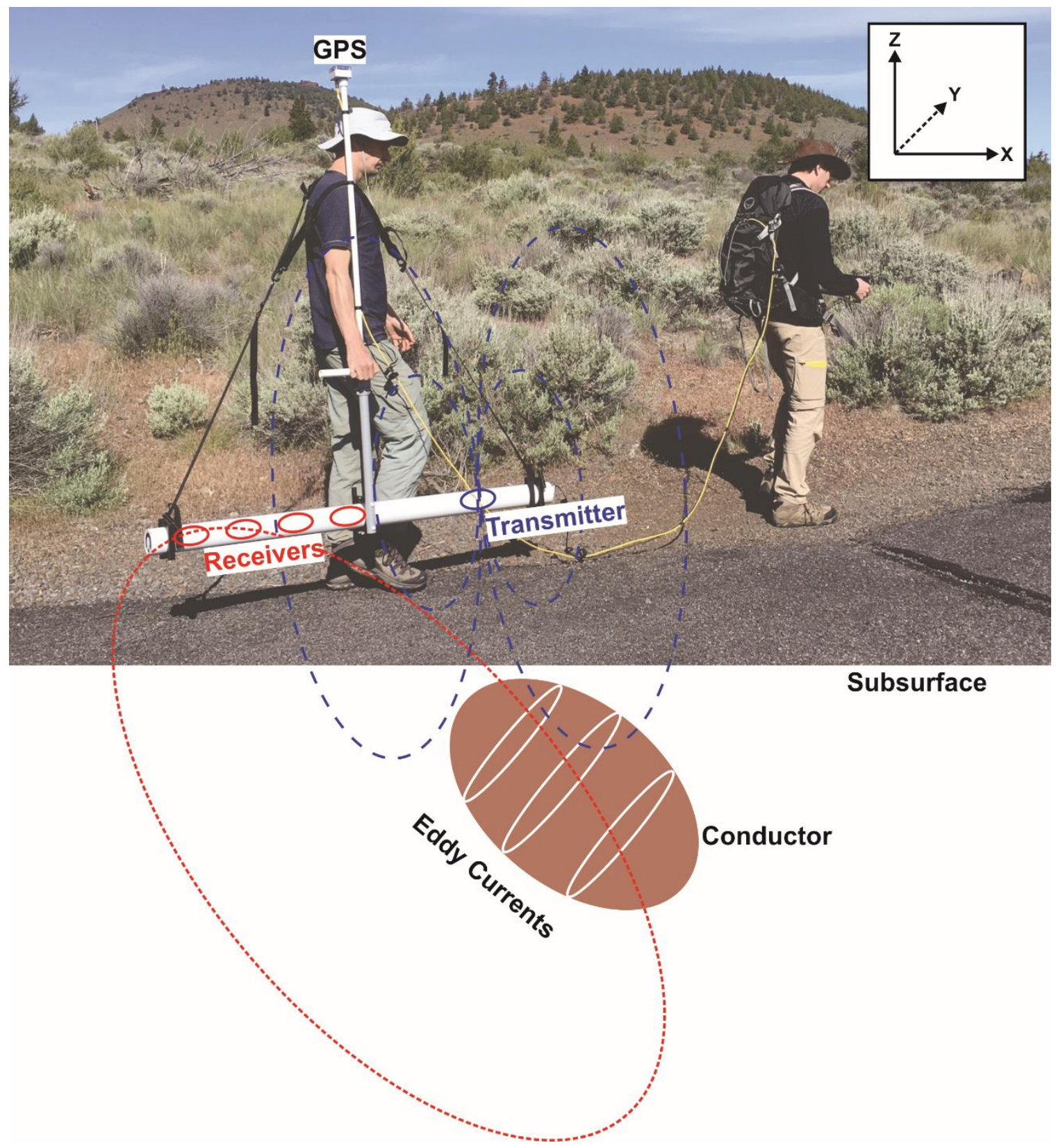

Figure 3.1: Sketch of the operative principle of the R4 EMIS. The primary field (dashed blue lines) generated by the transmitter induces eddy currents (solid white lines), which in turn induce the secondary field (dotted red lines) that is recorded by the four receivers. The cables shown connect the R4 EMIS and the GPS to a logger box carried in the backpack of the operator. 


\subsubsection{Instrumentation}

The sensor used for the EM component of this research project is the prototype R4 frequency-domain electromagnetic induction sounder (EMIS) from Geosensors Inc. (Figure 3.1). The R4 comprises of one transmitter loop and four receiver loops, all of which are oriented parallel to the transmitter coil (Figure 3.2). The R4 operates at a transmitter frequency of $9 \mathrm{kHz}$, and the transmitter and receivers are separated by distances of $50 \mathrm{~cm}$, $70 \mathrm{~cm}, 90 \mathrm{~cm}$, and $110 \mathrm{~cm}$. Because the transmitter and receivers are coplanar, the R4 EMIS can record data at almost any orientation. Though that is the case, the R4 is typically used in two orientations: $0^{\circ}$ roll, where the transmitter and receivers are oriented parallel to the ground (the $\mathrm{x}$-axis); or $90^{\circ}$ roll, where the transmitter and receivers are oriented perpendicular to the ground, which is parallel to the z-axis (Figure 3.2). The R4 is a ground conductivity meter that operates in the resistive limit, where in highly resistive, shallow environments the received signal is controlled by the geometry of the sensor. The R4 is a "geometric" sounder, where a parameter such as height or transmitter-receiver separation is varied to change the proportion of response from the ground. In this project, the transmitter-receiver separation controls the response as the survey height above ground is close to zero. For $0^{\circ}$ roll, the depth of exploration (DoE) is calculated as:

$$
D o E \approx 1.55 * X
$$

\section{Equation 3.1}

where $\mathrm{X}$ is the transmitter-receiver separation. The depth of exploration for $90^{\circ}$ roll orientation is half the depth of exploration for $0^{\circ}$ roll orientation for each receiver. Note that the depth of exploration is an approximation where $70 \%$ of the response is due to soil shallower than that depth, meaning that highly conductive artefacts in resistive 
environments well below the depth of exploration can be. However, outside the depth of exploration range, these high-conductivity features cannot resolve deeper structures or parameters. Thus, the depth of exploration can be greater in resistive environments, but at low resolutions or assumptions of that conductive feature need to be made. Specifications for the R4 EMIS are shown in Table 3.2.

Table 3.2: Specifications of the R4 EMIS from Geosensors Inc.

\begin{tabular}{|c|c|c|}
\hline \multicolumn{3}{|c|}{ Geosensors R4 EMIS } \\
\hline Transmitter Frequency & {$[\mathrm{kHz}]$} & 9 \\
\hline \multirow{2}{*}{ Components } & \multirow{2}{*}{ - } & 1 Transmitter \\
\hline & & 4 Receivers \\
\hline \multirow{4}{*}{$\begin{array}{l}\text { Transmitter-Receiver } \\
\text { Frequency }\end{array}$} & \multirow{4}{*}[\mathrm{cm}]{} & 50 (Receiver 1) \\
\hline & & 70 (Receiver 2) \\
\hline & & 90 (Receiver 3) \\
\hline & & 110 (Receiver 4) \\
\hline Length & [m] & 1.58 \\
\hline Mass & {$[\mathrm{kg}]$} & 5.1 \\
\hline Voltage & [V] & 12 \\
\hline Power & {$[\mathrm{W}]$} & 3 \\
\hline $\begin{array}{l}\text { Survey Height Above } \\
\text { Surface }\end{array}$ & {$[\mathrm{cm}]$} & 30 \\
\hline Sampling Frequency & {$[\mathrm{Hz}]$} & 2 \\
\hline \multirow{4}{*}{$\begin{array}{l}\text { Maximum Depth of } \\
\text { Exploration for } 0^{\circ} \text { roll } \\
\text { orientation (normal font) } \\
\text { and } 90^{\circ} \text { roll orientation } \\
\text { (italics) }\end{array}$} & \multirow{4}{*}[\mathrm{cm}]{} & $77.5,38.75$ (Receiver 1) \\
\hline & & $108.5,54.25$ (Receiver 2) \\
\hline & & $139.5,69.75$ (Receiver 3) \\
\hline & & $170.5,85.25$ (Receiver 4) \\
\hline
\end{tabular}




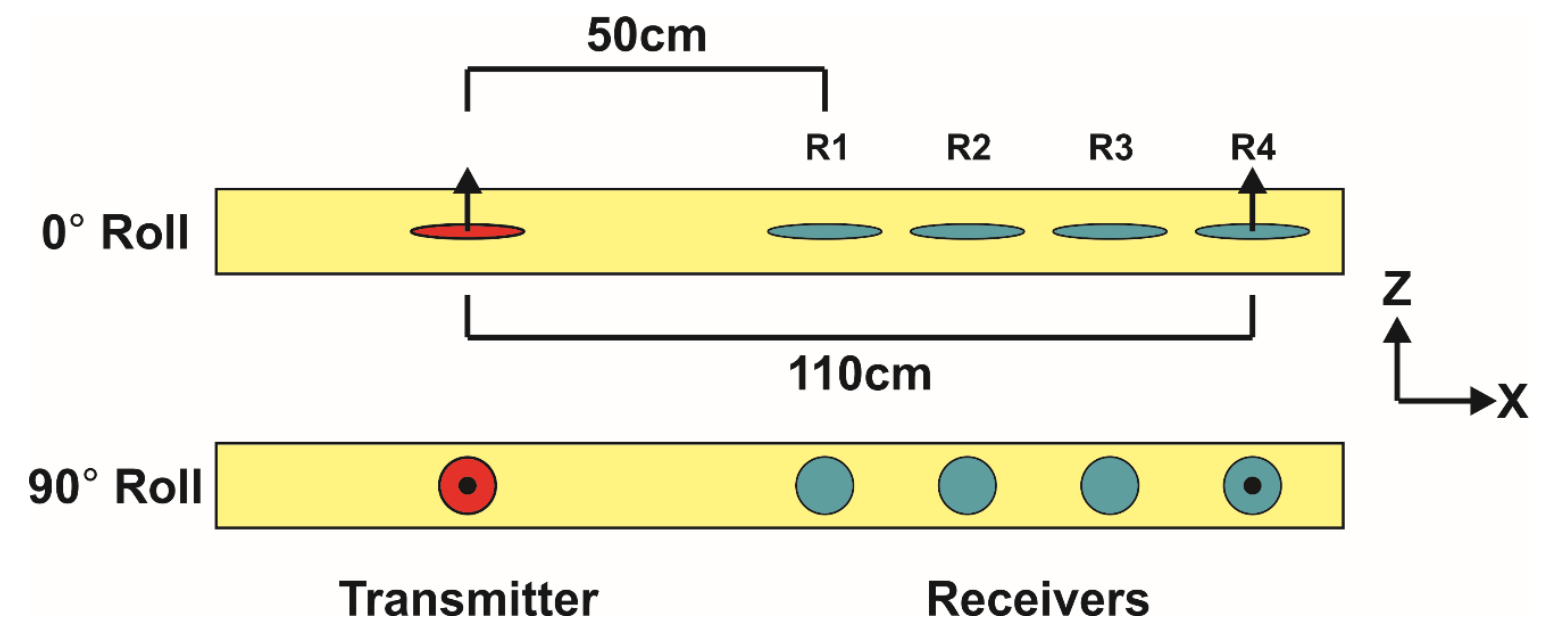

Figure 3.2: Internal components of the R4 EMIS in $0^{\circ}$ roll and $90^{\circ}$ roll.

The R4 EMIS is used to survey along traverses, where the sensor is taking measurements continuously at a sampling frequency of $2 \mathrm{~Hz}$. The $\mathrm{R} 4$ can be transported along the traverse either by being mounted on a non-conductive sled and dragged on the ground behind (Figure 3.8) or carried by the person using vertical PVC piping and a handle (Figure 3.1). To keep noise at a minimum, it is important to keep the R4 EMIS at the same height above the ground throughout the survey, which for this research project was approximately $30 \mathrm{~cm}$. Dragging the R4 on a sled is the preferred way to survey, as any variations in pitch and roll are due to topography. When the sensor is carried by an operator, human errors in pitch and roll are introduced; however, it is preferred in terrains where there is a lot of low-brush vegetation such as sites surveyed for this project (Figure 3.1). Pitch and roll of the sensor introduce errors in measurements and should be as close to zero as possible. Changes in the internal temperature of the sensor can cause changes in data, as the transmitter and receiver coils can expand and contract due to these changes. Therefore, when surveying in an area where there is a drastic change in air temperature, it is necessary to leave the sensor for about 15 minutes to thermally compensate. 
Data is collected by the receivers and stored in an external logger box (Figure 3.1). In addition to data coming from the receivers, longitude and latitude are recorded from the GPS (Figure 3.1) and sent to the logger box. The R4 EMIS is controlled using the Geosensors app on an iPad or iPad mini (Figure 3.3), which connects to the sensor through a Wi-Fi connection from the logger box. The app interface shows pitch and roll, either inphase or quadrature data of all 4 receiver coils, or raw data by swiping right on the bottom half of the page. Recording is done by pressing "start recording" on the app, and the instrument continues to record until the "stop recording" button is tapped. Surveying can be paused in the middle of a recording if there are any issue that occur as surveying is being conducted. The raw data is stored in the logger box until downloaded to the iPad through Wi-Fi connection from the logger box. Once downloaded, data can be sent from the app to any computer by email. 


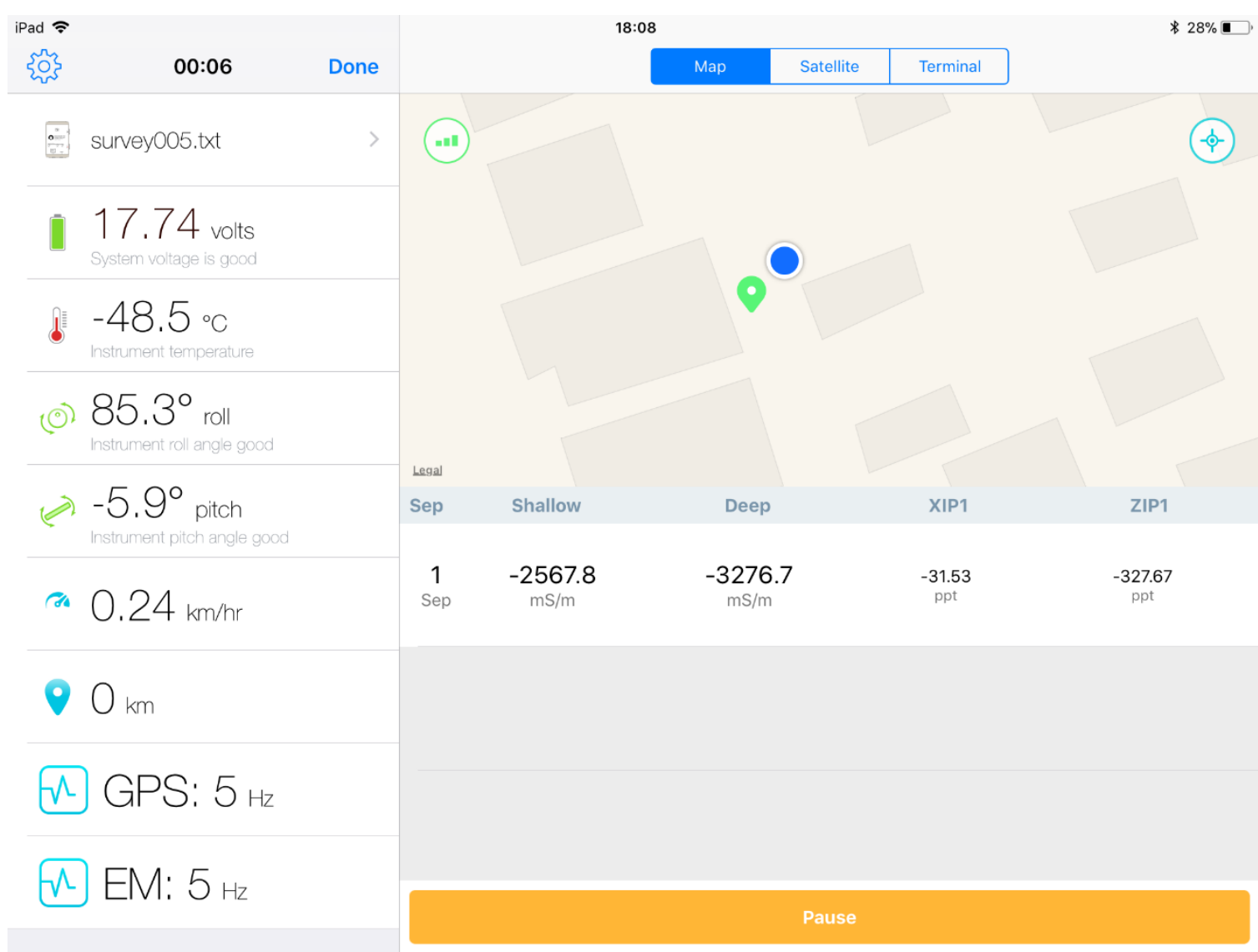

Figure 3.3: User interface of the Geosensors app on Apple IOS. The left toolbar shows data such as battery life, internal temperature, pitch and roll, speed, and sampling frequency for both the GPS and the sensor. The main page shows the location in real time, as well as quadrature and in-phase data. 


\subsubsection{Signal Processing}

Raw data from the R4 EMIS comes in .txt format, with each line showing information either from the instrument as "PGSI-", or the GPS as "GN---" (Figure 3.4). The .txt file is converted to .RAS by writing "ren*.txt*.RAS in the command prompt. After the file is converted to .RAS, it is then converted to .log through an application called NMEAXcrib which is run through the command prompt. The application works by typing "NMEAXcrib filename L" in the command prompt, with the L meaning that the application converts the file to .log (Figure 3.5). The application will ask for the approximate sensor height used for the survey to automatically correct data for that height. Because each receiver coil measures in-phase and quadrature data, values are labelled as "IP1" for inphase data and "QD1" for quadrature data for the receiver with the smallest Tx-Rx separation, and thus the smallest depth of exploration.

After the raw data to converted to $\log$ format, data is processed in MATLAB. A smoothing filter is applied to the data to reduce noise and provide an average representative curve. The filter used was made using Design Builder app in MATLAB and executed using the Designfilt function (Figure 3.6). Specifications for the filter specified in the bottom half of Figure 3.6. The passband and stopband frequencies were changed depending on how the filtered data looked compared to the raw data since over-smoothing can cause a problem later with interpretation. Therefore, some trial and error with the filter was needed to properly smooth data. The filter was applied to data using the zero-phase digital filtering function known as "filtfilt $(\mathrm{b}, \mathrm{a}, \mathrm{x})$ ", where $\mathrm{b}$ and a are transfer coefficient functions, and $\mathrm{x}$ is the input signal. This is done so that there is no shift in data on the x-axis (Figure 3.7). 
U Chris'_Bridge___Roll - Notepad

File Edit Format View Help

\$PGSI1 $114159.878,-4.8,-0.10,+0.8,-0.14 * 06$

\$GNVTG, , T, , M, $0.104, \mathrm{~N}, 0.192, \mathrm{~K}, \mathrm{D} * 37$

$\$ P G S I 2,114200.378,+0.0,+0.07,+0.3,+0.18^{*} 0 \mathrm{~A}$

\$GNGGA, 170254. 50, 4142.53851, N, 12130.81006, W, 2, 12, 0.47, 1503.9, M, - 23.6, M, , 0000*40

\$GNVTG, , T, , M, 0.174, N, 0.322, K, D*39

\$PGSIA $,+11.96,+20.9,-2.6,-4.4 * 7 \mathrm{C}$

\$PGSI1, $114200.878,-3.4,-0.09,+0.9,-0.12 * 0 \mathrm{D}$

$\$$ PGSI $, 114200.878,+0.7,+0.07,+0.1,+0.18 * 04$

\$GNGGA , 170255.00, 4142.53848, N, 12130.81003, W, 2, 12, 0.47, 1503.9, M, - 23. 6, M, , 0000*49

\$GNVTG , 8.42, T, , M, $0.638, N, 1.182, \mathrm{~K}, \mathrm{D} * 2 \mathrm{~F}$

\$PGSIA $,+11.99,+20.9,-3.3,-5.8 * 7 A$

\$PGSI1, 114201.378, $-2.1,-0.11,+0.8,-0.14 * 0 \mathrm{D}$

$\$ P G S I 2,114201.378,+0.5,+0.06,+0.0,+0.16 * 02$

\$GNGGA, 170255.50, 4142.53854, N, 12130.81002, W, 2, 12, 0.47, 1503.9, M, - 23.6, M, , 0000*40

\$GNVTG, 336.98, T, , M, 0.315, N, 0.584, K, D*2F

\$GNGGA, 170256.00, 4142.53850, N, 12130.81004, W, 2, 12, 0.47, 1503.9, M, - 23.6, M, , 0000*44

\$PGSIA $,+11.99,+20.9,-0.5,-6.3 * 77$

\$PGSI1 $114201.878,+1.6,-0.12,+0.7,-0.17 * 0 \mathrm{~B}$

$\$ P G S I 2,114201.878,+0.2,+0.02,+0.0,+0.12 * 0 \mathrm{E}$

\$PGSIA $,+11.97,+20.9,+1.1,-5.7 * 7 \mathrm{D}$

\$GNVTG, 135.43, T, , M , 1.272, N , 2.355, K, D*21

\$PGSI1 $114202.378,+3.4,-0.12,+0.2,-0.15 * 04$

$\$$ PGSI2, $114202.378,+0.3,+0.05,+0.1,+0.17 * 04$

Figure 3.4: .txt file showing raw data extracted from the R4 EMIS.

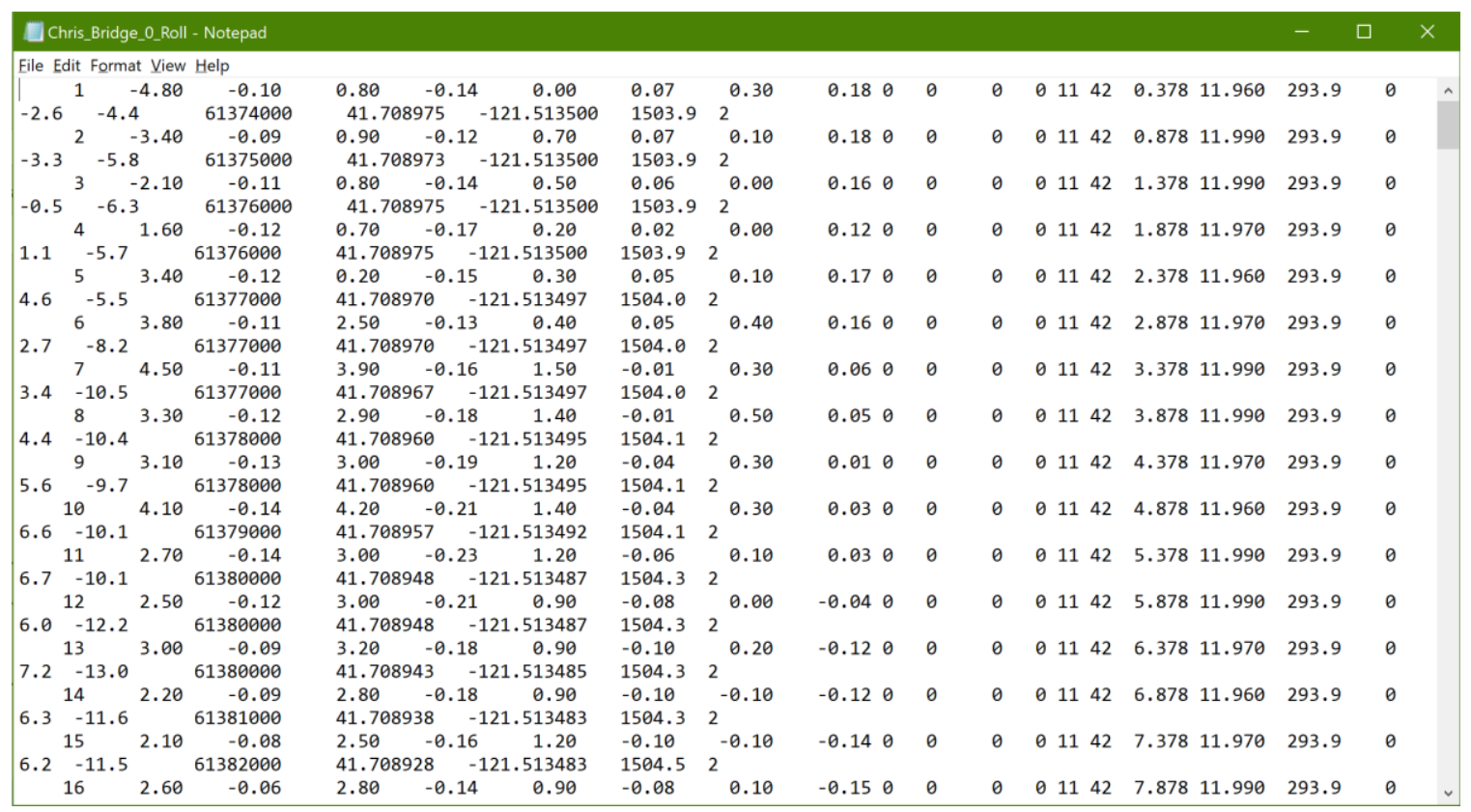

Figure 3.5: .log file showing raw data converted from the .txt file. 
A Filter Designer - [untitled.fda *]

File Edit Analysis Targets View Window Help

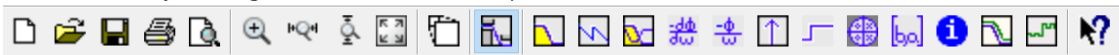

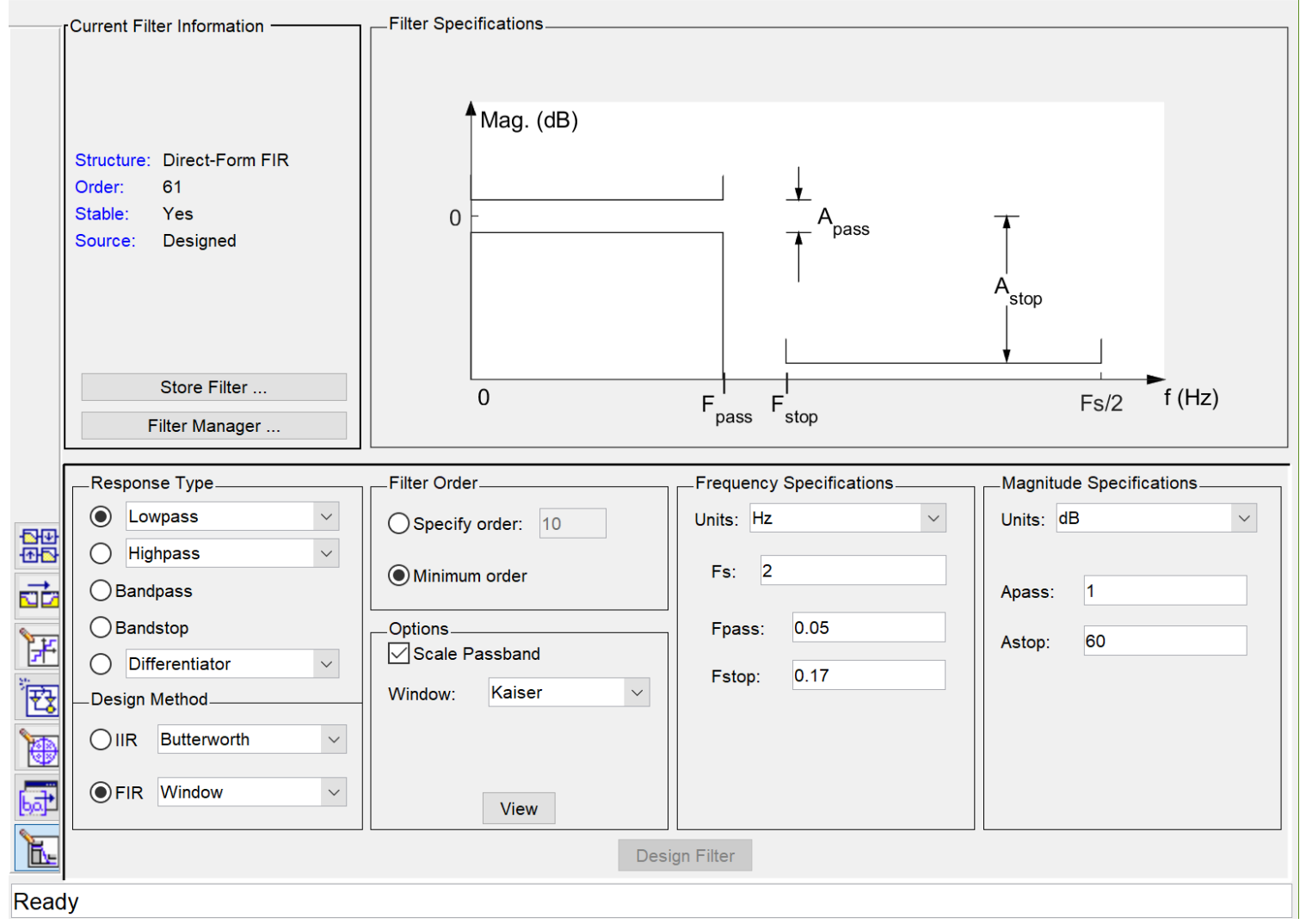

Figure 3.6: The Filter Design application in MATLAB. The parameters that need to be specified are shown on the bottom half of the figure. A visual representation of what each specification represents is shown in the top left corner of the window. The filter design shown is a lowpass response with the Kaiser window design method. 


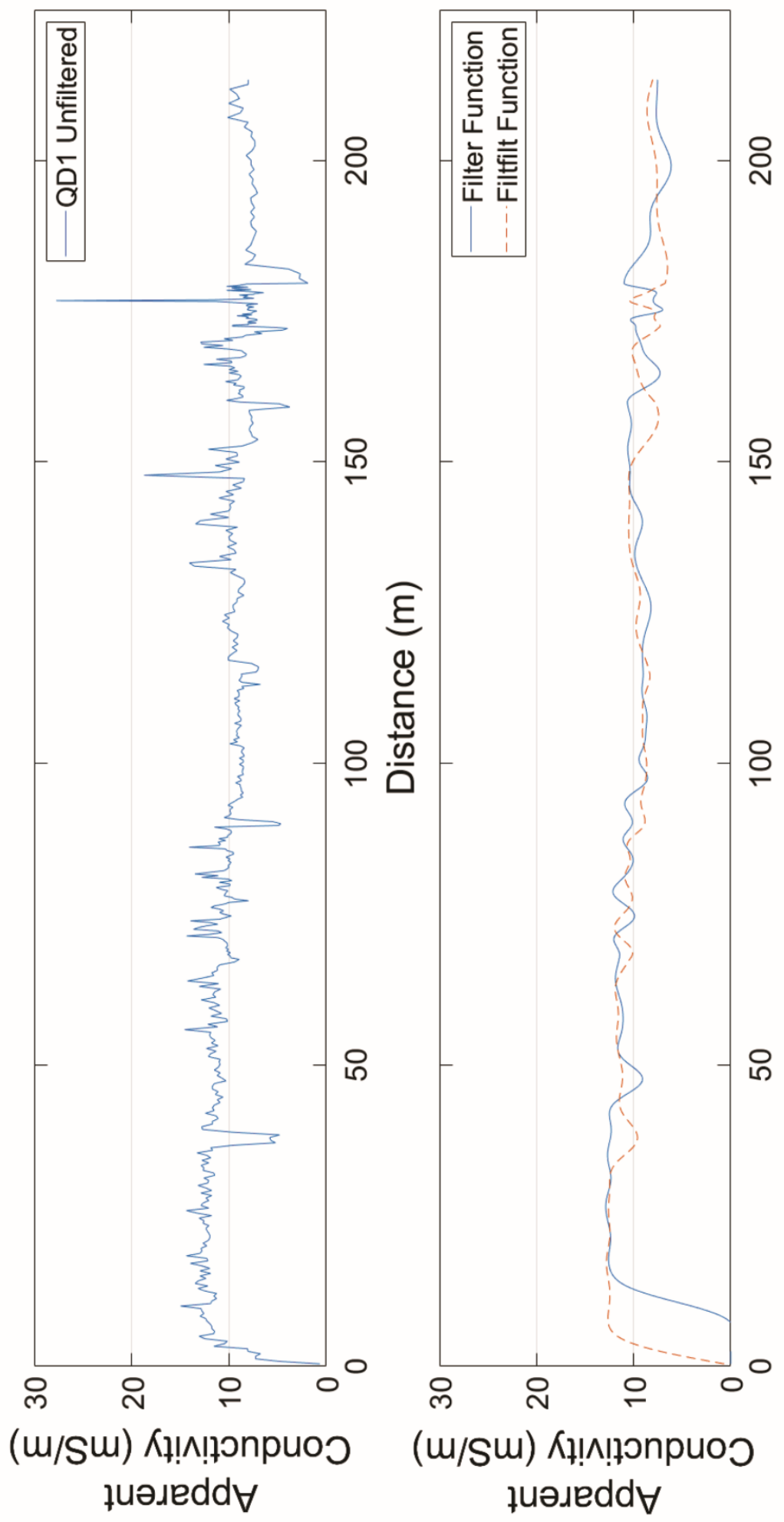

Figure 3.7: Comparison of the filter function (left) in MATLAB versus the filtfilt zerophase filtering function (right) using parameters shown in Figure 3.6. The right figure shows filter function (red line) and filtfilt function (black line). 


\subsubsection{Test Survey at Wilket Creek Park}

On May 4, 2017, a small test survey was conducted at Wilket Creek Park in Toronto, Ontario (Figure 3.8). The purpose of this survey was to become familiar with the operation procedures of the R4 EMIS, as well as an introduction to the processing of raw EMIS data. The survey consisted of 12 approximately parallel north-south traverse lines, with the survey starting in the east and ending at the west side of the field. The first line was approximately $60 \mathrm{~m}$ long, with the length of each line increasing progressively until the last line which was $80 \mathrm{~m}$ long. Figure 3.9 and Figure 3.11 show apparent conductivity results from the receiver with the smallest depth of exploration (Receiver 1 ) survey at $0^{\circ}$ roll and $90^{\circ}$ roll, respectively; Figure 3.10 and Figure 3.12 show magnetic susceptibility results from Receiver 1 at $0^{\circ}$ roll and $90^{\circ}$ roll surveys, respectively.

Looking at the apparent conductivity data from Receiver 1 (Figure 3.9), there is a strong anomaly in the northeast corner of the survey. This is interpreted to be a zone that was dug up and back-filled with clay-rich soil, which has higher conductivity than the surrounding material. There is are extremely high conductivity values on the south side of the field. This is interpreted as a sewer pipe situated just below the surface. Since the depth of exploration of Receiver 1 at $0^{\circ}$ roll is approximately $77.5 \mathrm{~cm}$ (Table 3.2 ), the signature of the pipe is clearly visible. The anomaly where the pipe is also coincides with a trench, which can be detectable by an anomaly in the in-phase data if the backfill material is more magnetic than the surrounding soil. Figure 3.10 confirms this, as there is a high magnetic susceptibility anomaly where the trench is.

Apparent conductivity at $90^{\circ}$ roll (Figure 3.11 ) shows very similar anomalies to that from the $0^{\circ}$ roll survey, especially the northwest anomaly. Because the depth of 
exploration at $90^{\circ}$ roll is half of the depth of exploration at $0^{\circ}$ roll, this implies that the backfill is very shallow so the anomaly would be stronger with $90^{\circ}$ roll. The anomaly corresponding to the sewer pipe was visible, but not as strong in magnitude as the anomaly in the $0^{\circ}$ roll survey. It is possible that that the pipe is deep enough that the sensor only detects the top of the pipe at $90^{\circ}$ roll.

There is also a subtle N-S anomaly connecting the two major anomalies in the park visible in Figure 3.9 and Figure 3.10. Because the traverse lines were approximately parallel to the anomaly, it is difficult to determine whether or not it is another sewer pipe or a smaller water pipe. It is recommended that another survey be conducted with traverse lines going perpendicular to the traverse lines done during this survey. 


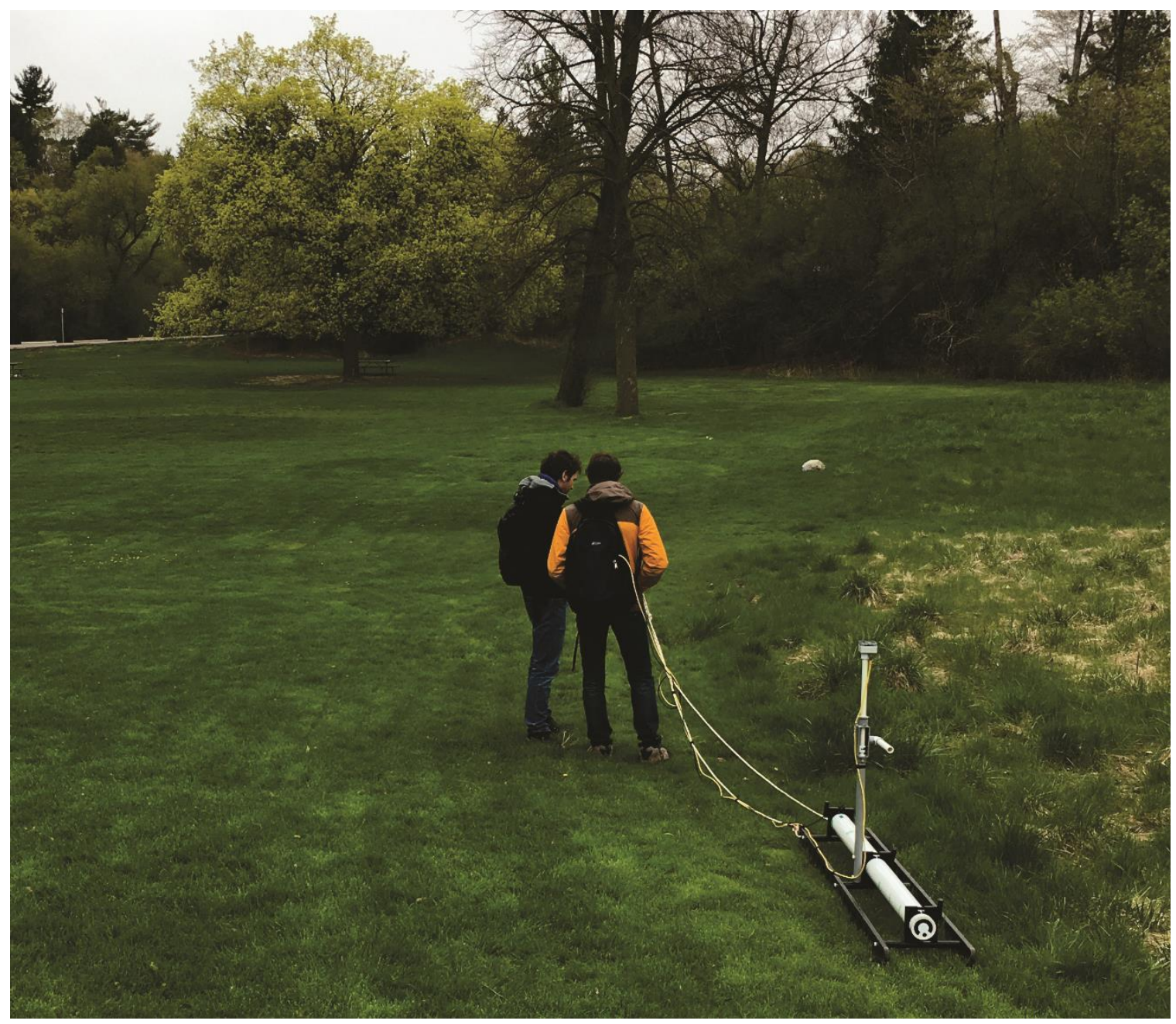

Figure 3.8: Test survey at Wilket Creek Park in Toronto, ON. The R4 EMIS is shown on a non-conductive sled, which was dragged behind using a rope attached to the end of both sides of the sled. The logger box is in the black backpack. 


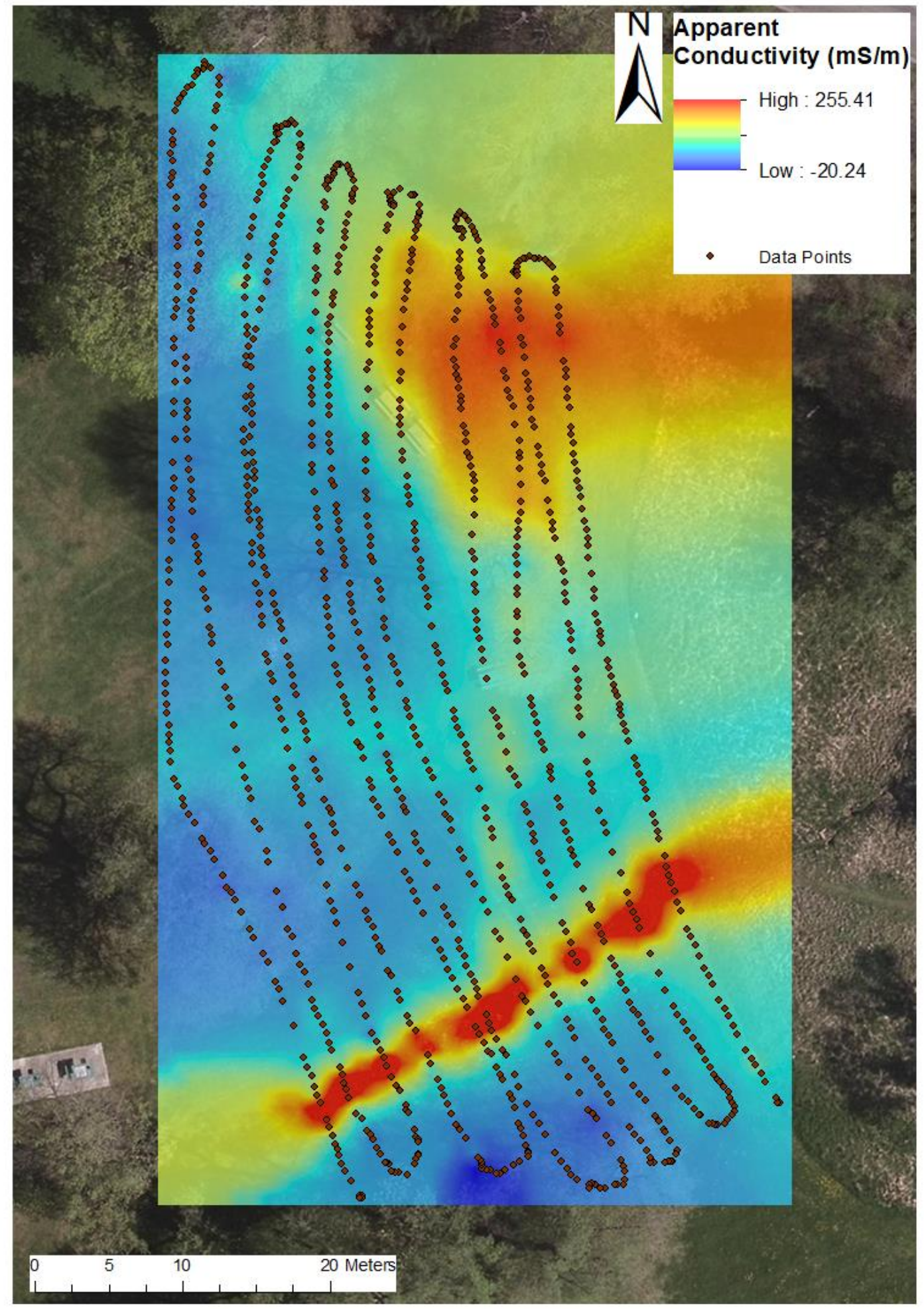

Figure 3.9: Apparent conductivity results from Receiver 1 at $0^{\circ}$ roll. Results were interpolated using inverse distance weighting with a cell size of $1 \mathrm{~m}$. Satellite imagery taken from Google Earth. 


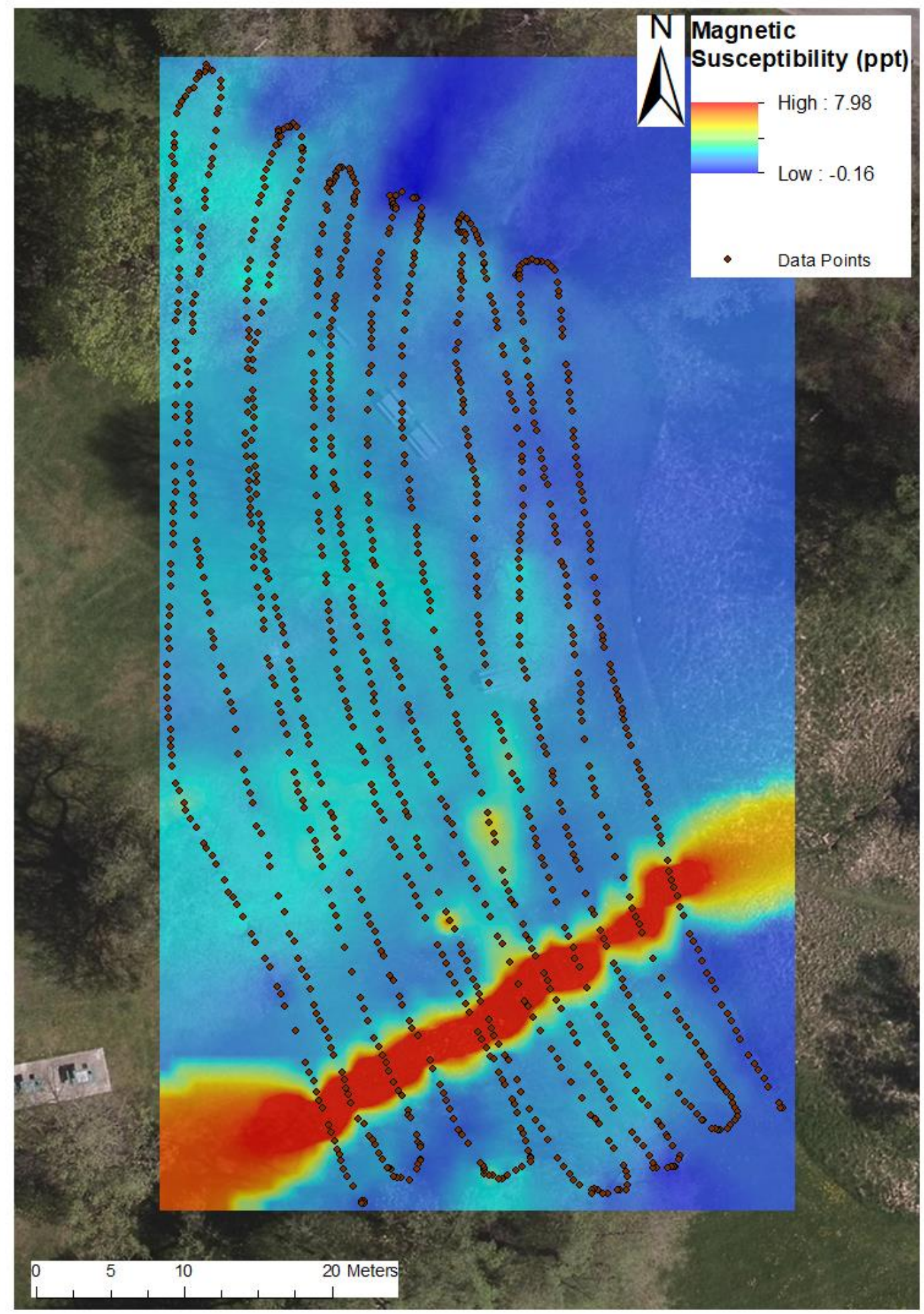

Figure 3.10: Magnetic susceptibility results from Receiver 1 at $0^{\circ}$ roll. Results were interpolated using inverse distance weighting with a cell size of $1 \mathrm{~m}$. Satellite imagery taken from Google Earth. 


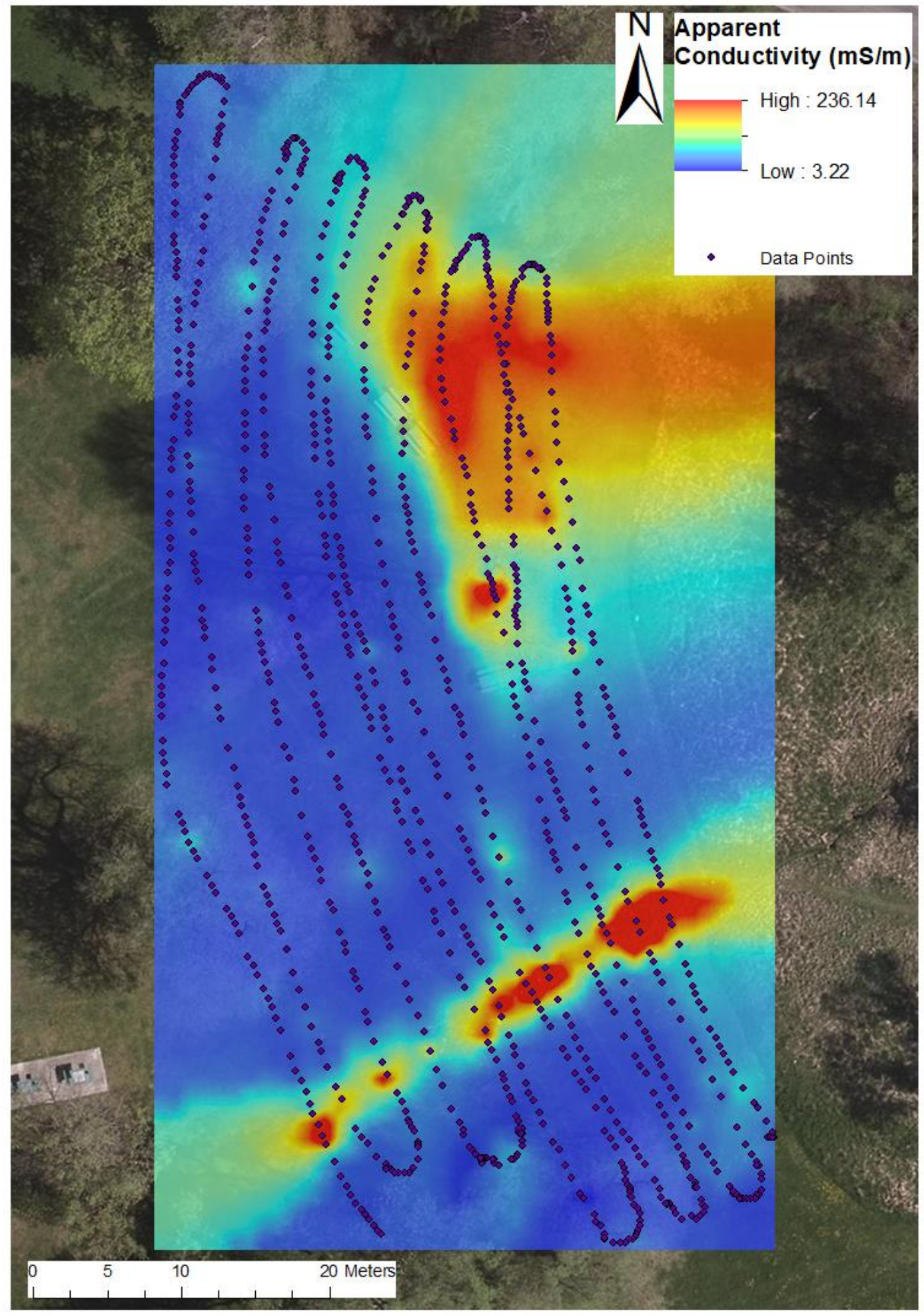

Figure 3.11: Apparent conductivity results from Receiver 1 at $90^{\circ}$ roll. Results were interpolated using inverse distance weighting with a cell size of $1 \mathrm{~m}$. Satellite imagery taken from Google Earth. 


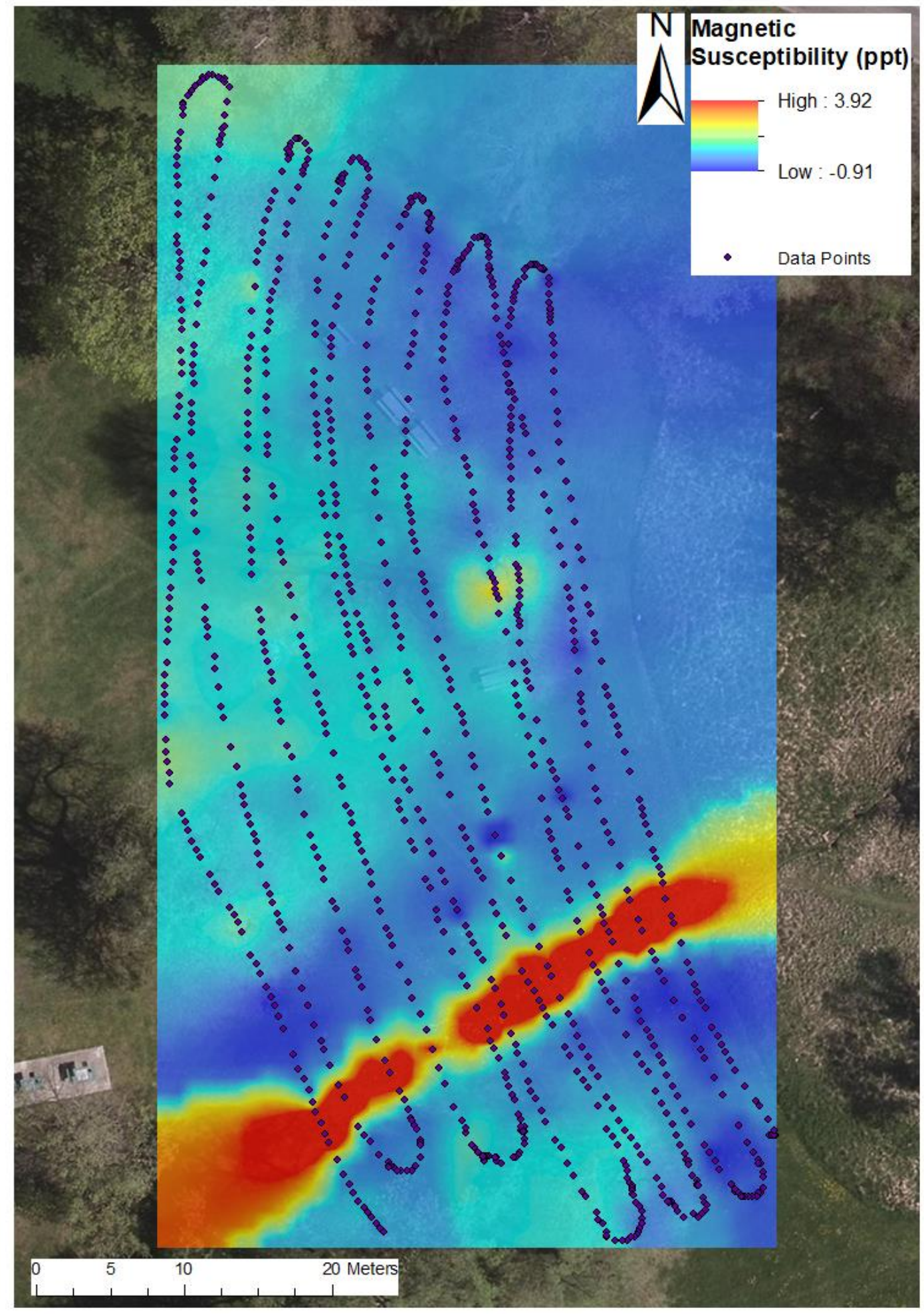

Figure 3.12: Magnetic susceptibility results from Receiver 1 at $90^{\circ}$ roll. Results were interpolated using inverse distance weighting with a cell size of $1 \mathrm{~m}$. Satellite imagery taken from Google Earth. 


\subsection{Magnetics}

3.2.1. Theory

Magnetic surveying is one of the most versatile geophysical methods for exploration since it can be applied to both deep and shallow structures and it is costeffective for both local and regional studies (Burger et al., 2006). Magnetic surveying, in short, measures the total magnetic field which comprises of the magnitude and orientation of the resulting magnetic field. Magnetic fields are defined in two ways according to different models: the force a magnetic pole exerts on a moving object (Ampere's Law); and the force the magnetic pole exerts on another magnetic pole (Gilbert's Model).

Earth's magnetic field is often cited using two measurements: inclination, which is the angle between the magnetic vector and the horizontal plane; and declination, which is the angle between the vector and geographic north (Telford et al., 1990). The source of a large portion of earth's magnetic field arises from currents within the outer core, which consists of primary and secondary non-dipole moment that produces variations in the total magnetic field (Burger et al., 2006). Magnetic fields are typically measured in teslas [T], but because magnetic fields for geophysical purposes are too weak to be measured in teslas the main unit of measurement is in nanoteslas (nT) which is equivalent to $10^{-9} \mathrm{~T}$. Magnetic field measurements can vary from $20000 \mathrm{nT}$ at the equator to $70000 \mathrm{nT}$ at the North and South poles. These variations are based on the International Reference Geomagnetic Field (IGRF), which is a worldwide model based on base station measurements from around the world as well as satellite measurements. The IGRF can provide the average direction and intensity of the main field at any location of Earth.

There are natural variations in Earth's magnetic field that can affect magnetic readings when surveying. The strength of Earth's magnetic field fluctuates throughout the 
day due to the flow of particles in Earth's magnetic field. This leads to a stronger magnetic field throughout the day, and weaker during the night, making a 24-hour cycle look like a sine (Figure 3.13). This is known as diurnal variations. Because Earth's magnetic field strength fluctuates throughout the day, magnetic data must be corrected based on the rate of change at the time of the measurement. To correct for diurnal variations, a base station is typically set up close to the survey area to record only the variations in the magnetic field strength. Base stations are typically recorded at one-minute intervals to give accurate variations for surveying purposes. An alternative is to set a location close to the survey that the survey returns to every 10 to 15 minutes to record repeated measurements at that spot. 


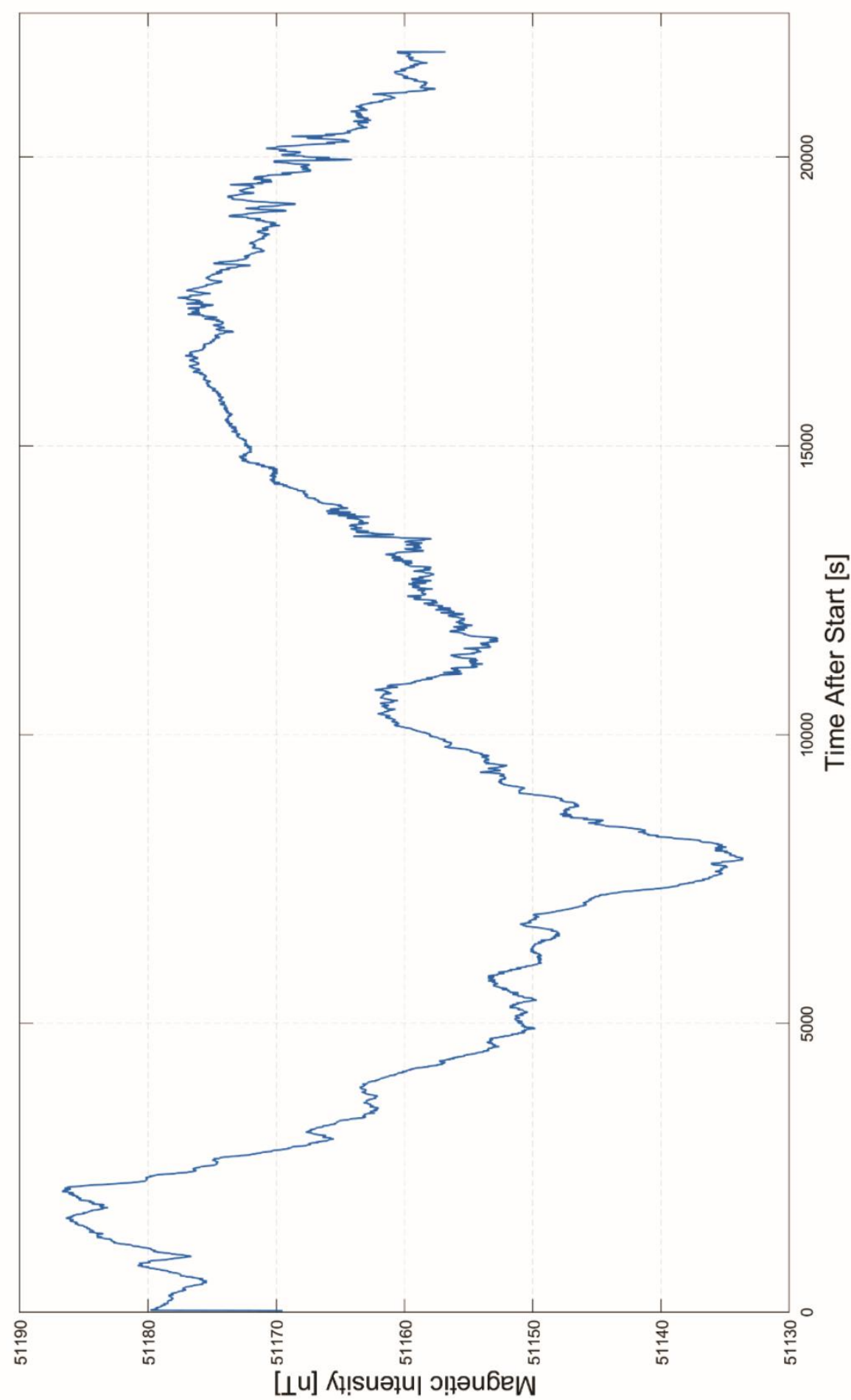

Figure 3.13: Diurnal variations in Earth's magnetic field on May $5^{\text {th }}, 2018$. Data was taken from the G-857 proton procession magnetometer from Geometrics Inc. during the 2018 Field Season. X-axis is the time after the base station started recording measurements for the day. 
As stated before, magnetic surveys for geophysical purposes measure the magnitude and orientation of the total magnetic field. This differs from time-domain electromagnetic surveying, which measures the change in total magnetic field over time. The total magnetic field comprises the primary magnetic field generated from the Earth's core ( $\left.\mathrm{B}_{\text {Earth }}\right)$, magnetic properties of surface materials including remanent magnetization of surface rocks $\left(\mathrm{B}_{\text {Crust }}\right)$, and other sources of magnetization such as solar, atmospheric and cultural influences. For this research project, the target is to measure induced and remanent magnetization from surface rocks and materials $\left(\mathrm{B}_{\mathrm{Crust}}\right)$.

Magnetization of surface rocks can be broken down into two components: induced magnetization and remanent magnetization (Burger et al., 2006). Induced magnetization is the magnetic response of the material when an inducing magnetic field is introduced (Figure 3.14). When the inducing magnetic field is applied, domain walls in the material re-order themselves such that favourably oriented domains are parallel to the applied field. If the inducing field is extremely strong, the induced magnetization of the material will increase to the saturation level, which is the point in which magnetization no longer increases due to increase of the inducing field (Telford et al., 1990). When the inducing field is reduced to zero, the reordering of favourably oriented domains was so substantial that these domain changes are retained, which allows the material to hold a net permanent magnetization. However, the induced component caused by Earth's magnetic field does not cause saturation, and the induced component is always aligned with Earth's magnetic field. During present-day measurements, the induced component will be parallel to the present-day Earth's magnetic field at that location. 


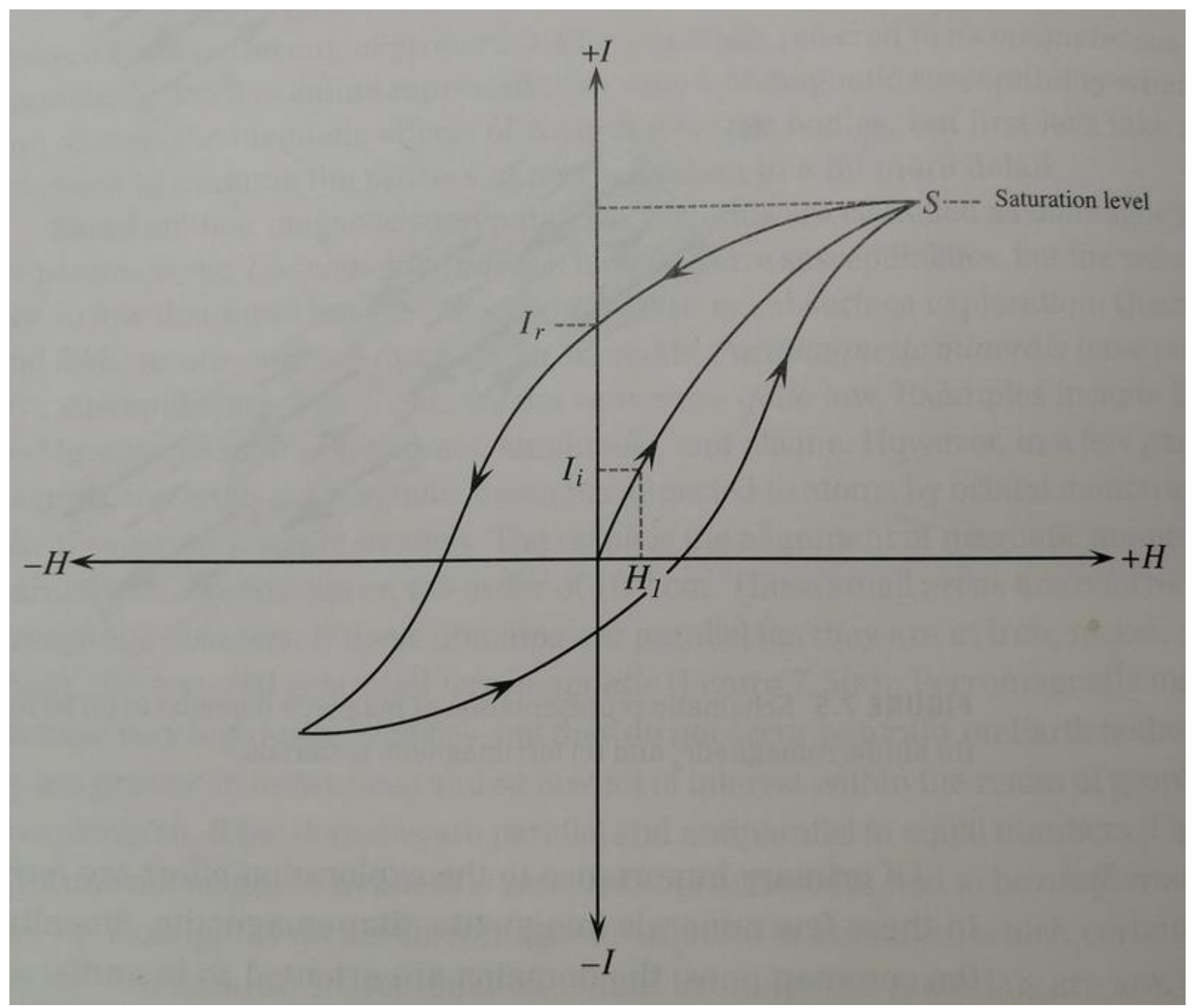

Figure 3.14: Plot of magnetization I against inducing magnetic field $\mathrm{H}$ showing how NRM occurs. NRM in this case Ir after the saturation point is reached. Taken from Burger et al., 2006.

The other type of magnetization is a permanent magnetization in the rock known as natural remanent magnetization (NRM) that can be produced in a number of ways. The most likely type of NRM at LBNM would be thermoremanent magnetization which is produced when ferrimagnetic minerals and their domains in the basalt align in the direction of the Earth's magnetic field during crystallization and cooling of the below the Curie temperature (Burger et al., 2006). For titanomagnetite - the key mineral in most basalts - 
the Curie point ranges from $500-580^{\circ} \mathrm{C}$. NRM is typically measured in amperes per meter $(\mathrm{A} / \mathrm{m})$ using the SI system of units, and as emu/ $\mathrm{cm}^{3}$ using the cgs unit of measurements. The magnitude of NRM in basalts can range from $0.1-46 \mathrm{~A} / \mathrm{m}$ (Larson et al., 1969), with basalts from more recent eruptions ranging from $0.07-13.2 \mathrm{~A} / \mathrm{m}$ (Pinton et al). The direction of NRM in rocks are parallel to Earth's magnetic field at the time of formation, meaning that Earth's pole reversals dictate whether the direction is in its current polarization or opposite. There is potential of self-reversal in rocks, where certain conditions in the mineralogy allow the rock to hold a magnetization that is directed opposite to Earth's magnetic field at the time of formation (Néel, 1951; Néel 1955; Krása et al., 2005). Self-reversal of flows is a rare feature, but the possibility of partial or complete self-reversal should be considered when inversion is done on magnetic data in basaltic environments. Because rock collapses are common in lava tubes, there is also the possibility of reorientation of boulders and their NRM direction due to partial or full collapses.

The effect of NRM on observed magnetic data depends on the Königsburger ratio (Q), which is the ratio between NRM and induced magnetization ( $\left.\mathrm{M}_{\text {Ind.) }}\right)$ expressed as such:

$$
Q=\frac{M_{N R M}}{M_{\text {Ind. }}}=\frac{M_{N R M}}{k H}
$$

\section{Equation 3.2}

where $\mathrm{k}$ is the magnetic susceptibility of the material and $\mathrm{H}$ is the intensity of the ambient magnetic field (Königsburger, 1938). Equation 3.2 implies that in low-susceptibility units, NRM will have a significant affect on the overall magnetic response whereas NRM will 
have little effect in high-susceptibility units. In basalts, the value of the Königsburger can range from $0.1-30$ with an average range of 1-10 (Mikhaltsov et al., 2012).

Magnetic surveys have different types depending on the form of transportation for the magnetometer. Magnetic surveys can be done by ground, by airplane, or more recently by unmanned aerial vehicles/systems (UAV or UAS). Airborne magnetic surveys can cover large and remote areas but are lower resolution compared to ground surveys since elevation is varying. Since it is more difficult and expensive, airborne survey flies as "drape surfaces" which smooths magnetic readings and can miss magnetic anomalies that ground surveys offer. Ground surveys are more optimal for small areas or areas that require high resolution. The limitation of ground surveys is that short-term variations in the external field are large and are removed from readings. Ground surveys need a base station to or reference point to get repeated measurements to remove diurnal variations. 


\subsubsection{Instrumentation}

Two different magnetometers were used in the magnetics component of this research project: the Geometrics G-857 magnetometer that acted as a base station magnetometer; and the Geometrics G-859 magnetometer that was used for the actual surveying component. The Geometrics G-857 magnetometer is a proton procession magnetometer that can be used as either a base station magnetometer or as a roving magnetometer. Proton procession magnetometers consist of a cylindrical conductor filled with a hydrogen-rich liquid surrounded by a coil. When the power is on, a magnetic field is created aligned parallel to the coil axis, which in turn aligns the hydrogen nuclei along the magnetic field orientation. When the power is turned off, atoms precess around Earth's magnetic field. The procession causes a small alternating current to flow in the coil at the precession frequency. The procession frequency is proportional to the magnetic field strength and a constant of proportionality (Geometrics, 2015). As a base station, the G-857 magnetometer is set up on a tripod away from roads and power lines where there can be magnetic interference (Figure 3.15). The sensor sends data to the logger box which is placed at least $3 \mathrm{~m}$ away from the sensor (Figure 3.15). Since the internal battery in the logger box did not have enough battery life to collect data all day, a car battery was used as the power source. Specifications of the G-857 magnetometer are listed in Table 3.3. 


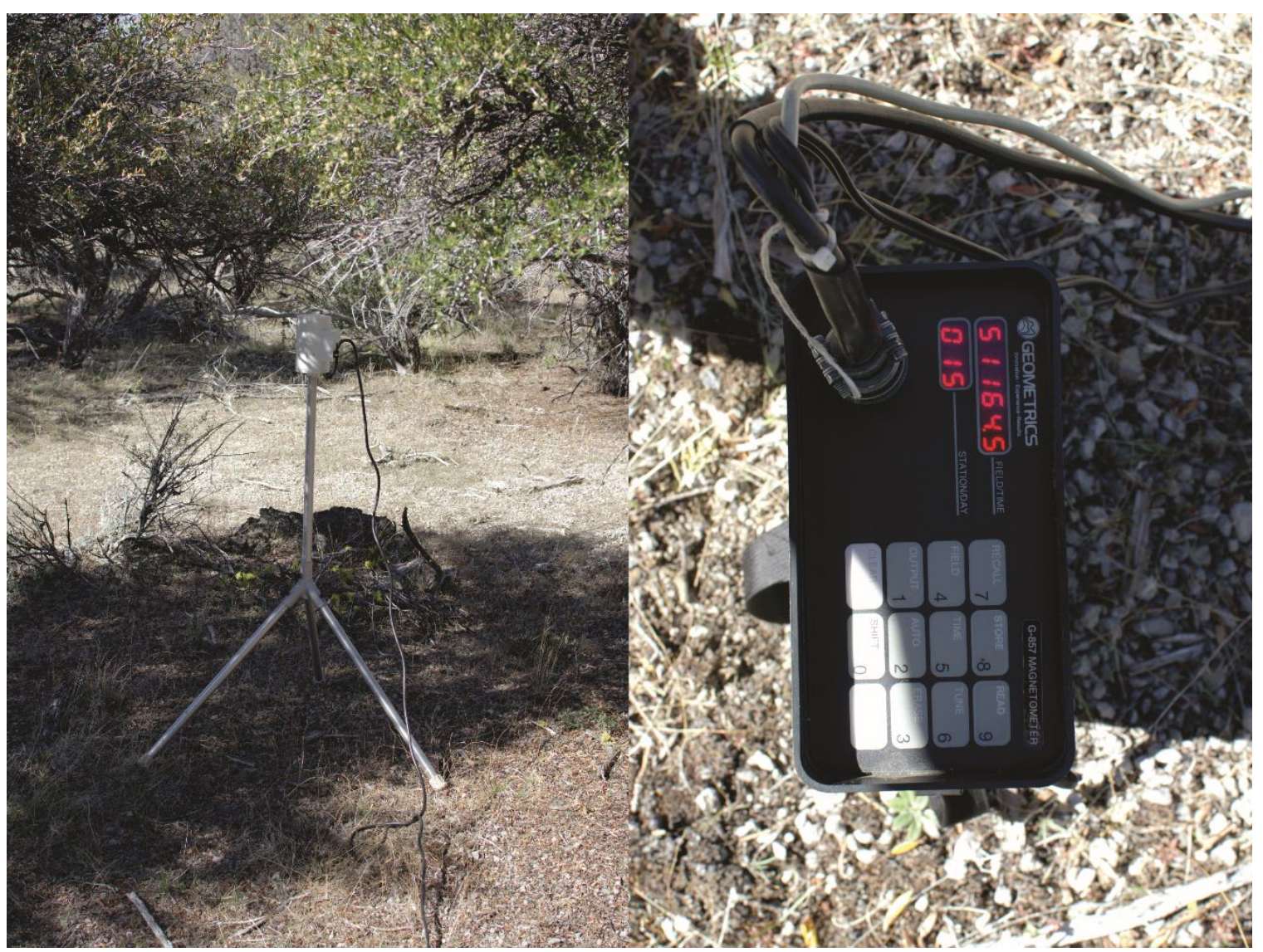

Figure 3.15: The G-857 magnetometer set up as a base station in LBNM. The sensor (left) was left in the shade to avoid the sensor overheating. The sensor sends data to the logger box (right). 
Table 3.3: Specifications of the Geometrics G-857 base station magnetometer (Geometrics, 2015).

\begin{tabular}{|c|c|c|}
\hline \multicolumn{3}{|c|}{ Geometrics G-857 Magnetometer } \\
\hline Resolution & {$[\mathrm{nT}]$} & 0.1 \\
\hline Accuracy & {$[\mathrm{nT}]$} & 0.5 \\
\hline \multirow{2}{*}{ Range } & \multirow{2}{*}[\mathrm{nT}]{} & 20000 (minimum) \\
\hline & & 90000 (maximum) \\
\hline Gradient Tolerance & {$[\mathrm{nT} / \mathrm{m}]$} & 1800 \\
\hline Cycle time & [s] & $1.6-999$ \\
\hline \multirow{2}{*}{ Dimensions } & \multirow{2}{*}[\mathrm{cm}]{} & $9 \times 13$ (Sensor) \\
\hline & & $17 \times 27 \times 9$ (Console) \\
\hline \multirow{2}{*}{ Weight } & \multirow{2}{*}[\mathrm{kg}]{} & 1.8 (Sensor) \\
\hline & & 2.7 (Console) \\
\hline Power & - & 12 V Gel Cell Battery \\
\hline Height Above Surface & {$[\mathrm{cm}]$} & 0.9 \\
\hline
\end{tabular}

The Geometrics G-859 is a cesium vapour magnetometer system that is used as a walking magnetometer with an integrated GPS system. Optically-pumped cesium vapour magnetometers consists of a photon emitter containing a cesium light emitter, an absorption chamber containing cesium vapour, a buffer gas that the emitted photons pass through, and a photon detector (Smith, 1997). The operating principle is that a very small AC magnetic field is applied to the cell. The difference in Zeeman-effect energy levels of electrons is determined by the external magnetic field, so there is a frequency at which the AC field makes electrons change states. The electron in the new state can absorb a photon of light, and the detector measures the light passing through the cell. This signal is then used to match the frequency corresponding to the external magnetic field (Hrvoic and Hollyer, 
2005). The G-859 magnetometer is carried on a custom backpack designed by Geometrics Inc. which holds the sensor on one side of the backpack, and the GPS on an extended pole on the other side of the backpack (Figure 3.16). Specifications of the G-859 magnetometer are listed in Table 3.4.

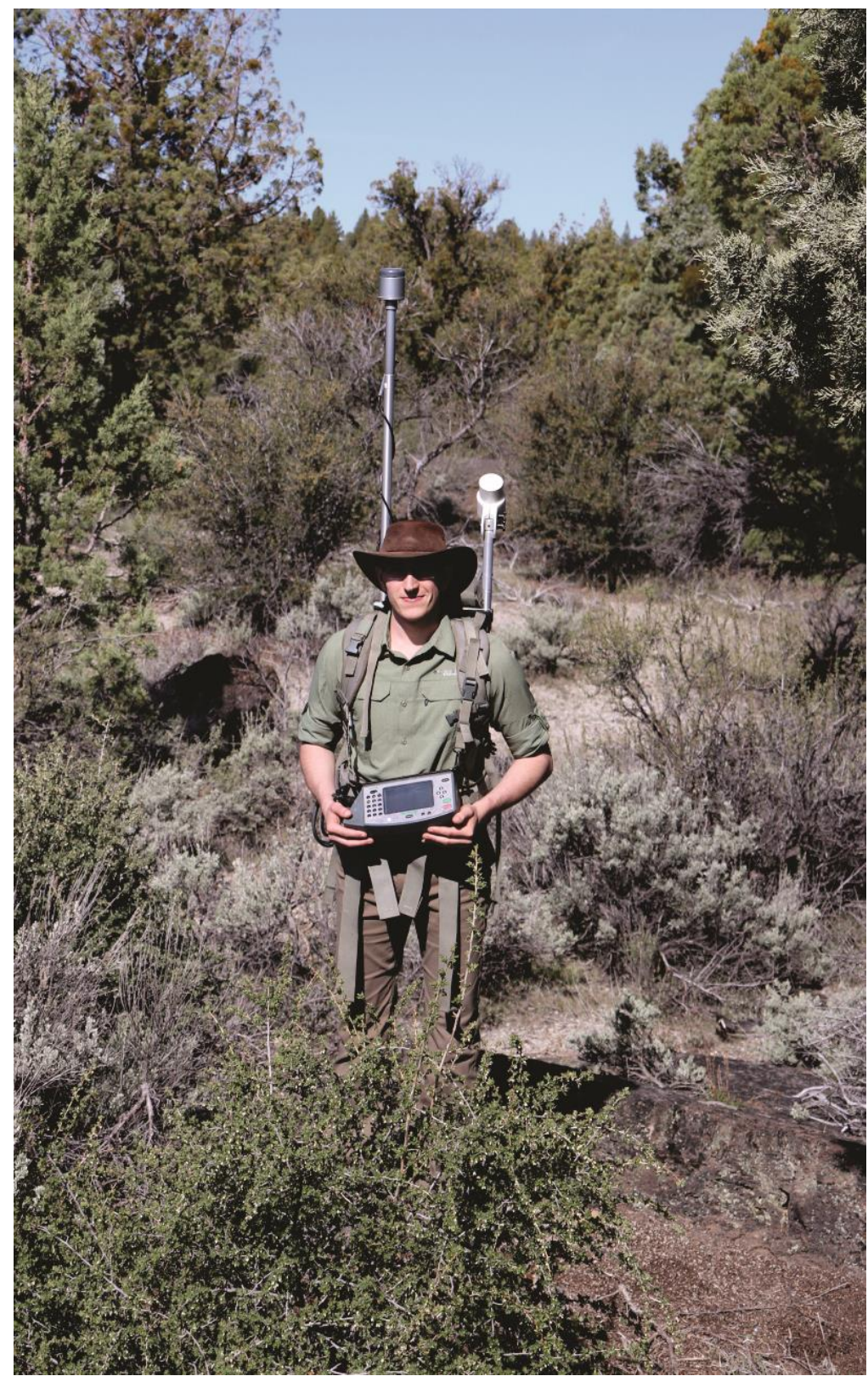

Figure 3.16: Surveying with the G-859 magnetometer with the backpack apparatus. The sensor is the white cylinder on the right side of the figure, and the GPS is on the extended pole. Person is approximately $188 \mathrm{~cm}$ for scale. 
Table 3.4: Specifications of the Geometrics G-859 walking magnetometer (Geometrics, 2011).

\begin{tabular}{|c|c|c|}
\hline \multicolumn{3}{|c|}{ Geometrics G-859 Magnetometer } \\
\hline Resolution & {$[\mathrm{nT}]$} & 0.01 \\
\hline Accuracy & {$[\mathrm{nT}]$} & 0.5 \\
\hline \multirow{2}{*}{ Range } & \multirow{2}{*}[\mathrm{nT}]{} & 18000 (minimum) \\
\hline & & 95000 (maximum) \\
\hline Temperature Drift & {$\left[\mathrm{nT} /{ }^{\circ} \mathrm{C}\right]$} & 0.05 \\
\hline Gradient Tolerance & {$[\mathrm{nT} / \mathrm{m}]$} & 20000 \\
\hline Cycle time & {$[\mathrm{s}]$} & $0.2-3600$ \\
\hline \multirow{2}{*}{ Dimensions } & \multirow{2}{*}[\mathrm{cm}]{} & $9 \times 13$ (Sensor) \\
\hline & & $17 \times 27 \times 9$ (Console) \\
\hline \multirow{2}{*}{ Weight } & \multirow{2}{*}[\mathrm{kg}]{} & 1.8 (Sensor) \\
\hline & & 2.7 (Console) \\
\hline Power & - & 24 V DC Gel Cell Battery \\
\hline Height Above Surface & {$[\mathrm{cm}]$} & 230 \\
\hline
\end{tabular}




\subsubsection{Signal Processing}

Data from both of the magnetometers is uploaded via MagMap2000, Geometric Inc.'s in-house software used to upload and process data from their products (Figure 3.17). Raw data from the base station G-857 magnetometer comes in .stn format (Figure 3.18), with the headings shown on the first line of the file, and each line after showing the reading from the magnetometer. Data from the G-859 magnetometer first comes in .bin format when uploaded (Figure 3.19 top), which is considered illegible unless processed through MagMap2000. After the data are uploaded, the GPS coordinates can be displayed by clicking "Draw new map using GPS data" under the GPS menu in the software. The new dataset can be exported as a dat file from the resulting figure by right-clicking on the figure, then clicking on "export". The exported dat file can then be imported into Excel or MATLAB for processing (Figure 3.19 bottom). 


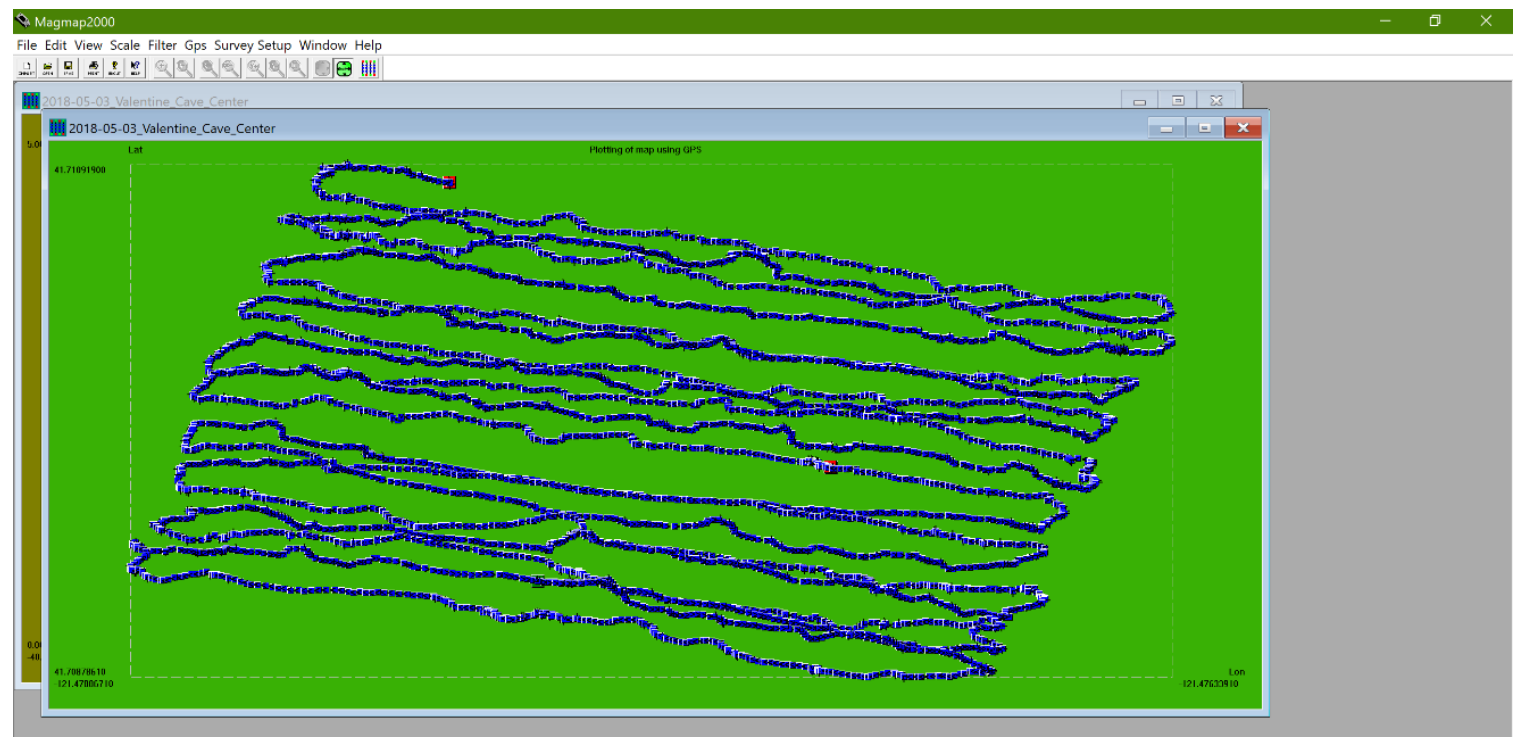

Figure 3.17: User interface of MapMap2000. The interface has the coordinates of the center section of Valentine Cave displayed.

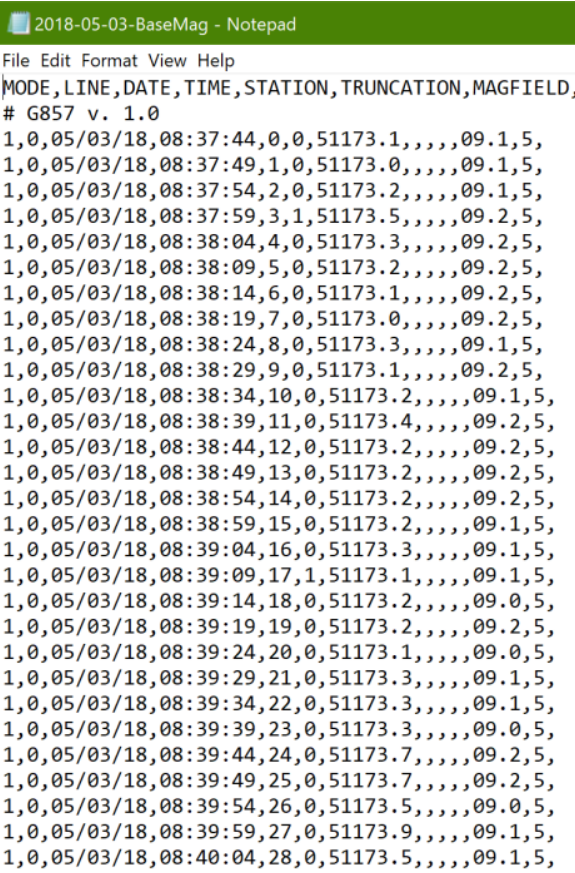

Figure 3.18: Raw data from the G-957 base-station magnetometer in .stn format. 


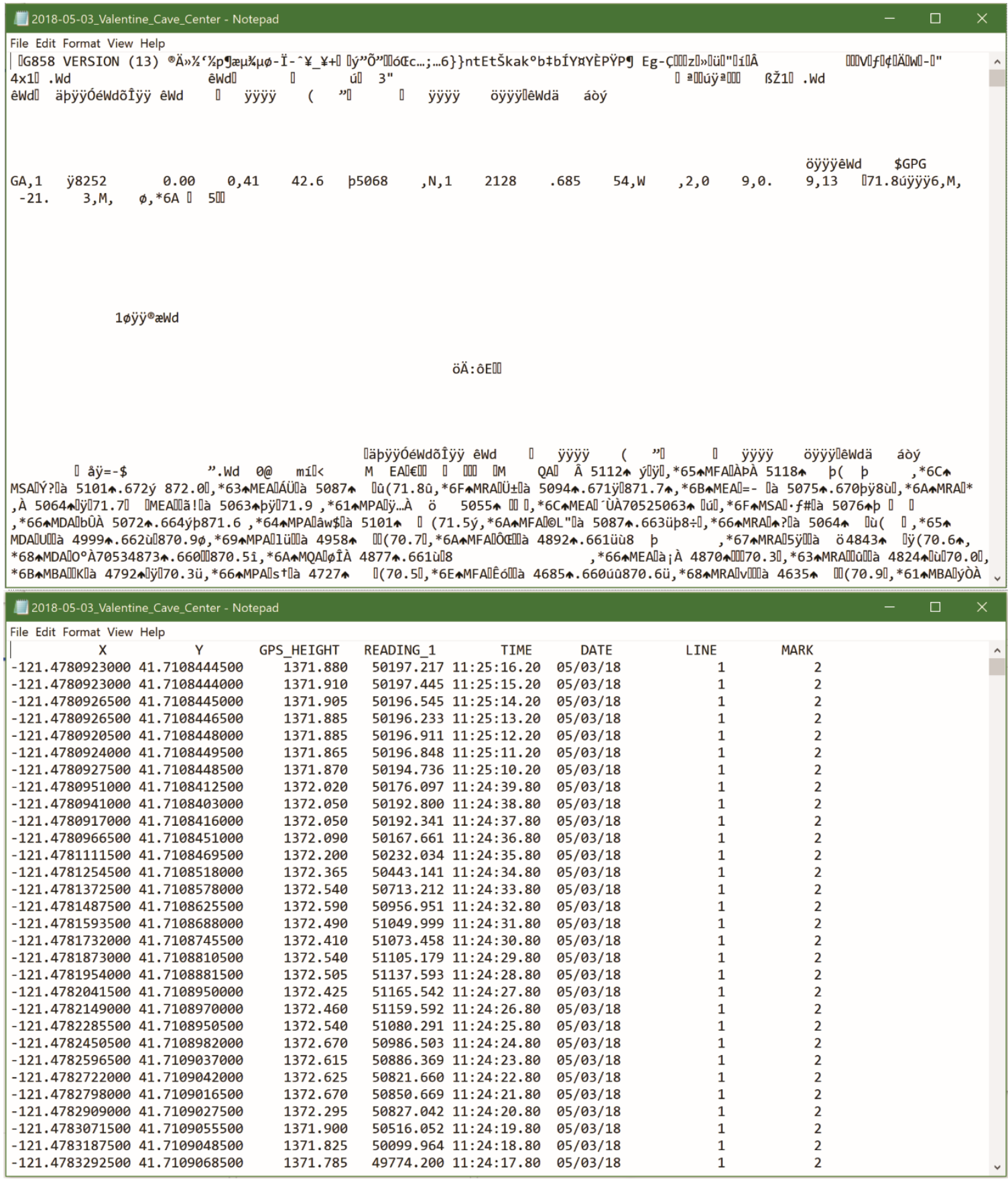

Figure 3.19: Raw data from the G-859 magnetometer in .bin format (top) and .dat format (bottom). 
For ground magnetometry, the primary step in signal processing are to correct for diurnal variations. As stated previously, recordings from the base station magnetometer will show variations in Earth's magnetic field throughout the day. Base station data relatively smooth. Therefore, the first step is to smooth magnetic data to minimize noise. To smooth the dataset from the base station, a moving average, where each point is an average of 12 points: 6 measurements before any given point, and 6 measurements after that point. The resulting dataset was considered a lot smoother compared to the original noise dataset. (Figure 3.20). The second step of correcting for diurnal variations is to fill the time and magnetic intensity so the base station data is in one-second intervals instead of five-second intervals. This is done by finding the slope between each magnetic intensity reading, then applying the slope in one-second intervals. Once the time is converted, the base station times can be matched up with the times recorded during a given survey. When the times are matched, the magnetic intensity can be subtracted from the data recorded during the survey. The result is the induced magnetization, which is the magnetic anomaly after correcting for diurnal variations. Another way of representing data is total magnetic intensity (TMI), which is the magnetic anomaly and the average magnetic field of Earth. 


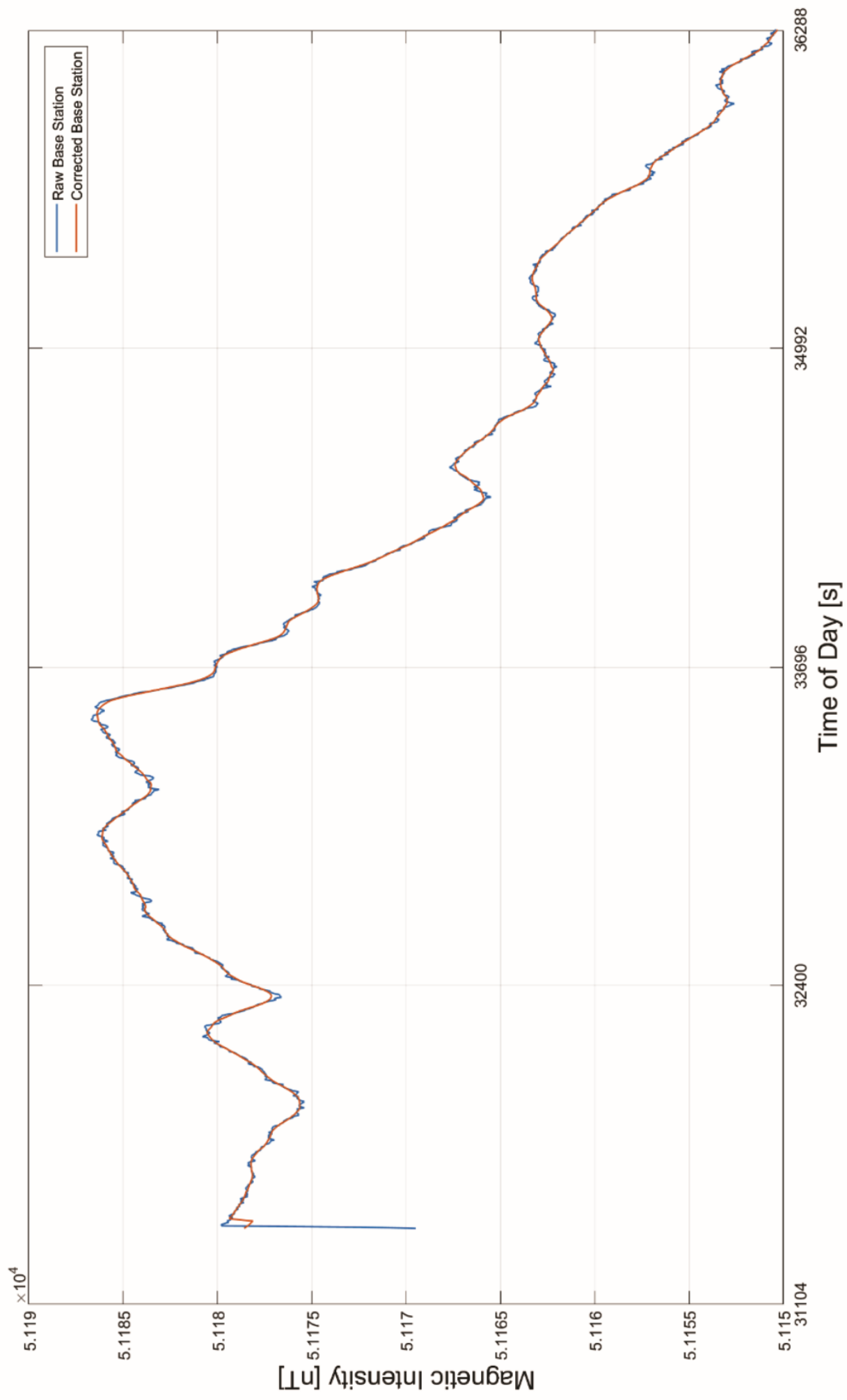

Figure 3.20: Base station data from May 5th, 2018. The plot shows diurnal variations before and after a moving average was applied to smooth the data in blue and orange, respectively. 
In addition to corrections for diurnal variations, magnetic datasets were reducedto-the-pole. Reduction-to-pole is a form of phase transformation in which the actual inclination is changed to vertical, and converts the magnetic datasets based on this change (Telford et al., 1990). It is typically used to simplify TMI maps by removing anomaly asymmetry caused by the inclination and places magnetic anomalies above the source of the anomaly. In other words, an anomaly signal can change from being a peak and a trough to a simple peak (Blakely, 1995). An example of a survey before-and-after reduction to the pole can be seen in Figure 3.21. The biggest differences between the two surveys is that the highs and lows are more accentuated, so they are smaller in size. In addition to the accentuation, there are more clearly defined areas where there is a magnetic high and low i.e. the magnetic highs and lows in the northern part of the survey.

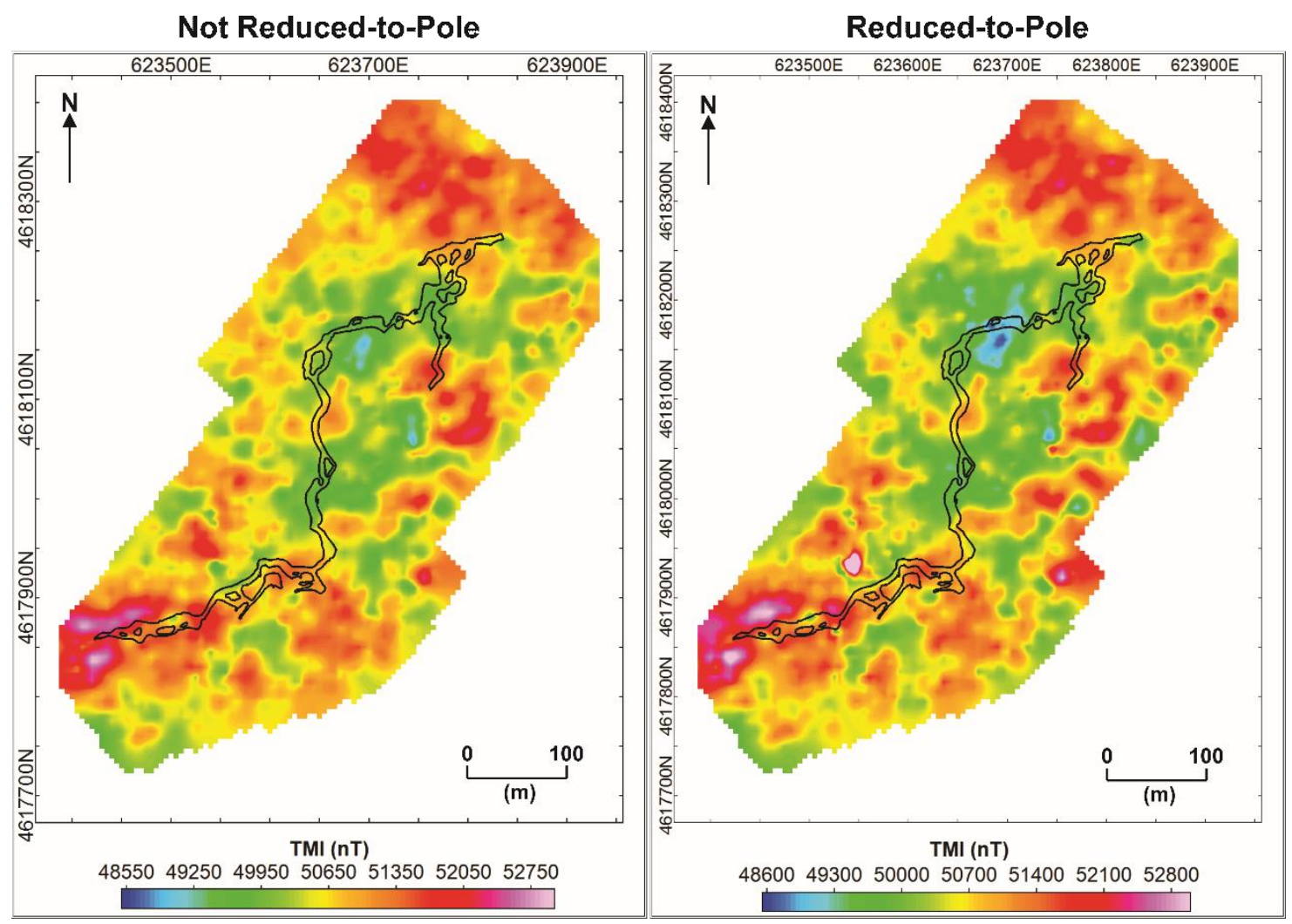

Figure 3.21: Comparison of TMI for the Juniper Cave survey before (left) and after (right) reduction-to-the-pole. Juniper Cave is outlined in black. 
In addition to reduction-to-pole being applied for surface results, Fast Fourier Transform Lowpass Filters were applied to the magnetic datasets that were reduced-to-thepole. Lowpass filters are smoothing functions that transform data over to the frequency domain, in which data below a specified wavelength can be removed from the data (Spector and Grant, 1970). The higher the wavelength cut-off is, the lower frequency the resulting dataset is. This means that the lowpass filter will reject higher frequency content which will result in less spatially detailed anomaly maps. This also means that the filter will be less affected by shallow structures and noise in data. The less-detailed results will also allow for more regional observations and interpretations in the scale of the survey areas. 


\section{Data Acquisition}

\subsection{Electromagnetic Surveying}

EM data acquisition occurred from May $30^{\text {th }}$ to June $9^{\text {th }}, 2017$. A test line was surveyed every day before and after surveying to ensure repeatability of the R4 EMIS and calculate potential instrument drift. The test line started at the LBNM research centre, going north on the road until the road ends (Figure 2.3). The R4 EMIS was turned on and left running for approximately 35 minutes before the morning line was surveyed to allow the internal temperature of the R4 EMIS to decrease to about $300 \mathrm{~K}$.

Two lava tubes were surveyed from the surface, as well as Devils Homestead and an attempt at mapping a fault contact. Data from Devils Homestead flow and the fault contact are not shown in the results section due to noisy data. Devils Homestead Flow at its most easily accessible location consisted entirely of a'a, which is extremely jagged and contained steep drops (Figure 4.1). The fault contact had a deep crevice which was approximately $2.5 \mathrm{~m}$ across and increasing in width going south, making it a safety hazard. In addition to surveying lava tubes from the surface, the interior of five lava tubes were surveyed. Those we chosen were studied for having a range in floor compositions, which in context of this research project, is the nature of the material that comprises the floor of the lava tube. Specifically (Table 5.1), Juniper Cave, Valentine Cave and Golden Dome Cave have floors of pahoehoe composition, Skull Cave has a floor covered in by thick ice, and Mammoth Cave has a floor of thick mud. In addition, Juniper Cave's floor was "frothy pahoehoe" - which had secondary mineralization on the surface giving the surface a whiteish appearance - while Golden Dome Cave's floor was "wet basalt with puddles". Note that the geochemistry of the floor material was not considered since analyses could 
not be carried on-site, and the necessary permits to take samples from LBNM were not readily available.

Data acquisition for the 2017 field season was originally planned to occur from June $1^{\text {st }}$ to June $7^{\text {th }}$. However, field work was cut short when the $3^{\text {rd }}$ pin clockwise from the key was broken off in the main connector, cutting off all communication between the logger box and the EMIS. This meant that there was no power going to the R4 to start the transmitter and receiver coils, as well as no data transfer from the R4 to the logger box. Therefore, EM surveying concluded two days earlier than planned. The additional two days were instead allocated to scouting potential lava tubes to survey for the 2018 field season and to assist other members of the ATiLT group with their respective field work.

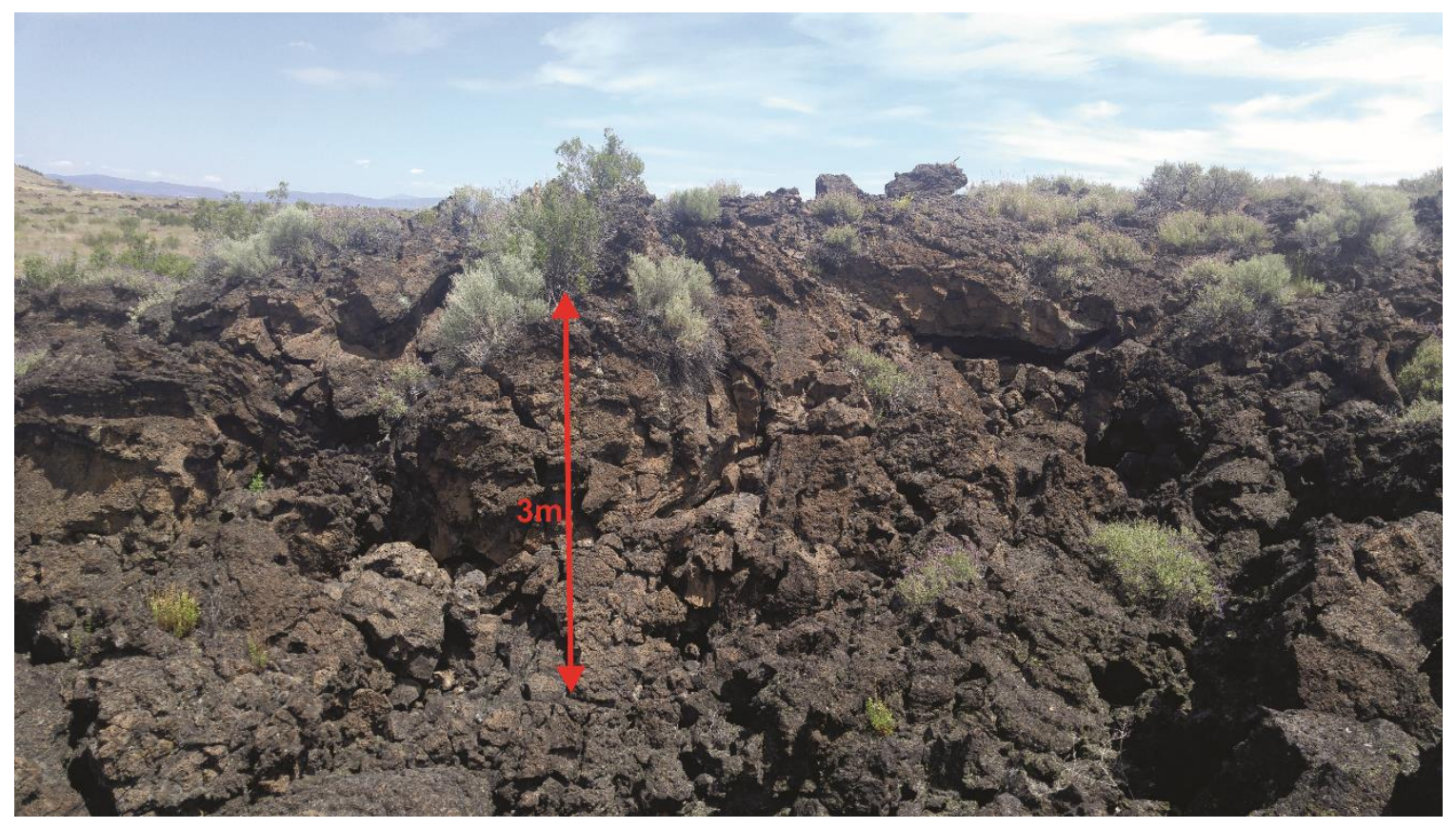

Figure 4.1: Northern end of Devils Homestead Flow. 


\subsection{Magnetic Surveying}

The field season for 2018 occurred from April $30^{\text {th }}$ - May $11^{\text {th }}, 2018$, with surveying being conducted from May $3^{\text {rd }}-$ May $8^{\text {th }}$. A summary of field notes can be found in Appendix A: Field Summary of 2018.. Field work consisted of only surface magnetic measurements instead of surface and interior survey as was done in 2017. The R4 EMIS was used inside lava tubes because the depth of exploration was small enough that it could theoretically characterize EM signatures of floors based their composition; this is not the case for the G-859 magnetometer. The G-857 magnetometer was set up as a base station before surveying for the day was conducted and taken down at the end of the day. The base-station location was chosen such that there was minimal chance of magnetic interference (power lines, moving cars, etc.), and recorded measurements every 5 seconds.

Three lava tubes were surveyed over 5 days: Valentine Cave, Juniper Cave, and Yellowstone Cave. Valentine Cave and Juniper Cave were surveyed because the structures are simple, one-leveled and shallow lava tubes. Yellowstone Cave was chosen as a survey site because it has two levels, adding a degree of complexity for surface magnetic surveys to apply the results of the other two more-simple-structured lava tubes. The length of lines and number of lines depended on the length and geometry of each lava tube. A summary of surface surveys is shown on Table 4.1. 
Table 4.1: Summary of surface surveys conducted during the 2018 field season. Distance is based on distance between planned coordinates. It does not represent the actual distance surveyed.

\begin{tabular}{|l|c|r|}
\hline \multicolumn{1}{|c|}{ Cave Surveyed } & Number of Lines & Line km Surveyed \\
\hline Valentine Cave & $49+2$ Tie & 11.908 \\
\hline Juniper Cave & $46+2$ Tie & 14.128 \\
\hline Yellowstone Cave (Regional) & $55+3$ Tie & 19.435 \\
\hline Yellowstone Cave (Focused) & $30+2$ Tie & 70.00 \\
\hline & Total & 52.471 \\
\hline
\end{tabular}

A major problem for surveying with magnetics, more so than electromagnetics, was planning survey lines around rock walls and rock collapses. The surface survey for Juniper Cave was bounded on the west side by a major rock collapse that made it unsafe to survey across (Figure 4.2). In addition to the rock collapse on the west side, the east side of the survey was partially restricted by large rock "walls" (Figure 4.3). These large walls made surveying over it difficult, and to a point where it became a safety risk to scale the walls. The same rock complex acted as the southern restriction for the Yellowstone Cave surveys. This was also a problem when surveying the southernmost section of Valentine Cave survey, where there was a major rock collapse that made surveying difficult. Because the magnetometer was carried by a custom-made backpack, low brush was no longer a major concert; however, for the Valentine Cave survey, trees became an obstacle since the GPS was approximately $2.5 \mathrm{~m}$ above the ground (Figure 3.16). 


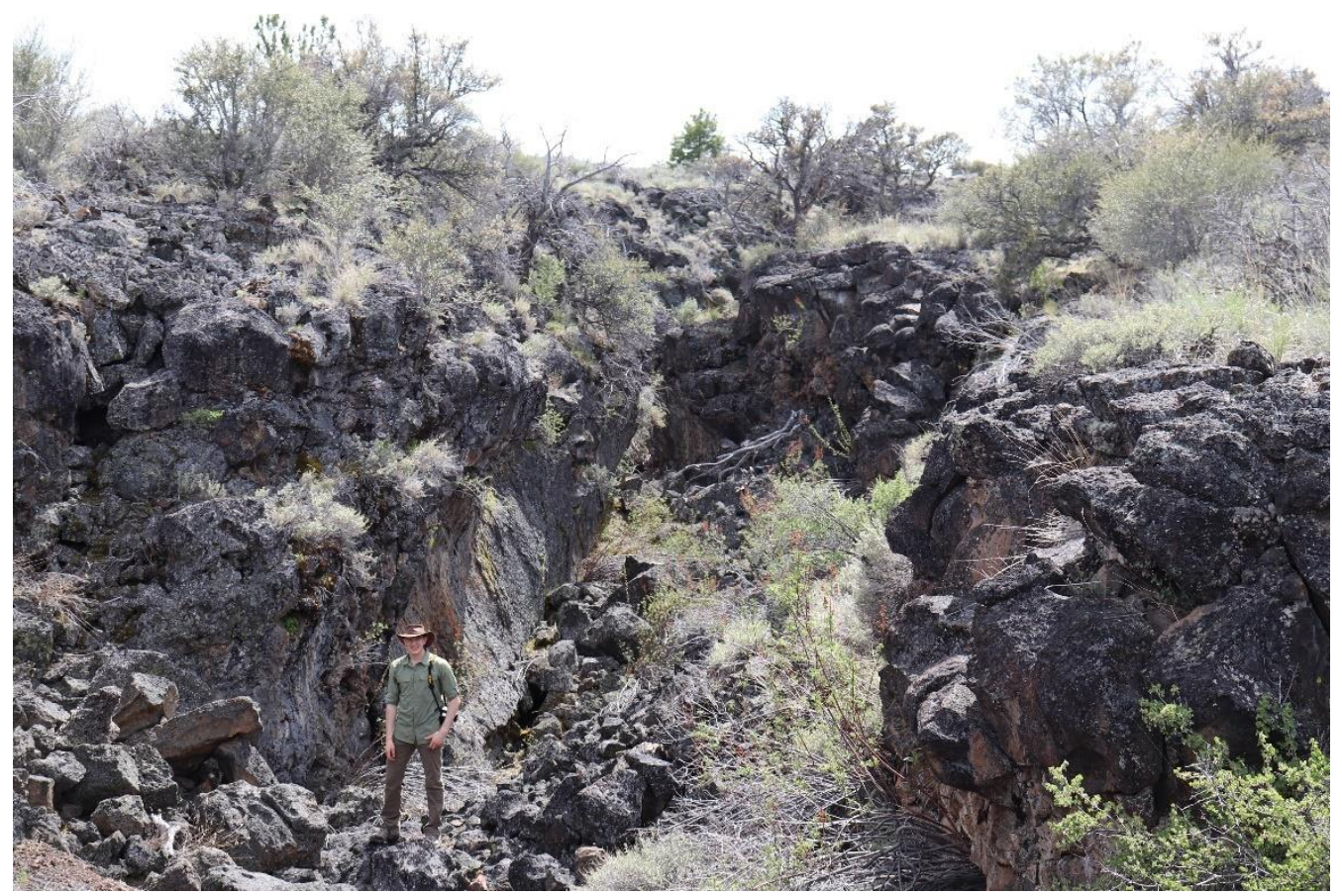

Figure 4.2: Rock collapse located in the middle of Cave Loop, which restricted survey lines for Juniper Cave on the west side. Person is approximately $188 \mathrm{~cm}$ for scale.

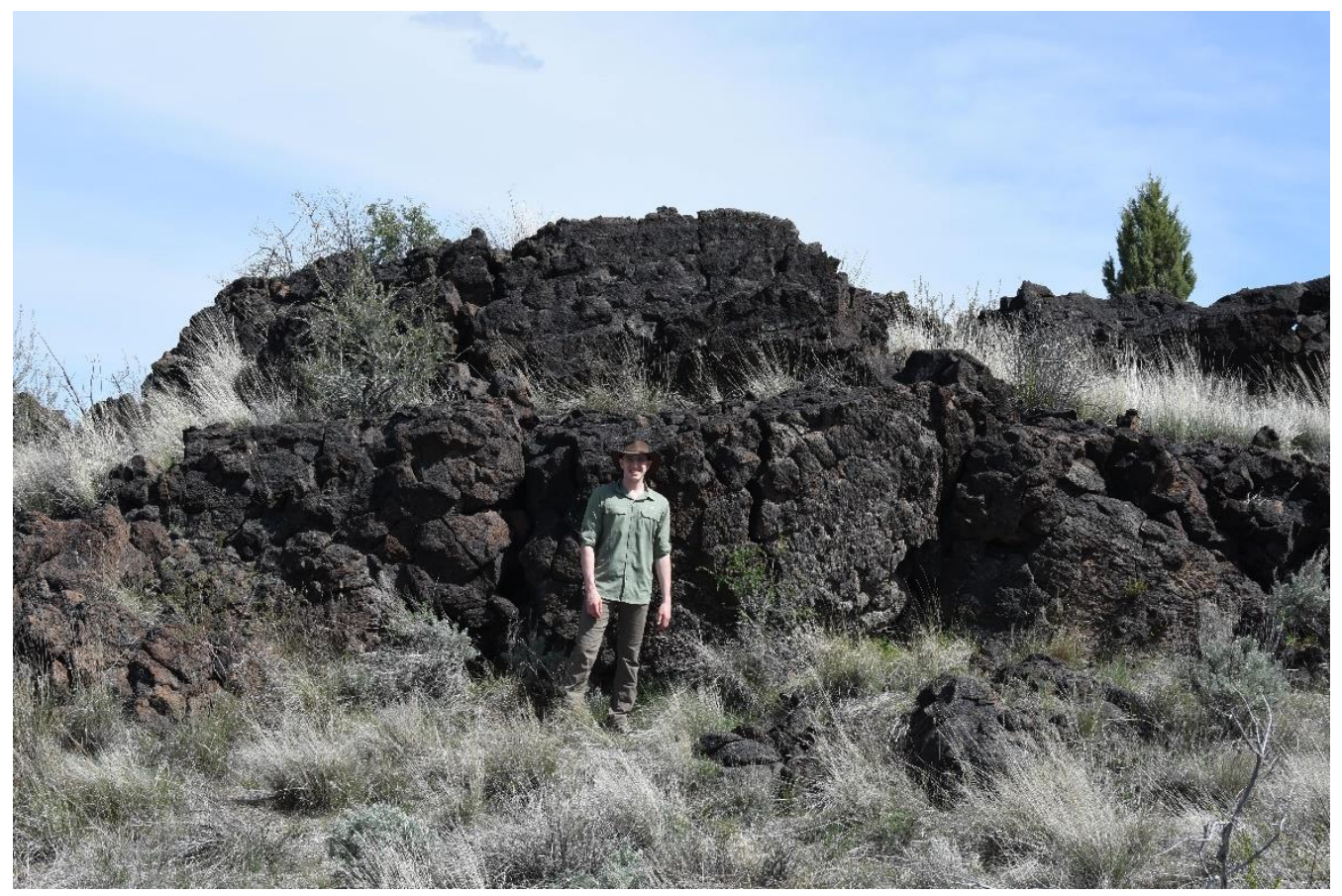

Figure 4.3: Rock "wall" located on the eastern section of the Juniper Cave, restricting survey lines on the east side. The same rock flow/formation also restricted survey lines for Yellowstone Cave on the south side. Person is approximately $188 \mathrm{~cm}$ for scale. 


\section{Results and Discussion}

\subsection{EM Induction}

\subsubsection{Instrument Performance}

A problem that was encountered when processing datasets collected with the R4

EMIS was the drift in apparent conductivity data due to changes in the internal temperature of the instrument. The issue was detected when surveying the interior of caves, when the apparent conductivity going down a cave was higher than the conductivity going back the other way (Figure 5.1 top). The decrease in apparent conductivity correlated to the decrease in the internal temperature of the R4 EMIS (Figure 5.1 bottom). This steady decrease in apparent conductivity affected mostly Receivers 1 and 2, which have the lowest Tx-Rx separation.

The internal temperature of the sensor must be as stable as possible since the transmitter and receiver coils expand and contract as the temperature increases and decreases. These changes in coil size affect the sensor readings. Since this is a known issue with FDEM ground conductivity meters, the R4 is equipped with a thermal compensation system that linearly corrects internal temperature effects. The thermal compensation system for each channel is based on a linear model of the response of the uncompensated EM channel with respect to temperature. The linear model is represented as:

$$
\text { Output }=A \times \text { Temperature }+B
$$

\section{Equation 5.1}

where $\mathrm{A}$ and $\mathrm{B}$ are compensation coefficients. The temperature corrections for this survey consisted of tuning the compensation coefficients of the apparent conductivity channels. All conductivity datasets featured in sections 5.1.2 and 5.1.3 have been corrected for change in temperature. Datasets that still show negative conductivities are considered 
unreliable for interpretation. Anything below $0 \mathrm{mS} / \mathrm{m}$ means that there might be interference affecting the results or that the temperature corrections might not have completely worked.

Temperature corrections were not applied to magnetic susceptibility datasets since temperature changes did not appear to affect the magnetic susceptibility datasets. Temperature corrections were done by Dr. Scott Holladay of Geosensors Inc. (Scott Holladay, personal communication), the designer of the R4 EMIS, as they required specialized knowledge of the internal working of the instrument. Magnetic susceptibility results from Golden Dome Cave are a good example of this, as there are no visible variations due to change in temperature (Figure 5.4).

It is useful to note that the R4 EMIS that was used for this survey was an early prototype. Production units of the R4 EMIS, built subsequently, contain a more reliable thermal compensation system. In addition, thermal drift is prominent in datasets from LBNM because it is a highly resistive environment. Thermal drift would not be as prominent in regularly conductive soils with an average conductivity on the order of tens of $\mathrm{mS} / \mathrm{m}$. 


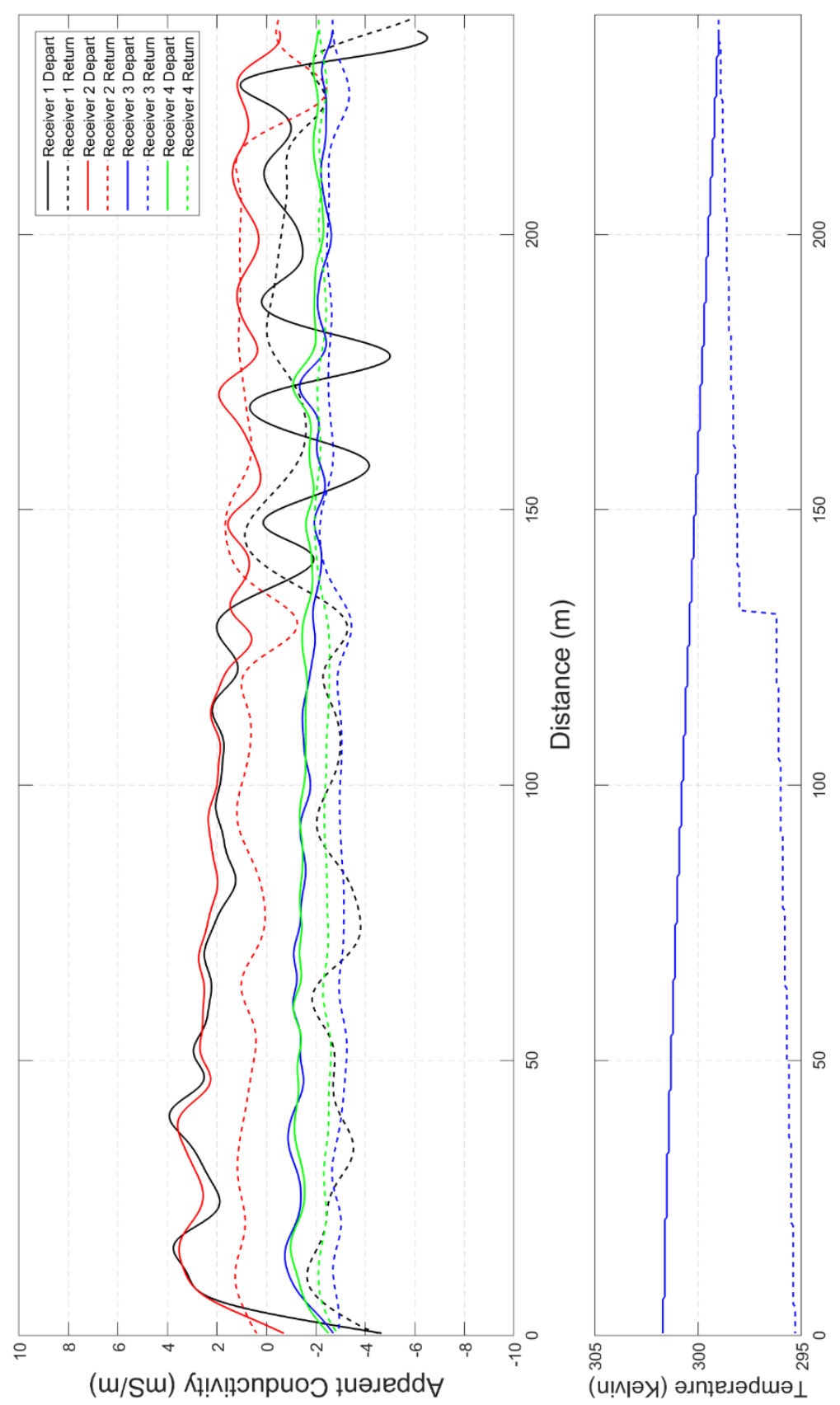

Figure 5.1: (Top) Apparent conductivity profile of Valentine Cave (solid lines: from opening to the end of the cave; dashed lines: from the end to the opening of the cave). (Bottom) internal temperature of the R4 EMIS. 


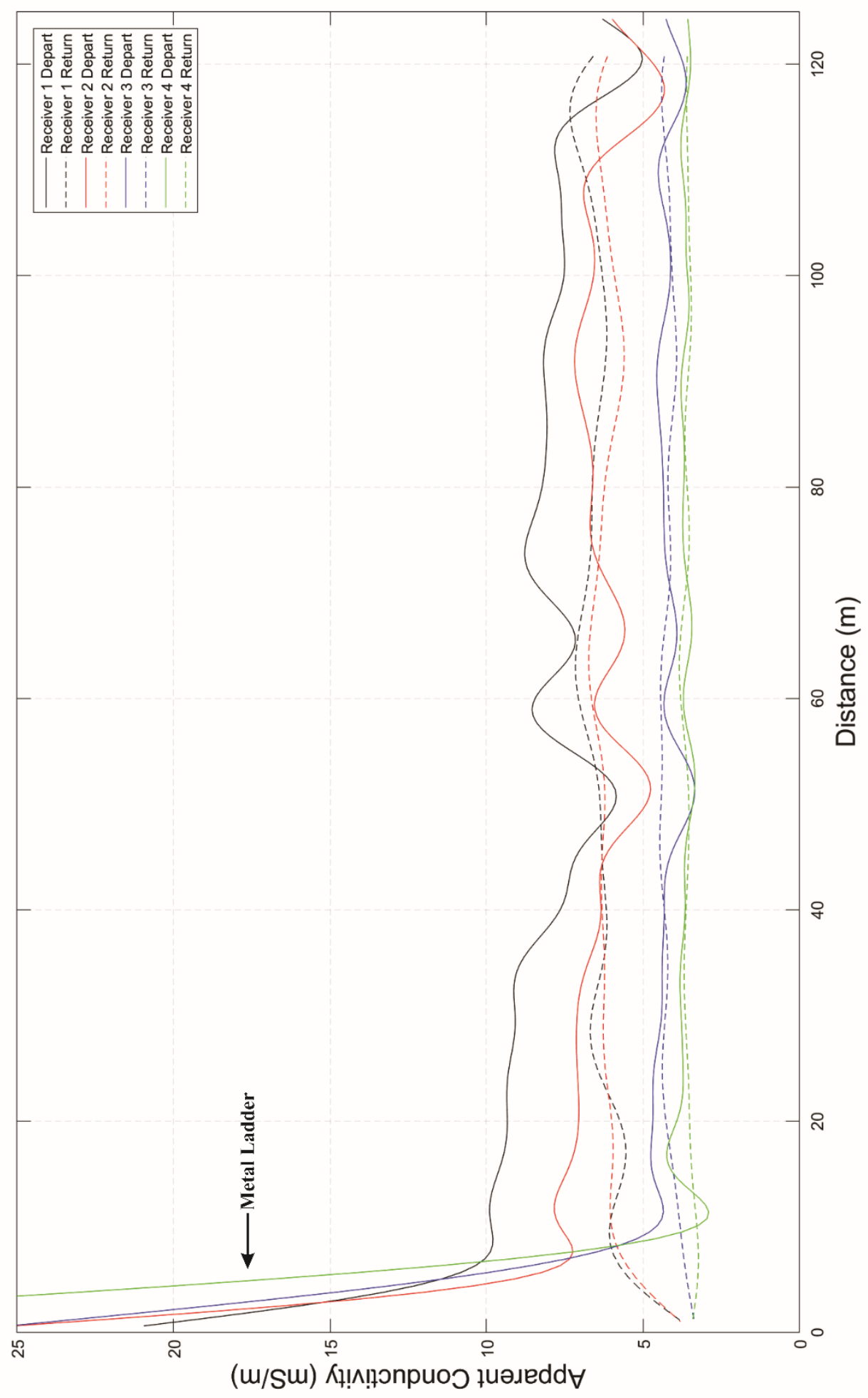

Figure 5.2: Apparent conductivity data for Golden Dome Cave after temperature corrections. 


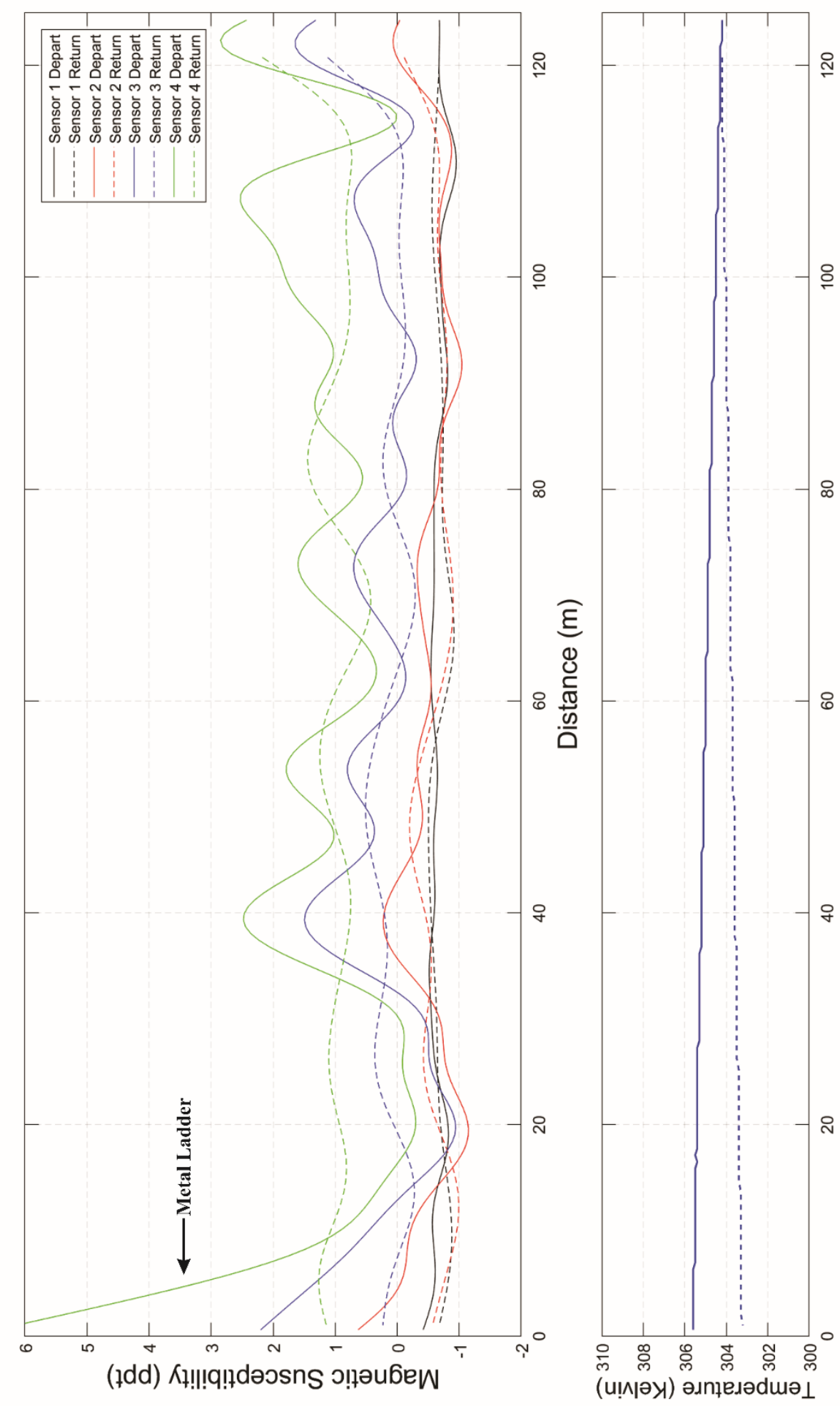

Figure 5.3: (Top) Magnetic susceptibility profile of Golden Dome Cave. (Bottom) Internal temperature of the R4 EMIS. 
Another problem encountered when surveying with the R4 was that, due to extensive low-brush vegetation, the R4 had to be carried using a vertical carrying apparatus made of PVC piping (Figure 3.1) rather than being dragged behind on a non-conductive sled as is normally done (Figure 3.8). Because of this, there were variations in pitch and roll introduced by the operator movements in addition to those due to changes in topography. The Indian Well Cave survey features several examples of changes in pitch and roll (Figure 5.4); the pitch fluctuates between $-10^{\circ}$ and $10^{\circ}$ and the roll averages at approximately $10^{\circ}$. Accuracy is defined as the percentage between a reading done when the instrument is tilted ( $\mathrm{pitch} \neq 0^{\circ}$ and roll $\neq 0^{\circ}$ ) and a reading done when the instrument is perfectly levelled ( $\mathrm{pitch}=0^{\circ}$ and roll $=0^{\circ}$ ), and is expressed mathematically as:

$$
\text { Accuracy }=\cos ^{2} \theta
$$

\section{Equation 5.2}

For a roll of $10^{\circ}$, the accuracy is $96.9 \%$; for a pitch of $5^{\circ}$, the accuracy is $99.2 \%$. Visual inspection of Figure 5.5, however, shows that changes in pitch and roll appear to have had no effect on the data. It is still recommended to survey using a non-conductive sled rather than carrying the instrument, if possible, to minimize pitch and roll errors. 

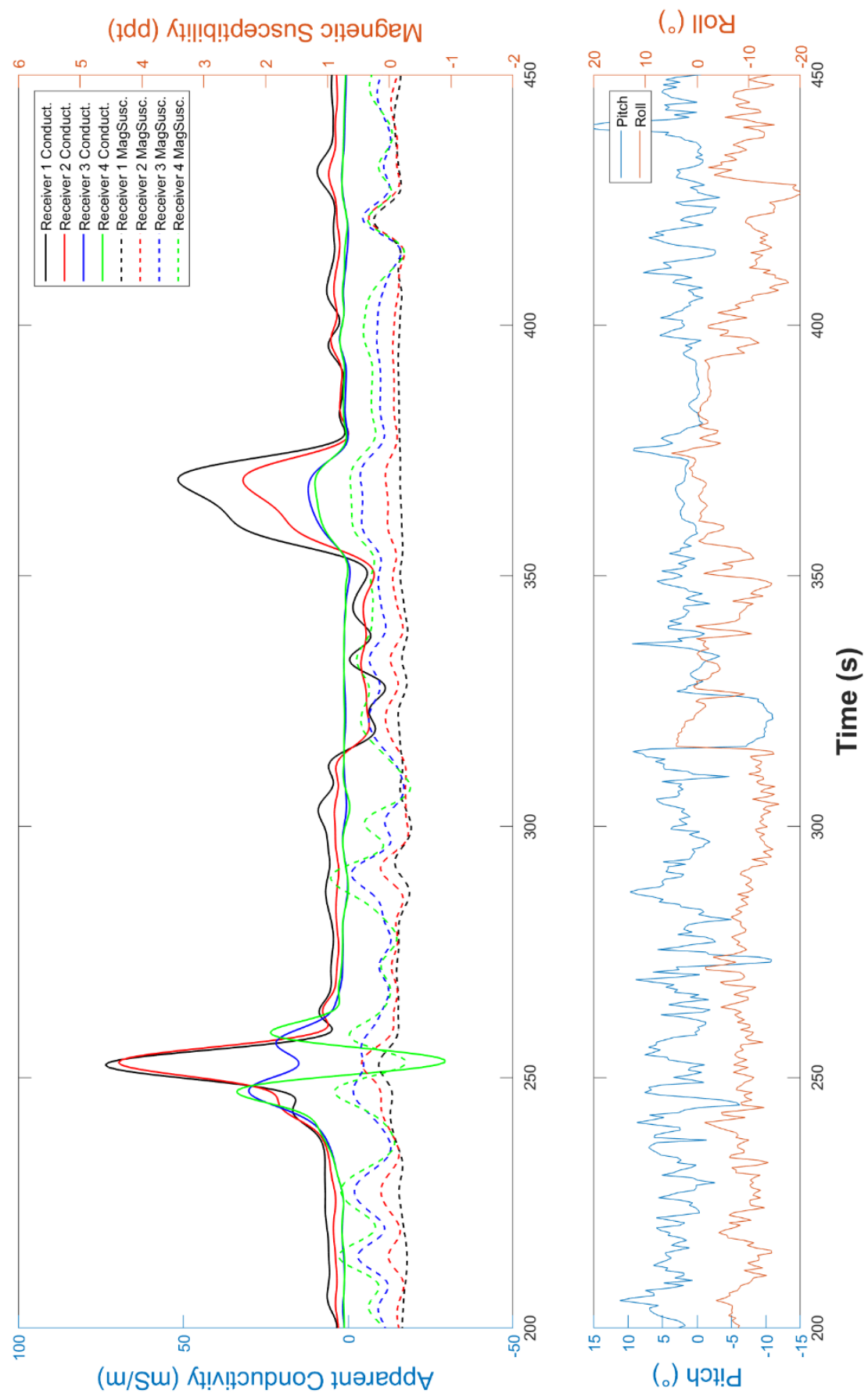

Figure 5.4: (Top) Apparent conductivity (Conduct.) and magnetic susceptibility (MagSusc.) profiles of Indian Well Cave at $0^{\circ}$ roll. (Bottom) Changes in pitch and roll of the R4 EMIS. 


\subsubsection{Surface Survey Results and Interpretations}

The main objective of the project is to detect and characterize signatures of lava tubes from the surface. Because the depth of exploration of the R4 EMIS is higher for $0^{\circ}$ roll than $90^{\circ}$ roll (approximately $170 \mathrm{~cm}$ versus $77.5 \mathrm{~cm}$ for Receiver 4), interpretations of surface surveys will be focused on data from the $0^{\circ}$ roll orientation. The most extensive surface survey conducted was in the vicinity of Indian Well Cave, located south of the Research Centre (Figure 2.3). The survey done with the instrument in $0^{\circ}$ roll orientation consisted of 7 traverse lines oriented approximately E-W, perpendicular to the trend of Indian Well Cave (Figure 5.5 and Figure 5.6). 

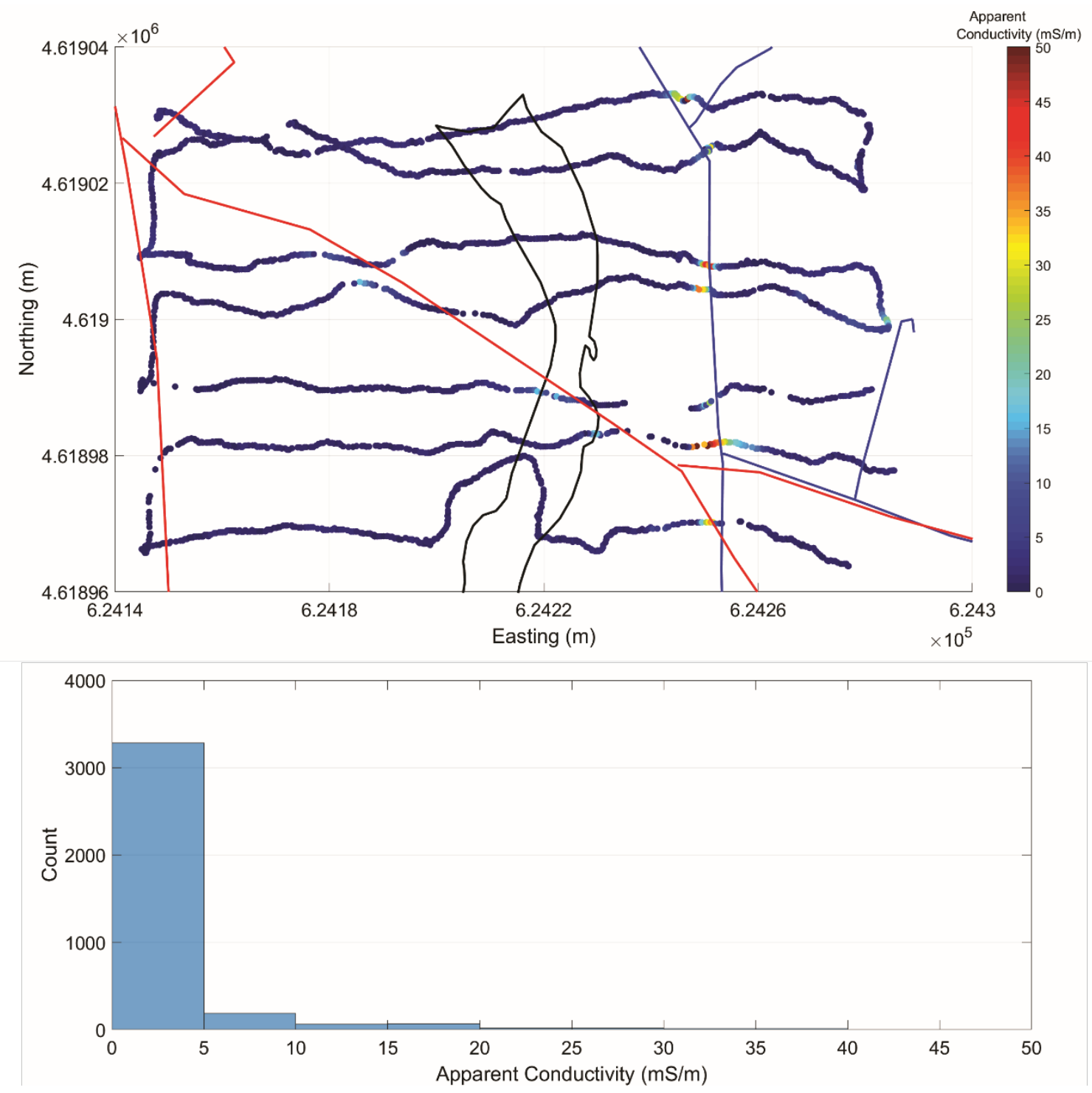

Figure 5.5: (Top) Scatter plot of apparent conductivity data in the vicinity of Indian Well Cave recorded by Receiver 4 at $0^{\circ}$ roll orientation. The outline for Indian Well Cave is in the center, the blue lines represent locations of buried water pipes, and the red lines represent where the roads are. (Bottom) Histogram showing the distribution of apparent conductivity values in the survey. 

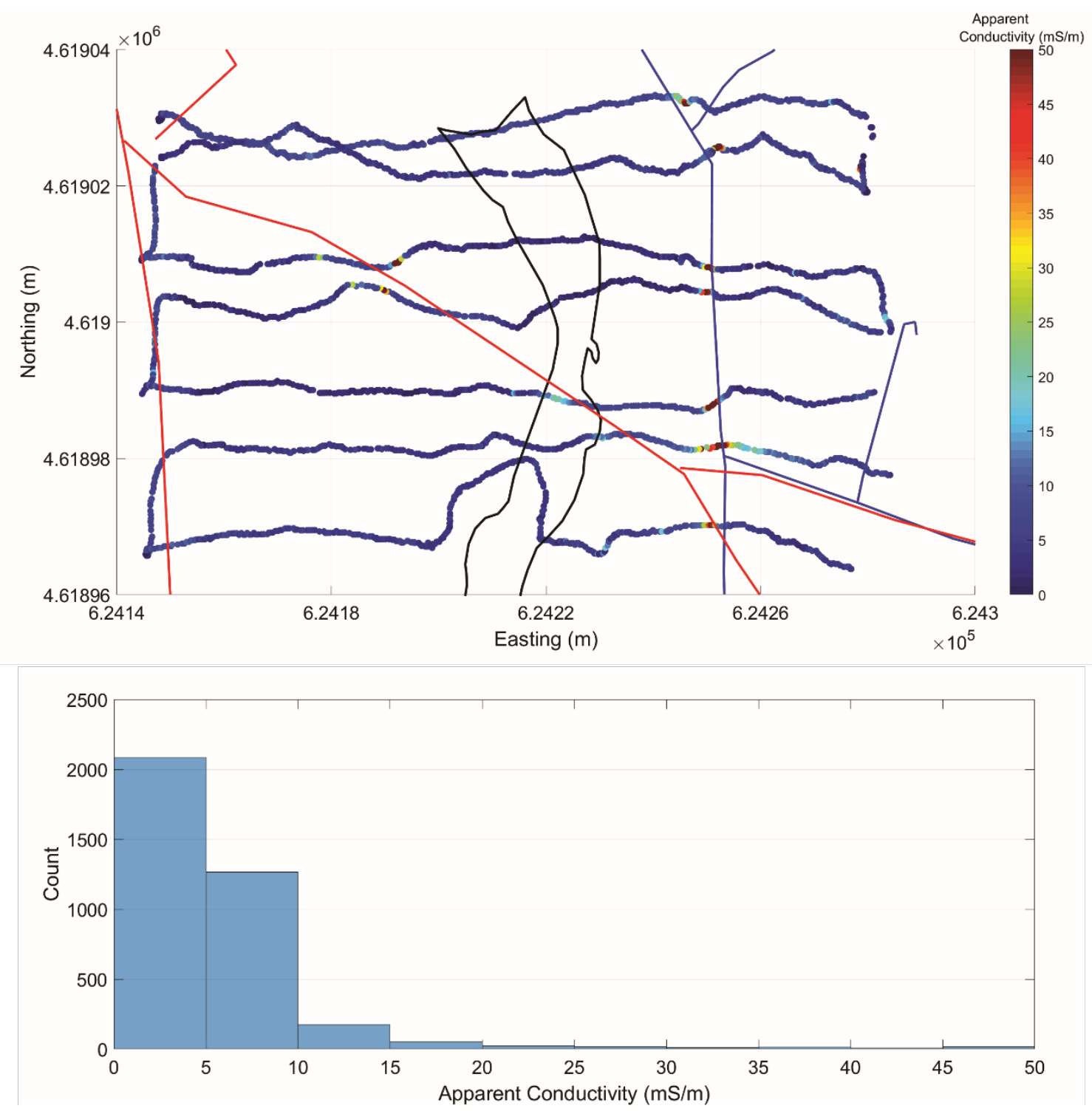

Figure 5.6: (Top) Scatter plot of apparent conductivity data in the vicinity of Indian Well Cave recorded by Receiver 1 at $0^{\circ}$ roll orientation. The outline for Indian Well Cave is in the center, the blue line represents locations of buried water pipes. (Bottom) Histogram showing the distribution of apparent conductivity values in the survey. 
Figure 5.5 top shows apparent conductivity values from Indian Well Cave from Receiver 4 at $0^{\circ}$ roll. Away from the roads (red lines), the ground has generally low apparent conductivity. The histogram showing the distribution of apparent conductivity values (Figure 5.5 bottom) show that over 3000 data points in the survey are in the $0-5$ $\mathrm{mS} / \mathrm{m}$ range, implying that the basalt in the survey area is highly resistive $(\sim 200 \Omega \cdot \mathrm{m})$. The histogram of apparent conductivity values from Receiver 1 (Figure 5.6 bottom) confirm this, as the majority of data points are in the $0-10 \mathrm{mS} / \mathrm{m}$ range. The difference is that data from Receiver 1 depth of exploration are closer to the surface, thus more likely to detect small man-made items, whereas data from Receiver 4 will be more representative of the basaltic bedrock.

For Receiver 4, A strong positive linear anomaly oriented N-S is visible at approximately $624250 \mathrm{E}$ on all 7 traverse lines. The location of this anomaly is correlated with the presence of buried water pipes (blue lines in Figure 5.5 - Figure 5.8), implying that the pipes are made from a conductive metal. The anomaly correlating with the water pipe is very thin, suggesting that only part of the pipe circumference is being observed. Apparent conductivity data from Receiver 1 (Figure 5.6 top) shows a much stronger positive anomaly with a slightly larger width at the same location. It is likely that the Receiver 1 and Receiver 4 data have captured the top and bottom of the pipe, respectively. Because the water pipe is clearly visible in data from both Receivers 1 (depth of exploration $=0.775 \mathrm{~cm})$ and Receiver 4 (depth of exploration $=170.5 \mathrm{~cm}$ ), the pipe is inferred to be buried at a depth of approximately $1 \mathrm{~m}$. Weakly positive anomalies surrounded by negative values are visible at intersections of the survey lines and the road (red lines in Figure $5.5-$ Figure 5.8), which are interpreted to be due to a man-made object buried beneath the road, 
likely a power cable. The strong positive anomaly on the easternmost edge of the survey at approximately $624285 \mathrm{E} 461900 \mathrm{~N}$ is next to a gas tank located beside one of the park ranger's residence.

Despite strong anomalies from man-made structures, it is evident that there are no anomalies that suggest that a lava tube is present in the apparent conductivity data. Directly over the outline of Indian Well Cave in Figure 5.5 and Figure 5.6, apparent conductivity values are approximately $1-5 \mathrm{mS} / \mathrm{m}$. The only anomaly present was where the road went over the lava tube. This implies that the R4 EMIS does not have the suitable depth of exploration to detect Indian Well Cave in this basaltic environment (Table 3.2).

Magnetic susceptibility data was plotted to determine if anomalies similar to those in the apparent conductivity dataset were visible (Figure 5.7 and Figure 5.8). Strong positive anomalies correlating with the road are present in Receiver 4 data (Figure 5.7), suggesting that the asphalt road is highly magnetic. In addition, there is a weaker positive linear anomaly that correlates with the water pipe at $624250 \mathrm{E}$. Because the anomalies correlating with the road were wider, the distribution of magnetic susceptibility values is approximately equal in the 1-2 and 2-3 ppt ranges (Figure 5.7 bottom). Away from the road, the majority of data points were in the $0-1 \mathrm{ppt}$ range, suggesting that there are no magnetic materials in the basaltic bedrock. The anomalies correlating to the road are not visible in the magnetic susceptibility dataset from Receiver 1; however, there are weak positive anomalies present that correlate to the water pipe (Figure 5.7 top). The dataset from Receiver 1 had a majority of values that were between -1.0-0 ppt; therefore, the map showing data above $0 \mathrm{ppt}$ is very scattered (Figure 5.8 top). Data from Receiver 1 above 0 ppt averages around $0.1 \mathrm{ppt}$, implying that the near-surface geologic materials in the area 
are not magnetic (Figure 5.8 bottom). As was the case for the apparent conductivity datasets, there are no visible magnetic signatures suggesting the presence of Indian Well Cave.
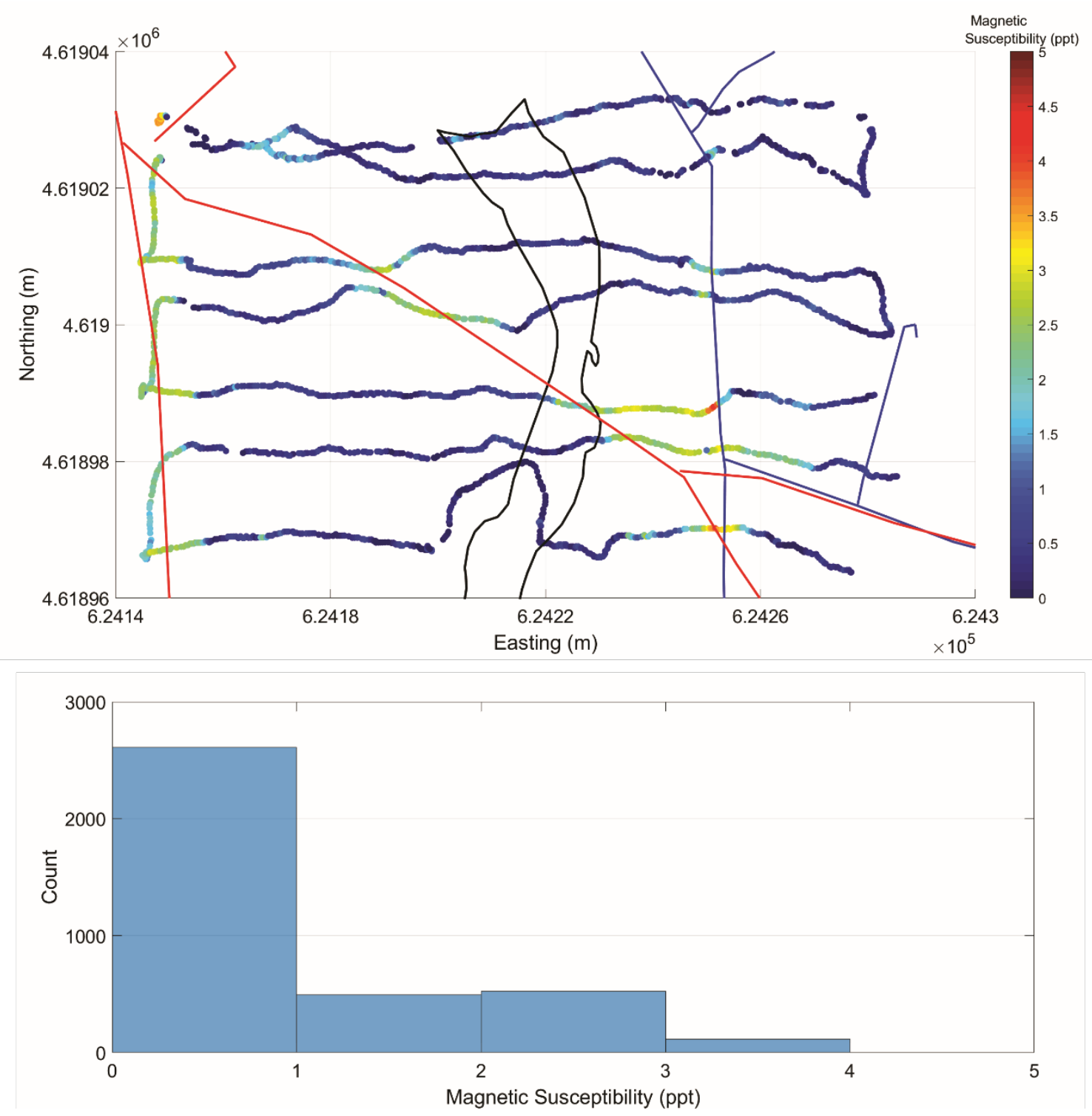

Figure 5.7: (Top) Scatter plot of magnetic susceptibility data in the vicinity of Indian Well Cave recorded by Receiver 4 at $0^{\circ}$ roll orientation. The outline for Indian Well Cave is in the center, the blue lines represent locations of buried water pipes, and the red lines represent where the roads are. (Bottom) Histogram showing the distribution of magnetic susceptibility values in the survey. 

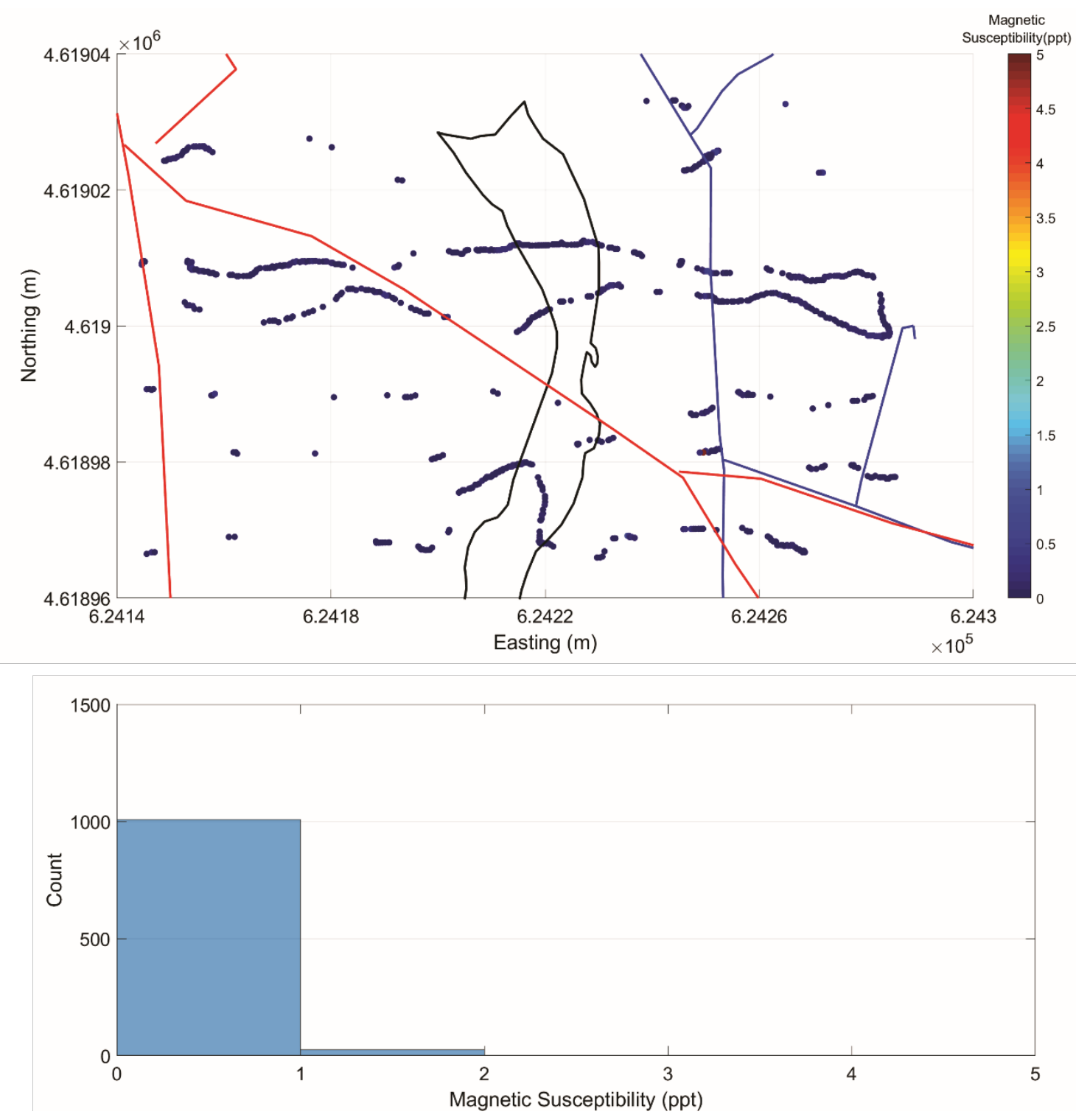

Figure 5.8: Scatter plot of magnetic susceptibility data in the vicinity of Indian Well Cave recorded by Receiver 1 at $0^{\circ}$ roll orientation. The outline for Indian Well Cave is in the center, the blue lines represent locations of buried water pipes, and the red lines represent where the roads are. (Bottom) Histogram showing the distribution of magnetic susceptibility values in the survey.

The magnetic susceptibility datasets confirm the hypothesis that the overcrust of Indian Well Cave is too thick for the R4 EMIS to detect the void beneath. This does not prove or disprove the suitability of EM induction for lava tube detection, but points to the limitations of the prototype R4 EMIS that was used for the survey. The R4 EMIS was an 
effective instrument for detecting near-surface man-made structures, but not for the detection of lava tubes. For future attempts to detect lava tubes using EM induction, it is recommended that a FDEM system with more transmitter power and a larger Tx-Rx separation be used. 


\subsubsection{Interior Surveys Results and Interpretations}

\subsubsection{Instrument Performance Inside Caves}

In addition to surface surveys, the R4 EMIS was used to investigate the effects of floor composition on EM signatures. Other methods such as magnetics and gravity are impractical geophysical methods for investigating the inside of lava tubes since readings are affected by the walls and ceiling. However, with the R4 EMIS, the limited depth of exploration offered the advantage of detecting readings only from the floor of the lava tube (with some interference from the ceiling in places where it was very low).

A disadvantage of recording in the interior of caves using the R4 EMIS is that the integrated GPS cannot record data while inside the cave. Therefore, to create a distance profile, the time when the end of the tube was reached was recorded, then the time it took to return to the starting point was recorded. For Juniper Cave, flags were placed throughout the survey to indicate different sections. The speed was then estimated based on the length of the path in the cave, which was itself estimated from GIS shapefiles, over the time it took to get from the start to the end.

Another disadvantage of surveying inside caves was that the temperature difference between inside the cave and outside the cave could cause temperature drift in the R 4 sensor (see Section 5.1.1). Temperature drift can be exacerbated when not enough time is allowed for the R4 EMIS to thermally compensate for the sharp change in temperature. Therefore, it is recommended that the R4 EMIS rest inside a cave for at least 15 minutes before surveying to prevent the temperature drift problem from occurring. 


\subsubsection{Results and Interpretation}

A summary of the results for interior surveys in each cave are shown in Table 5.1. Although there were no temperature changes when surveying, negative values were prominent in Skull Cave for both magnetic susceptibility and conductivity, which might be due to interference effects. Since the length of the line was extremely short with a low ceiling for most of the line, the R4 data from Skull Cave is not considered reliable and will not be added in the comparison between the floor composition of the different caves. In addition to Skull Cave, Valentine Cave had negative values in conductivity and magnetic susceptibility due to interference. Unlike Skull Cave, where interference was due to low ceilings, Valentine Cave was affected by a series of ledges as well as large pillars in the cave. Therefore, data collected in Valentine Cave are also considered unreliable. 
Table 5.1: Average magnetic susceptibility (IP) and conductivity values (QD) from interior surveys for each receiver, numbered 1 to 4 . The length of line is from the beginning to the end of the cave; it is not the total distance surveyed. Data from Skull Cave and Valentine Cave (in italics) might not be suitable because of interference from a low ceiling.

\begin{tabular}{|c|c|c|c|c|c|}
\hline & $\begin{array}{c}\text { Juniper } \\
\text { Cave }\end{array}$ & $\begin{array}{c}\text { Mammoth } \\
\text { Cave }\end{array}$ & $\begin{array}{c}\text { Golden } \\
\text { Dome }\end{array}$ & $\begin{array}{c}\text { Valentine } \\
\text { Cave }\end{array}$ & Skull Cave \\
\hline Composition & $\begin{array}{c}\text { "Frothy } \\
\text { Pahoehoe" }\end{array}$ & Thick mud & Wet basalt & $\begin{array}{c}\text { Wet basalt / dry } \\
\text { sand at mouth }\end{array}$ & Ice \\
\hline $\begin{array}{c}\text { Length of } \\
\text { Line (m) }\end{array}$ & 213.40 & 45.00 & 123.00 & 237.00 & 20.00 \\
\hline IP1 (ppt) & -0.38 & 0.14 & -0.67 & -0.25 & 0.13 \\
\hline IP2 (ppt) & -0.14 & 0.33 & -0.55 & -0.08 & -0.49 \\
\hline IP3 (ppt) & 0.55 & 0.66 & 0.25 & 0.57 & -0.89 \\
\hline IP4 (ppt) & 1.08 & 0.58 & 1.17 & 1.08 & -1.59 \\
\hline QD1 (mS/m) & 9.89 & 2.91 & 7.60 & -0.46 & -10.49 \\
\hline QD2 (mS/m) & 7.20 & 3.76 & 6.52 & 1.25 & -1.78 \\
\hline QD3 (mS/m) & 5.42 & 3.13 & 4.62 & -2.20 & -1.81 \\
\hline QD4 (mS/m) & 3.85 & 2.81 & 4.33 & -1.90 & \\
\hline
\end{tabular}




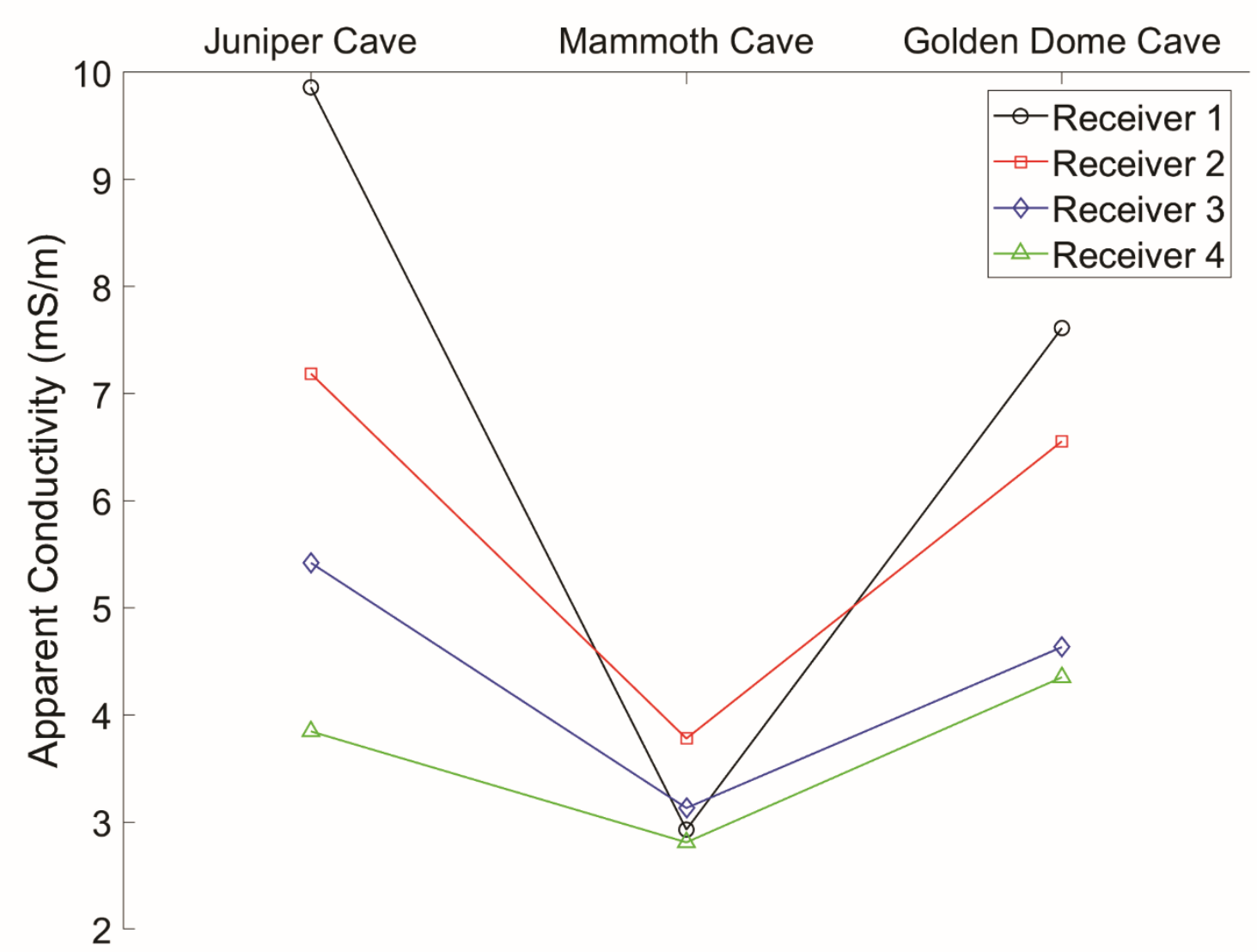

Figure 5.9: Average apparent conductivities of interior surveys for each receiver, categorized by cave.

The general trend for interior surveys is that the floors of caves become more resistive with depth, shown by the decrease in conductivity in Receivers 1 to 4 , as was the expected trend (Figure 5.9). The average apparent conductivities from Receivers 3 and 4 are very close for all three caves, whereas data from Receivers 1 and 2 for each cave are quite different from one another. This suggests that Receivers 3 and 4 detect the basaltic bedrock, and that Receivers 1 and 2 are more indicative of the cave floors. The data from Receivers 1 and 2 show that there are distinct EM signatures for all 3 caves based on floor composition. Mammoth Cave is an exception to the general trend where the average conductivity for all four receivers are similar to each other. 
Conductivity results from Juniper Cave were affected by variables other than just the floor composition. Juniper Cave was surveyed by setting up flagging tape at seven locations in the cave so the time at which the flag was passed could be recorded, and the speed can be calculated. There are visible troughs that correlate with the location of each flag (Figure 5.10). These dips are due to operator error, as the lead operator stopped to record the time at which the flag was reached, in which the backpack carrying the logger box and other conductive components on the lead operator got too close to the sensor, generating the dip in conductivity. The conductivity then increased to normal once the lead operator began to walk away from the R4 EMIS. Conductivity highs throughout the survey are due to the presence of rubble from collapses as well as low ceilings (Figure 5.10). The conductivity highs from rubble are prominent at the beginning of the survey where the path was surrounded by boulders (Figure 5.11), so the R4 EMIS was recording data from the walls and the floor, instead of just the floor. There were spikes in conductivity data in areas where the ceilings were low and there were nearby pillars. This was prominent between flags 2 and 3 where the ceiling was approximately $1.5 \mathrm{~m}$ high, and between flags 6 and 7 where there was a low-ceiling $(\sim 1.25 \mathrm{~m})$ tunnel approximately $5 \mathrm{~m}$ long. Finally, there was a spike after flag 5 where the R4 EMIS passed a massive basalt column followed by rubble. Despite these sources of higher conductivity values, there was a distinct EM signature from the "Frothy Pahoehoe" floor. The most representative conductivity signature for Juniper Cave's floor is the section between flags 4 and 5, which are close to the averages listed in Table 5.1 and shows little variation. 


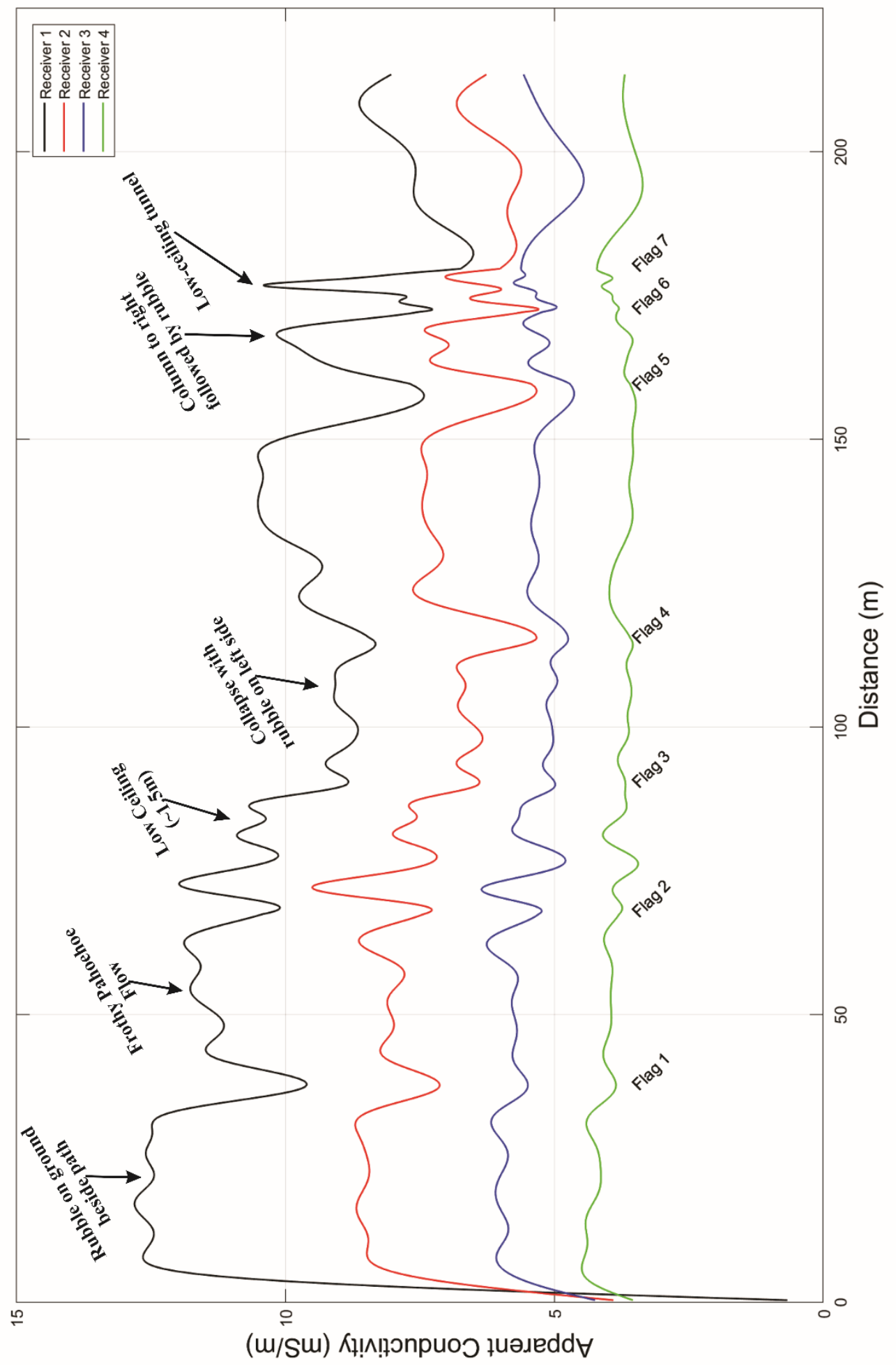

Figure 5.10: Apparent conductivity profile of Juniper Cave after thermal corrections. The survey was only one way and did not turn around after reaching the end. 


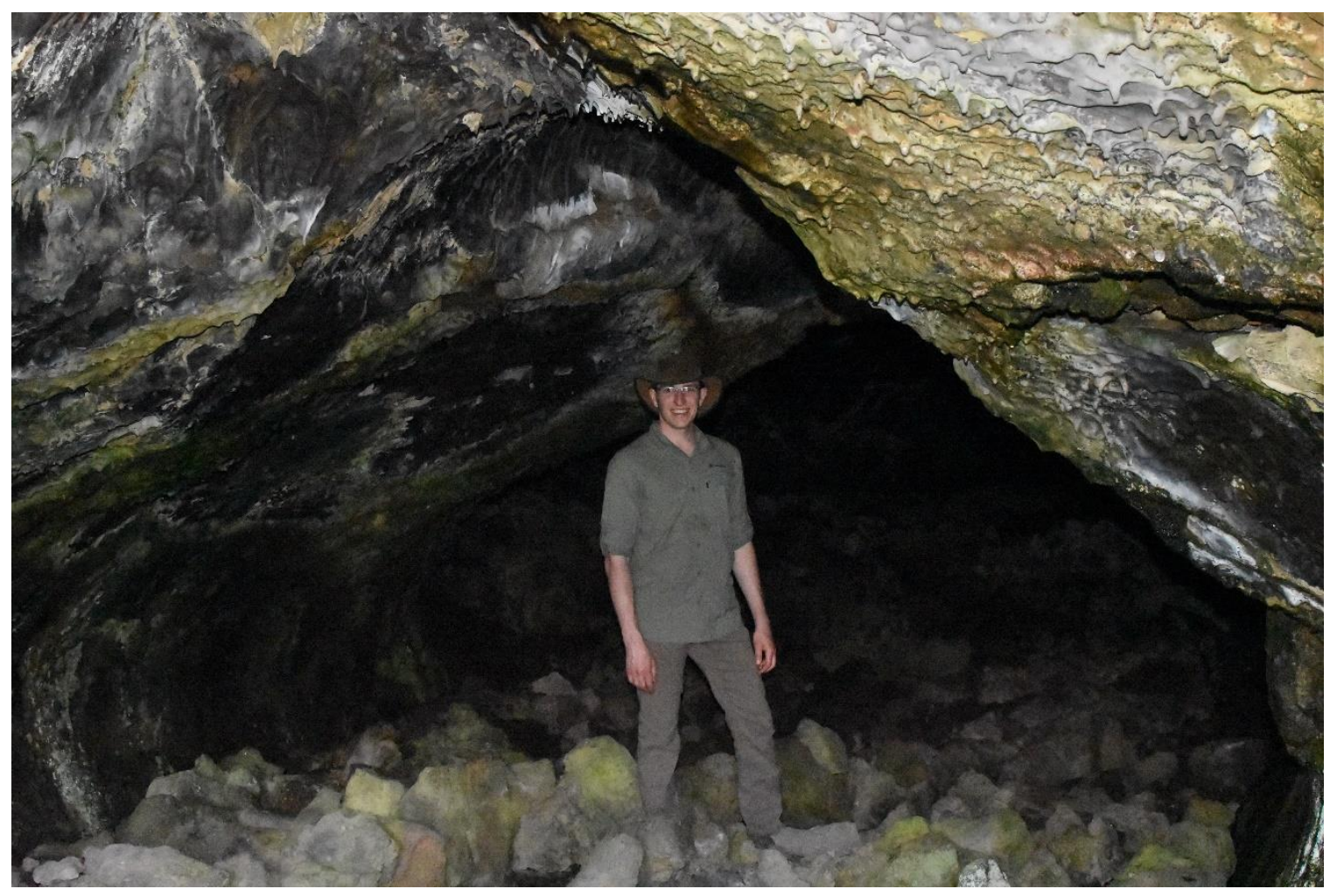

Figure 5.11: Inside of Juniper Cave, just past the entrance. Person is approximately $188 \mathrm{~cm}$ for scale. Note the boulders on the ground from collapses. 
Mammoth Cave also exhibited a distinct EM signature based on floor composition. (Figure 5.12). Mammoth had a lower ceiling than Juniper Cave throughout the cave, with the ceiling being approximately $2 \mathrm{~m}$ high. In addition, the turn-around was a column in the middle of the cave, but the R4 EMIS was not close enough to detect it. As is the case with Juniper Cave, Receivers 1 and 2 were highly affected by noise. At the beginning of the survey, there was a small slope where the floor transitioned from rock to a thick layer of wet mud. This transition is represented by an increase of apparent conductivity in Receivers 1 and 2 from around $-2.5-0 \mathrm{mS} / \mathrm{m}$ to approximately $5 \mathrm{mS} / \mathrm{m}$. This change in apparent conductivity suggests that the receivers with smaller transmitter-receiver separation show EM signatures more representative of floor compositions than the receivers with larger transmitter-receiver separation. Receivers 3 and 4 show a range of $3-5 \mathrm{mS} / \mathrm{m}$, which is only a slight increase from surface surveys and a similar range to Juniper Cave. This suggests that receivers 3 and 4 of interior surveys give a representative EM signature of the rock underneath the floor of the lava tube, rather than a signature of the floor. 


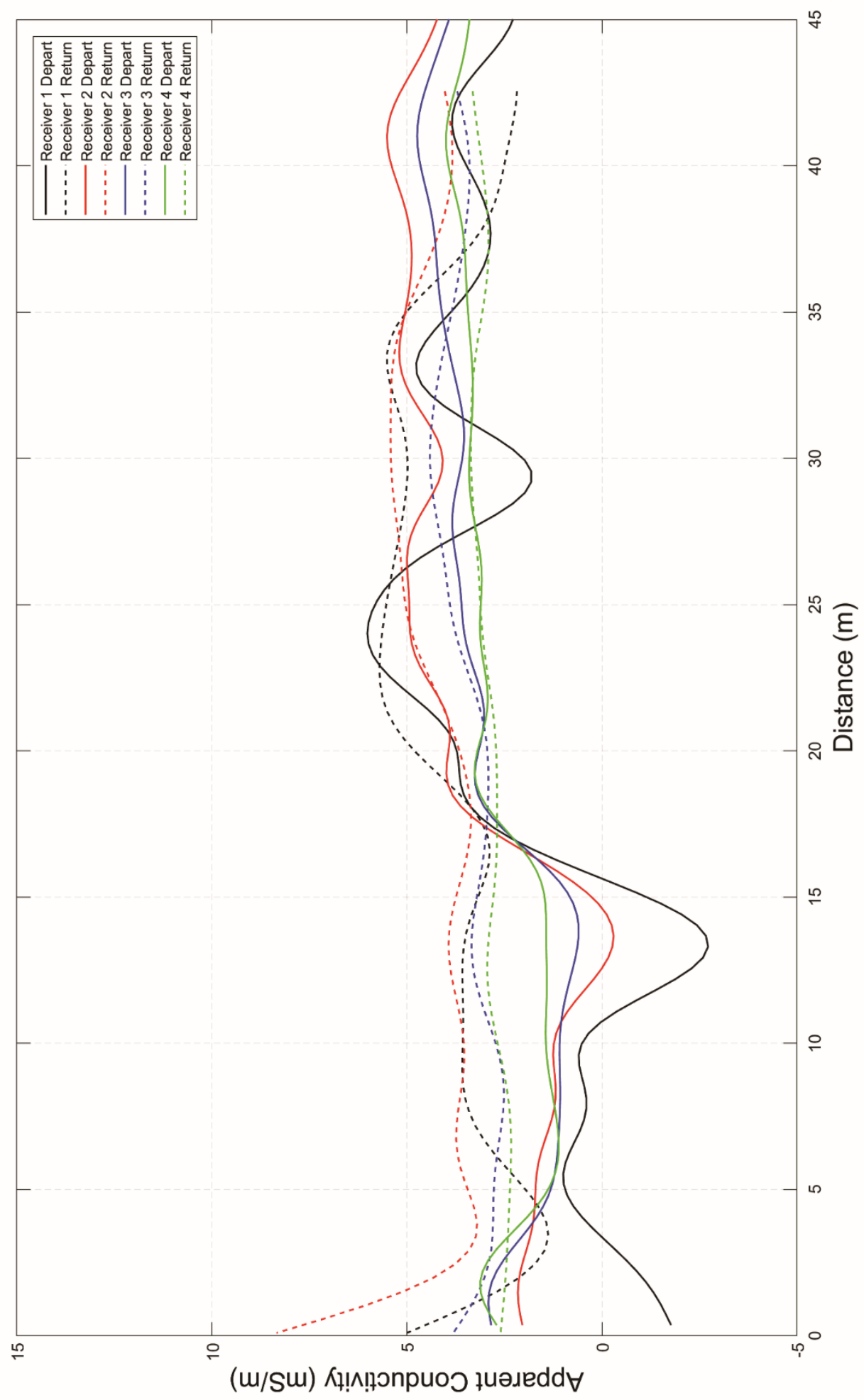

Figure 5.12: Apparent conductivity profile of Mammoth Cave. Solid lines show the survey from the start to the turnaround point. Dashed lines are results from the turnaround point to the end of the survey. 
Golden Dome Cave exhibited rather uniform results due to the lack of features throughout the survey, especially during the return survey (Figure 5.13). The only prominent feature that was detected during the survey was the metal ladder at the start of the survey line, as that was at the entrance into the cave. Another small feature in the cave was a "lava pool" approximately $115 \mathrm{~m}$ into the survey, in which there was a dip in conductivity in the "depart" section of the survey (Figure 5.12 solid lines). The majority of the cave consisted of wet basalt as the floor composition, although some sections were described as "Frothy Pahoehoe" by the National Monument (Waters et al., 1990). The conductivity values for Receiver 1 tend to average approximately $8 \mathrm{mS} / \mathrm{m}$ one way and 7 $\mathrm{mS} / \mathrm{m}$ the other direction, with a total average of about $7.5 \mathrm{mS} / \mathrm{m}$. Receiver 2 has similar results to Receiver 1, with a slightly higher average one way than the return section of the survey, with a total average of approximately $6.5 \mathrm{mS} / \mathrm{m}$. Receivers 3 and 4 are relatively uniform throughout the survey, besides the spike at the beginning of the survey where the ladder was. The averages conductivities for Receivers 3 and 4 were approximately 4.6 and $4.3 \mathrm{mS} / \mathrm{m}$, respectively. These numbers are very similar to those to the values at Receivers 3 and 4 for Juniper and Mammoth Caves, where the conductivity values were in the 3-5 $\mathrm{mS} / \mathrm{m}$ range. Since Receivers 3 and 4 provide a more representative EM signature of the underlying rock, it suggests that the true conductivity range of the basalts in the caves are $\sim 4 \mathrm{mS} / \mathrm{m}$. 


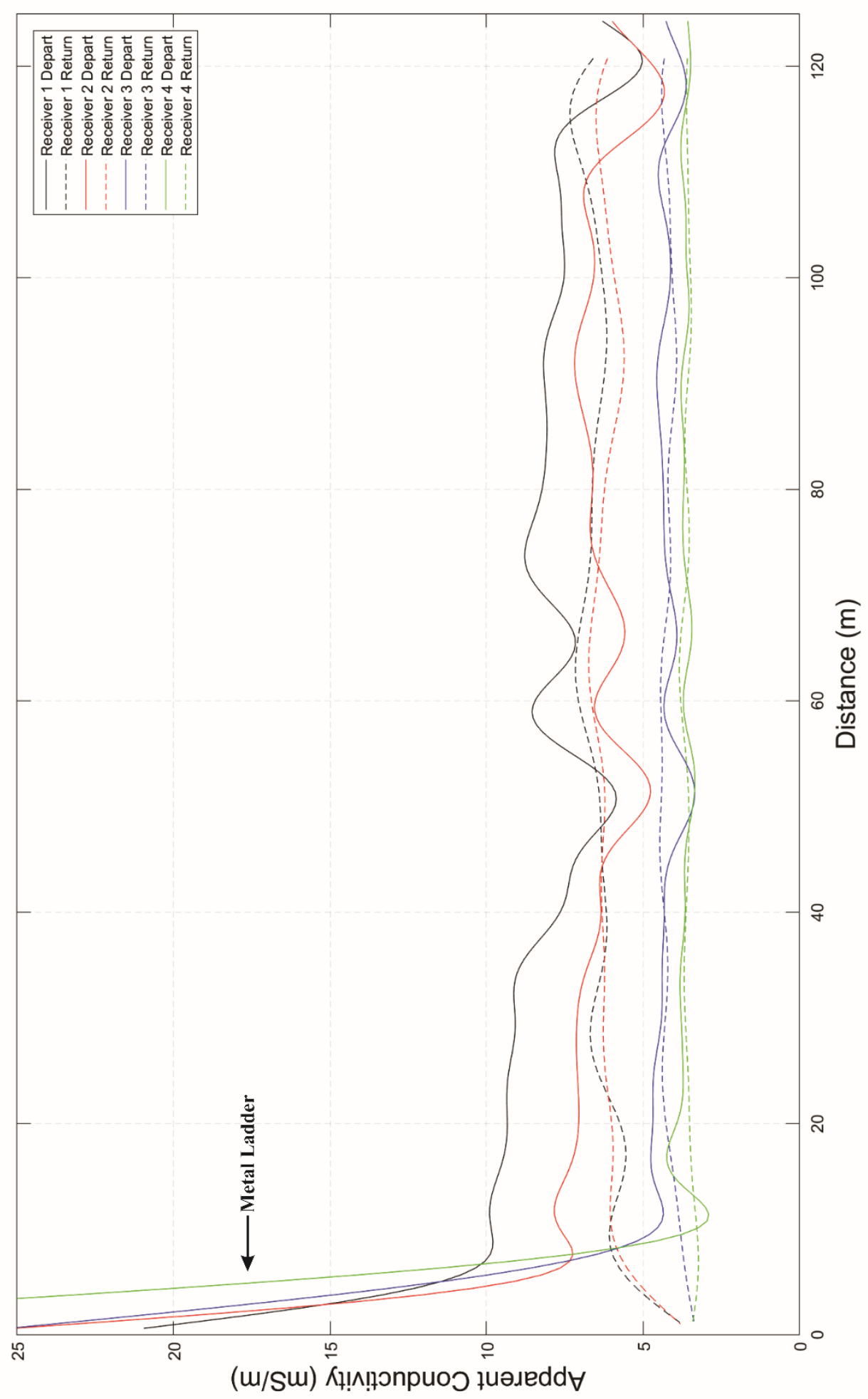

Figure 5.13: Apparent conductivity profile of Golden Dome Cave. Solid lines show the survey from the start to the turnaround point. Dashed lines are results from the turnaround point to the end of the survey. 
Valentine Cave had severe issues with noise that could not be filtered or taken out of the survey. The most prominent source of noise in the Valentine Cave surveys is a series of ledges where the operators had to take a careful step down. This is shown by 3 distinct troughs in the "depart" section of the data from $130 \mathrm{~m}-150 \mathrm{~m}$ into the survey line (Figure 5.14 solid lines), and by two troughs at the first and second step on the "return" section of the survey. The biggest ledge of the three was the first ledge which had an $\sim 1 \mathrm{~m}$ drop. Other sources of high conductivity values other than floor composition include a massive pillar near the start of the survey, sagging roof rocks just after the pillar, and a rock collapse at the end of the survey line. Receiver 1 was greatly affected by noise throughout the survey, as there is only one $60 \mathrm{~m}$ stretch at the beginning that was relatively consistent at approximately $2.5 \mathrm{mS} / \mathrm{m}$. Receiver 2 had a steady decrease from $3 \mathrm{mS} / \mathrm{m}$ to close to 0 $\mathrm{mS} / \mathrm{m}$, with the end of the survey line being close to the average conductivity in Table 5.1. Receivers 3 and 4 exhibited the decrease observed in Receiver 2 but had conductivity values in the negatives which would be a result of the temperature drift described in Section 5.1.1. After thermal corrections, the fact that the Valentine Cave averages are in the negatives suggest that the dataset is unreliable for interpretation. 


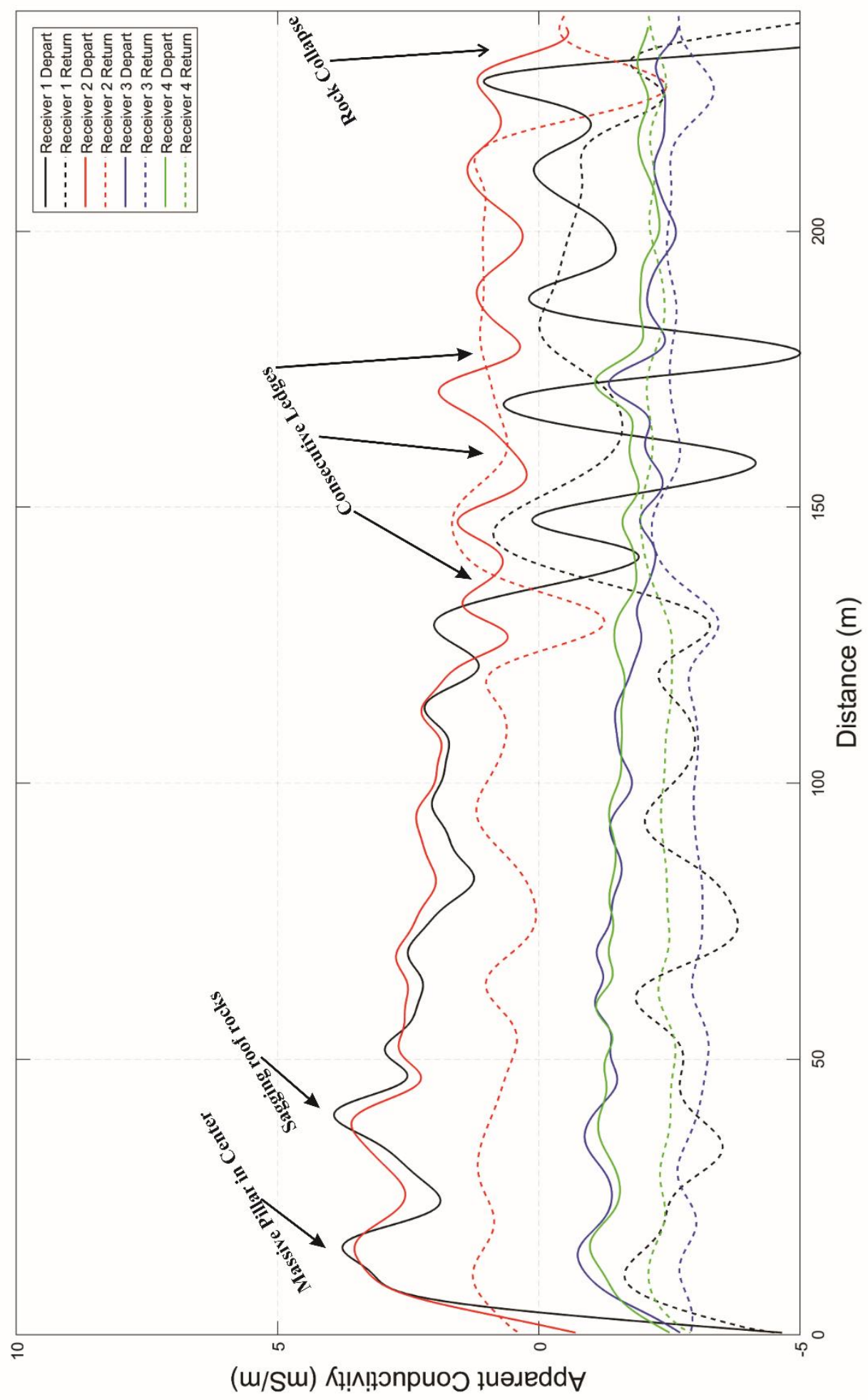

Figure 5.14: Apparent conductivity profile of Juniper Cave. Solid lines show the survey from the start to the turnaround point. Dashed lines are results from the turnaround point to the end of the survey. 
Despite slight differences in magnetic susceptibility averages between caves, the range of minimum and maximum magnetic susceptibility values being less than $2 \mathrm{ppt}$ suggests that there is not enough magnetic material in the floor and underlying rock for magnetic susceptibility to be a discriminating characteristic in cave exploration. 


\subsubsection{1D Inversion Modelling of Juniper Cave}

Inversion was done by Dr. Monteiro Santos based on the 1D-inversion methodology outlined in Monteiro Santos (2004). The approach consists in performing 1Dinversions at equally spaced locations along the survey line and applying constraints to smooth the results laterally. The section of Juniper Cave between Flags 4 and 5 was chosen for the inversion exercise due to lack of interference from walls, rubble, low ceilings, etc. (Figure 5.10). Elevation data was not collected since GPS signal cannot reach inside the cave, so a flat datum was assumed.

Figure 5.15 presents the inversion results showing the true conductivity and magnetic susceptibility versus depth. The north end of the conductivity cross-section (Figure 5.15 top) indicates the presence of a conductive upper layer with conductivity values greater than $10 \mathrm{mS} / \mathrm{m}$ that is approximately $0.3 \mathrm{~m}$ thick. This conductive layer is overlying a resistive lower layer with conductivity values below $5 \mathrm{mS} / \mathrm{m}$. The upper conductive layer is interpreted to be the frothy pahoehoe flow on the floor of the cave with water present in the pahoehoe; the resistive lower layer is the basaltic bedrock. The southern end of the model, however, does not exhibit a simple layered structure as the northern end does. There are higher conductivity values at depth and lower conductivity values at the surface. The low conductivity values at the surface between $30 \mathrm{~m}$ and $34 \mathrm{~m}$ might be an artefact due to change in sensor height: the R4 had to be lifted slightly higher because of rubble on the cave floor. The increase of high conductivity at greater depth in the same area is likely due to fractures in lava where water was able to travel through. 


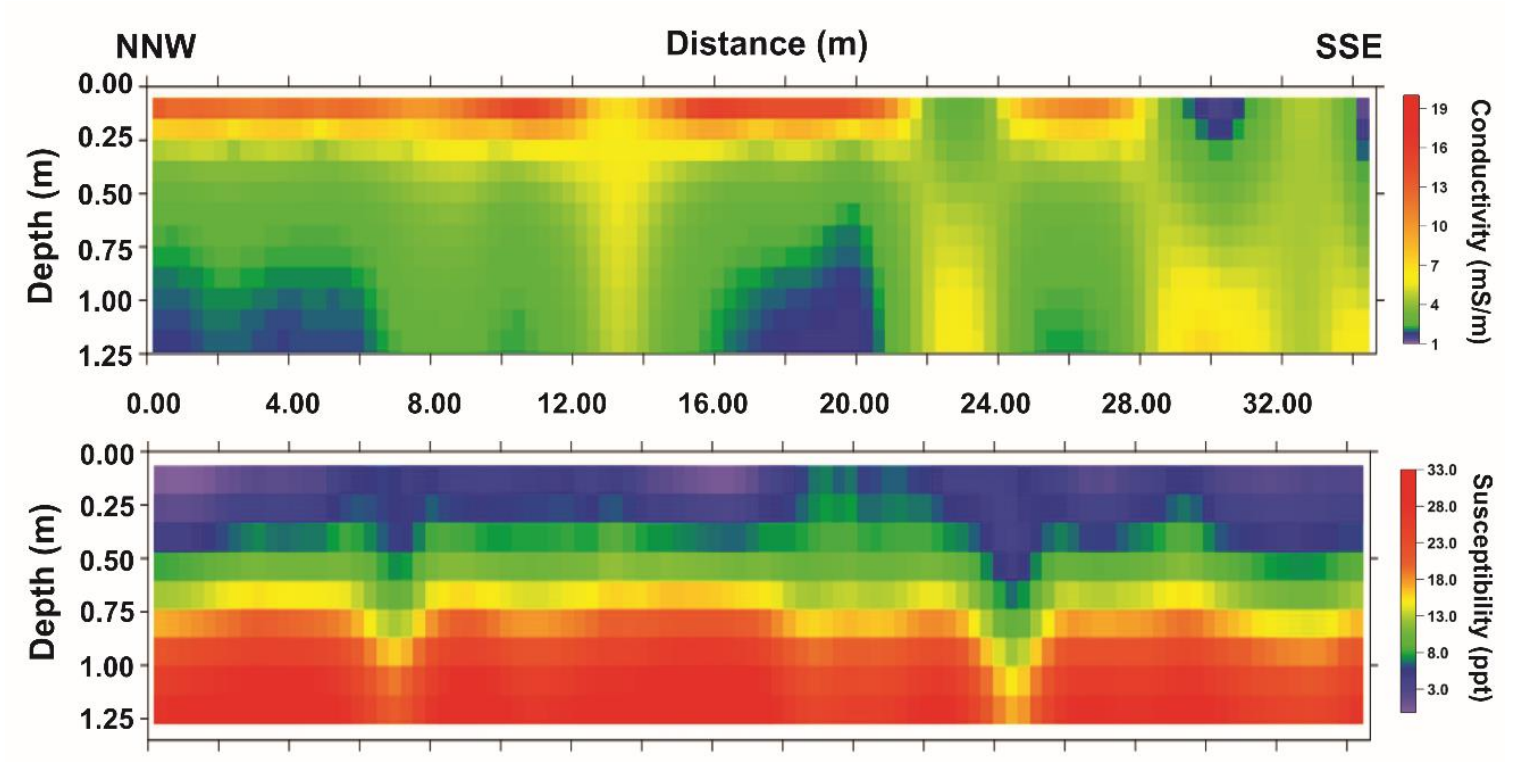

Figure 5.15: Depth models for conductivity (top) and magnetic susceptibility (bottom) derived from the $90^{\circ}$ roll EM data of Juniper Cave. Credit: Dr. Monteiro Santos. Flow direction is from SSE to NNW (right to left).

The magnetic susceptibility cross-section (Figure 5.15 bottom) shows a lowsusceptibility layer near the surface overlying a high-susceptibility layer with values of approximately $5 \mathrm{ppt}$ and $30 \mathrm{ppt}$, respectively. The thickness of the low susceptibility layer is approximately $0.4 \mathrm{~m}$ which is consistent with the thickness of the high-conductivity layer described above Figure 5.15 top). Therefore, the low-susceptibility layer is interpreted as the signature of the frothy pahoehoe floor with water, since water has an extremely low magnetic susceptibility $\left(\sim 9.04 \times 10^{-9}\right.$ ppt at $20^{\circ} \mathrm{C}$; Arrighini et al., 1968). The highsusceptibility layer is interpreted to be the signature of the basaltic bedrock. The lowsusceptibility anomalies at $7 \mathrm{~m}$ and $25 \mathrm{~m}$ suggest that there was loss in magnetic minerals in the basalt due to alteration from the presence of water. The correlation between the location of the low-susceptibility anomalies with high conductivity in the near surface at 7 $\mathrm{m}$ and 22-25 $\mathrm{m}$ suggest that the fractures are old enough for alteration to have occurred. 
Conversely, the lack of correlation between the location of the low-susceptibility anomalies with that of fractures at $13 \mathrm{~m}$ and $30 \mathrm{~m}$ suggests that these fractures are younger than the fractures at $7 \mathrm{~m}$ and $22-25 \mathrm{~m}$ as the water has not been present long enough to alter the basalt at depth and lower its magnetic susceptibility.

The 1D inversion showed that the R4 EMIS was successful in characterizing the floors of lava tubes based on their compositions. The R4 was able to characterize the frothy pahoehoe floor as a high-conductivity, low-susceptibility layer that is approximately $0.3 \mathrm{~m}$ thick, with the basaltic bedrock being resistive with a susceptibility of $30 \mathrm{ppt}$. The R4 was also able to detect potential fractures in the basalt due to the higher conductivity at depth, as well as potentially characterize different generations of fracturing. The susceptibility value of the basalt is consistent with the range quoted Telford et al. (1990) and will be used as the susceptibility of the basaltic bedrock in the magnetic modelling exercise in Section 5.2.1. 


\subsection{Magnetic Surveys}

5.2.1. Forward Modelling of a Lava Tube in Basaltic Host Rock

Forward modelling is when a model of the subsurface is created and the software calculates the corresponding magnetic response based on the magnetic field conditions at the time of surveying (i.e. magnetic field strength, inclination, declination). To provide insight for data interpretation and inversion, a series of modelling exercises were conducted to simulate the theoretical magnetic response to a simple subsurface void in basaltic host rock. Modelling was done using the GM-SYS 2D extension in Oasis Montaj.

The parameters used for the forward modelling exercise are shown in Table 5.2. The magnetic field strength was averaged from base station values recorded during the time in which surveying was conducted; the inclination and declination were calculated from the International Geomagnetic Reference Field (Natural Resources Canada, 2019). Elevation was averaged from values in Google Earth and is assumed to be constant. The lava tube model consists of a half-dome void with varying limiting depth and width. The void has a magnetic susceptibility of zero and is located in a rock with a constant magnetic susceptibility.

Table 5.2: Parameters used for the forward modelling exercise done in GM-SYS 2D.

\begin{tabular}{|c|c|r|}
\hline Parameter & Units & \multicolumn{1}{|c|}{ Value } \\
\hline Magnetic Field Strength & {$[\mathrm{nT}]$} & 51500 \\
\hline Inclination & {$[$ Deg. $]$} & 64.644 \\
\hline Declination & {$[$ Deg.] } & 14.188 \\
\hline Elevation & {$[\mathrm{m}]$} & 1517 \\
\hline
\end{tabular}


For the forward models for which depth varies and width and susceptibility are held constant, the void is $3 \mathrm{~m}$ high and $8.25 \mathrm{~m}$ wide, which are the dimensions of Juniper Cave based on USGS shape files; in addition, these are approximate dimensions for an average lava tube at LBNM based on field observation of multiple lava tubes $(\sim 3-4 \mathrm{~m}$ height, $\sim 6-8$ $\mathrm{m}$ width). The void is centered in the middle of a $70 \mathrm{~m}$ long survey line ( $\sim 35 \mathrm{~m})$ and depth increases in $1 \mathrm{~m}$ increments from $1 \mathrm{~m}$ to $15 \mathrm{~m}$. For the forward models in which width varies and depth and susceptibility are held constant, the void is $3 \mathrm{~m}$ high and located at a limiting depth of $3 \mathrm{~m}$. Width increases in $1 \mathrm{~m}$ increments from $3 \mathrm{~m}$ to $12 \mathrm{~m}$. For the forward models in which susceptibility varies and depth and width are held constant, the dimensions of the void are $3 \mathrm{~m} \times 8 \mathrm{~m}$ at $3 \mathrm{~m}$ depth and it is located at a limiting depth of $3 \mathrm{~m}$. Susceptibility increases in increments of $0.01 \mathrm{cgs}$ from $0.01 \mathrm{cgs}$ to $0.10 \mathrm{cgs}(0.1256 \mathrm{SI}$ units - 1.256 SI units). For the forward models in which NRM varies and depth and width are held constant, the dimensions of the void are $3 \mathrm{~m} \times 8 \mathrm{~m}$ at $3 \mathrm{~m}$ depth and it is located at a limiting depth of $3 \mathrm{~m}$. NRM increases logarithmically from $0.1 \mathrm{~A} / \mathrm{m}$ to $5 \mathrm{~A} / \mathrm{m}$, then in increments of $5 \mathrm{~A} / \mathrm{m}$ from $5 \mathrm{~A} / \mathrm{m}$ to $45 \mathrm{~A} / \mathrm{m}$. The values were chosen to be within the acceptable range of NRM of basalts. An example forward model is shown in Figure 5.16. An example forward model is shown in Figure 5.16.

Figure 5.17 shows the calculated responses when depth varies, and width and susceptibility are held constant. At shallow depths, the calculated magnetic response is characterized by a high-amplitude narrow magnetic low positioned slightly off-center from the vertical axis of symmetry of the lava tube, followed by a magnetic high to the northeast. As the depth increases, the amplitude of both the magnetic low and high decrease and the peaks broadens. In addition, the apex of the magnetic low shifts towards the south and the 
apex of the magnetic high towards the north decreases; this is due to the broadening of the response. Outside the area of influence of the lava tube, the calculated magnetic responses are approximately $51250 \mathrm{nT}$.

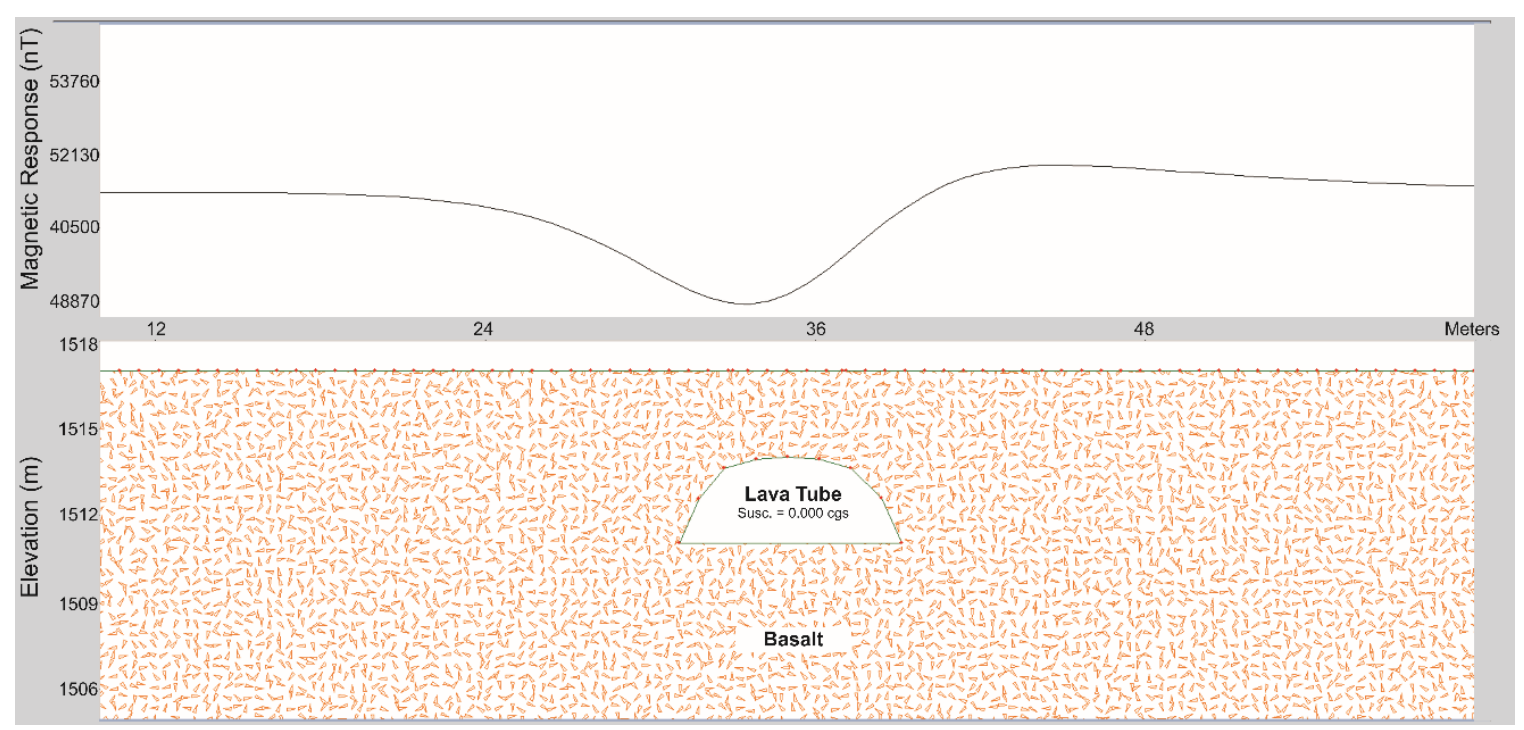

Figure 5.16: Example of forward modelling results from GM-SYS 2D showing the depth model at the bottom and the calculated response at the top. 


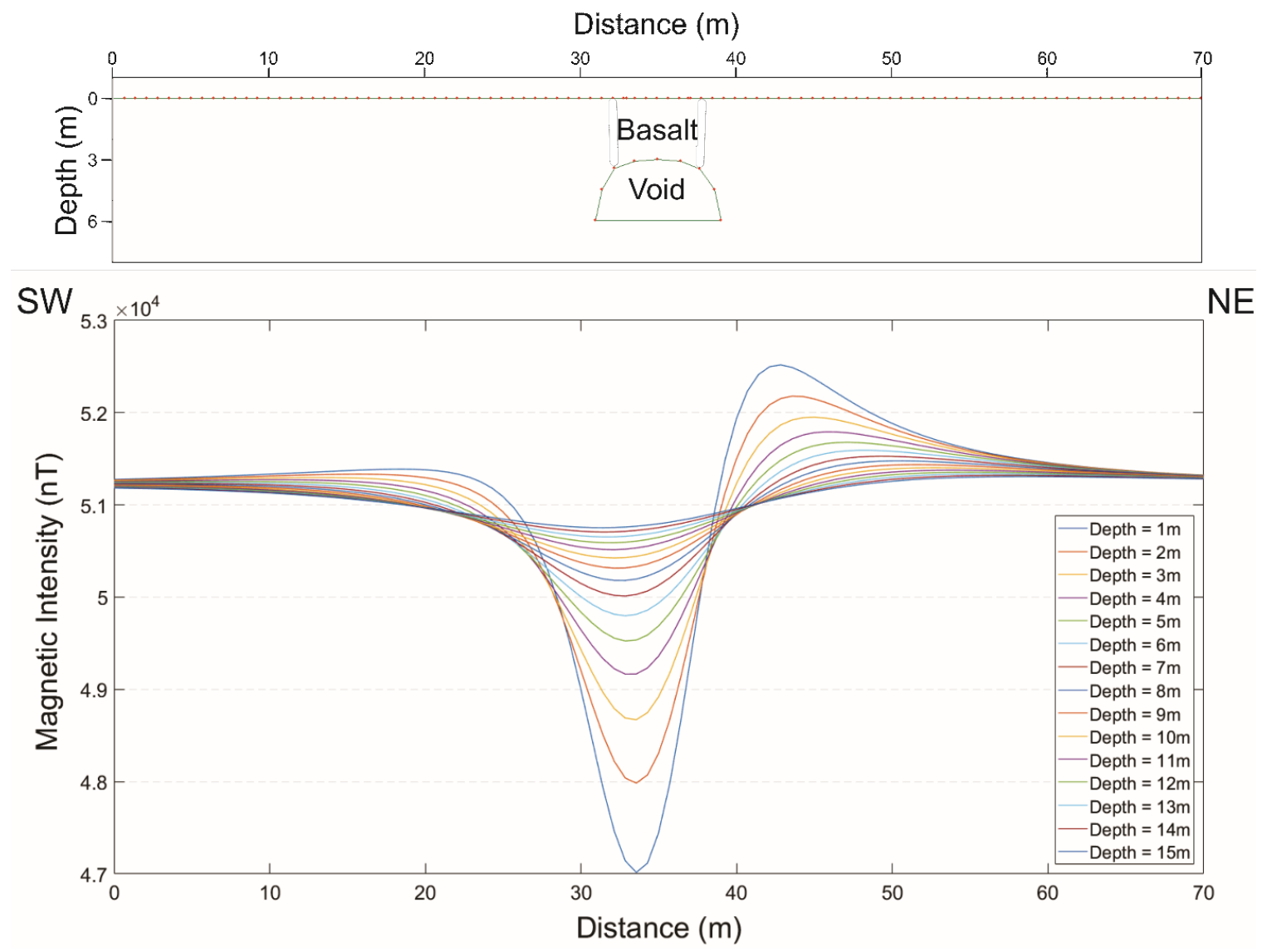

Figure 5.17: (Top) Depth model showing the placement of the tube for the forward models. (Bottom) Calculated magnetic response of a $3 \mathrm{~m} \times 8 \mathrm{~m}$ half-dome lava tube at various depths. The yellow curve indicating $3 \mathrm{~m}$ depth corresponds with the depth figure shown above.

The maximum and minimum values from each forward model are plotted in Figure 5.18 as another way to visualize the diminishing influence of the lava tube on the magnetic intensity as its depth increases. For this particular example, the difference between maximum and minimum values becomes almost constant when the lava tube is at a depth of $10 \mathrm{~m}$ or greater. 

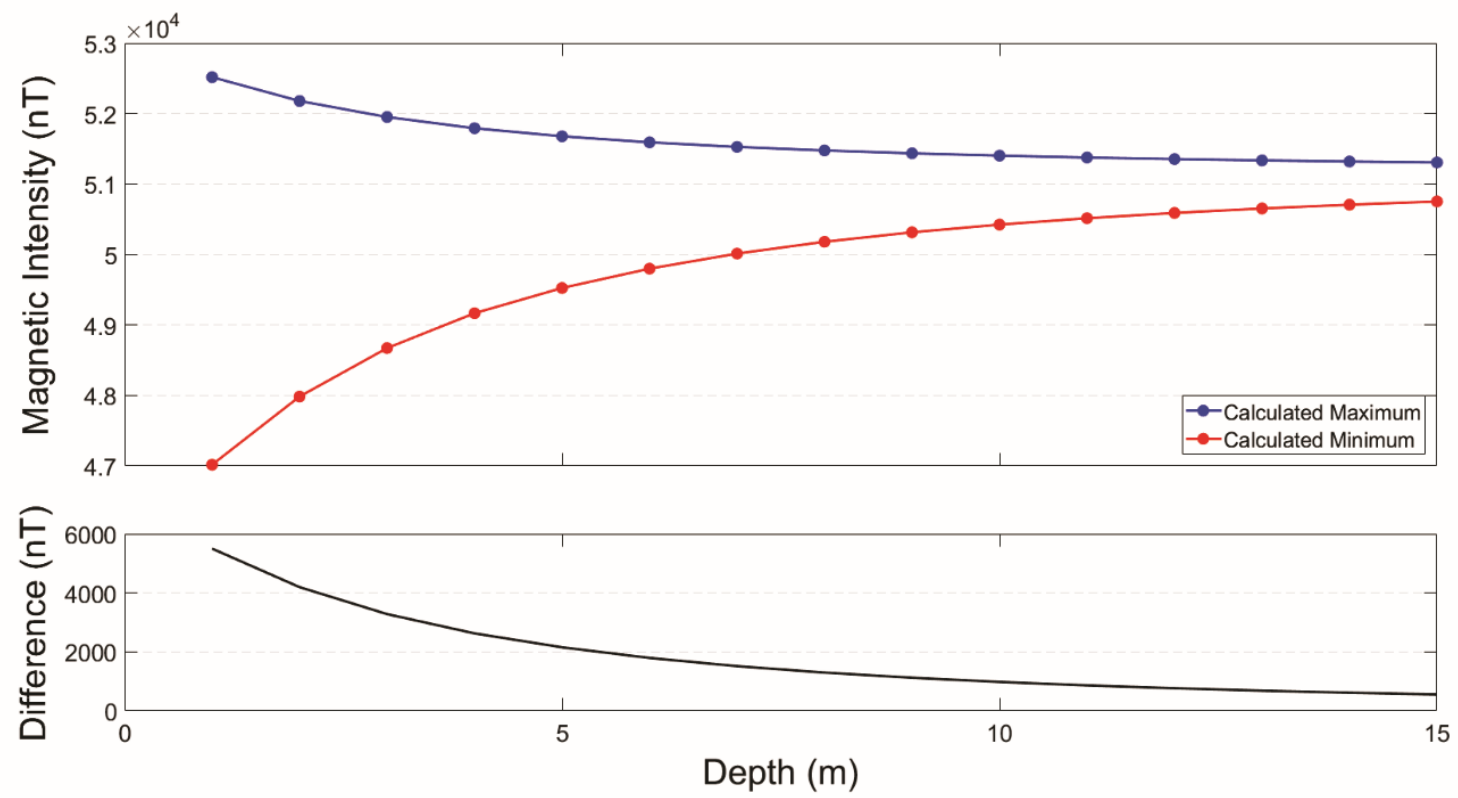

Figure 5.18: (Top) Maximum and minimum values of the observed and calculated magnetic responses shown in Figure 5.20. (Bottom) Difference between the maximum and minimum value for each depth.

In addition to modelling the effect of depth, modelling the effect of width was also conducted for widths ranging from $3 \mathrm{~m}$ to $12 \mathrm{~m}$. This range of widths was chosen to represent most lava tubes at LBNM, the notable exception being Skull Cave that has a diameter of $20 \mathrm{~m}$. The height of the lava tube is $3 \mathrm{~m}$ for consistency with the depth models. It is located at a limiting depth of $3 \mathrm{~m}$. Figure 5.19 shows the calculated responses from the width modelling. Increasing the width of the lava tube leads to an increase in magnitude as well as a broadening of the magnetic anomaly. In addition, there is a shift in the apex of the magnetic low to the south as the width increases; the apex of the magnetic high also shifts to the north as the width increases. 


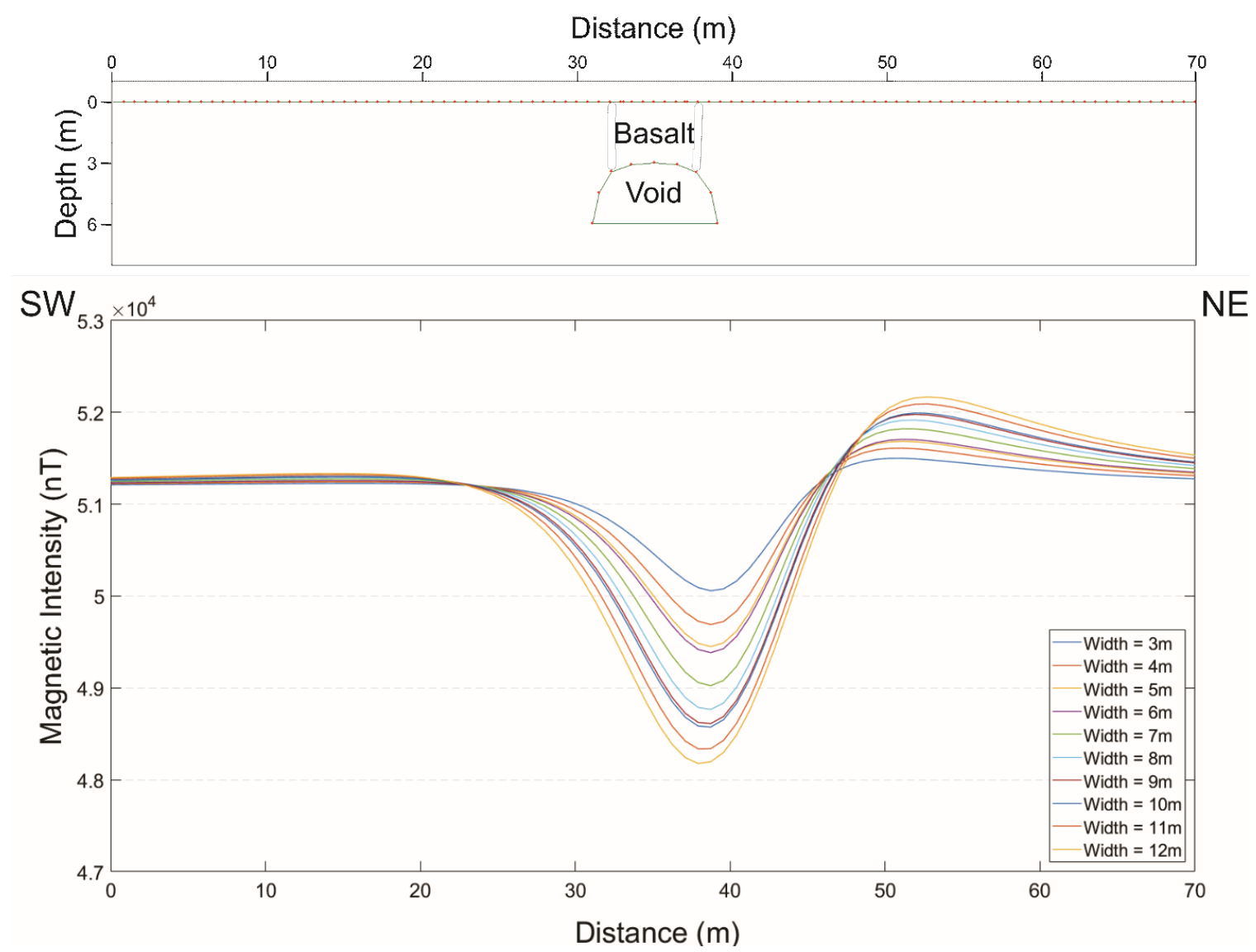

Figure 5.19: (Top) Depth model showing the placement of the tube for the forward models. (Bottom) Calculated magnetic response of a $3 \mathrm{~m}$-tall half-dome lava tube located at a limiting depth of $3 \mathrm{~m}$ with varying widths. The blue curve indicating $8 \mathrm{~m}$ width corresponds to the model shown above.

Figure 5.20 shows the maximum and minimum values from each forward model in Figure 5.19 to show the influence of the lava tube on magnetic intensity as the width increases. As width increases, the magnetic low and the magnetic high immediately northeast increase almost linearly in magnitude, with the rate of increase greater for the magnetic low than the magnetic high. 

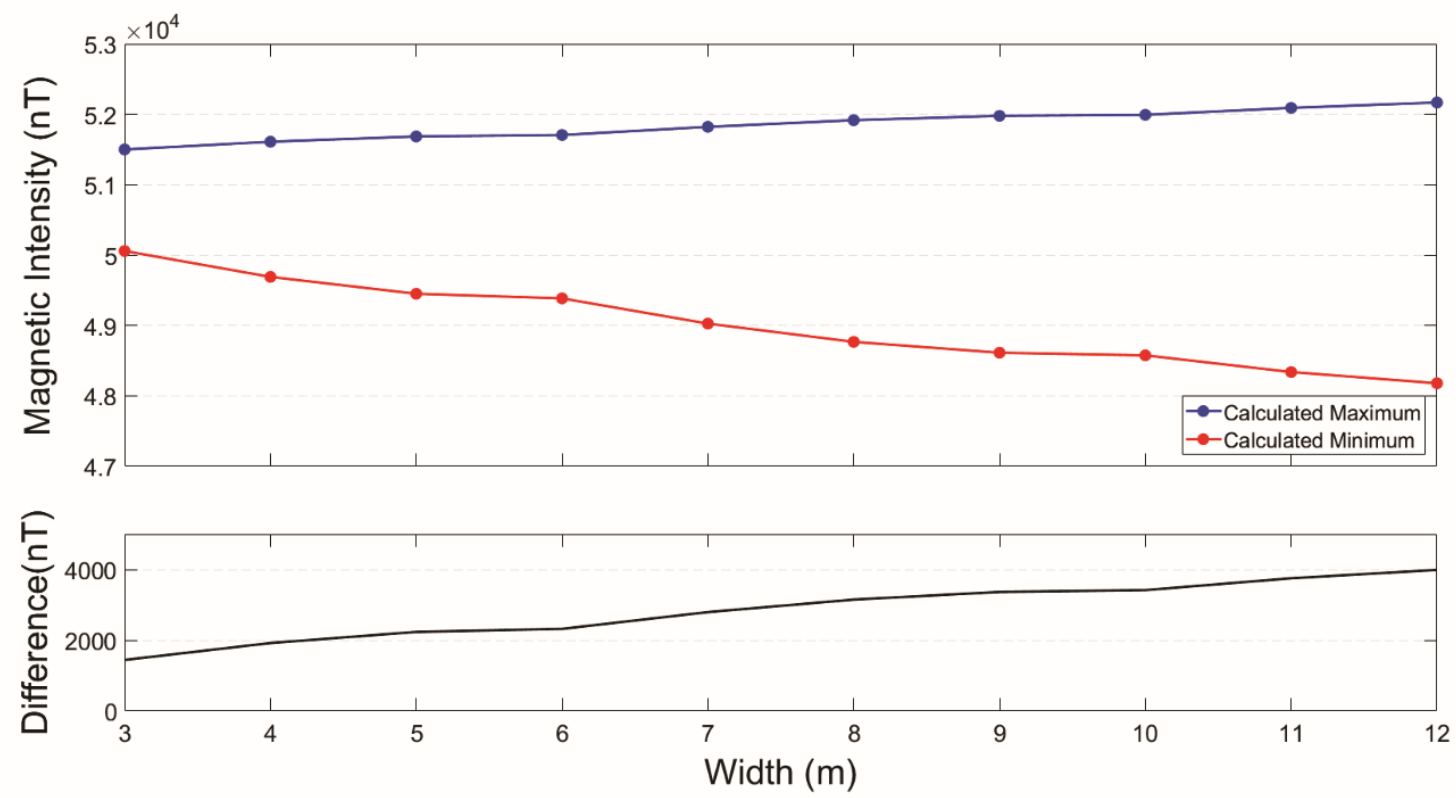

Figure 5.20: (Top) Maximum and minimum values of the observed and calculated magnetic responses shown in Figure 5.22. (Bottom) Difference between the maximum and minimum value for each width. The slight non-linearity is due to human error when the depth model was being modified in the software.

Changes in the magnetic susceptibility of the basalt were considered as part of the forward modelling exercise. The exercise consists of increasing magnetic susceptibility from 0.01 cgs units to $0.1 \mathrm{cgs}$ units for a $3 \mathrm{~m}$ x $8 \mathrm{~m}$ void located at a limiting depth of $3 \mathrm{~m}$. The calculated responses in cgs units are shown in Figure 5.21. As was the case for the depth and width modelling, the calculated response is characterized by a magnetic low offset from the vertical axis of symmetry of the lava tube, followed by a magnetic high to the northeast. The calculated responses increase in magnitude as the magnetic susceptibility of the basalt increases. The magnitude of the response is the only thing that changes; there is no change the general shape of the responses. Figure 5.22 shows the maximum and minimum values from each response in Figure 5.21. The magnetic response overall exhibits a linear relationship with increasing susceptibility. 


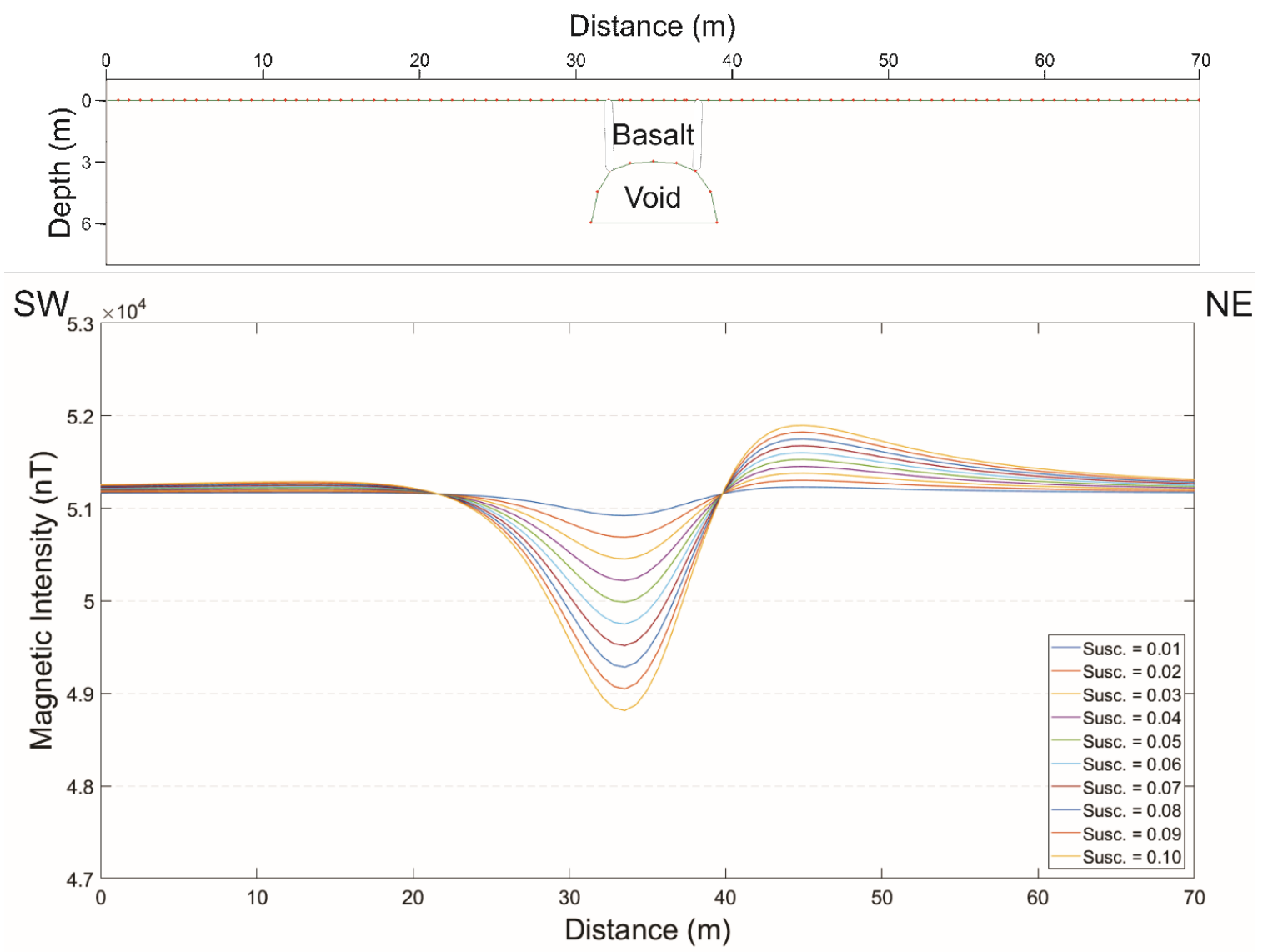

Figure 5.21: (Top) Depth model showing the placement of the tube for the forward models. (Bottom) Calculated magnetic response of a $3 \mathrm{~m} \mathrm{x} 8 \mathrm{~m}$ half-dome lava tube located at a limiting depth of $3 \mathrm{~m}$ with varying magnetic susceptibility values. Magnetic susceptibilities are in cgs units. The yellow curve indicating a susceptibility of $10 \mathrm{cgs}$ corresponds to the model shown above. 

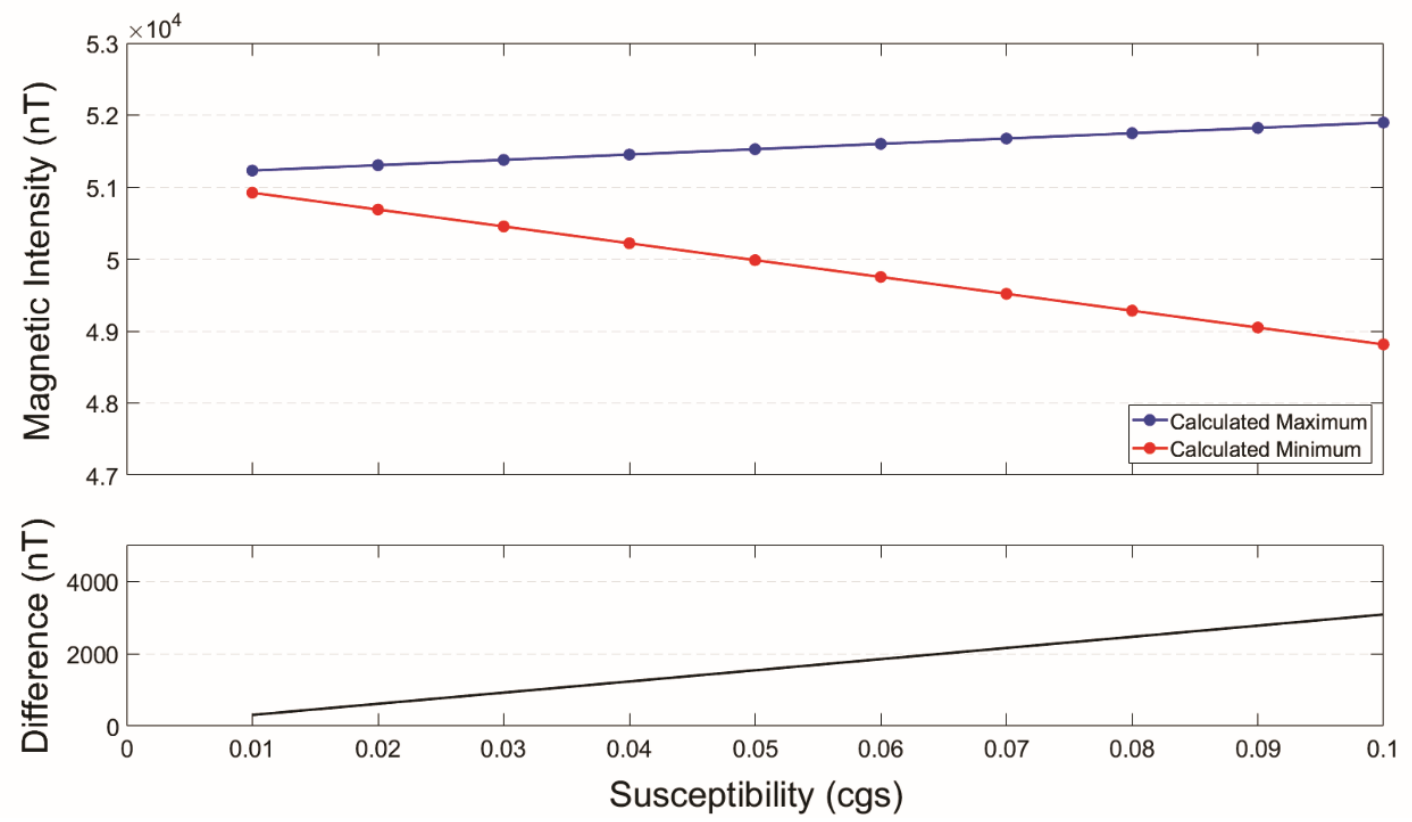

Figure 5.22: (Top) Maximum and minimum values of the observed and calculated magnetic responses shown in Figure 5.24. (Bottom) Difference between the maximum and minimum value for each susceptibility.

Finally, changes in NRM were considered as part of the forward modelling exercise. The exercise consists of increasing remanence from $0.1 \mathrm{~A} / \mathrm{m}$ to $45 \mathrm{~A} / \mathrm{m}$ for a $3 \mathrm{~m}$ $\mathrm{x} 8 \mathrm{~m}$ void located at a limiting depth of $3 \mathrm{~m}$. The susceptibility was kept constant at 0.1 cgs. The calculated responses are shown in Figure 5.23. The calculated response is characterized by a magnetic low offset of the vertical axis of symmetry of the lava tube. The calculated responses increase in magnitude as NRM increases, with the apex of the magnetic low shifting to the southwest as NRM increases. Figure 5.24 shows the maximum and minimum values from each response in Figure 5.23. The magnetic response exhibits a linear relationship with increasing NRM. 


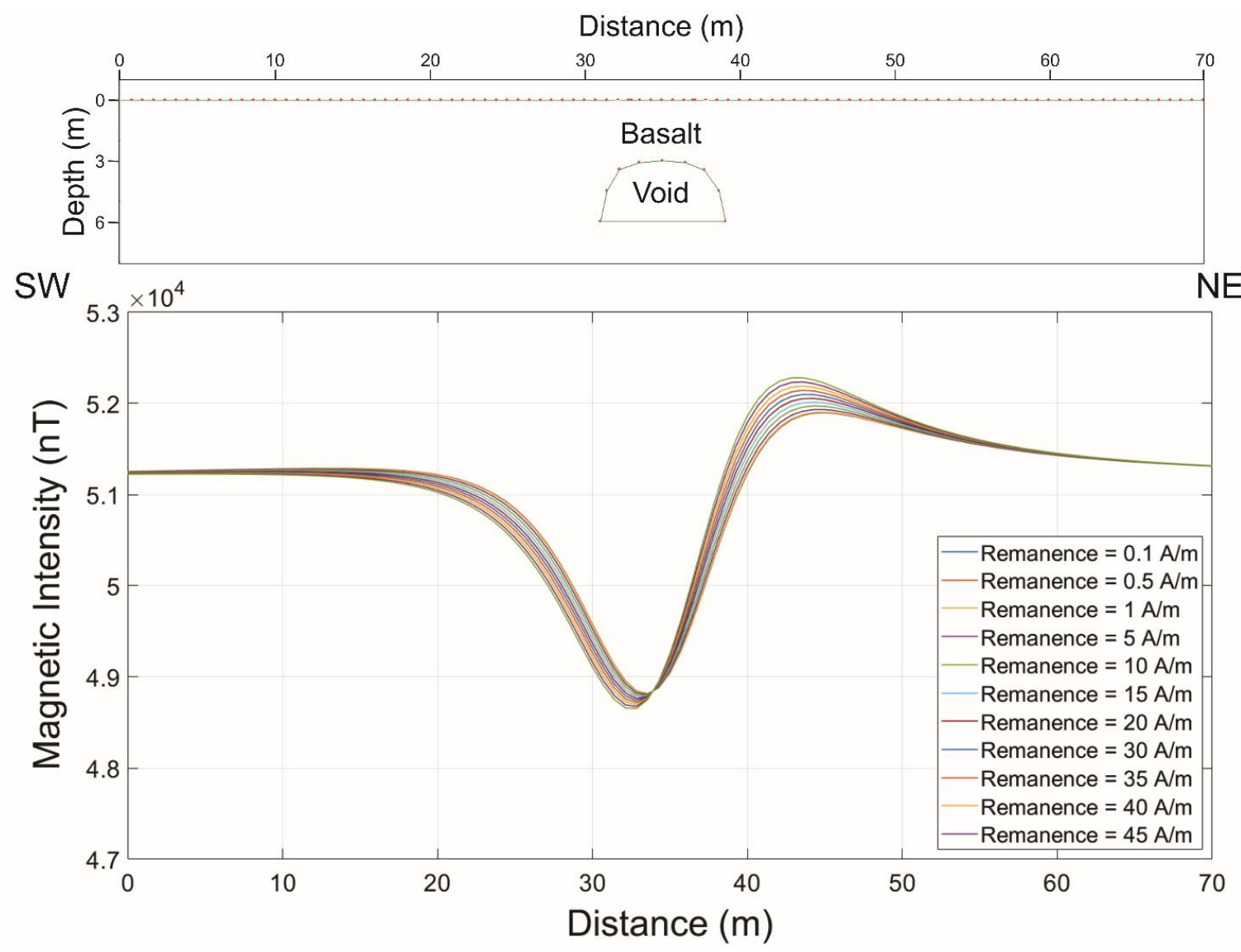

Figure 5.23: (Top) Depth model showing the placement of the tube for the forward models. (Bottom) Calculated magnetic response of a $3 \mathrm{~m} \times 8 \mathrm{~m}$ half-dome lava tube located at a limiting depth of $3 \mathrm{~m}$ with varying remanence values. NRM values are in $\mathrm{A} / \mathrm{m}$. 

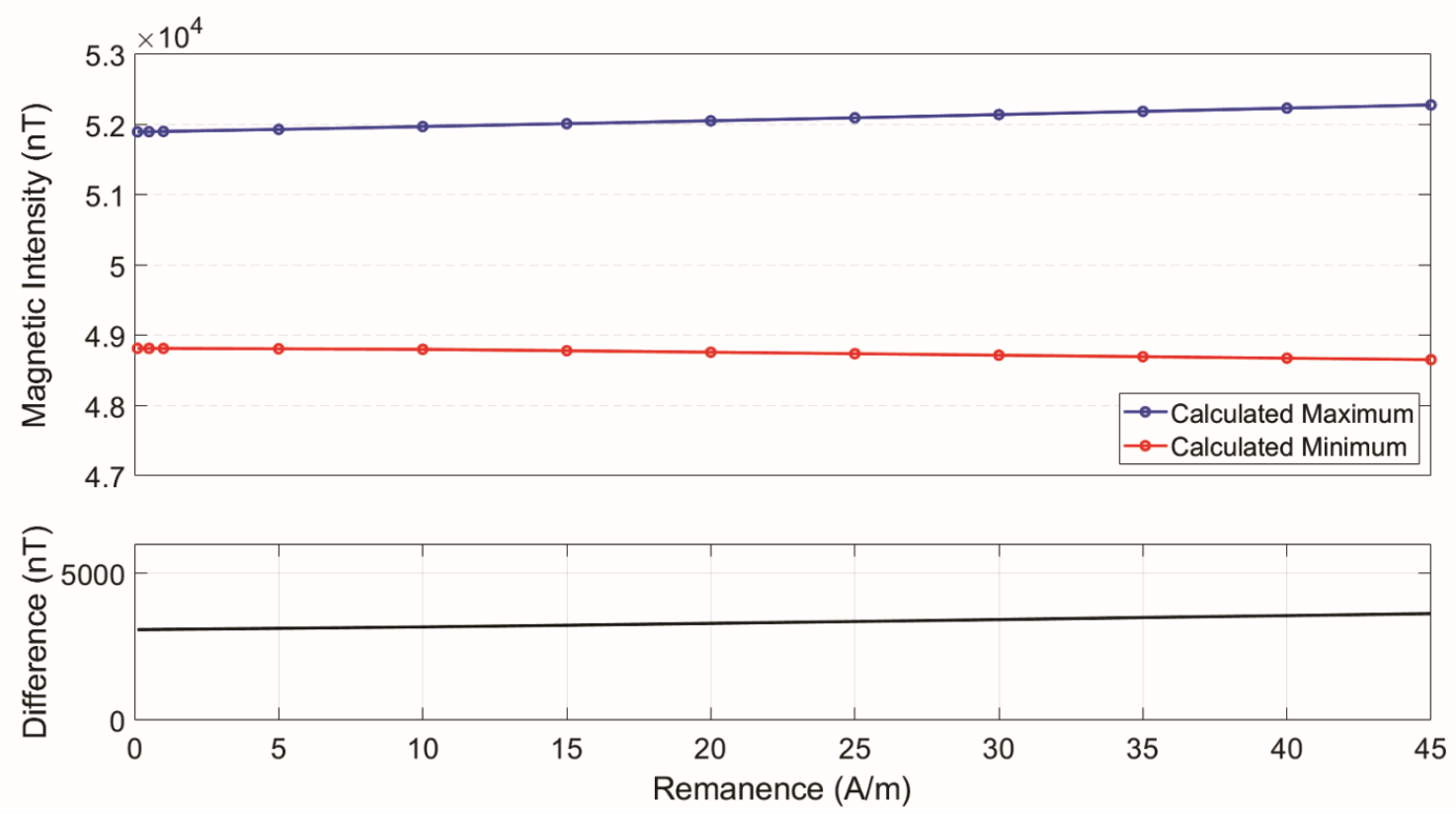

Figure 5.24: (Top) Maximum and minimum values of the observed and calculated magnetic responses shown in Figure 5.23. (Bottom) Difference between the maximum and minimum value for each susceptibility.

The forward modelling exercise with changing depths, widths, susceptibilities, and remanence of a simple half-dome lava tube will serve as a guide for inverse modelling. 


\subsubsection{Surface Survey Results and Interpretations}

A summary of the magnetic surface surveys is shown in Table 4.1. All surface survey data were processed for diurnal variations, reduced-to-the-pole, and have had lowpass filters with wavelength cut-offs of 25, 50, and $75 \mathrm{~m}$ applied (see Section 3.2.3). The total magnetic intensity (TMI) data from each survey were then interpolated using minimum curvature. They were plotted separately with the same colour scheme (range between 48500-53000 nT) to allow direct comparison.

Results from the forward modelling exercise predict that a near-surface lava tube of the size, depth, and host rock susceptibility that is similar to those found at LBNM should correspond to a negative anomaly bounded by magnetic high anomalies on either side. This section will present surface survey results that were reduced-to-the-pole so that the negative anomaly should be aligned directly above the outline of the lava tube and should be bounded by magnetic highs on either side.

Figure 5.25 shows the TMI maps of the Juniper Cave survey, with the outline of the cave shown in black. Upon visual inspection, there are multiple magnetic highs and lows present throughout the survey area; however, there is no consistent TMI anomaly that is associated with the presence of the lava tube. Magnetic highs at the southwest end of the cave and the northernmost section of the survey area are partially associated with manmade features such as a parking lot and roads for the visitor entrance into the cave. As higher wavelength cut-offs are applied to the lowpass filter, more large scale trends are revealed. There is an arcuate magnetic high that begins at the southwest corner of the map, extending parallel to the lava tube to the east side before trending north into the magnetic high located in the northwest corner of the map. The anomaly is not considered to be due 
to the presence of the lava tube, as it does not follow the trend of the lava tube. There is a circular magnetic low at approximately $623675 \mathrm{E} 4618150 \mathrm{~N}$, just south of Juniper Cave. This anomaly is not interpreted to be associated with Juniper Cave since it is circular in shape rather than elongated. This magnetic low is present on all maps in Figure 5.24; it is therefore likely related to a feature that is beneath the lava tube.

Highpass filters can be utilized to potentially detect lava tubes. As higher cut-offs are applied, more specific trends are revealed. Figure 5.26 shows TMI data from Juniper Cave with various highpass filters applied, with the cut-off wavelengths being the same as the lowpass filters used in Figure 5.25. Unfortunately, there are no anomalies in Figure 5.26 that correlate with the known position of the lava tube. Figure 5.27 shows TMI maps with various bandpass filters, where only signals of a specific wavelength range was passed. Again, there are no signatures associated with the lava tube.

To further highlight shallow features, the first horizontal derivative as well as the first and second vertical derivatives were applied to the Juniper Cave TMI dataset (Figure 5.28). As was the case with the previous applied filters, there are no clear signatures associated with the presence of the lava tube. The derivative maps show the same two large anomalies (at $623745 \mathrm{E} 4618050 \mathrm{~N}$ and $623550 \mathrm{E} 4617940 \mathrm{~N}$ ), corresponding to regions of strong variations in TMI, as expected. 


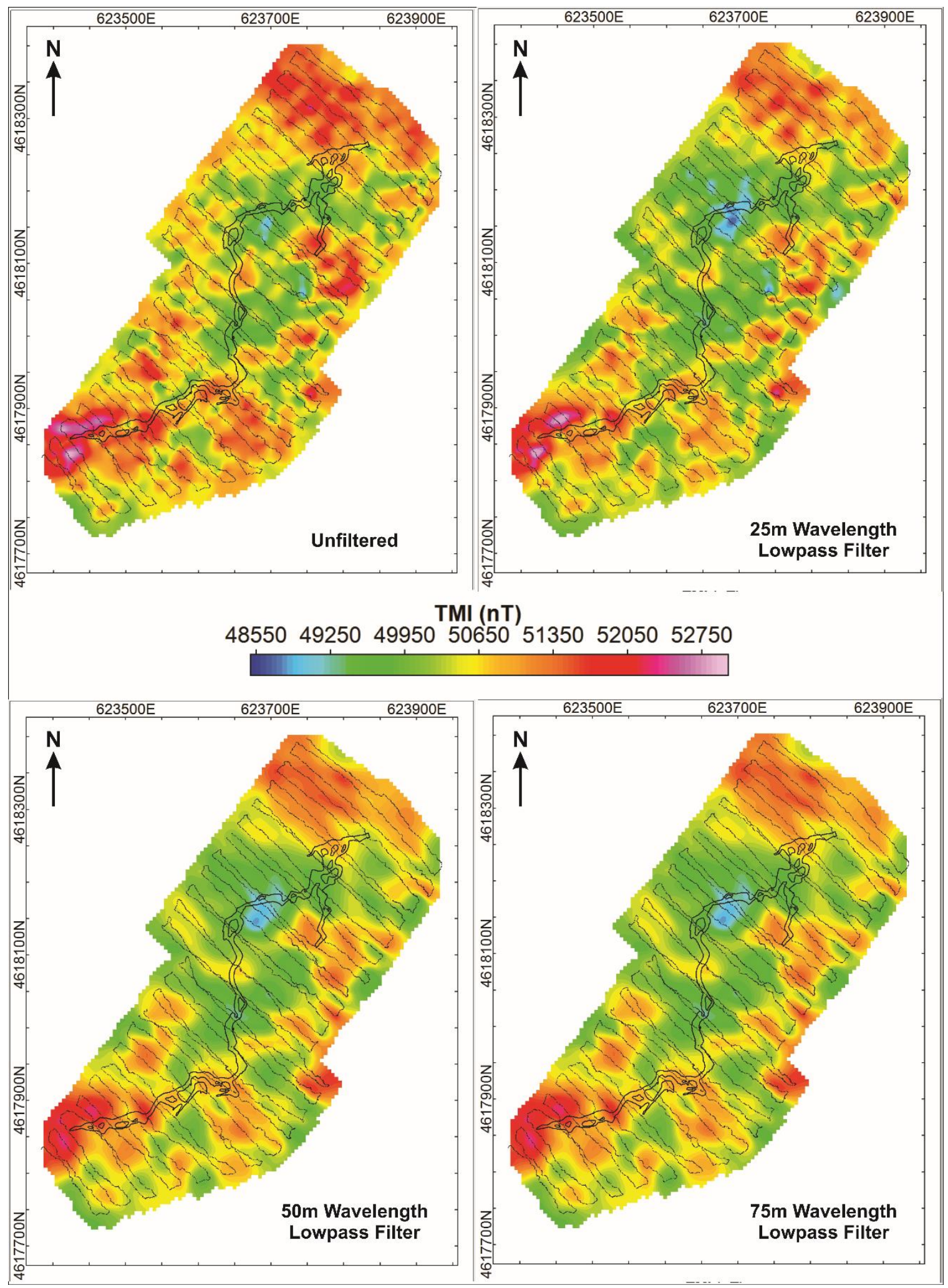

Figure 5.25: TMI maps of the Juniper Cave survey with various lowpass filters. Juniper Cave is outlined in black (shapefile provided by LBNM), and the dotted lines correspond to sample locations of the survey. 

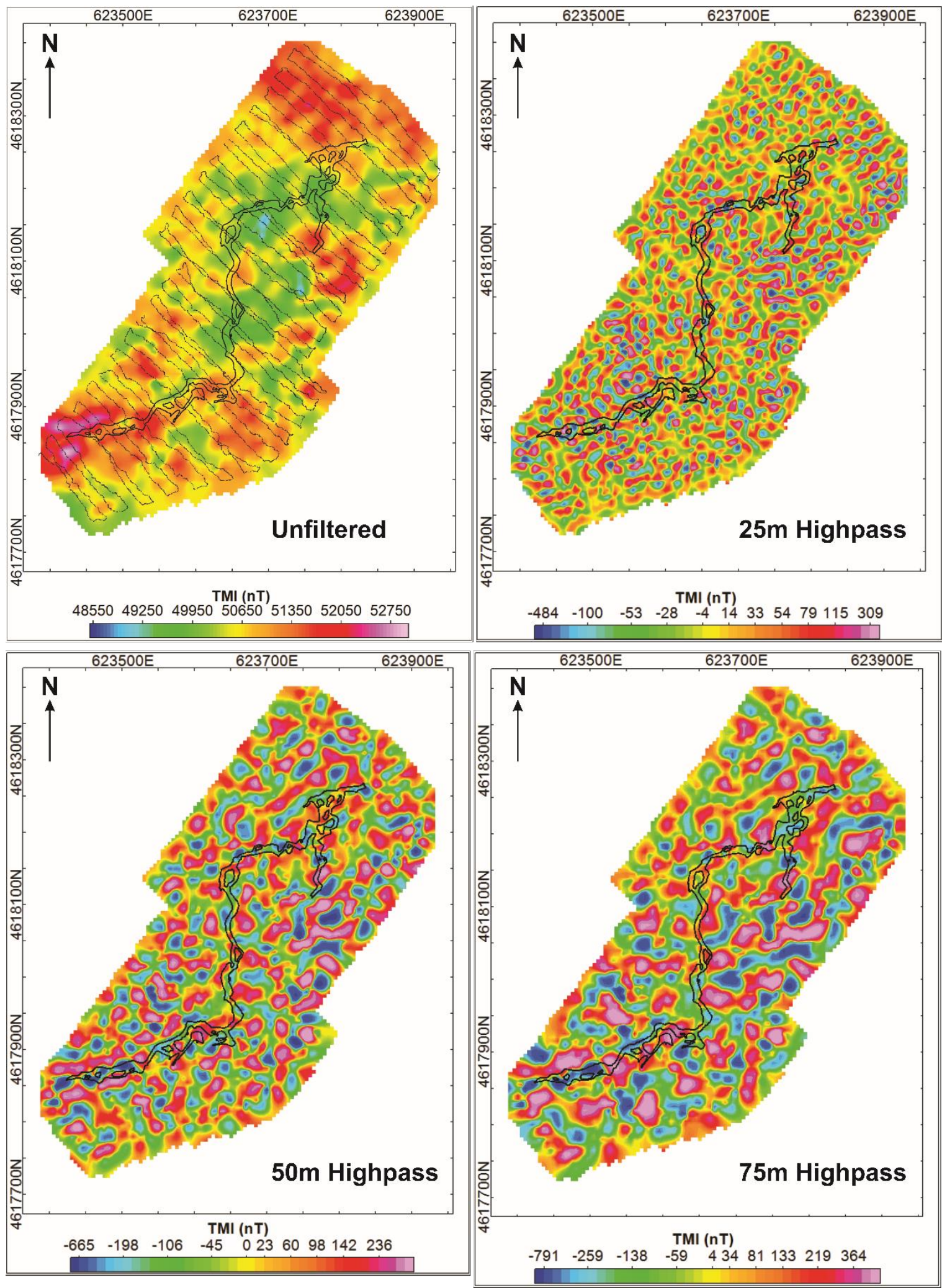

Figure 5.26: TMI maps of the Juniper Cave survey with various highpass filters. Juniper Cave is outlined in black (shapefile provided by LBNM), and the dotted lines correspond to sample locations of the survey. 

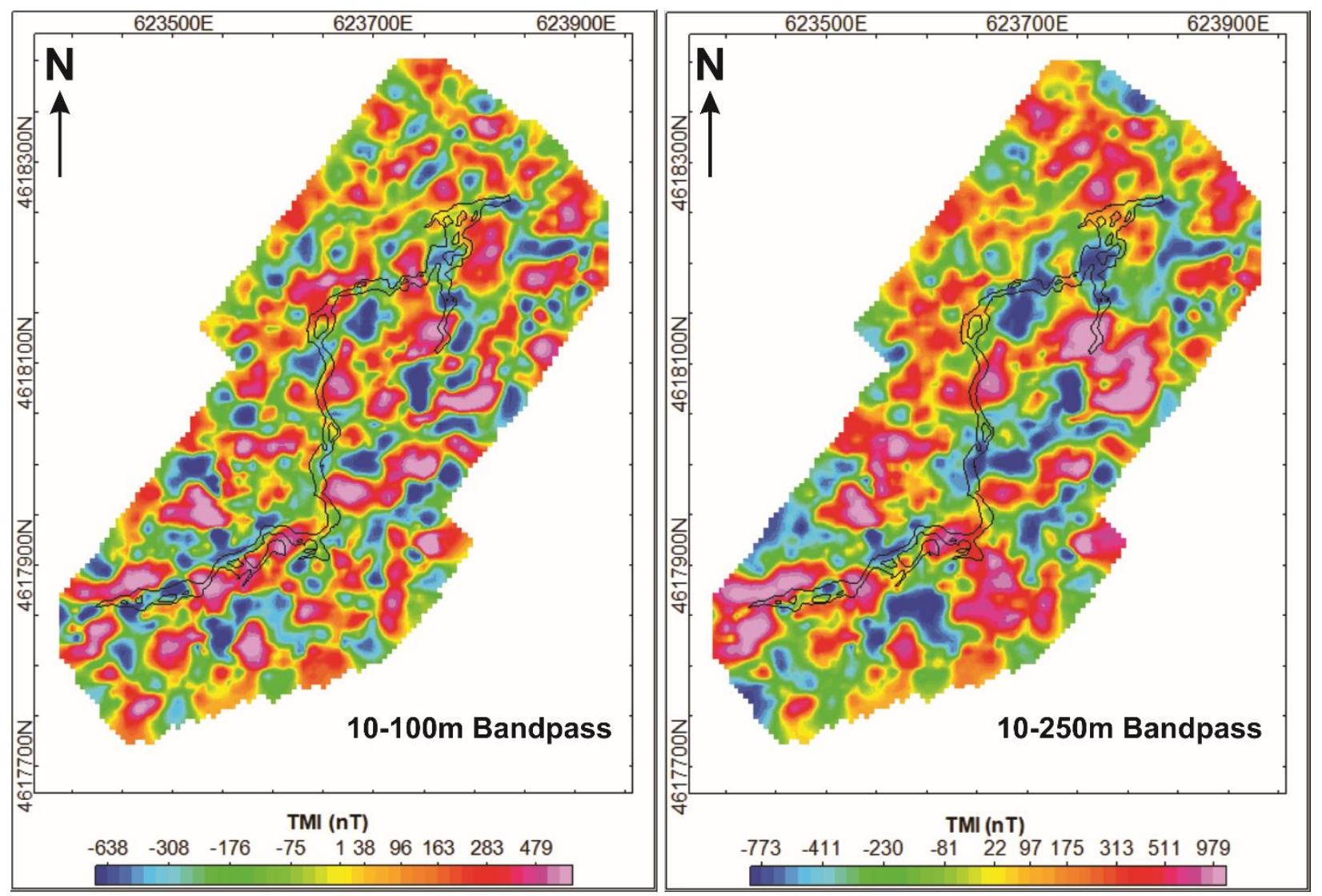

Figure 5.27: TMI maps of the Juniper Cave survey with various bandpass filters. Juniper Cave is outlined in black (shapefile provided by LBNM), and the dotted lines correspond to sample locations of the survey. 


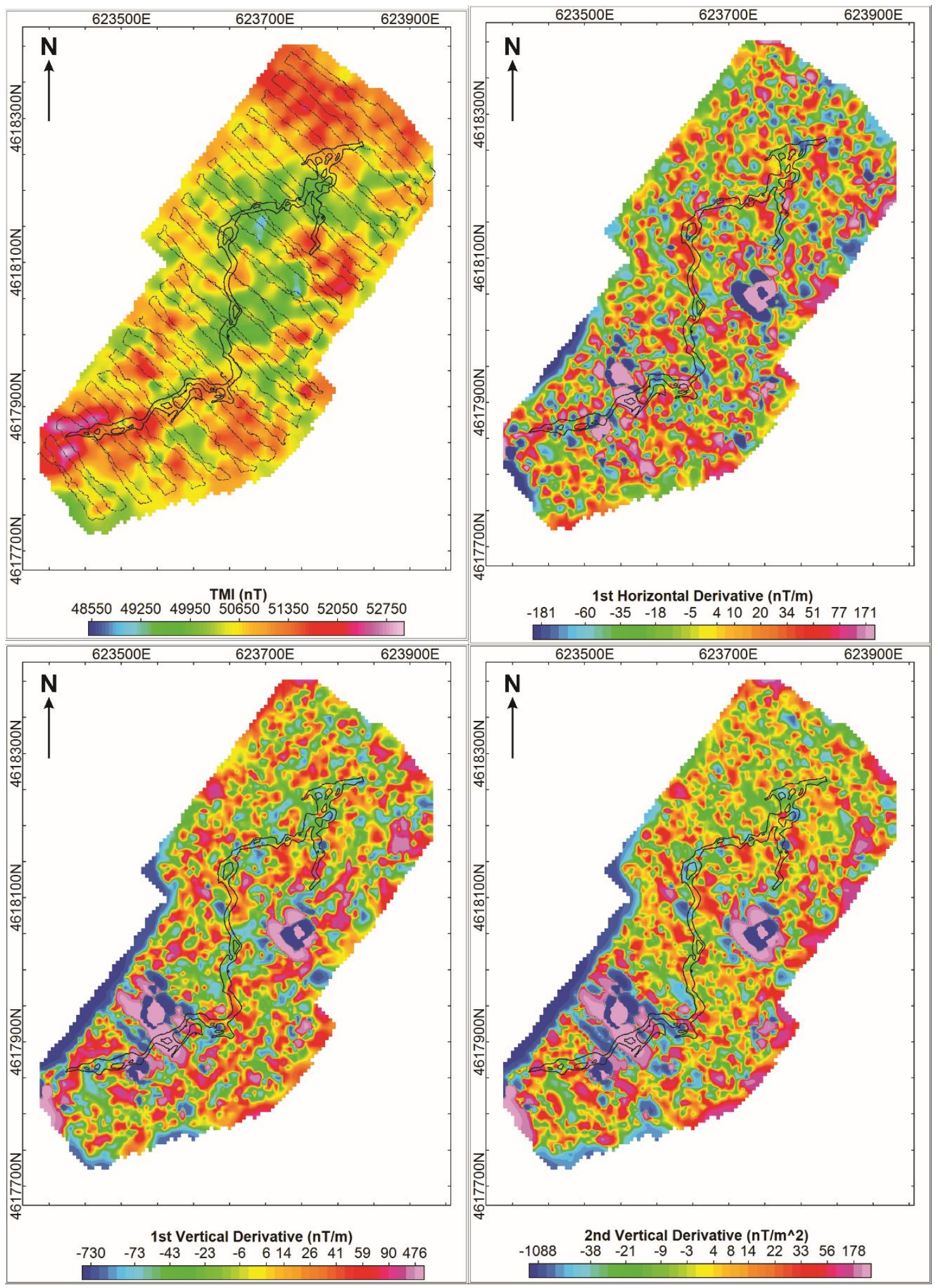

Figure 5.28: Horizontal and vertical derivatives of the Juniper Cave Survey, with the original TMI map shown in the top left for reference. Juniper Cave is outlined in black (shapefile provided by LBNM), and the dotted lines correspond to sample locations of the survey. 
Figure 5.29 shows TMI maps of the Valentine Cave survey, with the cave outlined in black. As for Juniper Cave, there are no anomalies that clearly correlate with the lava tube. The magnetic high at the entrance (southern end of the cave) is associated with multiple man-made structures as Valentine Cave is a popular tourist attraction at LBNM. North of the entrance (626650E, 4618625N, UTM NAD83 Zone 10N), a linear magnetic high is broken by an north-south trending magnetic low directly over the tube's location (Figure 5.30 - black ellipse), suggesting that the lava tube may have been successfully detected using surface magnetic surveying. There is also a slight magnetic low that trends north of the broken linear anomaly before being cut off by a magnetic high at $626700 \mathrm{E}$ 4618800 N. Further north, the magnetic low signature is no longer visible. This could potentially be due to the decreasing size of the tube further north (Figure 5.17 and Figure 5.19). Because the anomaly is only visible for a short distance and ends abruptly, it is unlikely that the magnetic low is associated with the lava tube.

In Figure 5.30 (white ellipse), a magnetic low begins in the southeastern section of the survey area and trends northwest to a strong magnetic low $(626575 \mathrm{E} 4618550 \mathrm{~N})$ correlating with a large rock collapse. This is believed to be a collapsed lava tube that was part of the network as Valentine Cave. The collapse diverted lava flow away from Valentine Cave, allowing the cave to drain (Waters et al., 1990). It is therefore possible that the magnetic low is a lava tube that was an extension of the collapsed lava tube.

The $75 \mathrm{~m}$ lowpass data shows that Valentine Cave can be divided into three distinct sections. The first section, in the south, includes the strong magnetic low associated to the lava tube collapse south to the entrance of Valentine Cave and its potential extension (Figure 5.30 - white ellipse). The subdued signature of this feature in the $75 \mathrm{~m}$ lowpass 
grid suggests that the possible lava tube extension is shallow, as it is clearly visible in the non-filtered grid and $25 \mathrm{~m}$ lowpass grid. The second section is an area characterized by magnetic highs $(656550 \mathrm{E} 4618575 \mathrm{~N}, 626600 \mathrm{E} 4618900 \mathrm{~N}, 626900 \mathrm{E} 4618800 \mathrm{~N}, 626750 \mathrm{E}$ $4618475 \mathrm{~N})$. These anomalies are interpreted to be a potential series of flow fronts from the eruptions that formed Valentine Cave. These flow fronts were potentially cut by Valentine Cave (Figure 5.30 - black ellipse). The third section, in the north, is a semi-circular magnetic low area encircled by magnetic highs.

Figure 5.31 shows TMI data from Valentine Cave with various highpass filters applied, with the cut-off wavelengths being the same as the lowpass filters used in Figure 5.29. There are magnetic low anomalies present in the $75 \mathrm{~m}$ wavelength grid that correlate locally to the lava tube in the same area as seen previously in Figure 5.30 (black ellipse). However, no definitive signature is present throughout the entirety of the lava tube. Figure 5.32 shows TMI maps with various bandpass filters applied, where only signal in a specific wavelength range was passed. As was the case with both the lowpass (Figure 5.29 and Figure 5.30) and highpass (Figure 5.31) filtered data, there is no definitive signature in Figure 5.31 that can be reliably associated with the presence of the lava tube.

To highlight shallow features, the first horizontal derivative as well as the first and second vertical derivatives were applied to the Valentine Cave TMI dataset (Figure 5.33). The first horizontal derivative (Figure 5.33 top right) does not have the characteristics magnetic low associated with the presence of the lava tube. The first vertical derivative, however, has a negative anomaly that follows the general trend of the lava tube until the fork at $626700 \mathrm{E} 4618790 \mathrm{~N}$. The lack of a definitive anomaly over the entirety of the lava tube as well as the questionable correlation from $4618725 \mathrm{~N}-4618770 \mathrm{~N}$ suggests that the 
correlation is not due to the lava tube. The second vertical derivative (Figure 5.33 bottom right) does not have a signature correlating with the presence of the lava tube. 


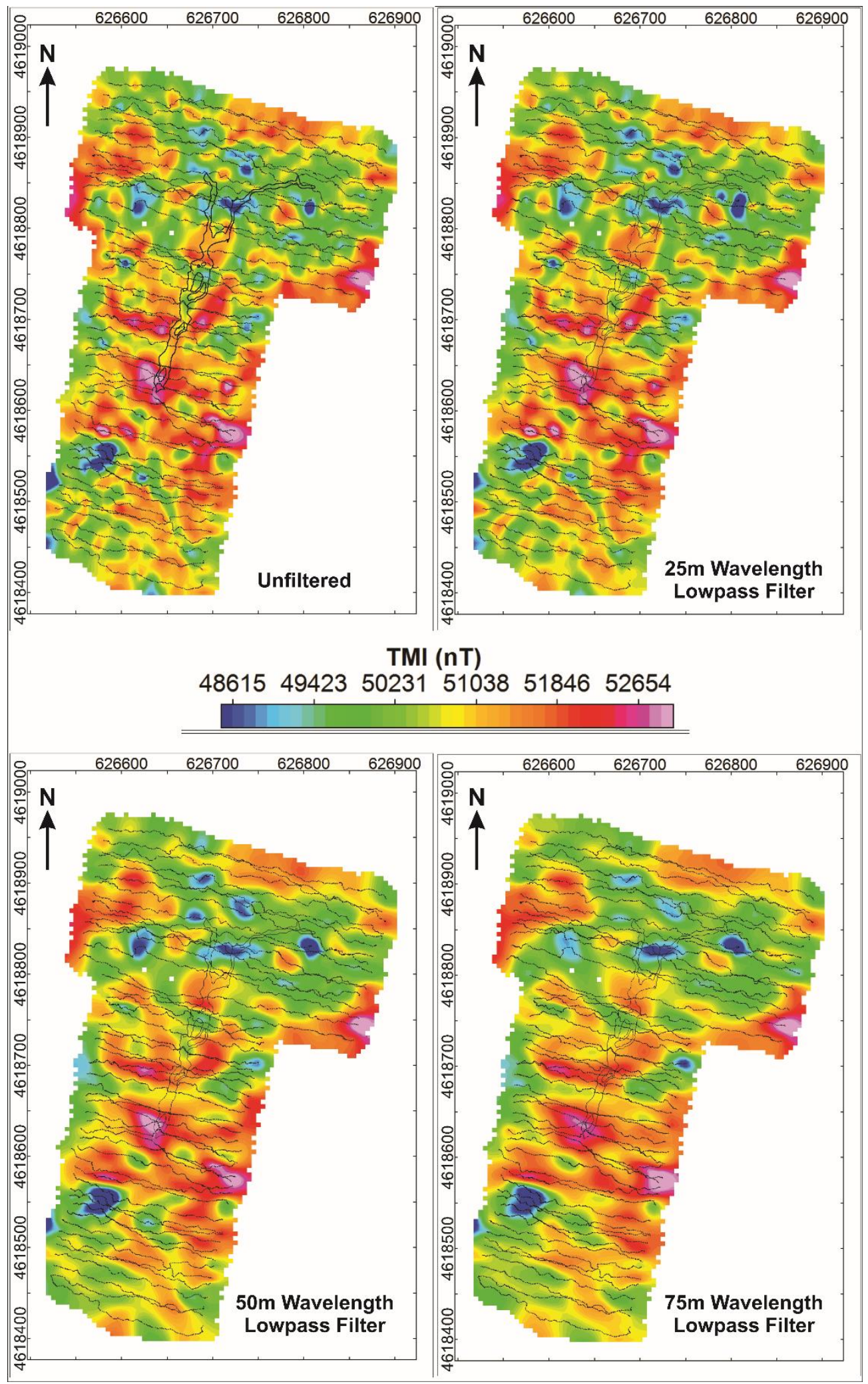

Figure 5.29: TMI maps of the Valentine Cave survey with various lowpass filters. Valentine Cave is outlined in black (shapefile provided by LBNM), and the dotted lines correspond to the path followed by the magnetometer for the survey. 


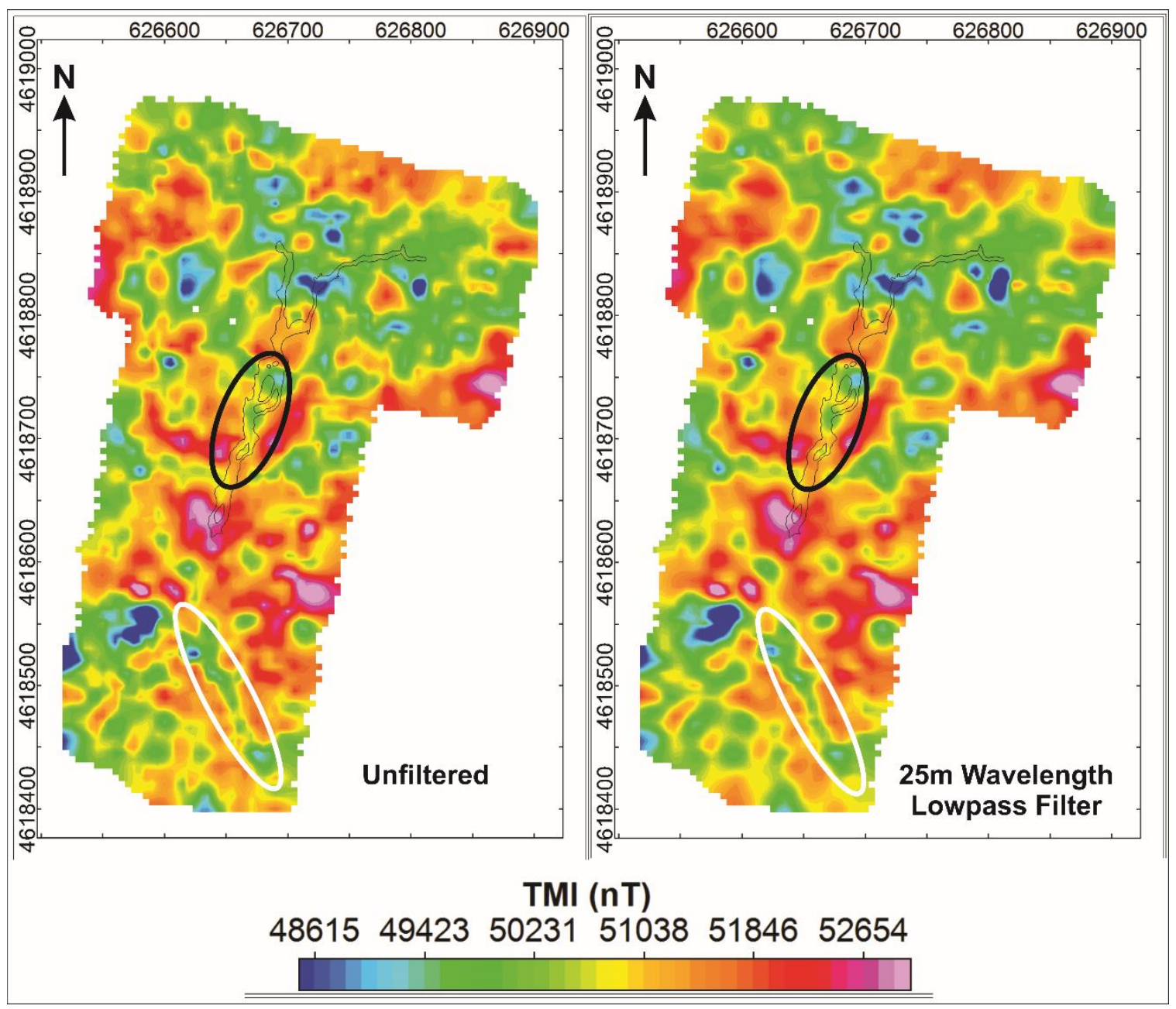

Figure 5.30: Zoomed-in TMI maps of Valentine Cave. The black ellipse indicates the possible magnetic low associated with Valentine Cave. The white ellipse indicates a possible extension of the lava tube network. 


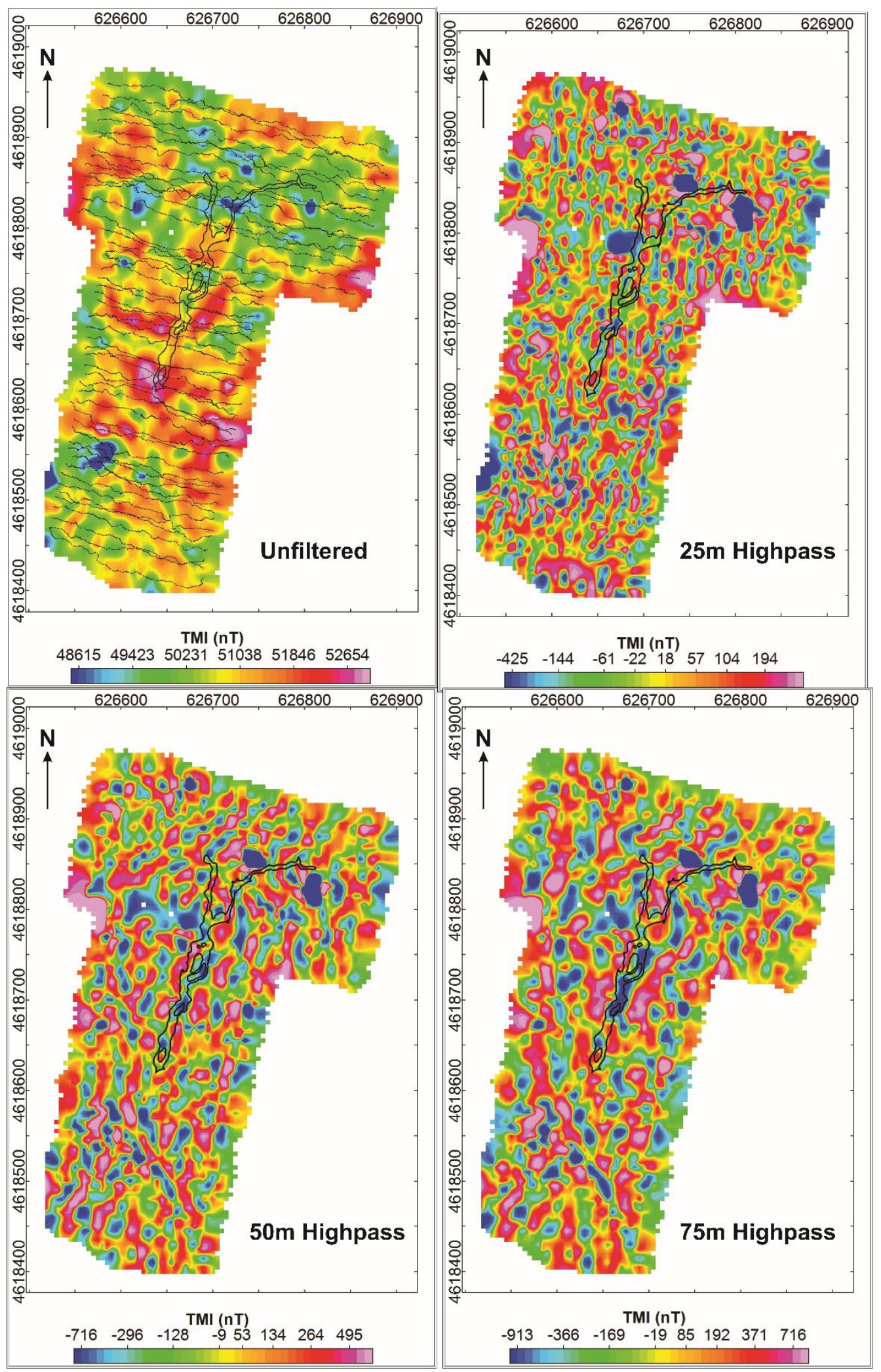

Figure 5.31: TMI maps of the Valentine Cave survey with various highpass filters. Valentine Cave is outlined in black (shapefile provided by LBNM), and the dotted lines correspond to the path followed by the magnetometer for the survey. 

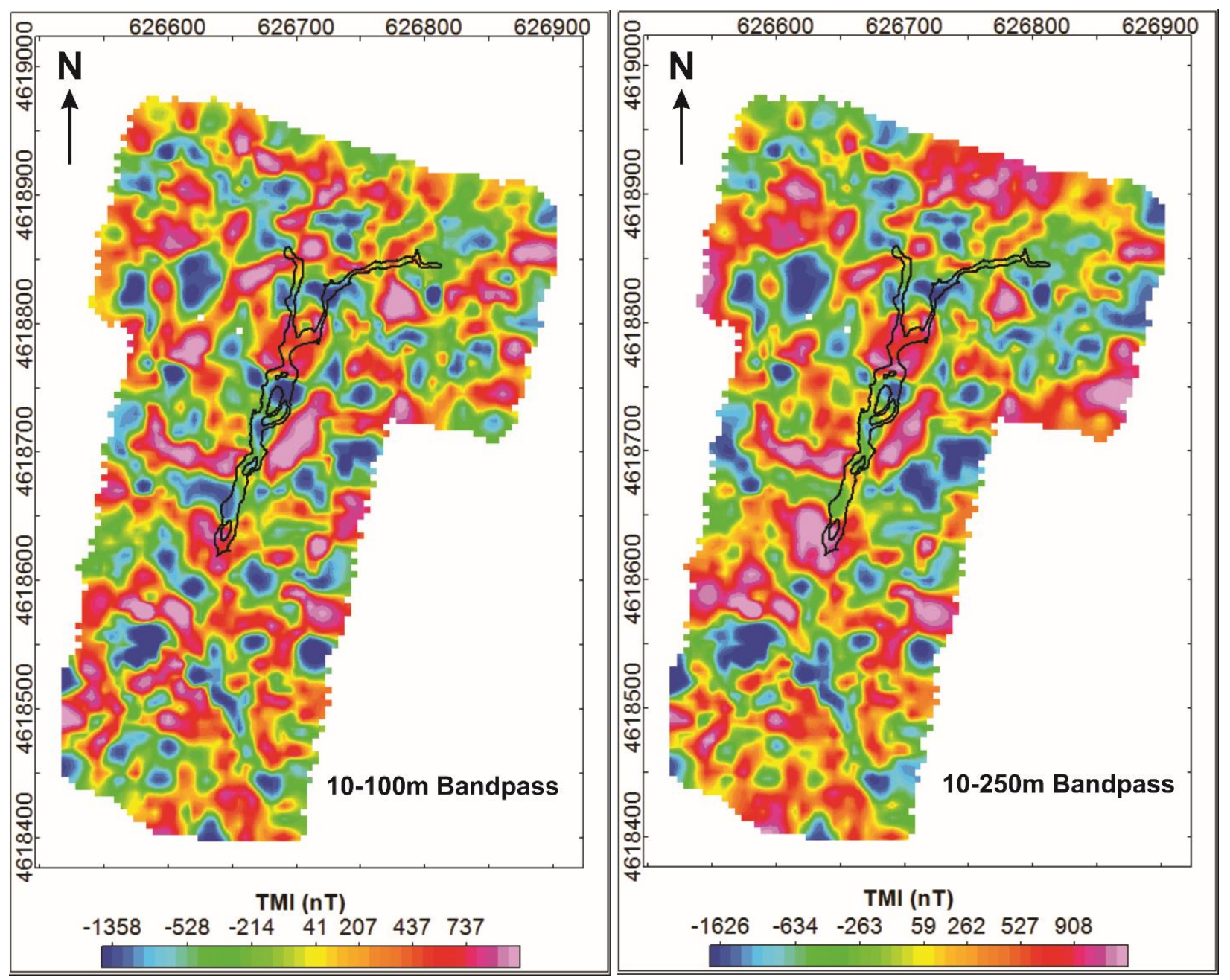

Figure 5.32: TMI maps of the Valentine Cave survey with various bandpass filters. Valentine Cave is outlined in black (shapefile provided by LBNM), and the dotted lines correspond to the path followed by the magnetometer for the survey. 


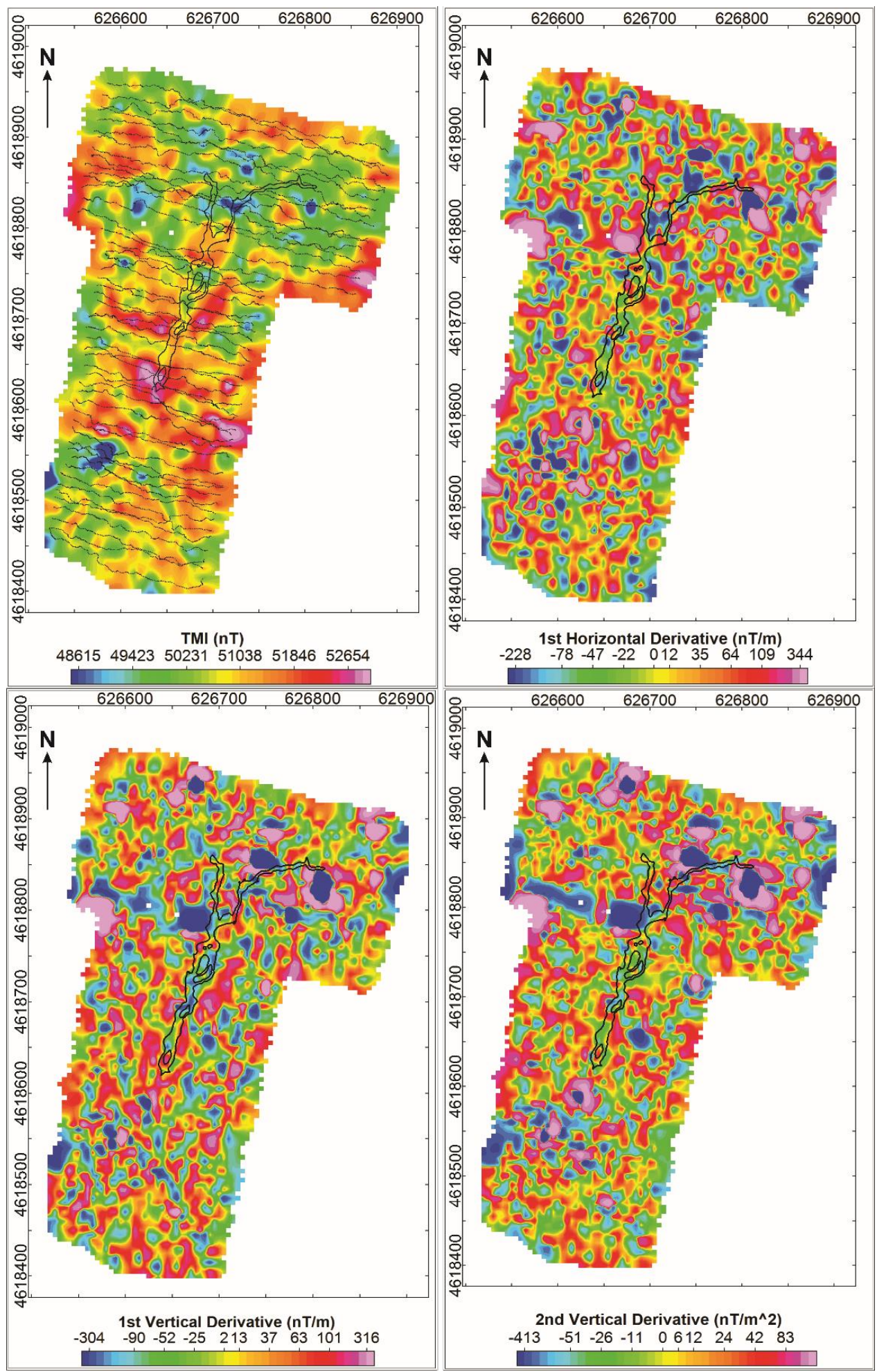

Figure 5.33: Horizontal and vertical derivatives of the Valentine Cave Survey, with the original TMI map shown in the top left for reference. Valentine Cave is outlined in black (shapefile provided by LBNM), and the dotted lines correspond to the path followed by the magnetometer for the survey. 
Figure 5.34 shows TMI maps of the Yellowstone Cave survey, with the cave outlined in black. During this survey, magnetic data was recorded at a sampling frequency of $5 \mathrm{~Hz}$, which is significantly higher than the $1 \mathrm{~Hz}$ sampling frequency used for the Juniper and Valentine Cave surveys. In addition, all data points south of $4618300 \mathrm{~N}$ were removed from the results due to very large magnetic lows correlating with a rock collapse bounding the southern end of the survey, disproportionally skewing the results of the rest of the survey. Because the Yellowstone Cave survey is significantly smaller in size that the Valentine and Juniper Cave surveys, only the unfiltered and $25 \mathrm{~m}$ lowpass filtered maps are used for interpretation, since the $50 \mathrm{~m}$ and $75 \mathrm{~m}$ lowpass maps have significant edge effects. The overall magnetic signal for the Yellowstone survey is subdued compared to the Juniper and Valentine cave surveys. The survey does not have any major anomaly correlating with the lava tube itself. The TMI maps exhibit a magnetic high over parts of the lava tube, which is opposite of what is expected to be observed from the forward modelling exercise. The TMI maps show magnetic highs oriented approximately N-S oriented that are tied by a moderate signal oriented E-W connecting all of the magnetic highs. The N-S magnetic highs could potentially be flow fronts from the eruptions forming Yellowstone Cave.

Figure 5.35 shows TMI data from Yellowstone Cave with various highpass filters applied, with the cut-off wavelengths being the same as the lowpass filters used in Figure 5.34. Figure 5.36 shows TMI maps with various bandpass filters applied, where only signal in a specific wavelength range was passed. As was the case with both the highpass and lowpass filtered data, there is no definitive signature associated with the lava tube in Figure 5.34 and Figure 5.35. 
To further highlight shallow features and potentially the lava tube, the first horizontal derivative as well as the first and second vertical derivatives were computed from the Yellowstone Cave TMI dataset (Figure 5.37). As for Juniper Cave and Valentine Cave, there are no signatures or anomalies on the derivative maps that correlate with the presence of a lava tube. 


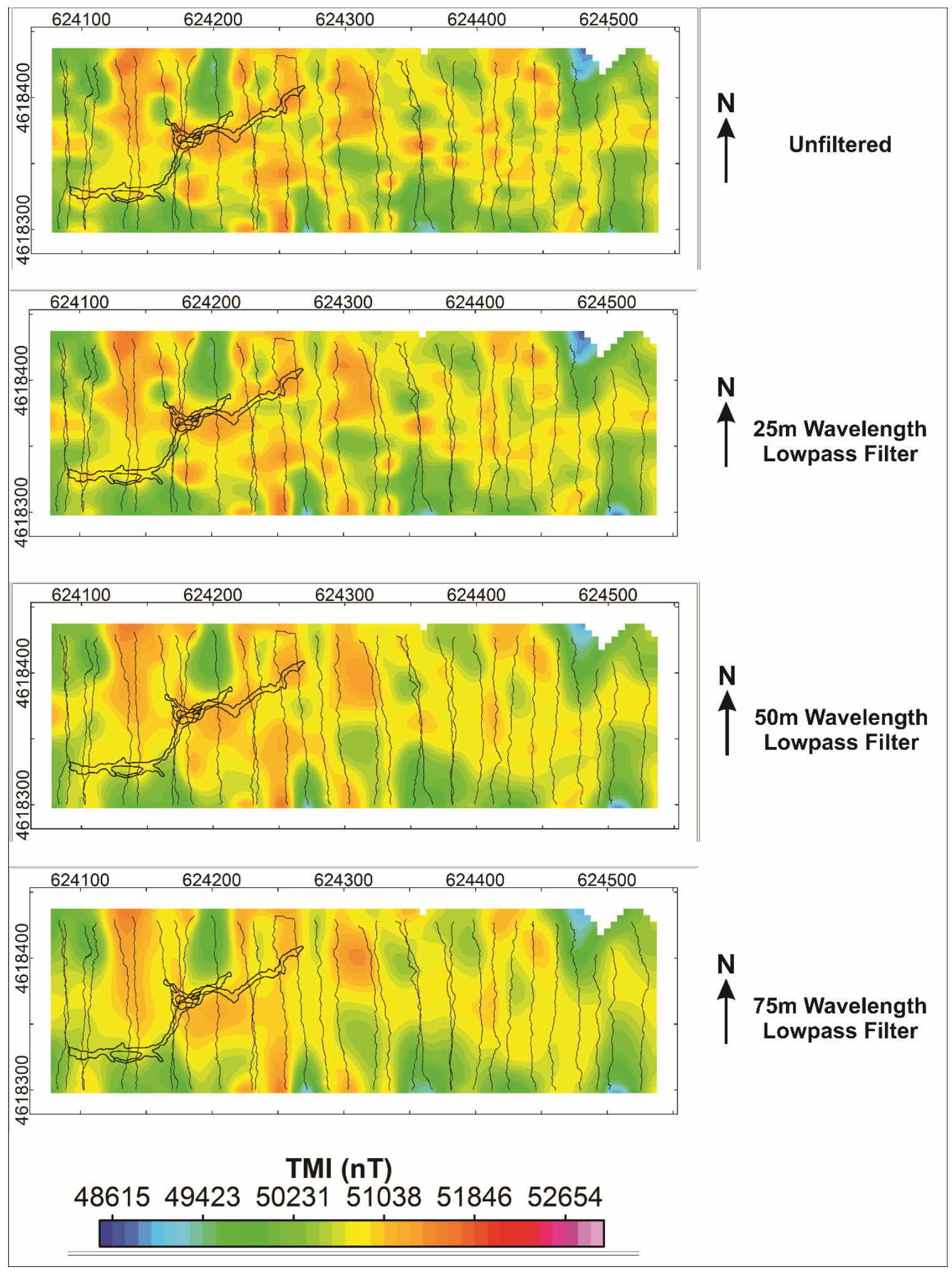

Figure 5.34: TMI maps of the Yellowstone Cave survey with various lowpass filters. Yellowstone Cave is outlined in black (georeferenced map shapefile provided by LBNM; digitizing done by author), and the dotted lines correspond to the path followed by the magnetometer for the survey. 


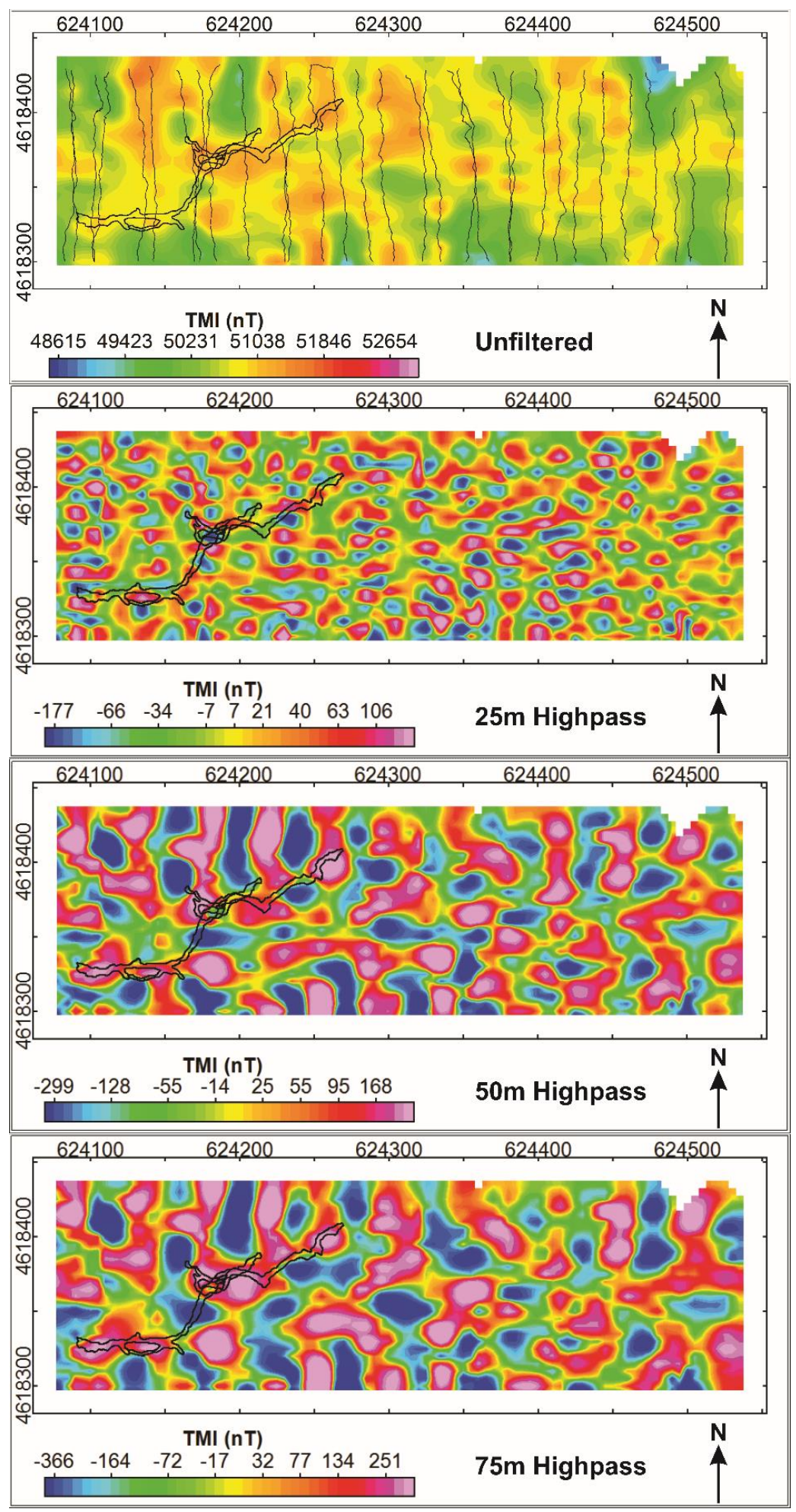

Figure 5.35: TMI maps of the Yellowstone Cave survey with various highpass filters. Yellowstone Cave is outlined in black (georeferenced map shapefile provided by LBNM; digitizing done by author), and the dotted lines correspond to the path followed by the magnetometer for the survey. 


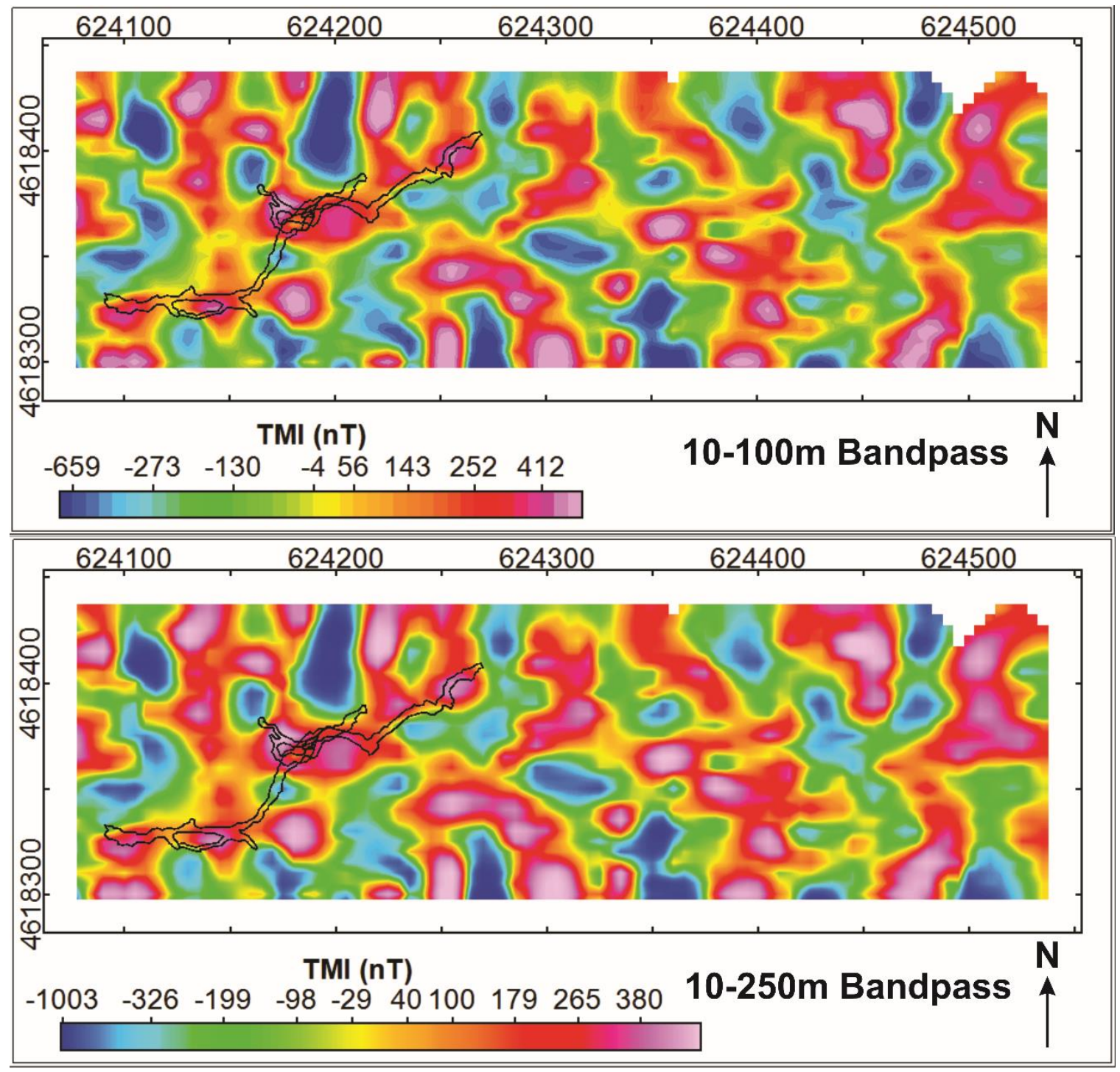

Figure 5.36: TMI maps of the Yellowstone Cave survey with various bandpass filters. Yellowstone Cave is outlined in black (georeferenced map shapefile provided by LBNM; digitizing done by author), and the dotted lines correspond to the path followed by the magnetometer for the survey. 


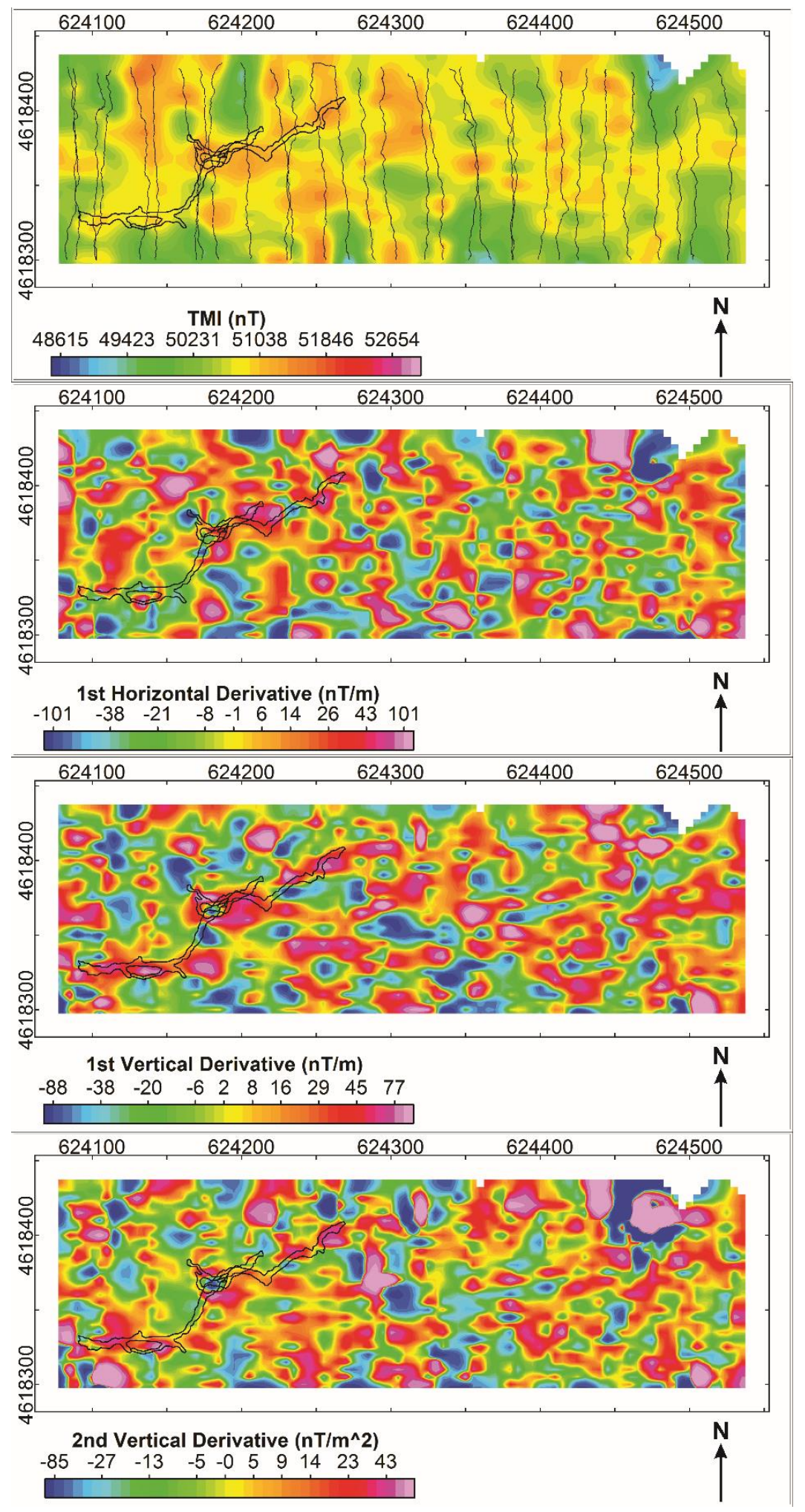

Figure 5.37: Horizontal and vertical derivatives of the Yellowstone Cave Survey, with the original TMI map shown in the top left for reference. Yellowstone Cave is outlined in black (shapefile provided by LBNM), and the dotted lines correspond to sample locations of the survey. 
Surface surveys of Juniper Cave, Valentine Cave, and Yellowstone Cave did not reveal any magnetic signature that could unequivocally correlate with the presence of a lava tube. Despite the disappointing results, there is still a clear signal from the basalt, as well as variations within the survey. It could be possible that the variation in the magnetic signal is due to spatial variances in magnetic susceptibility or NRM that is obscuring the signal of the lava tube, or grain size variation leading to changes in magnetic signal. Grain size variation could not be checked, as it was prohibited to collect rock samples at LBNM. Spatial variations in susceptibility and remanence can be checked through inversion modelling (see Section 5.2.3).

Results from a previous magnetic survey done by a Ph.D. student of the University of Maryland had contrasting results, where Skull cave was characterized by a magnetic high (Bell et al., 2018). In the same paper the TMI map of Valentine Cave exhibited a magnetic low in the same location observed in Figure 5.30 (black ellipse). The contrasting results from different caves calls into question the legitimacy of using magnetic surveying to detect lava tubes. Another study consisting of magnetic surveying at LBNM was a series of geophysical surveys by Meglich et al. (2003). Their survey results (anomaly map rather than TMI) showed a clear magnetic high anomaly of approximately $190 \mathrm{nT}$ over the lava tube. Their forward model to best fit the data showed a magnetic high, suggesting that the background basalt was cooled at a time when Earth's magnetic field was opposite to its current orientation.

The surface magnetic surveys done in this study to detect lava tubes produce disappointing results compared to a recent gravity survey conducted for the same purpose in a similar volcanic terrain. Brown et al. (2017) performed a gravity survey at Craters of 
the Moon, Idaho where a strong gravity low ( 300-400 mGal) correlated with the Indian Tunnel lava tube (Brown et al., 2017). The gravity method, however, proved to be very laborious in the field (a total of 126 measurements were performed over a course of 10 days). Magnetic surveying allows a larger area to be surveyed with less effort. Despite not detecting individual lava tubes, the magnetic method was successful is observing regional trends in the survey areas. 


\subsubsection{Inverse Modelling}

2D manual inversion was done for several cross-sections from all three surveys to further test the validity of magnetic surveying in detecting lava tubes. Using the forward models as a starting point, the calculated response from the forward model is compared with the observed magnetic data. The initial model is then modified to improve the fit between the calculated and observed data; this process is called inversion. The process is repeated until the calculated response matches the observed response with a small RMS error (Equation 5.3 and Equation 5.4). In this study, inversion is done manually; the model of the subsurface and its associated parameters are adjusted by hand rather than computationally.

Manual inversion was done using the GM-SYS 2D extension in Oasis Montaj. All models assume a lava tube void in a basaltic host rock of constant susceptibility. The approximate widths and heights of the lava tubes at the location of each cross-section were measured from maps provided by the USGS. The approximate positions of lava tubes along each cross-section were measured from the lava tube shapefiles provided by LBNM staff superimposed on the maps (Figure 5.25 -Figure 5.37). Elevation from the GPS attached to the survey equipment was also taken into consideration for each cross-section. The magnetic field strength $\mathrm{H}$, inclination $\mathrm{I}$, and declination $\mathrm{D}$ for each cave at the time of surveying are shown in Table 5.3. The locations and names for all models are shown on survey maps in Figure 5.38. Because 2D modelling takes into account the inclination and declination at the time of surveying, the interpolated grids used for the inversion show total magnetic intensity that was not reduced-to-the-pole. 
Table 5.3: Magnetic field parameters used for inversion.

\begin{tabular}{|l|c|c|c|c|}
\hline \multicolumn{1}{|c|}{ Cave } & \# of Models & $\begin{array}{c}\text { Magnetic Field } \\
\text { Intensity (nT) }\end{array}$ & Inclination (deg.) & Declination (deg.) \\
\hline Juniper Cave & 4 & 51156 & 64.644 & 14.194 \\
\hline Valentine Cave & 3 & 51163 & 64.656 & 14.188 \\
\hline Yellowstone Cave & 2 & 51160 & 64.648 & 14.191 \\
\hline
\end{tabular}

A manual inversion diagram (Figure 5.16) includes two parts: a magnetic response plot and a depth cross-section. The magnetic response plot shows the observed magnetic data from the minimum curvature map as black dots, the calculated magnetic response derived from the depth cross-section as a solid black line, the error as a solid red line, and the datum of the error as a solid blue line. The datum is positioned in the exact middle of the magnetic response plot. This acts as a reference guide to visualize the difference between the calculated response versus the observed response as shown in Equation 5.3:

$$
\operatorname{Error}(x)=\operatorname{Calculated}(x)-\operatorname{Observed}(x)
$$

\section{Equation 5.3}

where $\mathrm{x}$ is the position along the survey line. If the difference is negative, the "error" line (red line) will be below the datum. If the difference is positive, the "error" line will be above the datum. The root mean square (RMS) error in nanoteslas is shown in the bottom left of the magnetic response plot. The RMS error calculation is shown in Equation 5.4:

$$
\mathrm{RMS}=\sqrt{\frac{\sum_{i=1}^{N}(\text { Calculated }- \text { Observed })^{2}}{N}}
$$

\section{Equation 5.4}


where $\mathrm{N}$ is the number of points which is 100 for all models. The GM-SYS 2D extension by default sets an automatic "DC shift", which allows the calculated response to be moved up or down on the magnetic response plot to adjust to local conditions. The DC shift was chosen to minimize the RMS error outside the potential area of influence of the lava tube. RMS error for all inversions is summarized in Table 5.4. 
Table 5.4: Summary table of the manual inversion models. The summary includes the susceptibilities chosen for each cave, as well as the RMS error for the entire survey line and the area of influence (A.o.I.).

\begin{tabular}{|c|c|c|c|c|c|c|c|c|}
\hline $\begin{array}{l}\overrightarrow{0} \\
\dot{i} \\
1 \\
z\end{array}$ & 8 & in & $\stackrel{\infty}{+}$ & 8.4 & in is & sis & 17 & $=6$ \\
\hline 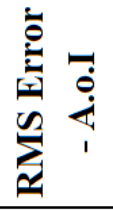 & $\mid \begin{array}{l}P \\
\stackrel{2}{ \pm} \\
-1\end{array}$ & $\begin{array}{l}\infty \\
n \\
n \\
\alpha\end{array}$ & $\begin{array}{l}2 \\
\dot{c} \\
\dot{m}\end{array}$ & 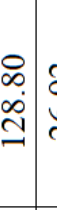 & 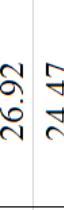 & 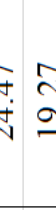 & & 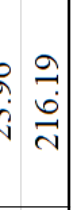 \\
\hline 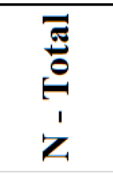 & 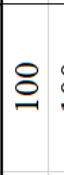 & ¿ & 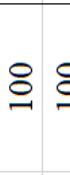 & $\stackrel{8}{-}$ & 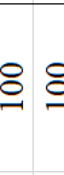 & 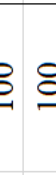 & $£$ & 8 \\
\hline 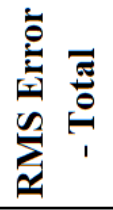 & $\begin{array}{l}\tilde{\alpha} \\
\grave{\partial}\end{array}$ & $\begin{array}{c}m \\
\stackrel{n}{N} \\
\stackrel{N}{N}\end{array}$ & $\begin{array}{l}\infty \\
\stackrel{0}{+} \\
\stackrel{m}{m}\end{array}$ & 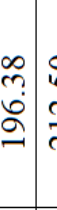 & 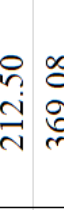 & 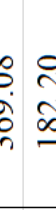 & & 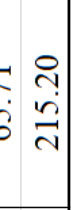 \\
\hline 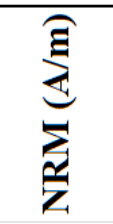 & $\begin{array}{c}8 \\
\text { in }\end{array}$ & 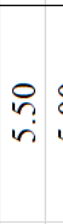 & $\begin{array}{l}8 \\
\qquad \dot{1} \\
\text { v }\end{array}$ & \begin{tabular}{l|l}
8 & \\
$\vdots$ & \\
$n$ &
\end{tabular} & & & & 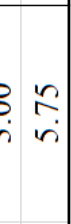 \\
\hline 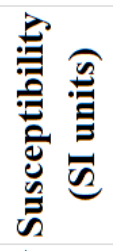 & $\begin{array}{l}\vec{n} \\
\overrightarrow{0}\end{array}$ & $\begin{array}{l}\infty \\
\stackrel{0}{0} \\
-1 \\
0\end{array}$ & $\begin{array}{ll}0 \\
\infty \\
\infty \\
0 \\
0 \\
0\end{array}$ & 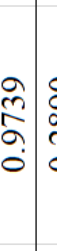 & 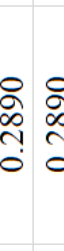 & 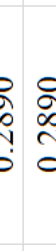 & 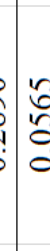 & $\begin{array}{cc}0 \\
0 \\
0 \\
0 \\
0 \\
0 \\
0 \\
0 \\
0\end{array}$ \\
\hline 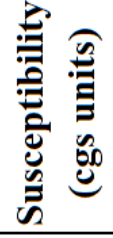 & 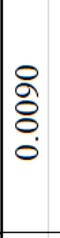 & $\begin{array}{l}2 \\
\ddot{o} \\
\dot{0} \\
\dot{0}\end{array}$ & 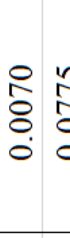 & 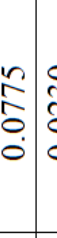 & 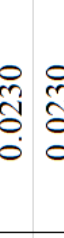 & 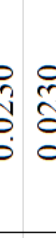 & 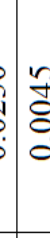 & 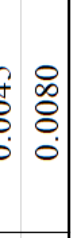 \\
\hline 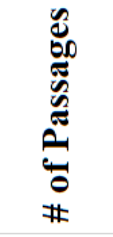 & -1 & $N$ & $\neg c$ & $N$ & $-c$ & v & -1 & -1 \\
\hline : & 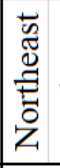 & 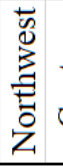 & $\stackrel{\vec{\Phi}}{\stackrel{0}{0}}$ & 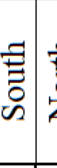 & Ũ & $\begin{array}{l}\vec{U} \\
\vec{U}\end{array}$ & & 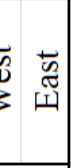 \\
\hline Uె & & . & 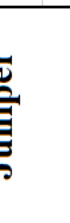 & & 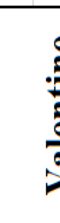 & e & & 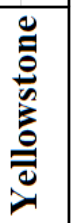 \\
\hline
\end{tabular}




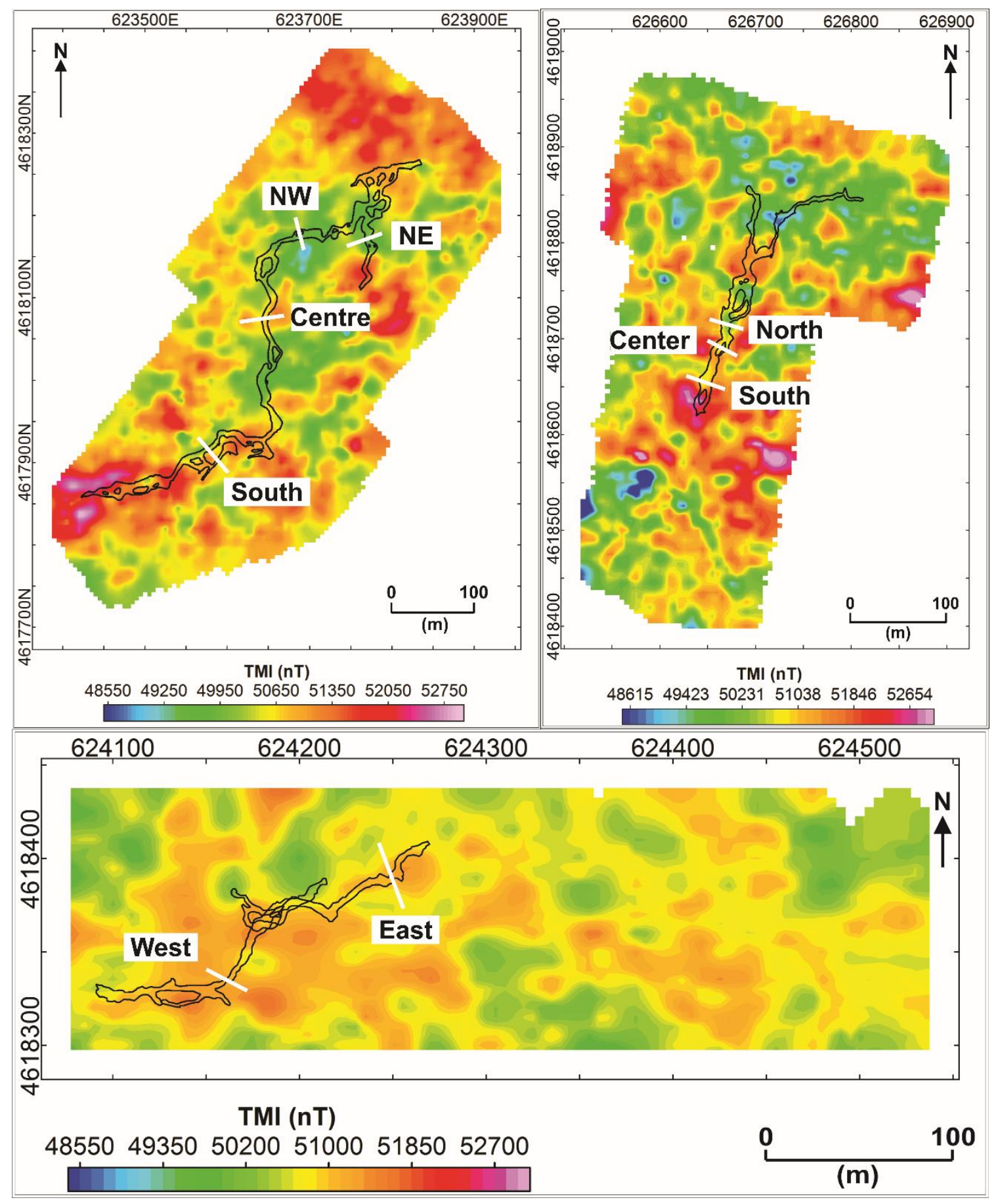

Figure 5.38: Locations and names for all inverse models. The TMI maps shown are not reduced to the pole. 
Figure 5.39 shows the inversion models located in the northern part of Juniper Cave. The northeast depth model (Figure 5.39 top) shows an oval-shaped lava tube that is approximately $3 \mathrm{~m} \times 8 \mathrm{~m}$ and has a limiting depth of $3.5 \mathrm{~m}$. Although there is good fit over the area of influence $(\mathrm{RMS}=14.5 \mathrm{nT}$, Table 5.4), there is a poor fit $(\mathrm{RMS}=129.92 \mathrm{nT})$ outside the area of influence as the observed magnetic response continues to increase to approximately $50350 \mathrm{nT}$ whereas the calculated response appears to flatten at $50000 \mathrm{nT}$.

The northwest depth model of Juniper Cave (Figure 5.39 bottom) consists of two passages of the same lava tube with a limiting depth of $2 \mathrm{~m}$, with the SE passage being significantly bigger than the NW passage ( $2 \mathrm{~m} \times 6 \mathrm{~m}$ for the SE passage vs. $1 \mathrm{~m} \times 3 \mathrm{~m}$ for the NW passage). The calculated response shows a good fit over the SE passage (RMS = $9.01 \mathrm{nT})$, but a poor fit over the rest of the model $(\mathrm{RMS}=272.35 \mathrm{nT})$. The observed data over the NW passage continue to increase to $50300 \mathrm{nT}$, whereas the calculated response shows a magnetic low over the NW passage.

Figure 5.40 shows the inversion models for the center and southern parts of Juniper Cave. The center depth model (Figure 5.40 top) shows a $2 \mathrm{~m} \times 6 \mathrm{~m}$ lava tube with a limiting depth of $4 \mathrm{~m}$. The calculated response shows a good fit to the observed data over the area of influence of the lava tube (RMS $=31.05 \mathrm{nT})$. Outside the area of influence, however, the observed data continues to increase to $51150 \mathrm{nT}$ whereas the calculated response flattens out at $50700 \mathrm{nT}$. To make the calculated response fit the observed data, the remanence would need to increase and the dimensions of the cave would have to be significantly larger, which would be unrealistic since data on the approximate dimensions of Juniper Cave are available. 
The south depth plot (Figure 5.40 bottom) shows two passages, with the NW passage being significantly larger than the SE passage ( $4 \mathrm{~m} \times 5 \mathrm{~m}$ for the NW passage vs. $1 \mathrm{~m} \times 3 \mathrm{~m}$ for the SE passage). The limiting depth of both caves is $3 \mathrm{~m}$. There is a good fit in-between the passages $(\sim 30 \mathrm{~m})$. In the northwest part of the survey line, the observed data continues to decrease to $50250 \mathrm{nT}$ whereas the calculated response increases before flattening at $50600 \mathrm{nT}$.

The magnetic susceptibility of the basalt that yielded the best fit over the area of influence for all Juniper Cave models was 0.007-0.009 cgs, and the NRM of the basalt was in the range of 5.0-6.0 A/m. Note the elevations of all depth plots: the elevation is highest to the south and decreases to the north, with the limiting depths being relatively consistent. This decrease in elevation and, thus, limiting depth of the lava tubes suggests that the lava that formed Juniper Cave was flowing northward. The change in overall elevation is also in agreement with this observation, as flows will always move downward under the influence of gravity. 

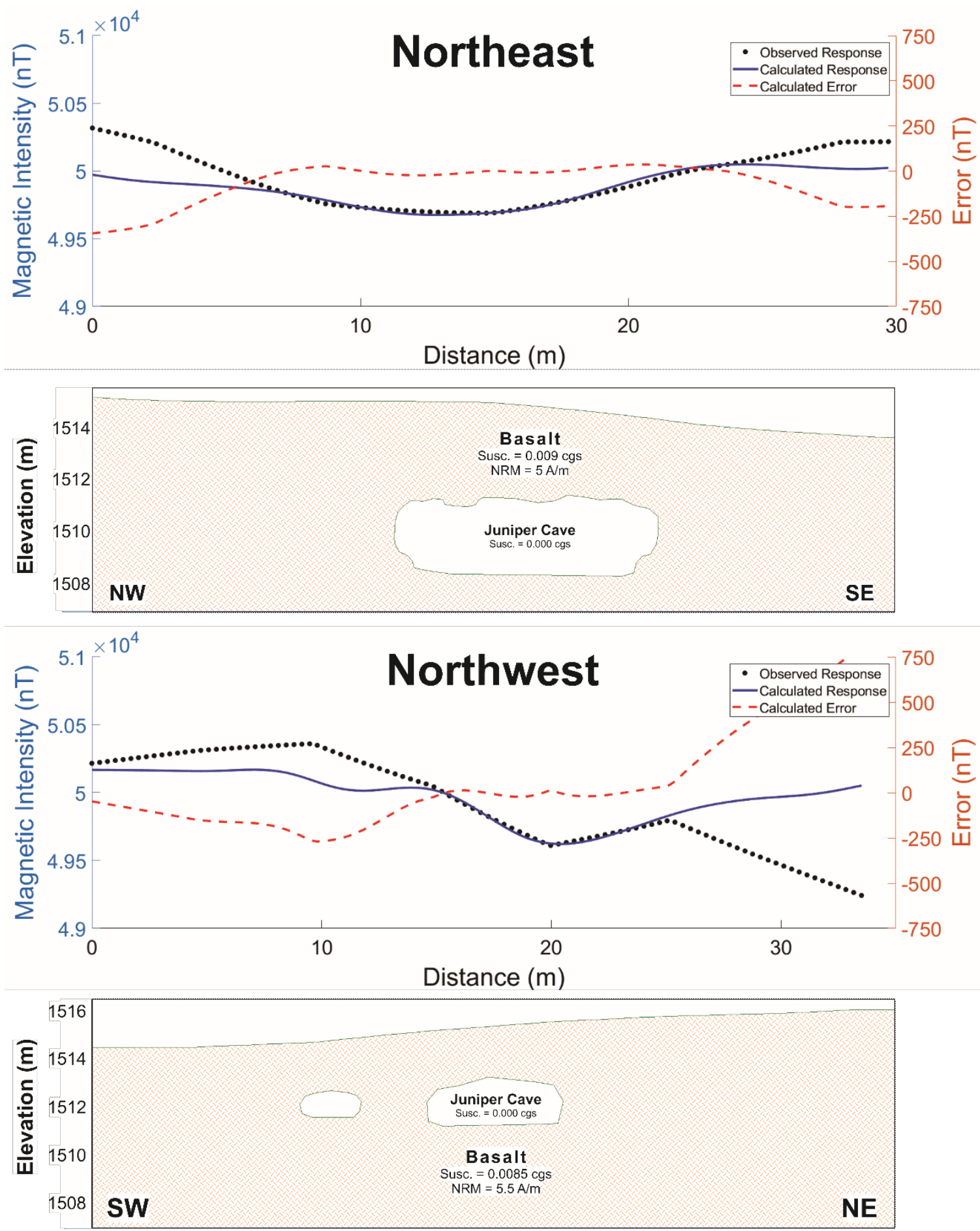

Figure 5.39: Manual inversion models of the northeast (top) and northwest (bottom) crosssections at Juniper Cave. 

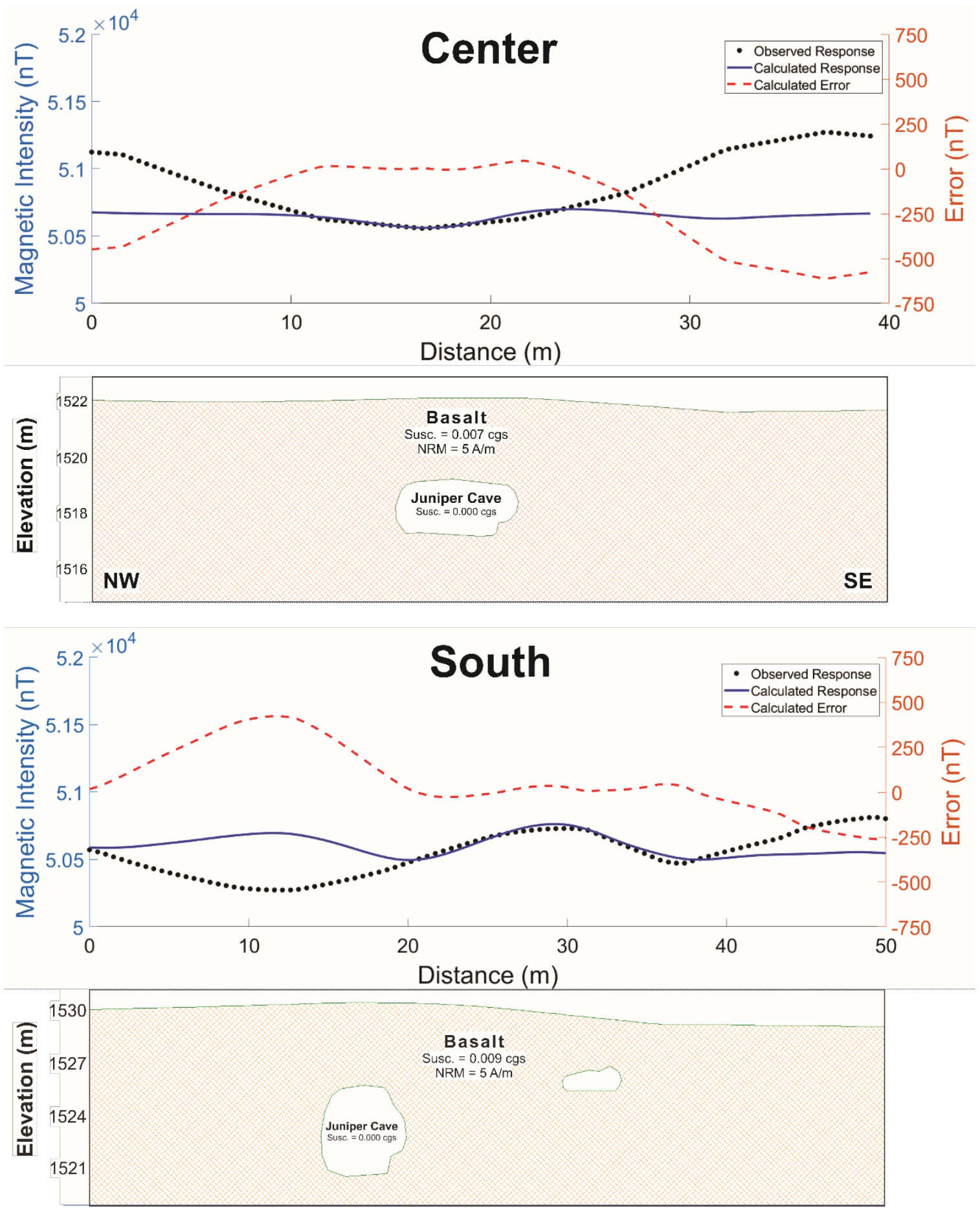

Figure 5.40: Manual inversion models of the center (top) and south (bottom) cross-sections at Juniper Cave. 
Figure 5.41 shows all inversion models for Valentine Cave. The location of all models coincides with the magnetic low north of the entrance of the cave as described in Section 5.2.2. The north depth plot (Figure 5.41 top) shows a lava tube that is approximately $3 \mathrm{~m} \times 10 \mathrm{~m}$ at a limiting depth of $2.5 \mathrm{~m}$. The fit between the calculated response and the observed data over the area of influence is good (RMS $=26.92 \mathrm{nT})$.

The center depth plot of Valentine Cave (Figure 5.41 center) shows two passages that have approximately the same height and limiting depth, but the width of the west passage is larger than that of the east passage $(5 \mathrm{~m}$ for the west passage vs. $3 \mathrm{~m}$ for the east passage). The fit over the area of influence is good over the outer side of each passage, but the fit is poor in between the passages. Where the observed data continue to decrease until a low of $50600 \mathrm{nT}$ at the center of the model, the calculated response increases slightly then decreases again as the calculated response leaves the area of influence of the west passage and enters the area of influence of the east passage.

The south depth plot of Valentine Cave (Figure 5.41 bottom) shows a lava tube that is approximately $3 \mathrm{~m} \times 10 \mathrm{~m}$ with a limiting depth of $4 \mathrm{~m}$. The calculated magnetic response shows a good fit over the area of influence $(\mathrm{RMS}=19.27 \mathrm{nT})$, where the largest deviation corresponds to the low in the observed data at $12 \mathrm{~m}$ along the survey line. There is a large deviation between the calculated response and the observed data on the east side of the model where the observed reading continues to increase when the calculated response flattens out at $51100 \mathrm{nT}$.

The susceptibility that best fits all three models of Valentine Cave was $0.023 \mathrm{cgs}$, which is more than double the magnetic susceptibility chosen for Juniper Cave and outside the range of typical magnetic susceptibility values for basalt $(0.0000159 \mathrm{cgs}-0.0135 \mathrm{cgs}$; 
Telford et al., 1990). This is likely due to the fact that the eruptions that formed Valentine Cave were compositionally different from the eruptions that formed the lava tubes at Cave Loop (Juniper Cave and Yellowstone Cave). Medicine Lake Volcano had an episodic eruptive history where the magmatic compositions changed over time. The eruptions that formed the lava tubes at Cave Loop were basaltic eruptions from Mammoth Crater occurring from $40 \mathrm{ka}$ to $30 \mathrm{ka}$ (Donnelly-Nolan et al., 2008). The series of eruptions that formed Valentine occurred at approximately $11.5 \mathrm{ka}$ and were a series of basaltic-andesitic eruptions from the Tickner Chimney complex and other nearby spatter vents (DonnellyNolan et al., 1990). Because the eruptions were basaltic-andesitic composition and andesite has a higher magnetic susceptibility than basalt, it is plausible that the host rock of Valentine Cave has a higher susceptibility value than that of Juniper Cave. The NRM value used for all three inversions was $9 \mathrm{~A} / \mathrm{m}$, which is within the range of NRM values for more recent basaltic eruptions. 

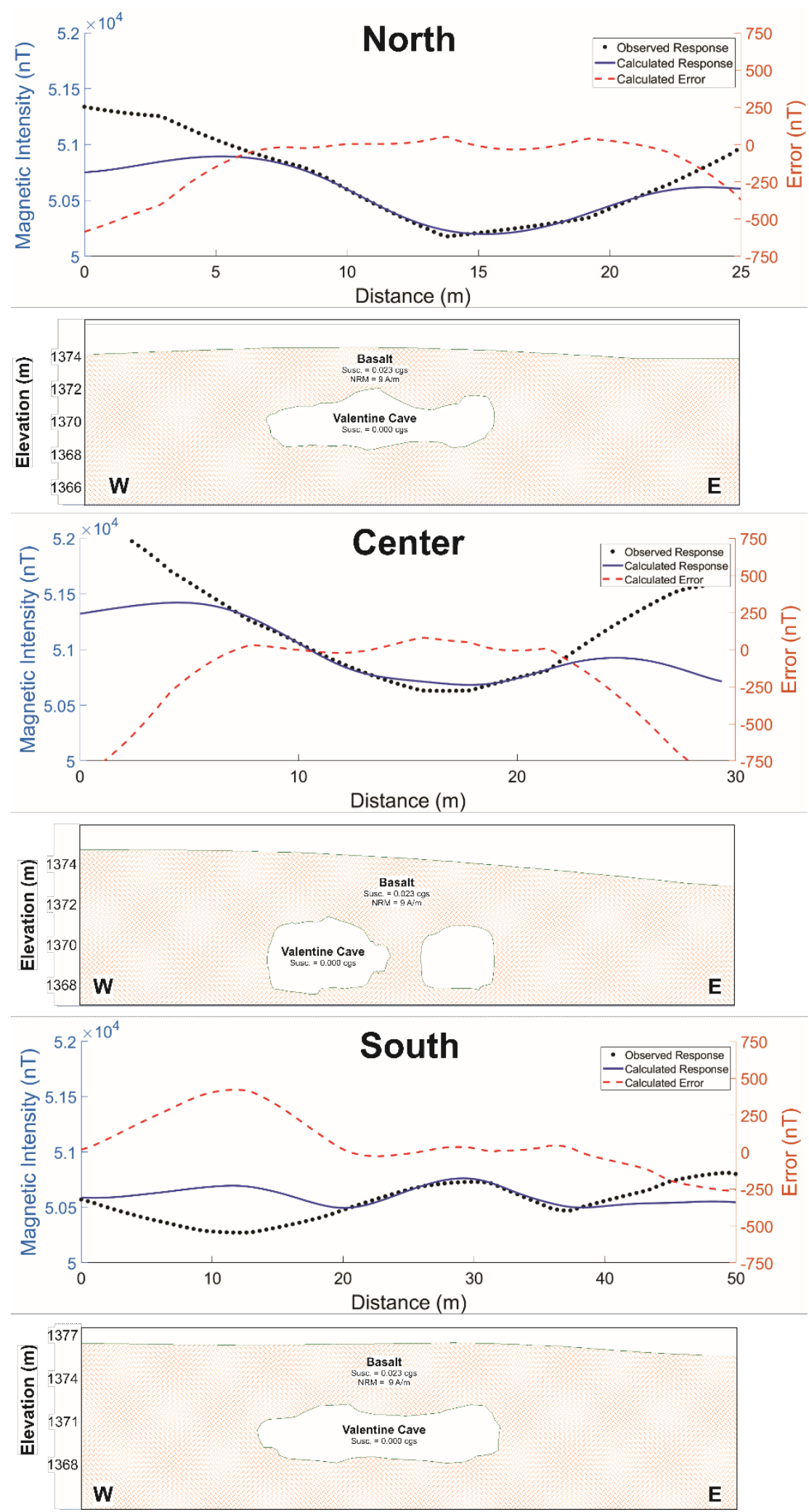

Figure 5.41: Manual inversion models of Valentine Cave. 
Figure 5.42 shows all inversion models for Yellowstone Cave. The western depth plot (Figure 5.42 top) shows a lava tube that is approximately $2.5 \mathrm{~m} \mathrm{x} 7 \mathrm{~m}$ with a limiting depth of $3.5 \mathrm{~m}$. Over most of the survey line, the calculated response shows a good fit to the observed data until the SE end of the survey line $(\mathrm{RMS}=65.71 \mathrm{nT})$, with a very good fit over the area of influence $(\mathrm{RMS}=23.96 \mathrm{nT})$. A susceptibility of $0.0045 \mathrm{cgs}$ best fits the data, which is just above half of the 0.007-0.009 cgs susceptibility chosen for Juniper Cave. In addition, the location chosen for this inversion was speculative as there was a magnetic high over most of Yellowstone Cave. This is highlighted in the east model, where there is a magnetic high in the observed data whereas the calculated response shows a magnetic low directly over the lava tube.

The eastern depth plot of Yellowstone Cave (Figure 5.42 bottom) shows a lava tube that is approximately $2 \mathrm{~m} \times 3 \mathrm{~m}$ with a limiting depth of $3 \mathrm{~m}$. The calculated response shows a poor fit over the area of influence, as shown by the RMS error over the area of influence versus that of the entire survey line (216.19 nT vs. 215.20 nT).

The susceptibility value that best fits the Yellowstone Cave dataset is the same susceptibility that was used for the Juniper Cave models (0.007-0.009 cgs), which suggests that an average value of $0.008 \mathrm{cgs}$ is representative of the susceptibility of the basalt at Yellowstone Cave (as opposed to a value of $0.0045 \mathrm{cgs}$ ). Note the elevation for the east model depth plot versus the elevation of the west model (1473 m vs. $1480 \mathrm{~m}$ ). This is due to the fact that Yellowstone is a two-level cave, where the west model corresponds to the upper level, and the east model to the lower level. 

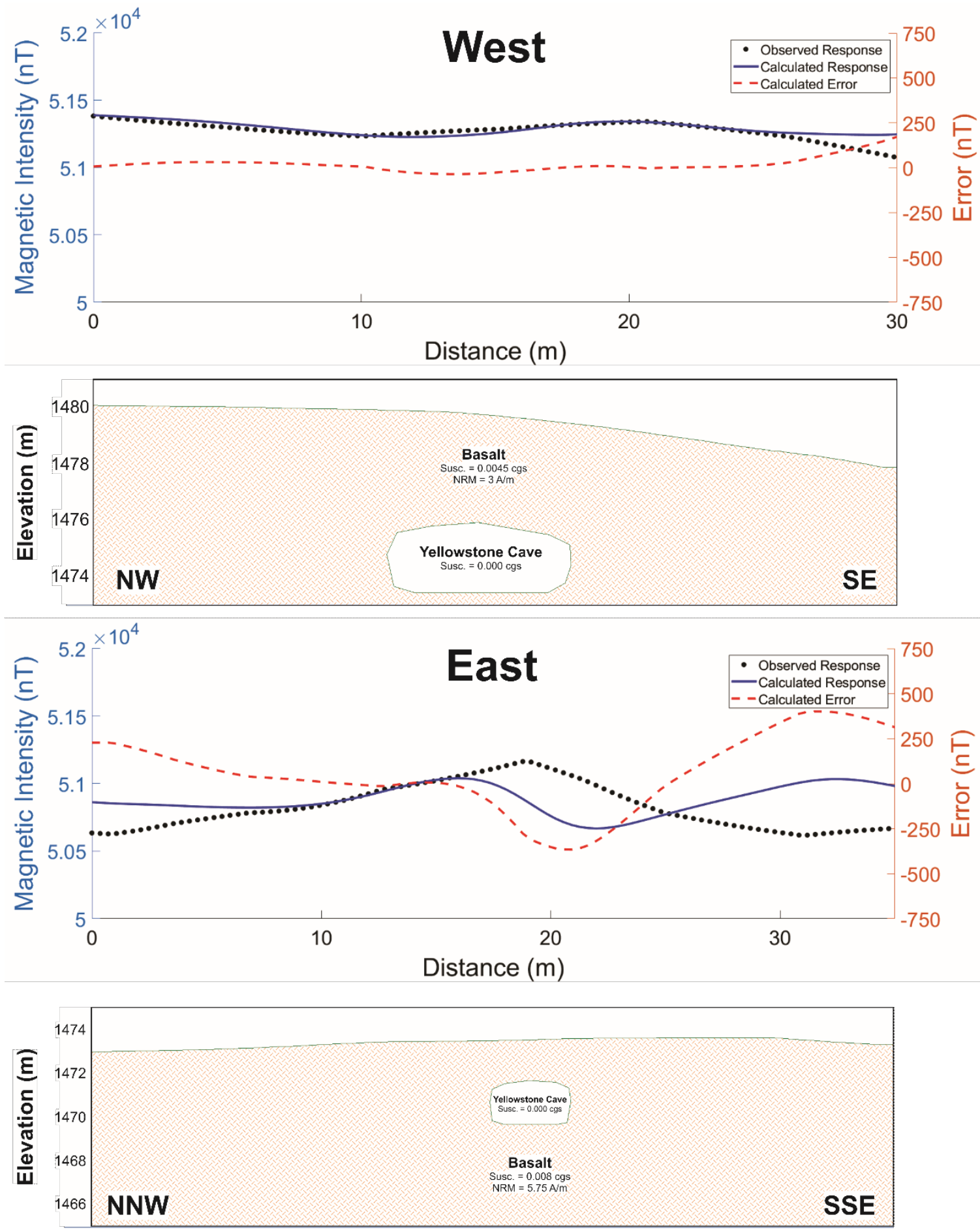

Figure 5.42: Manual inversion models of Yellowstone Cave. 
Manual inversion of surface magnetic data was successful in characterizing the magnetic susceptibility and remanence values of the Mammoth Crater basalts and Tickner Chimneys andesitic basalts. The basalts that form Juniper Cave and Yellowstone Cave are lower-susceptibility, low-remanence basalts with a value of approximately $0.008 \mathrm{cgs}$ and $5 \mathrm{~A} / \mathrm{m}$, respectively. The andesitic basalts that form Valentine Cave have a higher susceptibility value of $0.023 \mathrm{cgs}$ and a higher remanence value of $9 \mathrm{~A} / \mathrm{m}$. The differences in susceptibility and remanence in the inversion models confirm the suggestion outlined in Section 5.2.2 that the signature of the lava tube could be masked by NRM.

Manual inversion was also successful in delineating lava tubes over their area of influence where there was only one passage. For models with two passages, the fit over the area of influence was poor (Table 5.4). Overall, the fit for all inversion models is poor which suggests that there might be additional layers or constraints that were not considered when performing the manual inversion such as surficial geology or underlying structures.

Bell et al. (2018) made a catalog of lava tube cross-section models based on surface magnetic results from LBNM. The cross-section depth plot (Figure 5.43 bottom) shows two variations of a depth models: two lava tube voids in a host rock of constant susceptibility of $0.1 \mathrm{cgs}$, and two lava tube voids with a thermomagnetically modified tube floor of lower susceptibility. The calculated responses from Bell et al. (2018) are shown in Figure 5.43 (top). The depth model was replicated in GMSYS-2D (Figure 5.43 bottom), and the calculated magnetic responses along with observed data from this project are shown in Figure 5.43 (center). From the responses shown in Figure 5.43 (center), it is clear that having just the lava tube voids in a host rock of constant susceptibility gives a better fit to 
the observed data than adding a thermomagnetically modified tube floor. This study therefore found no evidence corroborating the existence of this feature.
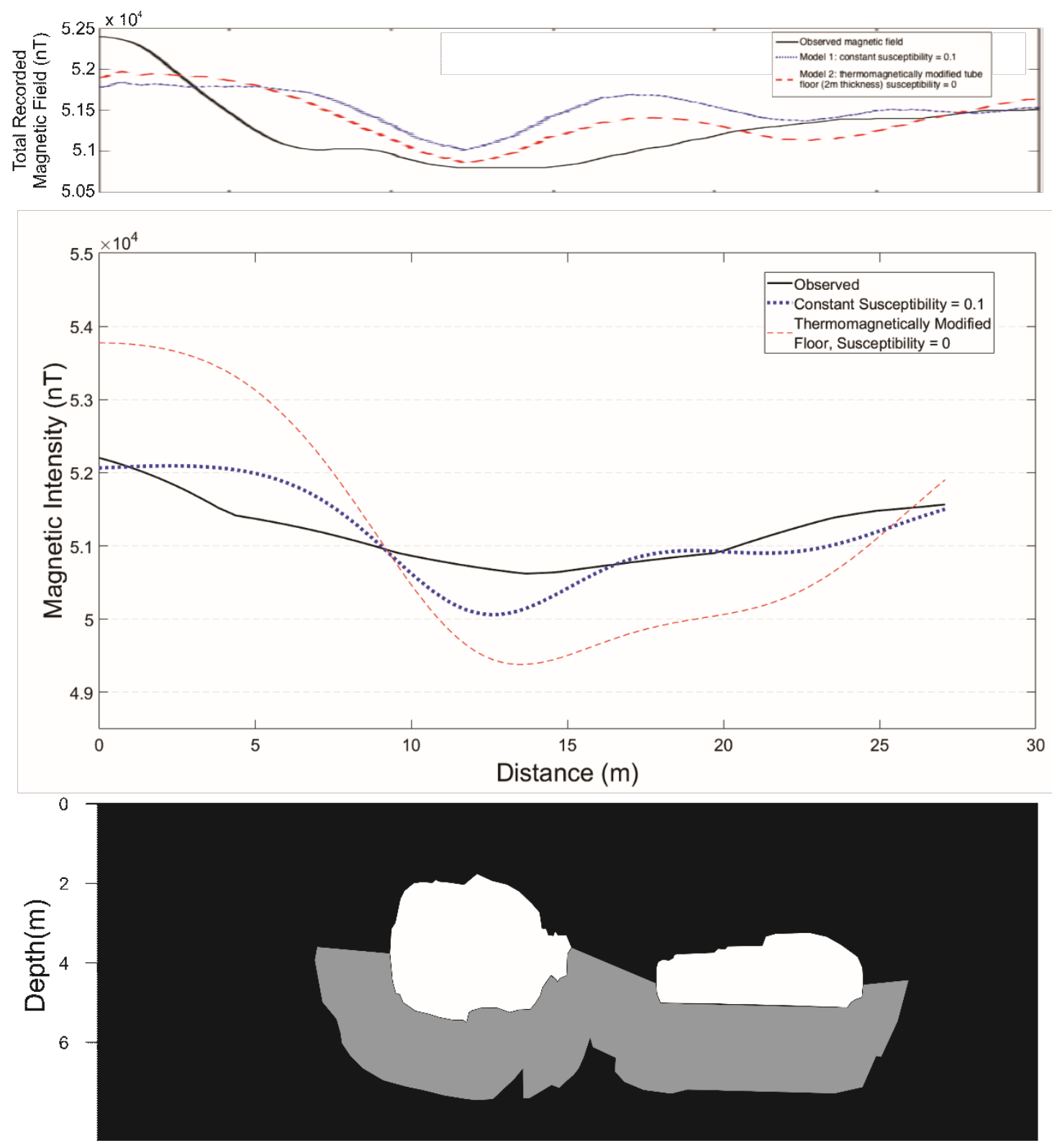

Figure 5.43: (Top) Observed data and calculated magnetic responses from Bell et al. (2018). (Middle) Observed Valentine Cave data from this project and calculated magnetic responses based on replicating the depth model and parameters from Bell et al. (2018). (Bottom) Replicated depth model from Bell et al. (2018) done in GM-SYS 2D. 


\section{Conclusions and Recommendations}

This research project focused on the effectiveness of two ground geophysical methods to detect lava tubes at LBNM as a contribution to the ATiLT project. Overall, 2.2 line $\mathrm{km}$ of surface EM induction surveying was conducted, five interior surveys to characterize the EM signatures of different floor composition were performed, and 52.5 line $\mathrm{km}$ of surface magnetic data were collected for this project. Two 2D cross-section inversions were performed on EM data from Juniper Cave based on a 1D inversion methodology. Finally, nine manual inversions were done from surface magnetic data from Juniper Cave, Valentine Cave, and Yellowstone Cave.

Surface surveying using EM induction surveying is considered to be inconclusive as the depth of exploration for the R4 EMIS was not sufficient to reach the limiting depth of any lava tubes surveyed at LBNM. Although EM induction was not successful in detecting lava tubes from the surface, EM induction surveying was successful in characterizing lava tube floors of various floor compositions. The EM inversion model successfully yielded the conductivity and magnetic susceptibility signatures of the floor and the basaltic bedrock. In addition, the EM inversion model showed generations of fracturing in the basaltic bedrock expressed as anomalies in the conductivity and susceptibility models.

Forward modelling of the magnetic data showed that at LBNM, the signature of a lava tube should be a magnetic low positioned slightly offset from its axis of symmetry. Surface magnetic data did not exhibit this signature. The magnetic method, however, proved effective at collecting a sizable amount of line $\mathrm{km}$ of data over a few days, which were used to observe trends at the scale of the survey area. The results of manual 2D 
inversion of the surface magnetic data were mixed: in several cases, lava tubes were successfully modelled over their immediate area of influence, but larger trends were not well captured. This indicates that a model comprising of a void within a uniform host rock is too simplistic. Interestingly, the manual inversion results identified two susceptibility signatures that could be related to the eruption sequence: the lower-susceptibility basalts from the Mammoth Crater eruptions that formed the caves at Cave Loop (Juniper and Yellowstone Cave), and the higher-susceptibility andesitic basalts from the eruptions that formed Valentine Cave.

As mentioned in Section 5.2.2, gravity surveying of lava tubes at Craters of the Moon produced a strong anomalous low over the lava tube (Brown et al., 2017). This suggests that gravity method is better suited for the detection of lava tubes from the surface that magnetic surveying. It is recommended that magnetics and gravity be used in unison for lava tube exploration. Magnetics would be used to observe large trends, and gravity would be used at a smaller scale to detect the lava tube itself. In addition to gravity, other methods that sense density contrasts, such as high-resolution shear wave seismic surveying, were conducted over roadways to successfully detect lava tubes (Meglich et al., 2003). It is also recommended that reflection seismic surveys be conducted to detect lava tubes to test the effectiveness and accuracy of the method.

For future Mars exploration missions, if a rover is designed to enter lava tubes and survey their interiors, an EMIS could be a useful addition to the instrument payload. This project has demonstrated that an EMIS can characterize lava tube floors and the underlying bedrock without interference from walls and pillars, which is not the case for magnetometers and gravimeters. Mars rovers have extensive levelling systems that allow 
for instruments to be as stable as possible, so a Mars rover would minimize pitch and roll during surveying as well as keep a consistent height above ground, ensuring the acquisition of good quality EM data. An important issue, however, is the EM field generated by the rover systems themselves. Instead of recording in continuous mode, the EMIS should be programmed to record at equally space stations. When the EMIS is recording, other systems are turned off.

Based on the results on this study, it is recommended that more planetary analog surveys be done on surface magnetics to better determine the capabilities of the technique for future planetary missions. Magnetometers have been in use for planetary exploration since several decades ago when stationary and portable fluxgate magnetometers were used to record magnetic data on the surface of the Moon from Apollo 14, 15, and 16 missions (Dyal and Gordon, 1973). Magnetic data from the Soviet Lunokhod 2, a lunar rover deployed in 1973, was used to model the subsurface of anomalous features on the moon (Vanyan et al., 1979). With respect to Mars exploration, the InSight lander has a stationary fluxgate magnetometer equipped in its payload and is currently collecting data in Elysium Planitia (Johnson et al., 2019). There are also magnetometers proposed for the Mars 2020 rover mission (Weiss et al., 2014), but none were chosen as payload for the rover. 


\section{References}

Anderson, C. A. (1941). Volcanoes of the Medicine lake highland, California. University of California Press.

Arrighini, G. P., Maestro, M., \& Moccia, R. (1968). Magnetic properties of polyatomic molecules. I. Magnetic susceptibility of $\mathrm{H} 2 \mathrm{O}, \mathrm{NH} 3, \mathrm{CH} 4, \mathrm{H} 2 \mathrm{O} 2$. The Journal of chemical physics, 49(2), 882-889.

Beamish, D. (2011). Low induction number, ground conductivity meters: A correction procedure in the absence of magnetic effects. Journal of Applied Geophysics, 75(2), 244-253. https://doi.org/10.1016/j.jappgeo.2011.07.005

Bell, E., Schmerr, N.,Young, K., Whelley, P., Garry, W., Kruse, S., Esmaeili, S., and Jazayeri S. (2018). Characterization of lava tubes with magnetometry, $49^{\text {th }}$ Lunar and Planetary Science Conference Abstract 2412

Bernold, L. E., \& Immer, M. (2004). Ground penetrating radar technology to locate plastic pipes and lava tubes. Engineering, Construction, and Operations in Challenging Environments: Earth and Space, 24-31.

Bernold, L. E. (2006). Effective processing of GPR data to investigate the sub-space, 2006, 114. https://doi.org/10.1061/40830(188)114

Blakely, R. (1995). Potential Theory in Gravity and Magnetic Applications. Cambridge: Cambridge University Press. https://doi.org/10.1017/CBO9780511549816

Blakely, R. J., Christiansen, R. L., Guffanti, M., Wells, R. E., Donnelly-Nolan, J. M., Muffler, L. J. P., ... Smith, J. G. (1997). Gravity anomalies, Quaternary vents, and Quaternary faults in the southern Cascade Range, Oregon and California: Implications for arc and backarc evolution. Journal of Geophysical Research, 102(B10), 2251322527. https://doi.org/10.1029/97JB01516

Boston, P. J., Frederick, R. D., Welch, S. M., Werker, J., Meyer, T. E., \& Sprungman, B. (2003). Human utilization of subsurface extraterrestrial environments. Gravitational and Space Biology Bulletin, 16(2), 121-131.

Briggs, I. C. (1974). Machine contouring using minimum curvature. Geophysics, 39(1), $39-48$.

Brown, C., Samson, C., Hay, A., Neish, C., Zanetti, M., \& Kukko, A. (2017). Detection and Characterization of Lava Tubes Using Surface Gravity Measurements in Support of Future Lunar and Martian Missions. 68th International Astronautical Congress, Adelaide, Australia, 25-29 September 2017. 
Burger, H.R., Sheehan, A.F., Jones, C.H. (2006) Introduction to applied geophysics: Exploring the shallow subsurface. WW Norton \& Company.

Canadian Space Agency. (2009). Canadian Scientific Priorities for the Global Exploration Strategy, 90.

Carr, M. H. (2007). The surface of Mars (Vol. 6). Cambridge University Press.

Cushing, G. E., Titus, T. N., Wynne, J. J., \& Christensen, P. R. (2007). THEMIS observes possible cave skylights on Mars. Geophysical Research Letters, 34(17), 4-8. https://doi.org/10.1029/2007GL030709

Daga, A., Allen, C., Mattler, M., Burke, J., Crawford, I., Léveillé, R., \& Tan, L. (2013). Lunar and Martian Lava Tube Exploration as Part of an Overall Scientific Survey. Science.

DeDecker, J. (2014). Evaluation of lava tube formation mechanisms using threedimensional mapping and viscosity modeling: Lava Beds National Monument, California (Master's thesis, University of North Carolina at Chapel Hill). Available from ProQuest Dissertations and Theses database. (UMI No. 1588990).

Des Marais, D. J., Achenbach, L., Bailey, J., Barnes, R., Baross, J., Bertka, C., ... Ciesla, F. (2015). 2015 Astrobiology Strategy. NASA Astrobiology, (October), 1-236. Retrieved from https://nai.nasa.gov/media/medialibrary/2016/04/NASA_Astrobiology_Strategy_20 15_FINAL_041216.pdf

Donnelly-Nolan, J. M., \& Champion, D. E. (1987). Geologic map of Lava Beds National Monument, Northern California.

Donnelly-Nolan, J. M., Champion, D. E., Miller, C. D., Grove, T. L., \& Trimble, D. a. (1990). Post-11,000-year volcanism at Medicine Lake Volcano, Cascade Range, northern California. Journal of Geophysical Research, 95(B12), 19693. https://doi.org/10.1029/JB095iB12p19693

Donnelly-Nolan, J. M., Nathenson, M., Champion, D. E., Ramsey, D. W., Lowenstern, J. B., \& Ewert, J. W. (2007). Volcano Hazards Assessment for Medicine Lake Volcano, Northern California. USGS Scientific Investigations Report, 2007-5174.

Donnelly-Nolan, J. M., Grove, T. L., Lanphere, M. A., Champion, D. E., \& Ramsey, D. W. (2008). Eruptive history and tectonic setting of Medicine Lake Volcano, a large rear-arc volcano in the southern Cascades. Journal of Volcanology and Geothermal Research, 177(2), 313-328. https://doi.org/10.1016/j.jvolgeores.2008.04.023

Geometrics. (2011). G-859 Operation Manual. 
Geometrics. (2015). G-857 Operation Manual.

Greeley, R. (1971). Observations and actively forming lava tubes and associated structures. NASA Technical Memorandum, X-62014.

Greeley, R. (1987). The role of lava tubes in Hawaiian volcanoes. U.S. Geological Survey Professional Paper, 1350(2), 1589-1602.

Grove, T. L., Donnelly-Nolan, J. M., \& Housh, T. (1997). Magmatic processes that generated the rhyolite of Glass Mountain, Medicine Lake volcano, N. California. Contributions to Mineralogy and Petrology, 127, 205-223. https://doi.org/10.1007/s004100050276

Halliday, W. R. (2002). What Is a Lava Tube?, AMCS Bulletin 7, 48-56.

Hodges, C. A., \& Moore, H. J. (1994). Atlas of volcanic landforms on Mars. US Geological Survey Professional Paper 1534, 194. Retrieved from http://pubs.er.usgs.gov/publication/pp1534

Hrvoic, I., Hollyer, G. M. (2005). Brief review of quantum magnetometers. GEM Systems Technical Papers.

Jones, B. (2001). Microbial activity in caves - A geological perspective. Geomicrobiology Journal, 18(3), 345-357. https://doi.org/10.1080/01490450152467831

Keszthelyi, L., Jaeger, W., Mcewen, A., Tornabene, L., Beyer, R. A., Dundas, C., \& Milazzo, M. (2008). High Resolution Imaging Science Experiment (HiRISE) images of volcanic terrains from the first 6 months of the Mars Reconnaissance Orbiter Primary Science Phase. Journal of Geophysical Research, 113(E04005), 1-25. https://doi.org/10.1029/2007JE002968

Léveillé, R. J., \& Datta, S. (2010). Lava tubes and basaltic caves as astrobiological targets on Earth and Mars: A review. Planetary and Space Science, 58(4), 592-598. https://doi.org/10.1016/j.pss.2009.06.004

Léveillé, R., Whyte, L., Wing, B., Pollard, W., \& Samson, C. (2015). Astrobiology Training in Lava Tubes - ATiLT, (Fast), 1-12.

McNeill, J. D. (1980a). Applications of transient electromagnetic techniques. Retrieved from http://geonics.com/pdfs/technicalnotes/tn7.pdf

McNeill, J. D. (1980b). Electromagnetic Terrain Conductivity Measurement at Low Induction Numbers. Technical Note TN. Retrieved from http://www.geonics.com/pdfs/technicalnotes/tn6.pdf 
Meglich, T. M., Williams, M. C., Hodges, S. M., \& Demarco, M. J. (2003). Subsurface geophysical imaging of lava tubes, Lava Beds National Monument, CA. Geophysics.

Miyamoto, H., Haruyama, J., Kobayashi, T., Suzuki, K., Okada, T., Nishibori, T., ... Masumoto, K. (2005). Mapping the structure and depth of lava tubes using ground penetrating radar. Geophysical Research Letters, 32(L21316), 1-5. https://doi.org/10.1029/2005GL024159

Monteiro Santos, F. A. (2004). 1-D laterally constrained inversion of EM34 profiling data, 56, 123-134. https://doi.org/10.1016/j.jappgeo.2004.04.005

National Research Council. (2007). An Astrobiology Strategy for the Exploration of Mars. https://doi.org/10.17226/11937

Natural Resources Canada. (2019). Magnetic field calculator. Retrieved from http://geomag.nrcan.gc.ca/calc/mfcal-en.php

Schultz, G., \& Ruppel, C. (2005). Inversion of inductive electromagnetic data in highly conductive terrains. Geophysics, 70(1), 16-28. https://doi.org/10.1190/1.1852775

Schulze-Makuch, D., Dohm, J. M., Fan, C., Fairén, A. G., Rodriguez, J. A. P., Baker, V. R., \& Fink, W. (2007). Exploration of hydrothermal targets on Mars. Icarus, 189(2), 308-324. https://doi.org/10.1016/j.icarus.2007.02.007

Smith, K. (1997). Cesium Optically Pumped Magnetometers. Technical Report M-TR91.

Spector, A., \& Grant, F. S. (1970). Statistical models for interpreting aeromagnetic data. Geophysics, 35(2), 293-302.

Tallysman Wireless. (2014). TW5340 Integrated GPS/GLONASS Receiver/Antenna, User Manual. Document \#61-0009-0.

Telford, W. M., Geldart, L. P., \& Sheriff, R. E. (1990). Applied Geophysics. Cambridge University Press.

Valerio, A., Tallarico, A., \& Dragoni, M. (2008). Mechanisms of formation of lava tubes. Journal of Geophysical Research: Solid Earth, 113(8), 1-14. https://doi.org/10.1029/2007JB005435

Waters, A. C., Donnelly-Nolan, J. M., \& Rogers, B. W. (1990). Selected caves and lavatube systems in and near Lava Beds National Monument, California, 1-102.

Whyte, L., Wing, B., Pollard, W., \& Samson, C. (2015). Astrobiology Training in Lava Tubes - ATiLT, (Fast), 1-12. 
Woo, K. S., Choi, D. W., \& Lee, K. C. (2008). Silicification of cave corals from some lava tube caves in the Jeju Island, Korea: Implications for speleogenesis and a proxy for paleoenvironmental change during the Late Quaternary, 177, 82-95. https://doi.org/10.1016/j.quaint.2007.05.008

Woo, S. K., Kim, J. C., Choi, D. W., Kim, J. K., Kim, R., \& Nehza, O. (2008). The origin of erratic calcite speleothems in the Dangcheomul Cave (lava tube cave), Jeju Island, Korea, 177, 70-81. https://doi.org/10.1016/j.quaint.2007.05.009

Wynne, J. J., Titus, T. N., \& Chong Diaz, G. (2008). On developing thermal cave detection techniques for earth, the moon and mars. Earth and Planetary Science Letters, 272(12), 240-250. https://doi.org/10.1016/j.eps1.2008.04.037

\section{Appendix}

Appendix A: Field Summary of 2018.

Date: $\quad$ May 1st, 2018

Weather: Sunny, warm, no clouds.

Objective: Pick up equipment, take part in short tutorial on operating procedures. Drive to Lava Beds National Monument.

\section{Timeline:}

\begin{tabular}{|c|c|}
\hline Time & Description \\
\hline $9: 00-10: 45$ & $\begin{array}{l}\text { Picked up G-859 Cesium Magnetometer and G-857 Proton Procession } \\
\text { Magnetometer from Geometrics headquarters in San Jose, California. } \\
\text { - Received a tutorial on set-up, operating procedures, and } \\
\text { importing data to a computer. Tutorial ran by Mike Ortuga. } \\
\text { - Downloaded MagMap2000 before leaving to ensure proper } \\
\text { installation. } \\
\text { - Signed paperwork before departing for Lava Beds National } \\
\text { Monument. }\end{array}$ \\
\hline 11:00 & Departed for National Beds National Monument. \\
\hline 13:00 & Stopped for lunch. \\
\hline $15: 30$ & $\begin{array}{l}\text { Stopped at Walmart to purchase car battery for base station } \\
\text { magnetometer }(\mathrm{G}-857) \text {. }\end{array}$ \\
\hline 19:00 & $\begin{array}{l}\text { Arrived at Winema Lodge, located about } 27 \mathrm{~km} \text { from Visitor's Centre } \\
\text { in LBNM. }\end{array}$ \\
\hline
\end{tabular}


Date: $\quad$ May $2^{\text {nd }}, 2018$

Weather: Sunny, hot, few clouds.

Objective: Test base station and roving magnetometer to ensure both are working properly. Look at various lava tubes to determine survey targets.

Timeline:

\begin{tabular}{|c|c|}
\hline Time & Description \\
\hline $8: 30$ & $\begin{array}{l}\text { Set up and turned on base station. Did test survey with roving } \\
\text { magnetometer during this time. } \\
\text { - Ran for } 30 \text { minutes before attempting to import data. } \\
\text { - MagMap2000 would keep crashing after importing and } \\
\text { attempting to open data in software. }\end{array}$ \\
\hline $9: 30-12: 00$ & $\begin{array}{l}\text { Troubleshot possible solutions for base station not importing. } \\
\text { - Base station was in "Legacy Mode" where the G857 acts } \\
\text { similar to the previous model (G-856). } \\
\text { - Had to revert base station back to recording as a G-857 instead } \\
\text { of "Legacy Mode". }\end{array}$ \\
\hline $12: 00-13: 00$ & Lunch. \\
\hline $13: 00-16: 00$ & 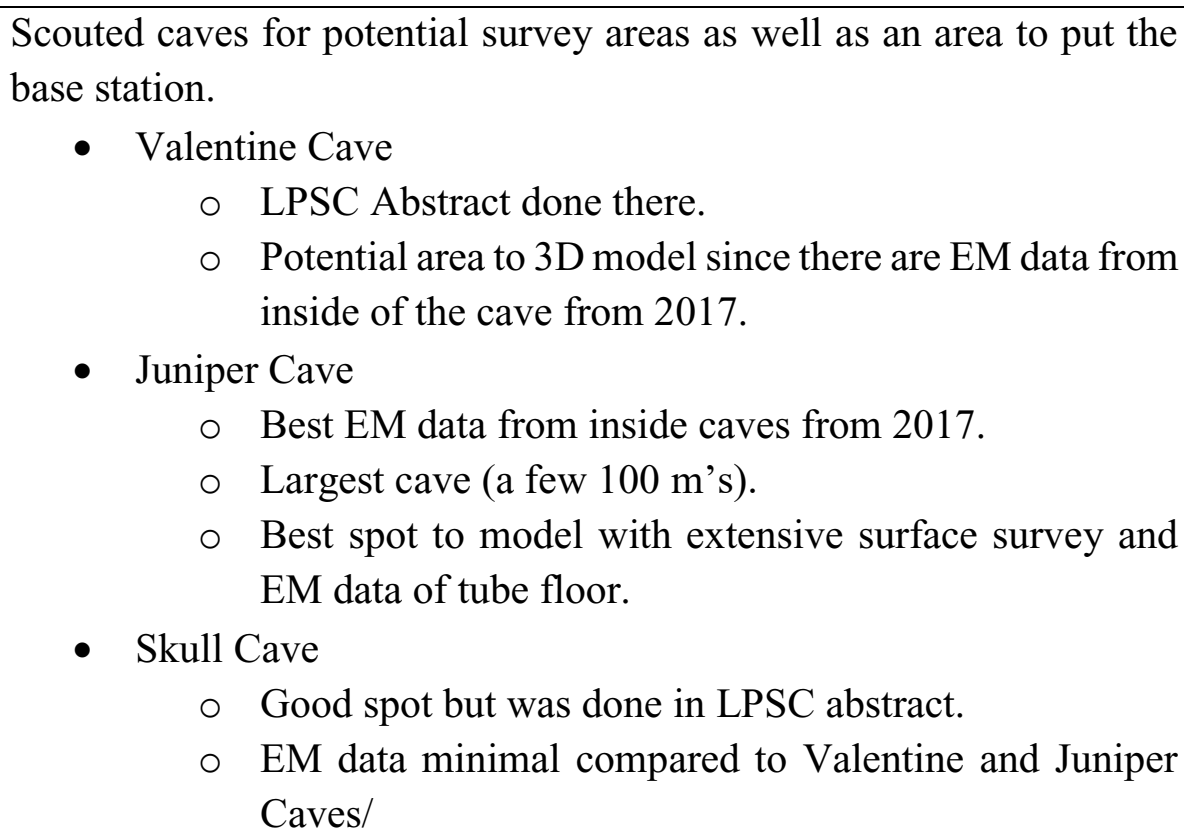 \\
\hline $16: 30$ & Arrived back at Winema Lodge, end of day. \\
\hline
\end{tabular}


Date: $\quad$ May $3^{\text {rd }}, 2018$

Weather: Sunny, warm with a light breeze.

Objective: Surface survey of Valentine Cave

\section{Timeline:}

\begin{tabular}{|l|l|}
\hline Time & Description \\
\hline $8: 10$ & Departed for LBNM. \\
\hline $8: 30-8: 37$ & $\begin{array}{l}\text { Arrived at base station location (located between Monument } \\
\text { headquarters and Valentine Cave), set up, and started base station } \\
\text { measurements. }\end{array}$ \\
\hline $8: 45$ & $\begin{array}{l}\text { Arrived at Valentine Cave and warmed up magnetometer. } \\
\bullet \quad \text { Put in coordinates of first half of survey. }\end{array}$ \\
\hline $10: 05-11: 25$ & $\begin{array}{l}\text { Started centre section for Valentine Cave survey. } \\
\bullet \quad \text { 200m lines for 19 lines, 300m lines for 15 lines. }\end{array}$ \\
\hline $11: 30-12: 45$ & Lunch and put in coordinates into GPS for second half of survey. \\
\hline $12: 51-14: 38$ & Second part of Valentine Cave survey. \\
\hline $14: 39-15: 01$ & Tie lines for Valentine Cave. \\
\hline $15: 22$ & Picked up base station. \\
\hline $16: 30$ & Arrived at Winema Lodge. \\
\hline
\end{tabular}


Date: $\quad$ May $4^{\text {th }}, 2018$

Weather: Warm, sunny with few clouds.

Objective: Finish Valentine Cave, start Juniper Cave survey.

\section{Timeline:}

\begin{tabular}{|l|l|}
\hline Time & Description \\
\hline $8: 10$ & Departed for LBNM. \\
\hline $8: 33$ & Turned on magnetometer at Valentine Cave. \\
\hline $8: 42$ & Set up and started base station measurements. \\
\hline 9:15-9:40 & Started tie line redo and line fill at Valentine Cave. \\
\hline 10:05 & Arrived at Juniper Cave, warm up magnetometer. \\
\hline 10:52-11:54 & Started north section of Juniper Cave survey. \\
\hline 12:00-12:50 & Lunch and put in GPS coordinates. \\
\hline 12:59-14:46 & Continued to centre section of Juniper Cave survey. \\
\hline 15:00 & $\begin{array}{l}\text { Packed up magnetometer, took pictures of obstacles, cave entrances } \\
\text { etc. }\end{array}$ \\
\hline $15: 30$ & Picked up base station. \\
\hline $16: 18$ & Arrived at Winema Lodge. \\
\hline
\end{tabular}


Date: $\quad$ May $5^{\text {th }}, 2018$

Weather: Cooler, overcast with a breeze.

Objective: Survey south extension of Valentine Cave, finish Juniper Cave survey.

\section{Timeline:}

\begin{tabular}{|l|l|}
\hline Time & Description \\
\hline $8: 15$ & Departed for LBNM \\
\hline $8: 44$ & Set up and started base station measurements. \\
\hline 9:00 & Arrived at Valentine Cave, warmed up magnetometer. \\
\hline 9:25-10:24 & Surveyed south section of Valentine Cave. \\
\hline 10:30-11:00 & Break for snacks and put in GPS coordinates. \\
\hline 11:04-11:13 & Tie lines for south extension. \\
\hline $11: 18-11: 30$ & Fill lines for original Valentine Cave survey. \\
\hline $11: 47$ & $\begin{array}{l}\text { Arrived at Juniper Cave, warmed up magnetometer. } \\
\quad \quad \text { Put in coordinates of survey and tie lines. }\end{array}$ \\
\hline 12:41-13:43 & Surveyed south section of Juniper Cave. \\
\hline $13: 51-14: 32$ & Tie lines for Juniper Cave survey. \\
\hline $14: 46$ & Picked up base station. \\
\hline $15: 17$ & Arrived at Winema Lodge \\
\hline
\end{tabular}


Date: $\quad$ May $6^{\text {th }}, 2018$

Weather: Sunny, warm, with a few clouds

Objective: Recovery day, go to Crater Lake National Park

\section{Timeline:}

\begin{tabular}{|l|l|}
\hline Time & Description \\
\hline $8: 15$ & Departed for Crater Lake. \\
\hline $11: 00$ & Arrived at Crater Lake. \\
\hline $11: 00-1: 30$ & $\begin{array}{l}\text { Hiked around part of rim. } \\
\text { Only a portion of it was open. Rest was closed due to snow on } \\
\text { the roads. }\end{array}$ \\
\hline $1: 30-2: 45$ & Drove to Klamath Falls. \\
\hline $3: 00$ & Lunch. \\
\hline $3: 15-3: 45$ & Grocery shopping at Walmart in Klamath Falls. \\
\hline $4: 15$ & Arrived at Winema Lodge. \\
\hline
\end{tabular}


Date: $\quad$ May $7^{\text {th }}, 2018$

Weather: Mid 20's Celsius, sunny with no clouds, occasional breeze.

Objective: Survey Yellowstone Cave. Approximately $21 \mathrm{~km}$ of lines planned. $15-$ $18 \mathrm{~km}$ expected.

Timeline:

\begin{tabular}{|l|l|}
\hline Time & Description \\
\hline $8: 10$ & Departed for LBNM. \\
\hline $8: 30$ & $\begin{array}{r}\text { Arrived at Juniper Cave parking area. } \\
\text { - Warmed up magnetometer. }\end{array}$ \\
& $\quad \begin{array}{l}\text { Left Claire with magnetometer while Mike and Skyler set up } \\
\text { base station. }\end{array}$ \\
\hline $8: 40$ & Started base station measurements. \\
\hline 9:09-11:54 & Started Yellowstone Cave survey on west side closest to Juniper Cave. \\
\hline 12:05-12:55 & Lunch. \\
\hline 13:09-15:00 & Continued Yellowstone Cave; finished planned lines. \\
\hline 15:02-15:51 & Tie lines for Yellowstone Cave. \\
\hline $16: 05$ & Picked up base station. \\
\hline $16: 40$ & Arrived at Winema Lodge. \\
\hline
\end{tabular}


Date: $\quad$ May $8^{\text {th }}, 2018$

Weather: Sunny, hot, little wind. Rained in the late afternoon.

Objective: Survey focused grid for Yellowstone Cave. Expected to take morning. Hoping to return car battery in the afternoon.

Timeline:

\begin{tabular}{|l|l|}
\hline Time & Description \\
\hline $8: 00$ & Departed for LBNM. \\
\hline $8: 25$ & $\begin{array}{r}\text { Arrived at Juniper Cave parking area. } \\
\quad \quad \text { Warmed up magnetometer. } \\
\quad \text { Left Claire with magnetometer while Chris and Skyler set up } \\
\text { base station. }\end{array}$ \\
\hline $8: 40$ & Started base station measurements. \\
\hline $8: 50$ & $\begin{array}{l}\text { Mike and Claire search for entrance to Yellowstone Cave to confirm } \\
\text { coordinates provided by Jenny. }\end{array}$ \\
\hline $9: 31-11: 27$ & Surveyed focused grid for Yellowstone Cave. \\
\hline $11: 29-11: 44$ & Tie lines for focused survey. \\
\hline $12: 05$ & Picked up base station. \\
\hline $12: 15$ & Mike and Claire go back to entrance of Yellowstone Cave for pictures. \\
\hline $13: 10$ & Arrived at Winema Lodge \\
\hline $13: 10-13: 40$ & Shower and change of clothes for afternoon errands. \\
\hline $13: 40$ & Left for Klamath Falls \\
\hline $14: 15$ & $\begin{array}{l}\text { Claire works in Starbucks due to high speed internet access; Skyler and } \\
\text { Mike have lunch. }\end{array}$ \\
\hline $15: 00$ & Return car battery to Walmart, medical supplies \\
\hline
\end{tabular}




\section{Appendix B: Electromagnetic and Magnetic Datasets}

There is too much data to properly attach to this thesis document. See attached USB for all datasets used in this research project. 